\title{
APPLICATION OF ADJOINT SENSITIVITY ANALYSIS FOR PERFORMANCE ENHANCEMENT OF POWER PLANTS' NITROGEN OXIDES CONTROL POLICIES
}

\author{
by
}

Seyyed Morteza Mesbah

A thesis submitted to the Faculty of Graduate and Postdoctoral Affairs in partial fulfillment of the requirements for the degree of

\author{
Doctor of Philosophy \\ in Environmental Engineering
}

Carleton University

Ottawa, Ontario

(C) 2014, Seyyed Morteza Mesbah 


\begin{abstract}
Significant investments in nitrogen oxide $\left(\mathrm{NO}_{\mathrm{x}}\right)$ emission controls in the U.S. have led to a substantial reduction in emissions. However, it is unclear whether these programs have optimally reduced ozone concentrations and their corresponding health damages. Current cap-and-trade program allocates emission quotas to participants and allows the trade of quotas on a one-to-one basis. However, it does not account for spatial and temporal differences in health damage of $\mathrm{NO}_{\mathrm{x}}$ emissions. This shortcoming in the current U.S. $\mathrm{NO}_{\mathrm{x}}$ control policy is explored in this research.

Spatial and temporal differences in $\mathrm{NO}_{\mathrm{x}}$ emissions can be included in policy design if emission quotas are valued differently (exchange rate policy) or if polluters pay time- or location-specific emission fees (taxation policy). The main objective of this work is to develop a decision support system model for evaluating different policies. The proposed model includes an optimization platform to predict the polluters' behavior, and an air quality model and its adjoint (or backward) sensitivity model to calculate the derivatives of the environmental or health damage function with respect to $\mathrm{NO}_{\mathrm{x}}$ emissions used for emission differentiations.
\end{abstract}

The results from a case study of U.S. power plants show that exchange rate trading outperforms current indiscriminate trading policies. These findings imply that by implementing exchange rate trading or taxation policies, current improvements in air quality could have been achieved at lower costs, or alternatively, more substantial improvements could have been reached at little to no additional costs. Furthermore, the results indicate that setting the emission fees on an hourly basis leads to a outcome 
comparable to setting fees based on location. Moreover, the per ton health benefit of $\mathrm{NO}_{\mathrm{x}}$ emission reductions is found to increase as emissions are reduced. This finding is particularly important from an environmental policy perspective as it impacts the optimal $\mathrm{NO}_{\mathrm{x}}$ emission reduction target. Our results also indicate that power plants in the restructured electricity market are willing to pay more for emission quotas. Uncertainties involved in the proposed model, challenges for implementation of the proposed policies, and inclusion of health impacts caused by exposure to particulate matter are main directions for future research. 


\section{PREFACE}

The following non-copyrighted articles have been reproduced in full in this thesis with permission from the co-authors:

- Mesbah, S. M., Hakami, A., Schott, S. "Non-convexity in ozonebased $\mathrm{NO}_{\mathrm{x}}$ health damage: an application of the adjoint of CMAQ" (Revised draft in preparation, chapter 7).

- Mesbah, S. M., Hakami, A., Schott, S., "Optimal ozone control with inclusion of spatiotemporal marginal damages and electricity demand" (Final draft in preparation, chapter 6).

- Mesbah, S. M., Schott, S., Hakami, A., "Short-term $\mathrm{NO}_{\mathrm{x}}$ emissions control behavior in the regulated and restructured electricity market" (Final draft in preparation, chapter 8).

The following copyrighted articles have been reproduced in full in this thesis with permission from the co-authors and the journal, Environmental Science and Technology:

- Mesbah, S. M., Hakami, A., Schott, S., (2013) "Optimal ozone reduction policy design using adjoint-based NOx marginal damage", Environmental Science and Technology, Vol. 47 (23), 13528-13535, (chapter 5).

- Mesbah, S. M., Hakami, A., Schott, S., (2012) "Improving NOx cap-and-trade system with adjoint based emission exchange rate", Environmental Science and Technology, Vol. 46 (21), 1190511912, (chapter 4).

All materials should be cited as outlined above. 


\section{ACKNOLEDGMENTS}

This thesis is the outcome of my interdisciplinary $\mathrm{PhD}$ research on air pollution modeling and environmental economics at Carleton University. I had a wonderful time in Carleton working on my $\mathrm{PhD}$ with great faculty members and staff.

I would like to express my deepest thanks to many whom without their support and help the creation of this thesis was impossible. I would like to thank my supervisor, Dr. Amir Hakami, and co-supervisor, Dr. Stephan Schott, whose wise advice, passion, continuous support, critiques, comments, encouragement, and positive attitude kept me motivated in my $\mathrm{PhD}$ journey. I would also like to thank my advisory committee members: Mr. Michael Donohue, Dr. Deniz Karman, Dr. Leigh Mazany, and Dr. Daniel Cohan for their time and valuable advice and comments. I would like to thank the members of the atmospheric research group at Carleton University whose help at different stages of my thesis was greatly appreciated. I want to thank, Matthew Russell who devoted his time to assist the group in fixing computer related issues, which came up very often. I would also like to thank Farid Amid, Maryam Mirzajani, Amanda Pappin, and Dr. Shunliu Zhao who each helped me with different aspects of my thesis. Help from Dr. Yongtao Hu from Georgia Institute of Technology was also greatly appreciated.

I would like to extend my deepest thanks to my parents who have always been supportive. Words cannot express how grateful I am for their support. I would like to dedicate my thesis to my wife whose continuous support, understanding, and proofreading was a great help in accomplishing this thesis.

\section{S. Morteza Mesbah}




\section{TABLE OF CONTENTS}

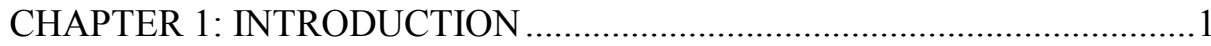

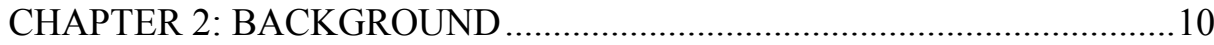

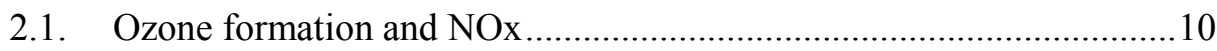

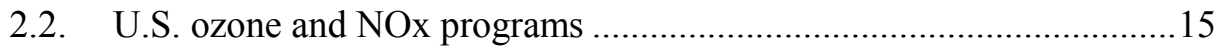

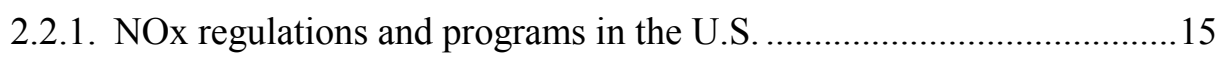

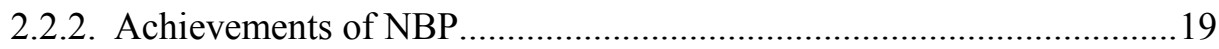

2.2.3. Performance of NOx control programs in the U.S................................22

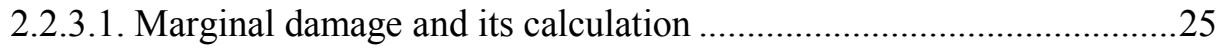

2.2.3.2. Re-dispatching of electricity generation ...............................................34

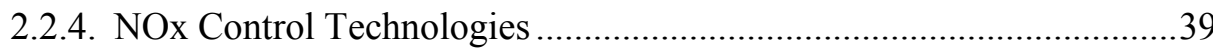

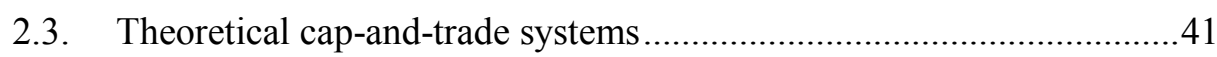

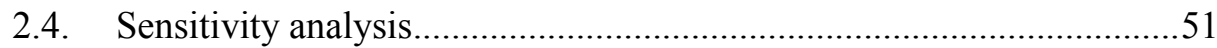

CHAPTER 3: METHODS AND MODELING

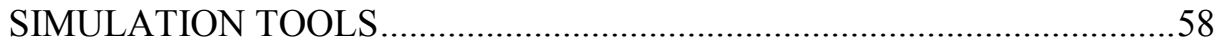

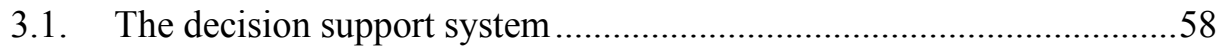

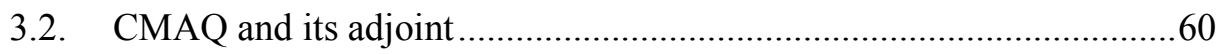

3.2.1. Adjoint cost function and forcing term ................................................64

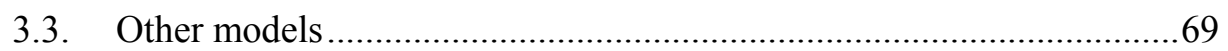

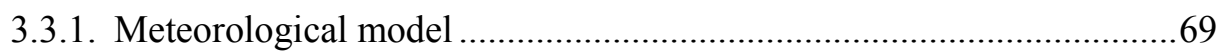

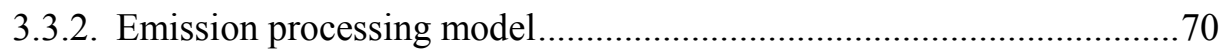

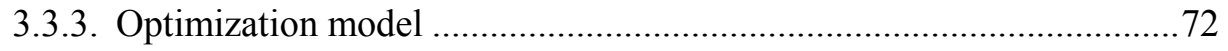

CHAPTER 4: IMPROVING NOX CAP-AND-TRADE

SYSTEM WITH ADJOINT-BASED EMISSION

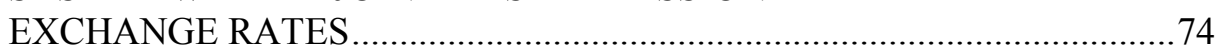

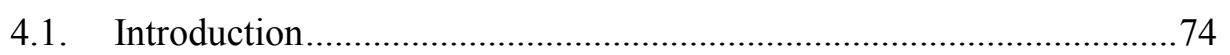

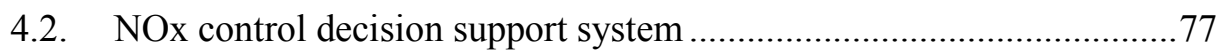

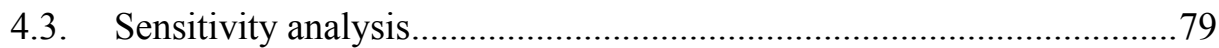

4.4. Exchange rate enhanced cap-and-trade system...................................... 81

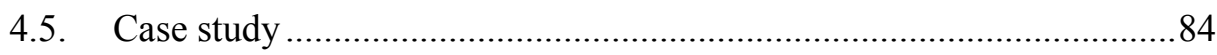

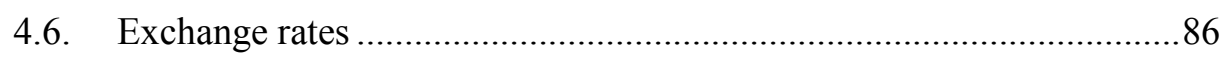

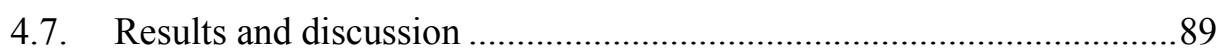

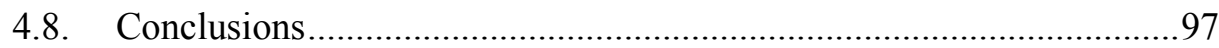

CHAPTER 5: OPTIMAL OZONE REDUCTION POLICY

DESIGN USING ADJOINT-BASED MARGINAL

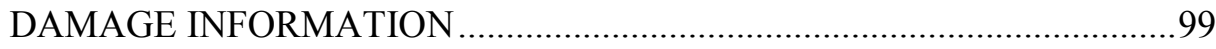

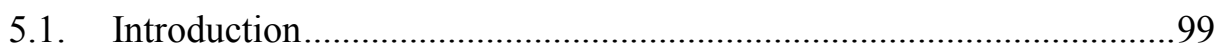




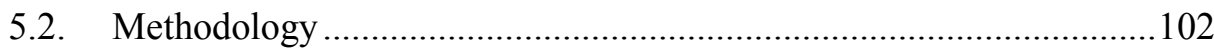

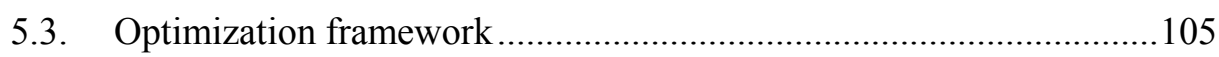

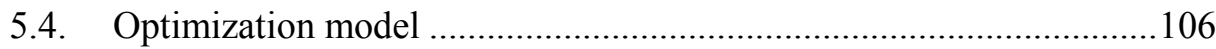

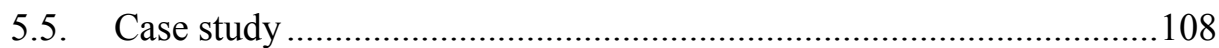

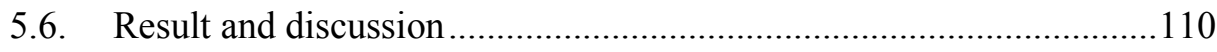

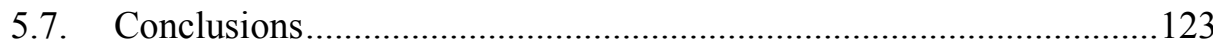

CHAPTER 6: OPTIMAL OZONE CONTROL WITH

INCLUSION OF SPATIOTEMPORAL MARGINAL

DAMAGES AND ELECTRICITY DEMAND …….......................................125

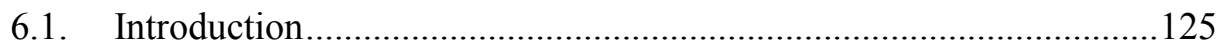

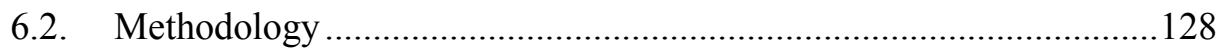

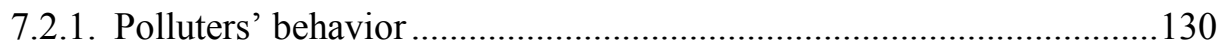

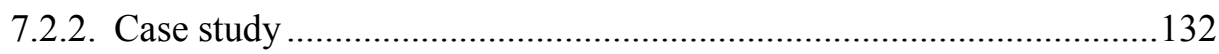

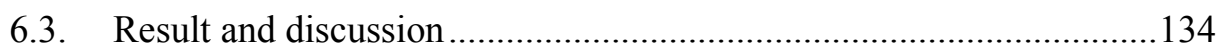

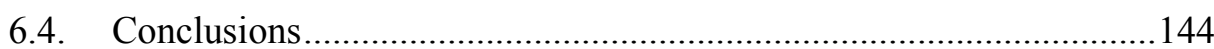

CHAPTER 7: NON-CONVEXITY IN OZONE-BASED

NOX HEALTH DAMAGE: AN APPLICATION OF THE

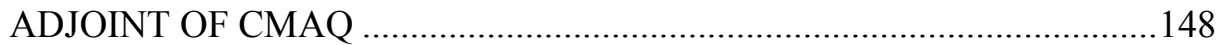

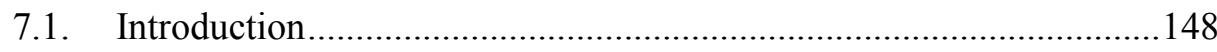

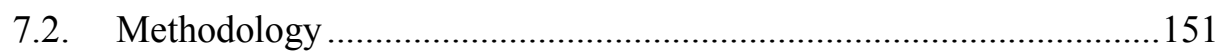

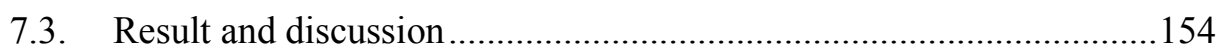

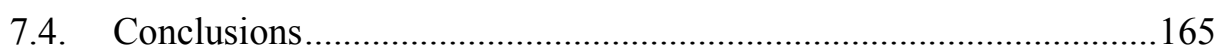

CHAPTER 8: SHORT-TERM NOX EMISSIONS

CONTROL BEHAVIOR IN THE REGULATED AND

RESTRUCTURED ELECTRICITY MARKET............................................166

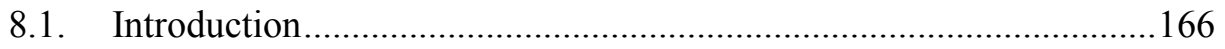

8.2. NOx control technologies and regulations..........................................169

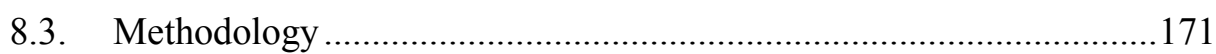

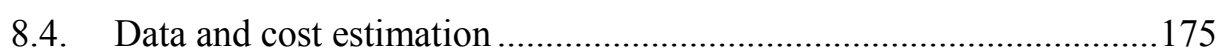

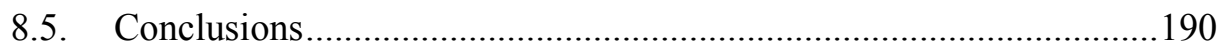

CHAPTER 9: CONCLUSIONS AND FUTURE WORK ..............................193

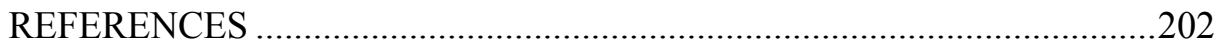




\section{TABLE OF FIGURES}

Figure 2.1. A typical ozone isopleth used in U.S. EPA

Empirical Kinetic Modeling Approach (EKMA) (Doge,

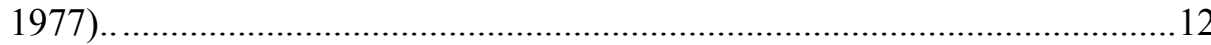

Figure 2.2. Number of NBP sources by type (EPA 2008) .............................20

Figure 2.3. NOx emissions from all NBP sources (EPA, 2008).

Figure 2.4. Seasonal average 8-hour ozone concentration in NBP region (EPA, 2008).

Figure 3.1. Components of the proposed decision support system

Figure 3.2. Model-3 components (Byun and Schere, 2006).

Figure 4.1. The components of the proposed decision support system.

Figure 4.2. Exchange rates for all plants before and after trade (CaT-EX policy). All exchange rates are for trades with the plant with the average pretrade sensitivity.

Figure 4.3. a) Average daily maximum 8-hour, and b) 3rd highest daily maximum 8 -hour ozone for the base case simulation.

Figure 4.4. Normalized exchange rates for CaT-EX (a) and CaT-EXP (b) policies. The normalized exchange rate represents the ratio by which a power plant can exchange its emissions with the plant with the average sensitivity in the base case simulation

Figure 4.5. Differences between CaT and CaT-EXP (left) policies. The panels show differences in ADM8 ozone (top) and 99th percentile DM8 ozone (bottom). Negative values correspond to air quality improvements. Values in each plot are calculated (as average or percentile) from 92 daily values.

Figure 4.6. Change in DM8 ozone between CaT and CaT-EX (left) and CaT-EXP (right) policies. Each data point is the DM8 ozone in one grid-day. Days with small changes ([-0.1, $0.1]$ ) are not included in the frequency distributions. Negative values indicate air quality improvements.

Figure 5.1. Components of the proposed decision support system for emission differentiation

Figure 5.2. MACs (left) and MDs (right) for the power plants in the case study.

Figure 5.3. a) The ADM8 ozone (left) and b) the 4th highest DM8 ozone (right) for a 5-month modeling period for the CaT policy. ....

Figure 5.4. Differences in ozone concentrations by switching from the CaT policy to the DMIN policy (left), and to the 
SCMIN policy (right). The panels show change in the ADM8 ozone (top) and the 4th highest DM8 ozone (bottom) for the 5 -month modeling period. Negative values represent improvements.

Figure 5.5. Differences in damages caused by the CaT and DMIN (left) or the SCMIN (right) policies.

Figure 5.6. The spatial differences in the ADM8 ozone (upleft), the 4th highest DM8 ozone (up-right), and the spatial differences in health damage (bottom-left) comparing the CaT-EXP and CaT policies. The negative values represent improvement.

Figure 6.1. Average location-specific MDs for the selected power plants

Figure 6.2. Color-coded location- and hour-specific MDs for the studied power plants. The dark blue cells of the matrix are locations and times with negative MDs. The graph on the right panel is the average of each row and represents the average location-specific $\operatorname{MDs}(\overline{M D}(x, y))$. The graph at the bottom is the average of each column and represents the average timespecific MDs $\left(\overline{M D}_{t}\right)$.

Figure 6.3. Hourly electricity generation (a) and hourly NOx emissions from the power plants studied during the ozone season under flexible demand policies (b) and demand-based policies (c)

Figure 7.1. PNT-MDs for different emission reduction scenarios when point source emissions are reduced uniformly across the domain. Each panel shows PNT-MDs as average daily NOx MDs weighted by point-source emissions in various model layers.

Figure 7.2. MB-MDs when mobile emissions are reduced uniformly across the domain. MB-MDs are average daily NOx MDs weighted by mobile-source emissions.

Figure 7.3. MDs at different locations when point (top) or mobile source emissions (bottom) are reduced. MD values are MB-MDs for few major cities (left) and PNT-MDs for selected power plants (right).

Figure 7.4. MDs at different locations when point and mobile source emissions are reduced. The MD values are MB-MDs for a few major cities (left) and PNT-MDs for selected power plants (right). The grey dashed lines are the aggravation of MDs from point source and mobile source emission reductions presented in Figure 7.3

Figure 7.5. Schematic of traditional and negatively sloped MD curves in an economic equilibrium framework. 
Figure 8.1. Output-emission relationship for units of the Rochester Power Plant. Each point represents the daily emissions and the daily output.

Figure 8.2. Input-output relationship for units of the Rochester Power plants. One point represents daily input and daily output.

Figure 8.3. Selected units by region. The restructured states are shown in bold text. The columns represent the percentage of selected units in the restructured market and the percentage of units with SCR control technologies at each region.

Figure 8.4. Comparison of the units' behavior (seller/buyer) based on the estimated MACs and actual compliance data. A positive number of traded quotas indicates the number of quotas sold. Note that the vertical axis intersects with the horizontal axis where MAC is equal to quota price (i.e., $\$ 825 /$ ton). 


\section{TABLE OF TABLES}

Table 2.1. MD estimations by different studies .33

Table 4.1. Abatement costs and health benefits of CaT, CaT-

EX, and CaT-EXP policies (million \$). ..96

Table 5.1. Abatement costs and health benefits for different policies (\$ million)

Table 6.1. Differences under considered cost minimization policies

Table 6.2. Abatement costs and health benefits (million dollar) for different policies compared to the CMIN policy.

Table 8.1. MAC for the Rochester Power Plant in the ozone season of 2007 .

Table 8.2. Compliance data for the Rochester Power Plant in the ozone season of 2007 (Clean air market U.S. EPA). 178

Table 8.3. Unit-level descriptive statistics by region 181

Table 8.4. Regression statistics and estimated regression variables.

Table 8.5. Compliance data for Cross Power Plant in the ozone season of 2007 (Clean air market U.S. EPA)

Table 8.6. Regression statistics and estimated regression variables. 


\section{LIST OF ABBREVIATIONS}

ADE

ADM8

APS

APEEP

BACT

BEIS

BCON

BenMAP

CAA

CAMx

CAIR

$\mathrm{CaC}$

$\mathrm{CaT}$

CaT-EX

CaT-EXP

CEM

CMAQ

CMIN

CRDM

CSAPR

CTM

DMIN

DSS

DDM

DM8
Atmospheric diffusion equation

Average daily maximum 8-hour

Ambient-permit system

Air Pollution Emission Experiments and Policy

Best Available Control Technology

Biogenic Emission Inventory Systems

Boundary condition processor

Environmental Benefits Mapping and Analysis Program

Clean Air Act

Air Quality Model with Extensions

Clean Air Interstate Rule

Command-and-control

Cap-and-trade

Cap-and-trade with an exchange rate

Cap-and-trade with an exposure-based exchange rate

Continuous Emission Monitoring

Community Multiscale Air Quality

Cost minimization

Climatological Regional Dispersion Model

Cross State Air Pollution Rule

Chemical transport model

Damage minimization

Decision support system

Decoupled direct method

Daily maximum 8-hour 


$\begin{array}{ll}\text { D-SCMIN } & \text { Demand-based social cost minimization } \\ \text { EGU } & \text { Electric generation utility } \\ \text { EPA } & \text { Environmental Protection Agency } \\ \text { ERCAM-NOx } & \begin{array}{l}\text { Emission Reduction and Cost Analysis Model for Oxides of } \\ \text { Nitrogen }\end{array} \\ \text { ERS } & \text { Exchange-rate emission trading system } \\ \text { FIP } & \text { Federal Implementation Plan } \\ \text { F-SCMIN } & \text { Flexible social cost minimization } \\ \text { LAER } & \text { Lowest Available Emission Rate } \\ \text { GAD } & \text { Gross annual damage } \\ \text { GDP } & \text { Gross domestic production } \\ \text { ICON } & \text { Initial condition processor } \\ \text { IDA } & \text { Inventory Data Analyzer } \\ \text { IPM } & \text { Integrated Planning Model } \\ \text { KPP } & \text { Kenetic pre-processor } \\ \text { LNB } & \text { Low NO } x \text { burner } \\ \text { MAC } & \text { Marginal abatement cost } \\ \text { MD } & \text { Marginal damage } \\ \text { MPO } & \text { Modified pollution-offset } \\ \text { MCIP } & \text { Meteorology Chemistry Interface Processor } \\ \text { NAAQS } & \text { National Ambient Air Quality Standards } \\ \text { NAM } & \text { North American Mesoscale } \\ \text { NBP } & \text { Non-degradation offset } \\ \text { NDO } & \text { National Emission Inventory } \\ \text { NEI } & \text { Nitrogen oxides } \\ \text { NPRI } & \end{array}$




\begin{tabular}{ll} 
NSR & New Source Review \\
OTC & Ozone Transport Commission \\
OPF & Optimal power flow \\
OFA & Over fire air \\
ORISPL & Office of Regulation Information System Plant Location \\
PHEV & Plug-in hybrid electric vehicles \\
PJM & Pennsylvania-New Jersey-Maryland \\
PM & Particulate matter \\
POS & Pollution-offset system \\
PSD & Prevention of Significant Deterioration \\
RACT & Reasonably Available Control Technologies \\
SIP & State Implementation Plan \\
SMOKE & Sparse Matrix Operator Kernel Emission \\
SCMIN & Social cost minimization \\
SPT-D-SCMIN & Spatial demand-based social cost minimization \\
SPT-F-SCMIN & Spatial flexible social cost minimization \\
TMP-SCMIN & Temporal social cost minimization \\
SCR & Selective catalytic reduction \\
SNCR & Selective non-catalytic reduction \\
TAC & Total abatement cost \\
TD & Total damage \\
TRS & Trading ratio system \\
TLM & Tangent linear model \\
TMP-D-SCMIN & Temporal demand-based social cost minimization \\
VOC & Temporal flexible social cost minimization \\
\hline
\end{tabular}


VMT

WRF

WPS

WTP
Vehicle mile traveled

Weather Research and Forecasting

WRF Preprocessing System

Willingness to pay 


\section{LIST OF SYMBOLS}

ambient quality (chapter 2), abetment activity (chapter 8)

target ambient quality at receptor $\mathrm{j}$

background pollution

emission from source $\mathrm{i}$

emission reduction from source $\mathrm{i}$

transfer coefficient from source i to receptor $\mathrm{i}$

number of ambient permits that source $i$ holds at receptor $j$

abatement cost of source $\mathrm{i}$

marginal abatement cost of source i

exchange rate between sources $\mathrm{i}$ and $\mathrm{j}$

allocated permit to source $\mathrm{i}$

number of permits source $i$ buys from source $\mathrm{j}$

cap on total system-wide damage

concentration of species $i$

three-dimensional the wind field

air density

turbulent diffusivity tensor

chemical reaction rate for species $\mathrm{i}$

emission rate of species $\mathrm{i}$

ith row of the Jacobian of the chemical reaction rates

adjoint cost function

local cost function

adjoint variable (or Lagrangian multiplier in an optimization framework) 


\begin{tabular}{|c|c|}
\hline$\varphi$ & adjoint forcing term \\
\hline $\mathcal{N}$ & numerical operator for forward method \\
\hline $\mathcal{L}$ & numerical operators for forward sensitivity method \\
\hline $\mathcal{L}^{*}$ & numerical operators for adjoint sensitivity method \\
\hline$P_{i}$ & population at grid $\mathrm{i}$ \\
\hline$P_{q}$ & electricity price \\
\hline$Q$ & electricity generation level \\
\hline$R_{i o}$ & rate of transformation between input and output \\
\hline$P_{i}$ & input price \\
\hline$c_{p}$ & power plant's capital and operating cost \\
\hline$c_{c}$ & control technology's capital and operating cost \\
\hline$R_{e o}$ & rate of transformation between the output and emissions \\
\hline$\lambda_{i}$ & ozone metric sensitivities to $\mathrm{NO}_{\mathrm{x}}$ emissions from polluters $\mathrm{i}$ \\
\hline$\alpha_{i j}$ & exchange rates between polluters $\mathrm{i}$ and $\mathrm{j}$ \\
\hline$e_{i}^{0}$ & allocated emission quotas to polluter i \\
\hline$e_{i}^{\max }$ & maximum possible emission level for polluter i \\
\hline$\beta$ & epidemiological concentration response factor \\
\hline$\Delta M$ & change in mortality \\
\hline$M_{0}$ & baseline non-accidental mortality rate \\
\hline$V_{S L}$ & value of statistical life \\
\hline$\triangle T D$ & change in total damage \\
\hline$D_{i}$ & damage function for source $i$ \\
\hline$E_{T}$ & total ozone season cap on emissions \\
\hline$M D$ & marginal damage \\
\hline$Q_{T}$ & total electricity demand in the ozone season \\
\hline
\end{tabular}


$G_{i}$ $R_{i}$

$Q_{t}$ generation capacity of polluter $i$

generation intensity (MWh/ton) for polluter $i$

total electricity demand in the ozone season for hour $t$ 


\section{CHAPTER 1:}

\section{INTRODUCTION}

Surface ozone is a serious threat to public health even at very low concentrations because it can contribute to premature mortality resulting from shortterm and long-term exposure (Bell et al. 2004; Jerrett et al. 2009). The first ozone regulation effort in the U.S. was promulgated in 1970 and introduced the National Ambient Air Quality Standards (NAAQS). NAAQS standards defined the limit for six main pollutants, called criteria pollutants by the U.S. EPA, including ozone.

Ozone is formed in the atmosphere through a series of photochemical reactions and is therefore considered a secondary pollutant. The reactions occur when there are adequate amounts of $\mathrm{NO}_{\mathrm{x}}\left(\mathrm{NO}_{2}\right.$ and $\left.\mathrm{NO}\right)$, volatile organic compounds (VOCs), and sunlight. $\mathrm{NO}_{\mathrm{x}}$ emission sources include mobile (emissions produced by vehicles) and point sources, as well as other combustion processes (e.g., biomass burning) and natural emissions (e.g., soil $\mathrm{NO}_{\mathrm{x}}$ ). Ozone concentrations are usually higher in hot seasons because the photochemical reaction depends often on the amount of sunlight. Accordingly, ozone control programs are usually in place during the ozone season from May $1^{\text {st }}$ to September $30^{\text {th }}$. The first $\mathrm{NO}_{\mathrm{x}}$ control program was started in the 1990s as a nationwide program to prevent acid rain (formed from either $\mathrm{NO}_{\mathrm{x}}$ or $\mathrm{SO}_{2}$ emissions); the program, however, was not designed to deal with surface ozone problem. There were two options for control of $\mathrm{NO}_{\mathrm{x}}$ under the acid rain program: reduction of the emission rates for all units of a facility (power plant) to 
below a defined level, or reduction of the average emission rates for a facility to below a certain level (EPA, 2007).

The Ozone Transport Commission (OTC) $\mathrm{NO}_{\mathrm{x}}$ trading program was the first cap-and-trade program, and was established in 1999 in the northeastern U.S. Since then, a number of $\mathrm{NO}_{\mathrm{x}}$ cap-and-trade programs have been implemented in the eastern U.S. The number of states participating in these cap-and-trade programs has also increased (EPA 2008).

Cap-and-trade programs are popular due to their flexibility. Participants in cap-and-trade programs are assigned emission quotas and have the option to trade in a free market, but need to keep enough quotas to cover their emissions for a specific period of time. The emission market motivates participants with different emission reduction costs to trade emission quotas in a way designed to reduce their expenses. Cap-and-trade programs are also attractive for regulators because they allow them to reduce the total emissions in the system by reducing the total number of quotas. The total $\mathrm{NO}_{\mathrm{x}}$ emissions in the eastern U.S., where cap-and-trade programs have been in place for the past two decades, has been reduced drastically (EPA 2008). However, ground-level ozone is still in violation of the NAQS standards in several regions in the eastern U.S.

The current U.S. cap-and-trade $\mathrm{NO}_{\mathrm{x}}$ program does not account for location and time specific effects of $\mathrm{NO}_{\mathrm{x}}$ emissions on ozone formation. In the current $\mathrm{NO}_{\mathrm{x}}$ cap-and-trade program, one unit of emissions at one location can be traded for one unit of emissions at any other location. Issuing trading permits on a one-to-one basis 
(with no exchange rate) is not problematic for long-lived pollutants species, such as carbon dioxide $\left(\mathrm{CO}_{2}\right)$, because they exist long enough to be uniformly mixed. For ozone or its precursors, the shorter lifetime results in spatial variability in the transport path from sources to receptors. In particular, the response of ozone to $\mathrm{NO}_{\mathrm{x}}$ emissions is very location-dependent and nonlinear (Hakami et al. 2004; Tong and Mauzerall 2006). The ozone formation potential of $\mathrm{NO}_{\mathrm{x}}$ emissions depends on where and when they are emitted and what chemical atmospheric regime they are exposed to during their trajectory. Therefore, the effectiveness of $\mathrm{NO}_{\mathrm{x}}$ emission reduction is affected by the time and location of the reduction. Inclusion of these temporal and spatial effects can improve the performance of the current system (Muller and Mendelsohn 2009; Nobel et al. 2001; Sun et al. 2012).

The first step to include the differences in ozone formation potentials in the policy making process is an accurate estimation of the impacts of $\mathrm{NO}_{\mathrm{x}}$ for different times and locations. The estimation of individual source impacts is not an easy task when it comes to modeling the fate of pollutants in a complex atmospheric system with different chemical and physical processes. The variability associated with the emissions from different sources and varied meteorological conditions, contributes to the complexity of atmospheric pollution modeling.

Calculation of source impacts on health or other policy outcomes relies on simplified or formal sensitivity methods. Both approaches are used to calculate the relationships between sources and receptors, and to identify the contribution of the sources to the pollutant concentrations at the receptors. Simplified methods, such as 
once-at-a-time perturbation approach (also called brute-force method), are straightforward but become computationally infeasible for large number of sources. Formal sensitivity approaches rely on calculation of derivatives of concentrations with respect to emission rates through mathematical differentiation of the governing equations. Simplified and formal sensitivity methods can be applied to atmospheric models with different levels of complexity from dispersion models to threedimensional photochemical air quality models (Cho et al. 2012; Fann et al. 2009; Muller and Mendelsohn 2009; Tong et al. 2006; Hakami et al., 2004; Pappin and Hakami 2013).

Sensitivity analyses that rely on simplified models often do not account for physical and chemical processes occurring during the transport of pollutants from sources to receptors, and thus, have lower accuracy for calculation of source-receptor relationships particularly for secondary pollutants such as ozone. The traditional sensitivity methods, known as brute-force methods, account for physical and chemical processes in the atmosphere but are more expensive because they rely on computationally challenging simulations. The brute-force methods need conducting simulation by air quality models for multiple perturbed scenarios and therefore are only affordable for identifying the impacts from a limited number of sources (Nobel et al. 2001; Tong et al. 2006; Wang, Thompson, et al. 2007).

Formal sensitivity methods can calculate the source-receptor relationships efficiently with realistic computational costs. Formal sensitivity approaches are categorized into forward and backward (adjoint) sensitivity methods. Both methods 
can establish source-receptor relationships but with different efficiencies. For a matrix of source-receptor relationships with $M$ rows for sources and $N$ columns for receptors, there are $M \times N$ source-receptor coefficients. A forward sensitivity model can calculate one row of the matrix in a single simulation, while a backward sensitivity model can estimate one column of the matrix in a single model run. Therefore, if of interest is the relationships between a few sources and all receptors, the forward method is more efficient, whereas the relationships between a few receptors and all sources are more efficiently addressed by the backward (adjoint) method.

This thesis employs a recently developed adjoint sensitivity tool for a state-ofthe-art air quality model and investigates its applications in environmental policy making. We present a methodology for differentiating between $\mathrm{NO}_{\mathrm{x}}$ emission sources which can, in turn, lead to the design of optimal control strategies and policies for various environmental and health objectives, and an environmentally improved emissions trading system. This work aims to provide decision makers with a decision support system that can assist quantification of the effect of different control programs on air quality, and help establish more effective environmental guidelines. In this study, the following questions will be addressed:

- What is the contribution of each power plant to the damage caused by the elevated levels of ambient ozone? How do the per ton benefits of $\mathrm{NO}_{\mathrm{x}}$ emission reductions vary temporally and spatially? How can the inclusion of such information in policy design improve environmental performance? 
- How can adjoint sensitivity analysis and targeted trading (trading that differentiates between sources) be used towards establishment of an ozone trading system that outperforms the current $\mathrm{NO}_{\mathrm{x}}$ cap-and-trade system?

- How different is the environmental performance of a trading system when targeted trading is in place? What emission distribution would maximize environmental performance?

- How does the benefit per ton of $\mathrm{NO}_{\mathrm{x}}$ emission reductions change when emission are reduced and what are the policy implications of these changes?

- How do power plants response to different types of electricity markets in the short-term? How does it impact their emission trading behavior?

This thesis is organized into 9 chapters. Five chapters are organized in a paper format and contain more detailed introductory sections. Chapters 4 to 8 have their own introduction and methodology as a paper, and as such chapters 2 and 3 are mainly provided to be complements, which may introduce some redundancy.

In chapter 2, the background and relevant literature are reviewed. This review covers chemical reactions in the atmosphere, ozone and $\mathrm{NO}_{\mathrm{x}}$ control programs and regulations in the U.S., $\mathrm{NO}_{\mathrm{x}}$ control technologies for power plants, methods for estimation of pollution health damages, and the theoretical basis for cap-and-trade systems and its variants. As this work uses adjoint sensitivity analysis for estimation health damages attributable to $\mathrm{NO}_{\mathrm{x}}$ emissions, the adjoint sensitivity analysis is also reviewed. 
Chapter 3 of this thesis describes the methods and tools used in this work. The components of the proposed decision support system are introduced and the process through which the proposed model can inform decision making process is discussed. The components of the decision support model including the air quality model, the sensitivity analysis model and the optimization tool are presented and discussed.

Chapter 4 presents the details of a theoretical but improved $\mathrm{NO}_{\mathrm{x}}$ cap-and-trade system. Unlike the current policy in the U.S., which treats $\mathrm{NO}_{\mathrm{x}}$ emissions from all sources equally, this system differentiates among $\mathrm{NO}_{\mathrm{x}}$ emissions by accounting for their location-specific ozone formation potentials through use of emission exchange rates. Two different $\mathrm{NO}_{\mathrm{x}}$ control policies (i.e., the cap-and-trade with and without exchange rates) are compared, and their efficiency is evaluated. We demonstrate that the decision support model can predict $\mathrm{NO}_{\mathrm{x}}$ emission trading behavior and post-trade ozone concentrations. The environmental outcomes and abatement cost performances of the two policies are examined in a case study for 218 U.S. power plants.

Chapter 5 addresses the inclusion of spatially different benefit per ton of emission reductions (marginal damages) in policy design and setting location-specific emission fees. It demonstrates which distribution of emissions results in a socially optimal environmental performance. This chapter addresses the potential performance enhancement of switching from the current policy to a taxation policy. The benefits gained by redistributing of emissions are estimated for a case study similar to that presented in chapter 4 . .. 
We include temporal differences in the marginal damages of emissions in the study presented in Chapter 6. This chapter investigates how marginal damages vary with time, and how such variations can be incorporated into an economic instrument such as cap-and-trade. The benefits gained by redistributing electricity generation are also investigated. Under the proposed policies, the interaction of the electricity market and $\mathrm{NO}_{\mathrm{x}}$ control policies is considered. This chapter identifies optimal times and locations for electricity generation resulting in minimized costs of emission reductions and health damages.

Marginal damage value can change in times as significant reductions in emissions take place. The study presented in Chapter 7 investigates how marginal damages change with nationwide reductions in emissions. Source-specific marginal damages of $\mathrm{NO}_{\mathrm{x}}$ emissions are calculated when emissions from different sectors (i.e., mobile and point sources) are reduced. Using the calculated marginal damages for different baseline emissions, source-specific marginal damage curves are constructed and relevant policy insights are discussed.

Chapter 8 proposes a methodology to calculate the short-term willingness to pay for emission permits in the U.S. using plant specific data. This estimation is based on plant-level benefit maximization in both the electricity and emissions permit markets. In this chapter, using the proposed methodology, the behavior of power plants is estimated for the 218 coal-fired electric generation units that took part in the $\mathrm{NO}_{\mathrm{x}}$ Budget Program (NBP) during the ozone season of 2007. 
In Chapter 9, a summary of the findings of this thesis is provided and insights and conclusions from these results are discussed. The thesis is concluded with suggestions for potential areas for future research. 


\section{CHAPTER 2:}

\section{BACKGROUND}

In this chapter, first ozone and $\mathrm{NO}_{\mathrm{x}}$ chemistry will be explained which will clarify how ozone concentrations respond to $\mathrm{NO}_{\mathrm{x}}$ controls for different atmospheric regimes. Then, the relevant regulations and programs in the U.S. and their success in $\mathrm{NO}_{\mathrm{x}}$ and ozone control will be discussed. Next, costs and benefits of the U.S. cap-and-trade programs calculated by different studies will be reviewed. Finally, $\mathrm{NO}_{\mathrm{x}}$ control technologies, theoretical emissions trading models for different types of pollutants, and sensitivity analysis methods that are used for the proposed improvements to current cap-and-trade systems will be elaborated.

\subsection{Ozone formation and $\mathrm{NO}_{\mathrm{x}}$}

Ozone and $\mathrm{NO}_{\mathrm{x}}$, one of its main precursors, are the two main species considered in this thesis. There is a significant spatial and temporal variability in response of ozone concentrations to $\mathrm{NO}_{\mathrm{x}}$ emissions. Identifying differences in $\mathrm{NO}_{\mathrm{x}}$ emissions are of importance in policy design and can be used for targeted emission reductions. Furthermore, the relationships between ozone and $\mathrm{NO}_{\mathrm{x}}$ is very complex because an increase in $\mathrm{NO}_{\mathrm{x}}$ emissions may lead to an increase or decrease in ozone concentrations depending on the governing atmospheric regime. This section aims to explain the chemistry behind the $\mathrm{NO}_{\mathrm{x}}$-ozone relationship which is essential information for chapters 4 to 7 . 
The ozone molecule includes three atoms of oxygen. It exists in both the stratosphere and troposphere. The stratospheric ozone protects the earth against ultraviolet wavelengths from the sun. In contrast, the tropospheric ozone, or surface ozone, is harmful to humans, plants, and animals. In this work, all the discussions are about tropospheric, or more accurately, surface ozone which will simply be referred to as ozone.

Ozone is a secondary pollutant, in that it is not directly emitted into the atmosphere. It is formed by a set of photochemical reactions that require volatile organic compounds (VOCs), nitrogen oxides or $\mathrm{NO}_{\mathrm{x}}$ (which include $\mathrm{NO}$ and $\mathrm{NO}_{2}$ ), and sunlight. Summer has the most favorable conditions for ozone formation because it is hot, dry and sunny. Correspondingly, ozone is regulated during the ozone season (May $1^{\text {st }}$ to September $30^{\text {th }}$ ). The main source of $\mathrm{NO}_{\mathrm{x}}$ is combustion, which mainly occurs in vehicle engines, industries, and electric generation utilities (power plants).

Ozone's response (increased/decreased concentration) to changes in its precursor (VOCs and $\mathrm{NO}_{\mathrm{x}}$ ) emissions, is nonlinear and differs from one location and/or time to another (Muller and Mendelsohn 2009; Tong et al. 2006). This response can be well represented by the ozone isopleth (Figure 2.1). All points on an isopleths contour line have the same ozone concentration. 


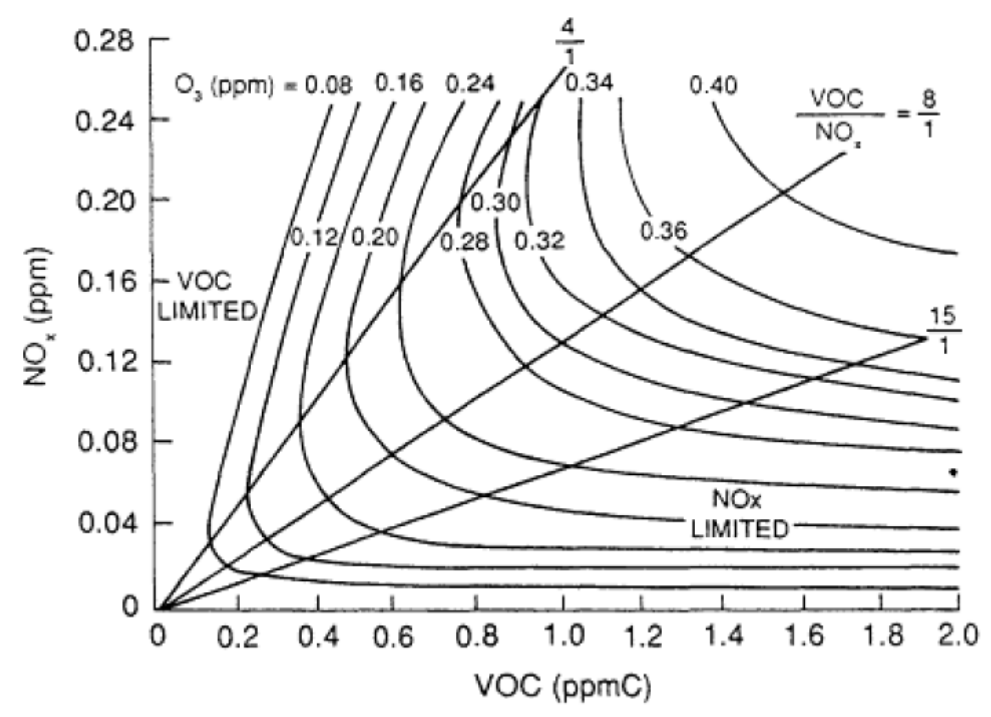

Figure 2.1. A typical ozone isopleth used in U.S. EPA Empirical Kinetic Modeling Approach (EKMA) (Doge, 1977).

There are two main regimes described by ozone isopleth: the $\mathrm{NO}_{\mathrm{x}}$-limited and the $\mathrm{NO}_{\mathrm{x}}$-inhibited (VOC-limited) regimes. In the $\mathrm{NO}_{\mathrm{x}}$-limited regime, the ratio of $\mathrm{NO}_{\mathrm{x}}$ to VOC is low. This regime exists mainly in rural areas where there are higher (biogenic) VOC concentrations compared to $\mathrm{NO}_{\mathrm{x}}$. For this chemical regime, a reduction in the $\mathrm{NO}_{\mathrm{x}}$ concentration reduces ozone formation. On the other hand, in the $\mathrm{NO}_{\mathrm{x}}$-inhibited (or VOC-limited) regime, the ratio of $\mathrm{NO}_{\mathrm{x}}$ to $\mathrm{VOC}$ is high. Urban areas with high $\mathrm{NO}_{\mathrm{x}}$ vehicular emissions or power plants are good examples of $\mathrm{NO}_{\mathrm{x}^{-}}$ inhibited regimes. For $\mathrm{NO}_{\mathrm{x}}$-inhibited conditions, $\mathrm{NO}_{\mathrm{x}}$ emission reduction can cause increased ozone. For each predominant chemical regime, various chemical reactions dominate the ozone production/loss pathways.

Atmospheric chemical reactions take place in a state of dynamic balance where the species involved are consciously formed and consumed. The concentration 
of a species increases when its rate of production is greater than its rate of consumption. The reactions below are a simplified representation of the ozone/ $/ \mathrm{NO}_{\mathrm{x}}$ chemical cycle (Seinfeld and Pandis 2006):

$$
\begin{aligned}
& \mathrm{NO}_{2} \stackrel{h v\left(\mathrm{O}_{2}\right)}{\longrightarrow} \mathrm{NO}+\mathrm{O}_{3} \\
& \mathrm{NO}+\mathrm{O}_{3} \rightarrow \mathrm{NO}_{2}+\mathrm{O}_{2} \\
& \mathrm{O}_{3} \stackrel{h v}{\longrightarrow} \mathrm{O}\left({ }^{1} \mathrm{D}\right)+\mathrm{O}_{2} \\
& \mathrm{O}\left({ }^{1} \mathrm{D}\right)+\mathrm{H}_{2} \mathrm{O} \rightarrow 2 \mathrm{OH} \\
& \mathrm{OH}+\mathrm{RH}^{\mathrm{O}}+\mathrm{O}_{2} \rightarrow \mathrm{RO}_{2}+\mathrm{H}_{2} \mathrm{O} \\
& \mathrm{RO} / \mathrm{HO}_{2}+\mathrm{NO}^{\mathrm{N}} \rightarrow \mathrm{NO}_{2}+\mathrm{RO} / \mathrm{OH} \\
& \mathrm{OH}+\mathrm{NO}_{2} \rightarrow \mathrm{HNO}_{3} \\
& \mathrm{OH}+\mathrm{CO}^{\mathrm{C}} \mathrm{CO}_{2}+\mathrm{H} \\
& \mathrm{H}+\mathrm{O}_{2}+\mathrm{M}^{\mathrm{M}} \rightarrow \mathrm{HO}_{2}+\mathrm{M}
\end{aligned}
$$

Among the above equations, the photolysis reactions, and those dependent on radicals formed trough photolysis reactions only occur in the presence of sunlight. During the day, ozone is formed by reaction $2-1$ and is consumed by reaction $2-2$. During night, reaction 2-2 consumes part of the ozone produced during the day by reaction 2-1. Reaction 2-6 can change the ozone formation/consumption balance by converting $\mathrm{NO}$ to $\mathrm{NO}_{2}$ without consuming $\mathrm{O}_{3}$ (i.e., reaction 2-2) which amounts to a net production of ozone. The rate of reaction 2-6 (which is essential for enhanced production of ozone during photochemical smog episodes) depends on the availability 
of radicals. Radicals (i.e., species with a free electron such as $\mathrm{OH}$, or $\mathrm{RO}_{2}$ ) are key components in photochemical ozone production. Availability of peroxy radicals (i.e., $\mathrm{HO}_{2}$ and $\mathrm{RO}_{2}$ ) depends on hydroxyl radical availability. The production of $\mathrm{HO}_{2}$ is also dependent on the availability of hydroxyl radical for oxidation of $\mathrm{CO}$ and VOCs (reaction 2-5 and 2-8). The hydroxyl radical is often referred to as the atmospheric cleansing agent as it initiates the majority of oxidation pathways in the atmosphere.

The availability of radicals (e.g., OH) and the rate of reaction 2-6 depends on the $\mathrm{NO}_{\mathrm{x}}$ regime. The effectiveness of $\mathrm{NO}_{\mathrm{x}}$ emissions in producing ozone is the result of ongoing competition between various reactions for reacting with active radicals taking part in the photochemical production of ozone. In particular, VOCs (shown as $\mathrm{RH}$ ) and $\mathrm{NO}_{\mathrm{x}}$ compete for $\mathrm{OH}$ (reaction 2-5 and 2-7) and it is the $\mathrm{NO}_{\mathrm{x}}$ regime that determines which reaction wins. Note that while reaction 2-5 leads to eventual production of ozone, reaction 2-7 removes radicals from the system and slows down ozone production.

In a $\mathrm{NO}_{\mathrm{x}}$-inhibited regime, reaction 2-7 is the governing reaction because $\mathrm{NO}_{\mathrm{x}}$ availability limits reaction 2-6. In this case, $\mathrm{NO}_{\mathrm{x}}$ reduction causes increased ozone concentrations as the decrease in $\mathrm{NO}_{\mathrm{x}}$ through reaction 2-7 provides more $\mathrm{OH}$ radicals for initiation of oxidation processes (reactions 2-5 and 2-8) and the subsequent enhancement in the rate of reaction 2-6.

In the $\mathrm{NO}_{\mathrm{x}}$-limited regime, the chemical system is constrained by the availability of VOCs, rather than $\mathrm{NO}_{\mathrm{x}}$, in the atmosphere. In this case, the rate of reaction 2-6 is controlled by availability of $\mathrm{NO}_{\mathrm{x}}(\mathrm{NO})$ and decreases in $\mathrm{NO}_{\mathrm{x}}$ emissions 
leads to reduction in ozone formation. The different responses of ozone to $\mathrm{NO}_{\mathrm{x}}$ are of interest in control policy design because they result in negative or positive benefit per ton of emission reductions. A negative benefit per ton usually occurs in large urban locations with high $\mathrm{NO}_{\mathrm{x}}$ concentrations, and it means that emission reductions are not beneficial and increase the damages to human health. More discussions on $\mathrm{NO}_{\mathrm{x}}$ health damages and benefit per ton of emission reductions will be provided in chapters 5,6 , and 7.

The transition region between $\mathrm{NO}_{\mathrm{x}}$-limited and $\mathrm{NO}_{\mathrm{x}}$-inhibited regimes is often referred to as the ozone ridge. This region represents a chemical regime where $\mathrm{NO}_{\mathrm{x}}$ to VOC ratios are near optimal and ozone production occurs with high efficiency. The ozone response to $\mathrm{NO}_{\mathrm{x}}$ reductions in $\mathrm{NO}_{\mathrm{x}}$-limited and $\mathrm{NO}_{\mathrm{x}}$-inhibited regimes is close to linear. Nonlinearity in the ozone response to $\mathrm{NO}_{\mathrm{x}}$ emissions happens when changes in $\mathrm{NO}_{\mathrm{x}}$ availability causes transition from one regime to another (Hakami et al., 2004).

\subsection{U.S. ozone and $\mathrm{NO}_{\mathrm{x}}$ programs}

\subsection{1. $\mathrm{NO}_{\mathrm{x}}$ regulations and programs in the U.S.}

$\mathrm{NO}_{\mathrm{x}}$ regulations in the United States date back to 1970 when ozone was designated as one of the six criteria pollutants by Congress in the Clean Air Act (CAA). The 1970 amendment required the EPA to establish the NAAQS for criteria pollutants. It also required states to develop State Implementation Plans (SIPs) to 
control their emission levels to satisfy NAAQS. The 1970 amendment focused on new sources and existing sources which were planning on major modification. These sources were subjected to an emissions standard called the New Source Performance Standard (NSPS). In 1970, The CAA mandated the EPA to develop NSPS emission standards. NSPS determined an emission rate (lb/MMBtu) based on the Best Available Control Technology (BACT) for the new sources.

In 1977, Congress added more provisions to the CAA to protect against degradation of air quality. The two main additions were the Prevention of Significant Deterioration (PSD) provision in attainment areas and the New Source Review (NSR) provision in nonattainment areas. Non-attainment areas are defined in CAA as the areas where air quality does not meet the standard. PSD was added to the CAA to prevent the degradation of the ambient quality and NSR was added for prevention of increased emissions in nonattainment areas. All sources in non-attainment areas were required to use Reasonably Available Control Technologies (RACT). According to the NSR, new sources in nonattainment areas were only permitted if they used the Lowest Available Emission Rate (LAER) and offset emissions from existing sources (Burtraw and Szambelan, 2009).

The 1977 CAA amendment did not lead to $\mathrm{NO}_{\mathrm{x}}$ emissions reductions since they had no strict limitations for the existing stationary sources. Emissions restrictions for existing sources were added to the CAA in 1990. The changes imposed strict rules for emissions reductions, and they gave some authority to the EPA for regulating these sources. Title I and Title IV of the CAA 1990 amendments were two ways to 
limit $\mathrm{NO}_{\mathrm{x}}$ emissions. Title IV, which created the Acid Rain Program, required a 2 million ton yearly reduction in $\mathrm{NO}_{\mathrm{x}}$ emissions from coal-fired power plants. Title I of the 1990 CAA amendment included provisions for attainment and maintenance of NAAQS. It also outlined a timetable for states to meet the NAAQS requirements (Burtraw et al., 2005).

The CAA revision of 1990 also created the Ozone Transport Committee (OTC). In 1994, the OTC was formed under the CAA to consider the ozone problem in the eastern U.S. In 1999, the OTC states signed a memorandum and the OTC Trading Program started in 11 states and the District of Columbia. The OTC states were grouped into outer, northern, and inner zones. The inner zone included the populated eastern states, most of which were among the ozone non-attainment regions, affected by emissions from up-wind emitters in the outer zone. To protect the ambient air quality in the inner zone, the original OTC trading program was designed based on zonal trading limits. Unlike a non-zonal emission trading which allows the exchange of emission quotas on a one-to-one basis between zones, a zonal trading sets a ratio for the exchange of quotas between zones to discourage the increase of emissions from up-wind states contributing to the concentrations in down-wind states. However, further studies suggested that non-zonal trading would not degrade the ambient air quality leading to the implementation of non-zonal trading by OTC states. The OTC was not under the EPA, but it was helped by the EPA monitoring system and its air quality models (EPA, 2003). 
The ozone problem in the eastern states occurred in wider areas than OTC regions. States were not able to meet the 1997 NAAQS, because downwind states received sizeable contributions to their ambient air quality from up-wind out of state sources. According to the CAA amendment of 1990, states could send petitions to the EPA if upwind states contributed to their ambient air quality. Following receipt of such petitions, the EPA used its power under the CAA to revise SIPs in 1998. The rule is known as the $\mathrm{NO}_{\mathrm{x}}$ SIP Call since it calls states to revise their implementation plans. According to the $\mathrm{NO}_{\mathrm{x}}$ SIP Call rule, states could either follow an emission rate limit in the state or could take part in a regional cap-and-trade program. The trading program under the $\mathrm{NO}_{\mathrm{x}}$ SIP Call $\left(\mathrm{NO}_{\mathrm{x}}\right.$ Budget Program (NBP)) started in 2003 after regulatory steps took place. 19 states and the District of Colombia took part in the NBP (EPA, 2008).

In 2005, the EPA used its power under the 1990 amendment and established the Clean Air Interstate Rule (CAIR). This rule is known as the CAA good neighbor rule since neighbor states must reduce their emissions cap if they have a significant negative contribution to other states' air quality. CAIR, which is the current trading program in place in the U.S., was promulgated in 22 eastern states in 2008. The rule was temporarily vacated in 2008 in a litigation brought before the D.C. circuit court before being reinstated by the appeal court later in the year.

In 2011, the EPA finalized the Cross State Air Pollution Rule (CSAPR) which was intended to replace CAIR. Under the CSAPR, if the contribution of upwind states to ozone formation in downwind states were more than a limit, the upwind states were 
required to make additional emission reductions. Out of 28 states covered by CSAPR, 5 states were required to additionally reduce $\mathrm{NO}_{\mathrm{x}}$ emissions. In 2012, the U.S. supreme court vacated CSAPR and ordered the EPA to keep CAIR in place while working on a replacement rule. There were two main reasons for the court's decision. First, the court found that the EPA mandated upwind states to reduce their emissions under the Federal Implementation Plan (FIP), and did not allow them to develop their own SIPs to meet emission reduction requirements. Second, the court concluded that the EPA forced upwind states to reduce more emissions than their contribution to downwind states. The court ruling was one of the main reasons for the significant drop in the $\mathrm{NO}_{\mathrm{x}}$ permit price. The $\mathrm{NO}_{\mathrm{x}}$ price was $\$ 825 /$ ton in the ozone season of 2008 , but dropped significantly after 2008 . The price stayed below $\$ 30 /$ ton during the ozone season of 2012. Other reasons for such a low $\mathrm{NO}_{\mathrm{x}}$ price included the significant emission reductions and high availability of banked emission quotas (EPA 2013).

\subsubsection{Achievements of NBP}

NBP sources are about 20 percent of the total $\mathrm{NO}_{\mathrm{x}}$ emissions in NBP regions. The other major sources of $\mathrm{NO}_{\mathrm{x}}$ are natural (e.g., lightening, soil, and wildfire), mobile sources, area sources, and point sources that are not part of the NBP. There were 2569 units participating in the NBP in 2008. Among these units 88 percent were electric generation utilities (EGUs). Figure 2.1 shows the number of units participating in the NBP by type. 


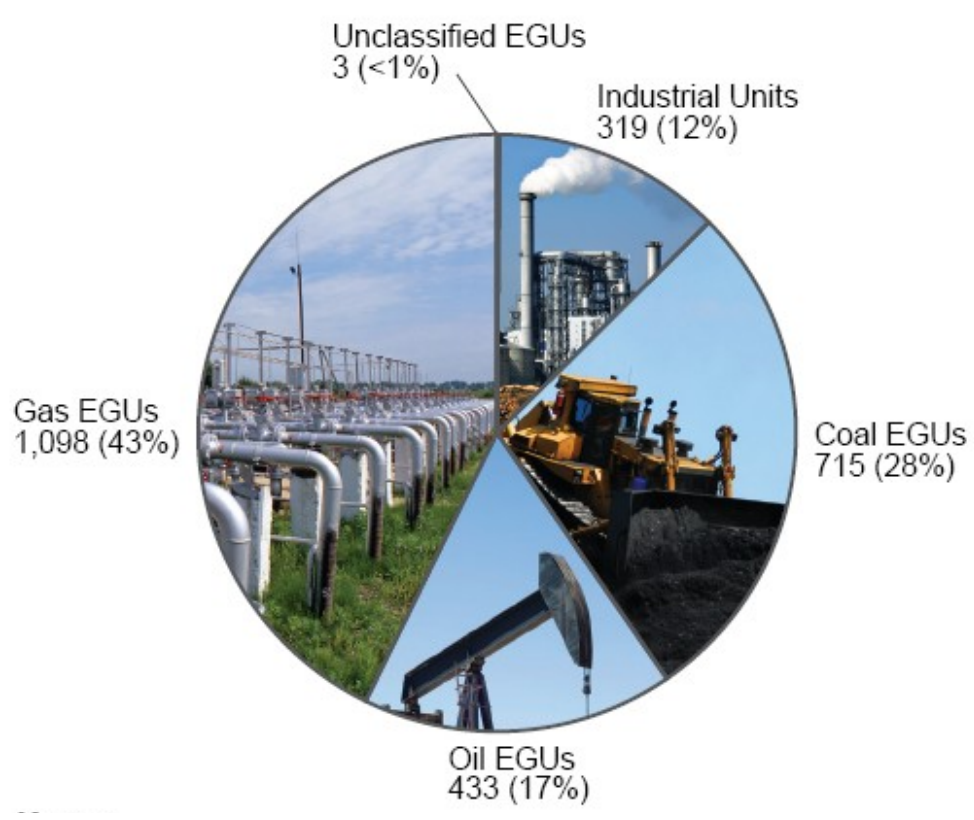

Figure 2.2. Number of NBP sources by type (EPA 2008).

The implementation of different programs in the U.S. has decreased the emissions from affected sources significantly. In 2008, the ozone season $\mathrm{NO}_{\mathrm{x}}$ emissions from NBP sources decreased to 62 percent below the year 2000 level (before the implementation of NBP) and to 75 percent below the year 1990 emission level (before the implementation of CAA amendments). The total emissions in 2008 were 9\% below the cap (Figure 2.3). The overall region-wide ozone concentration since the implementation of NBP has decreased between 11 to 14 percent (EPA, 2008). The seasonal average 8-hour ozone concentration in NBP regions is presented in Figure 2.4. Recent years (after CAIR) have witnessed an even more drastic reduction in $\mathrm{NO}_{\mathrm{x}}$ emissions from EGUs. 


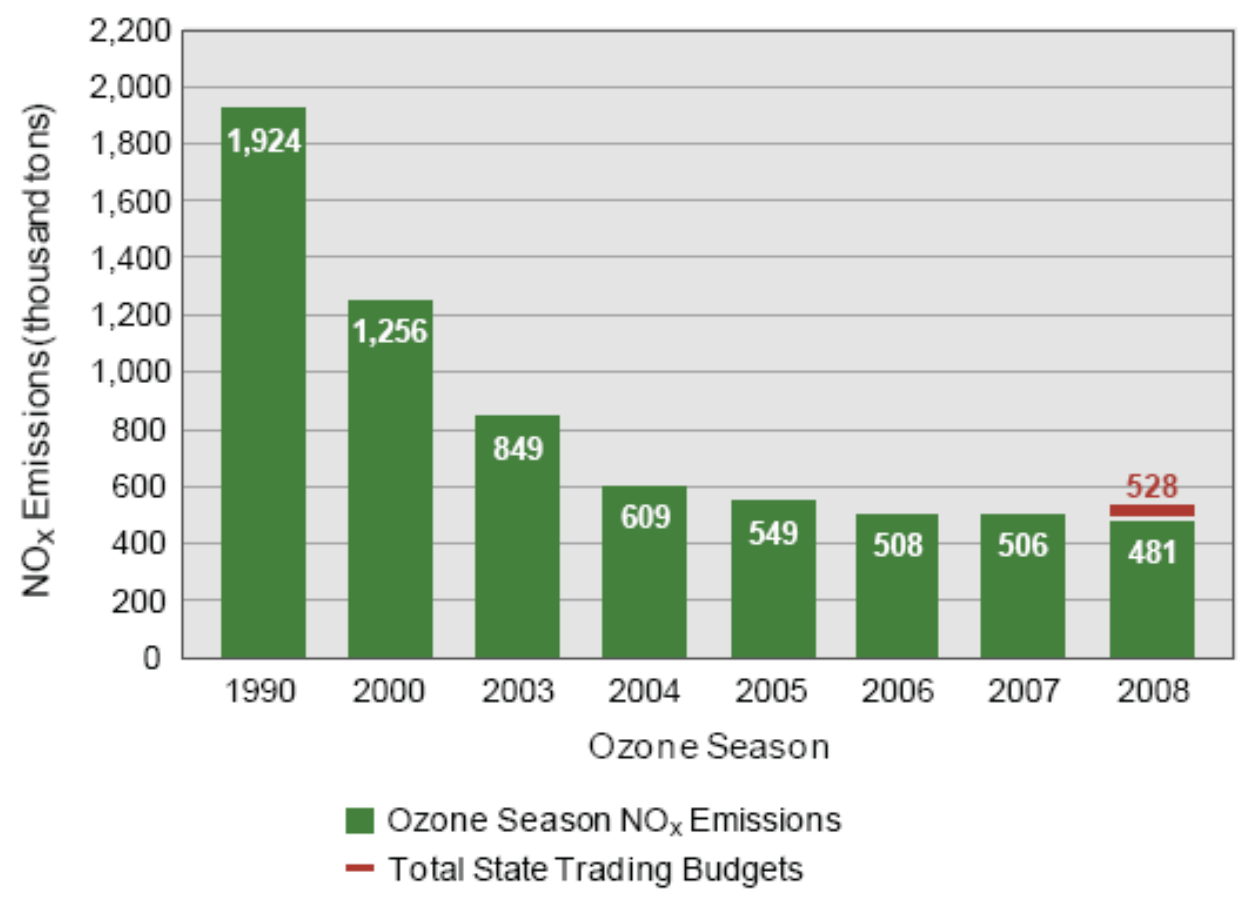

Figure 2.3. NO $_{\mathrm{x}}$ emissions from all NBP sources (EPA, 2008).

Since meteorology also influences ozone formation, in order to evaluate the effect of emission reduction on ozone concentrations in different years, equal meteorological conditions should be imposed. As shown in Figure 2.4, the average ozone concentration in 2004 (unadjusted for weather) is lower than 2007 although the total emissions in this year were higher than emissions in 2007. This was because the ozone season in 2007 was warmer than in 2004 . Removing the meteorological effect results in a higher concentration in 2004 and lower concentration in 2007 (EPA, 2008). 


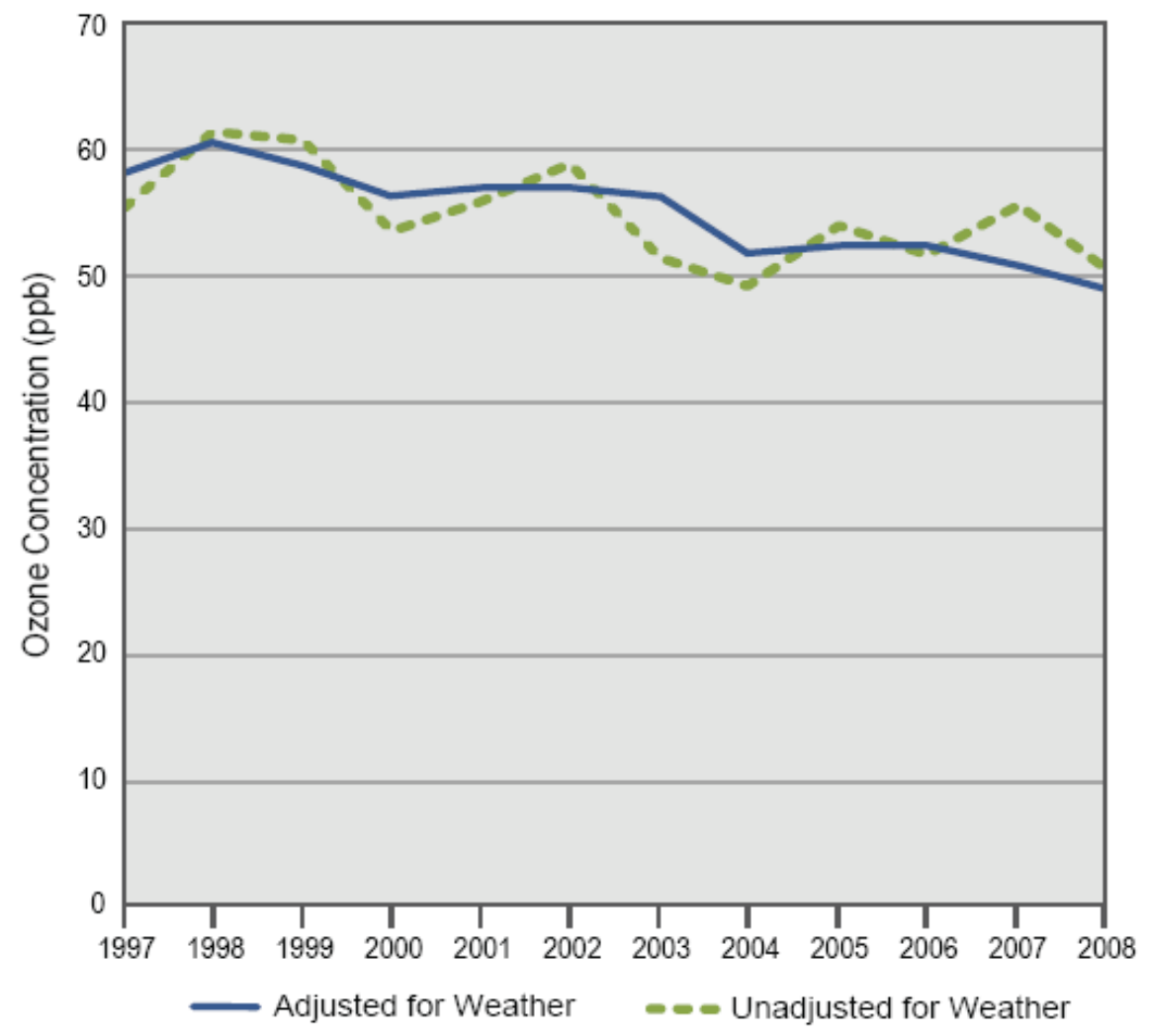

Figure 2.4. Seasonal average 8-hour ozone concentration in NBP region (EPA, 2008).

\subsubsection{Performance of $\mathrm{NO}_{\mathrm{x}}$ control programs in the U.S.}

Despite the improvement in ambient air quality (ozone concentration) under the $\mathrm{NO}_{\mathrm{x}}$ cap-and-trade programs in the U.S., the approach may not be optimally efficient because it neglects the source-specific ozone formation potentials. A socially optimal control program minimizes the social cost of emissions which is defined as the emission reduction costs plus the damage costs to the environment and health, known as external costs. The U.S. $\mathrm{NO}_{\mathrm{x}}$ cap-and-trade is a market-based program that provides cost-saving incentive for participants to trade emission quotas. In the market, participants with high emission reduction costs purchase quotas and save in emission 
reduction costs. In contrast, participants with low emission reduction costs reduce more emissions and benefit by selling their unused emission quotas. Hence, the cost of emission reduction is minimized in the system. However, the current U.S. emission market does not account for the external costs and may result in shifting emissions from low-damage to high-damage locations and lead to an increase in health damage costs. Therefore, the social cost of emissions is not necessarily minimized under a traditional cap-and-trade system. We will discuss social cost minimization policies in further details in chapters 5 and 6. Previous studies have estimated the cost saving obtained by an efficient $\mathrm{NO}_{\mathrm{x}}$ emissions reduction in the U.S. Seskin et al. (1983) examined the cost of reducing $\mathrm{NO}_{\mathrm{x}}$ emissions from stationary sources to the standard $\left(250 \mu \mathrm{g} / \mathrm{m}^{3}\right)$ levels in the Chicago air quality control region. They estimated the annual control costs at 9 million dollars under the least cost strategy and 130 million dollars under the State Implementation Plant (93.1 \% saving). Farrell et al. (1999) compared $\mathrm{NO}_{\mathrm{x}}$ cap-and-trade systems with traditional command and control from 1999 to 2006 in the northeastern U.S. They predicted that the total cost decreased from $\$ 1930$ million dollars to $\$ 1030$ million dollars (47\%) by implementation of a cap-and-trade program.

Krupnick (1986) estimated the potential cost savings from 200 of the largest $\mathrm{NO}_{\mathrm{x}}$ emission sources in Baltimore. His work compared the least-cost strategy with a combined least-cost and command-and-control strategy based on reasonably available control technology (RACT) for three different $\mathrm{NO}_{\mathrm{x}}$ ambient quality standards $(250$, 375 , and $500 \mu \mathrm{g} / \mathrm{m}^{3}$ ). Note that under the combined strategy, emission trading was 
allowed after participants met the RACT requirements. His results showed that changing the strategy from combined command-and-control and least-cost strategy to the least-cost strategy leads to a significant cost saving in the system. Based on his results, the savings are $24 \%$ (from $\$ 2.2$ million to $\$ 1.66$ million per year) when the $\mathrm{NO}_{\mathrm{x}}$ ambient air quality standard is $250 \mu \mathrm{g} / \mathrm{m}^{3}, 69 \%$ (from $\$ 1.10$ million to $\$ 0.37$ million per year) when the standard is $375 \mu \mathrm{g} / \mathrm{m}^{3}$, and $96 \%$ (from $\$ 1.52$ million to $\$ 0.07$ million per year) when the standard is $500 \mu \mathrm{g} / \mathrm{m}^{3}$.

In a study similar in scope to this one, Krupnick et al. (2000) examined the effectiveness of the $\mathrm{NO}_{\mathrm{x}}$ cap-and-trade programs in the eastern U.S. They compared three different policies: command-and-control, cap-and-trade with a one-to-one exchange rate, and cap-and-trade with an ozone exposure exchange rate. Their exchange rate (the ratio at which various partners trade their emissions) was based on ozone exposure and was calculated by running an air quality model (Urban Airshed Model UAM-V) for three two-day typical episodes from the 1990 ozone season. They used the Emission Reduction and Cost Analysis Model for Oxides of Nitrogen $(\text { ERCAM-NO })_{x}$ (Pechan, 1997) to estimate the abatement costs for different categories of point sources (including but not limited to EGUs). They concluded that the EPA's policy (one-to-one ton exchange of $\mathrm{NO}_{\mathrm{x}}$ ) is efficient compared to other policies. They found that there is a large saving (50\%) in migrating from a commandand-control approach to one-to-one trading policies, but that there is not a significant savings (only $2 \%$ ) between one-to-one trading and the exchange rate policy. The reported costs from their work were 1369 million dollars per year for command-and- 
control, 680 million dollars per year for one-to-one trading policy, and 666 million dollars per year for ozone exposure trading.

Burtraw et al. (2001) also calculated the cost and benefits from a $\mathrm{NO}_{\mathrm{x}}$ budget program. They calculated the cost of post-combustion technologies (selective catalytic reduction (SCR) and selective non-catalytic reduction (SNCR)) in 2008 for three different policies: ozone season trading in SIP regions $(\$ 2,146$ million), annual trading in SIP regions $(\$ 2,728$ million), and annual trading throughout the U.S. (\$4,434 million). They reported the necessity of implementation of an annual program by calculating a higher benefit $(\$ 1,777$ million) for an annual trading program in SIP regions compared to seasonal program (\$749 million). Their benefit analysis, however, only considered the health benefits from particulate matter (PM) reductions, and not improvement in ozone air quality. As such, their work underestimates the benefit that can be achieved in the ozone season but captures the more seasonally diverse impact from the PM exposure.

\subsubsection{Marginal damage and its calculation}

The benefits obtained by implementation of cap-and-trade programs in the U.S. has been achieved without consideration of spatial and temporal differences in the marginal damage of pollution. Marginal damage (MD) or the damage per ton caused by pollution represents the monetary value of damage caused by an additional unit of emissions. MDs, or benefits per ton of emission reductions, are important information, which can be used to calculate the total benefit gained by emission reductions under different policies. They are also essential for setting optimal 
emissions reduction targets. MD information, which is not included in the current policy, is especially important for a pollutant whose damages are time and location dependent because they can be used by regulators to target emission reductions for high MD locations and times, which in turn results in a significant reduction in system-wide damages.

Estimation of health damages caused by air pollution is an inter-disciplinary research topic and involves economics, epidemiology, and air quality modeling. Epidemiological studies are used to link the change in air pollutant concentrations to change in mortality. Economic studies estimate the value of statistical life, expressing the monetary value of loss of one human life. Air quality models are used to construct source-receptor relationships which are used to identify how emissions from different sources contribute to pollutant concentrations at receptors. Through combination of economics, epidemiology, and air quality modeling, source-specific marginal damages, can be calculated. The calculation of source-receptor relationships for atmospheric pollutants is often difficult in a large domain without some simplification.

Sensitivity coefficients represent the change in concentrations at receptors as the result of a small change in emissions from sources. The brute-force method is traditionally used to model source-receptor relationships. Under this method, an air quality model is run multiple times (i.e., an additional time per additional source). Before each additional run, the emissions from the source of concern are perturbed. Then, the model is re-run and the resulting concentrations are subtracted from the 
concentrations under the base case to identify the impact of source of concern on receptors across the modeling domain. One of the limitations of the brute-force method is that it requires numerous model runs to construct source-receptor relationships. This limitations results in using state-of-the-art air quality models only for a limited number of sources (e.g., Mauzerall et al. 2005; Tong et al. 2006) or using simplified dispersion models for a large number of sources (e.g., Levy et. al 1999; Rowe et al. 1995). However, as explained in chapter 1, the simplified models do not account for all physical and chemical process in the atmosphere and therefore may lack accuracy.

To estimate the source-receptor relationships, Levy et al. (1999) used three dispersion models to simulate the primary pollutant close to the source (ISCST3), primary pollutants at a certain distance from the source and secondary particles (SLIM3), and the secondary pollutant, ozone (SOMS). They compared three older methods for the estimation of health damages caused by power plants (European Commission 1995; Ridge 1994; Rowe et al. 1995), and suggested a method for the calculation of health damages. The three studies reported the damage costs for oil fueled power plants to be between $\$ 0.0001 / \mathrm{kWh}$ to $\$ 0.019 / \mathrm{kWh}$, which was mainly due to human health damage (between $\$ .000003 / \mathrm{kWh}$ and $\$ 0.017 / \mathrm{kWh}$ ). Levy et al.'s method was an extension of the previous methods with some improvement in air quality modeling for ozone, an updated epidemiological section, and additional accounting for co-pollutant confounding. The species that were included in their damage function were CAA criteria pollutants: PM, ozone, carbon monoxide, $\mathrm{NO}_{2}$, 
$\mathrm{SO}_{2}$, and lead. They found that the plant location was a key determining factor for the contribution of pollutants to total damage. They estimated marginal damages for the year 1997 for different species as follows: $\$ 12,000 /$ ton for $\mathrm{PM}_{10} ; \$ 770 /$ ton for $\mathrm{NO}$; $\$ 790 /$ ton for $\mathrm{SO}_{2}$; and $\$ 8100 / \mathrm{GWh}$ for the total criteria pollutants.

In addition to the simplified dispersion models, reduced-form models are used to construct source-receptor relationships for a large number of sources (e.g., Levy et. al 2009; Fann et al. 2009; Muller and Mendelsohn 2007, 2009; Muller 2011). Reduced-form models rely on multiple response points from the base model to construct source-receptor relationships using the outputs of an air quality model such as Multiscale Air Quality (CMAQ) model (Fann et. al 2009) or the Climatological Regional Dispersion Model (CRDM)) (Levy et al 2009; Muller and Mandelson 2007, 2009). As these models do not fully account for photochemical processes in the atmosphere, they are not well-equipped to characterize the response of secondary pollutants such as ozone.

Levy et al. (2009) calculated health damages based on PM-based mortality using a reduced-form of CRDM. They investigated the uncertainty associated with the calculation of MDs for 407 coal-fired power plants in the U.S. The reduced form model was used to construct source-receptor relationships and calculate $\mathrm{MDs}$ for $\mathrm{NO}_{\mathrm{x}}$, $\mathrm{SO}_{2}$, and $\mathrm{PM}_{2.5}$. Their $\mathrm{MD}$ calculation was based on $\mathrm{PM}_{2.5}$ related mortality. Their calculated MDs varied from $\$ 500 /$ ton to $\$ 15 \mathrm{k} /$ ton for $\mathrm{NO}_{\mathrm{x}}$; from $\$ 6 \mathrm{k} /$ ton to $\$ 50 \mathrm{k} /$ ton for $\mathrm{SO}_{2}$; and $\$ 30 \mathrm{k} /$ ton to $\$ 500 \mathrm{k} /$ ton for $\mathrm{PM}_{2.5}$, which translated into $\$ 0.02 / \mathrm{kWh}$ to $\$ 1.57 / \mathrm{kWh}$. The multivariable regression analysis indicated that the variability in 
damage per ton was mainly due to variability in population and meteorology, and the variability in damage per $\mathrm{kWh}$ was due to population, meteorology, fuel, and control technologies. Their results also indicated that removing 4 million tons of $\mathrm{SO}_{2}$ and 1.5 million tons of $\mathrm{NO}_{\mathrm{x}}$ would result in about $\$ 100$ billion in benefits.

Muller and Mendelsohn (2007) used reduced-form model based on the CRDM and developed an integrated assessment model, called the Air Pollution Emission Experiments and Policy (APEEP) model, to calculate the marginal damage from 10,000 sources in the U.S. The total damage of each source was estimated by multiplying the source's marginal damage and its total emissions. They named the aggregation of total damage caused by individual sources the gross annual damage (GAD) which was estimated as a parallel accounting for gross domestic product (GDP). They calculated the marginal damage for $\mathrm{SO}_{2}, \mathrm{NO}_{\mathrm{x}}, \mathrm{NH}_{3}, \mathrm{VOC}, \mathrm{PM}_{2.5}$, and $\mathrm{PM}_{10}$. Their results showed that the GAD varies from 0.7 to $2.8 \%$ of the total U.S. GDP. Moreover, they found that the majority of the damage was to human health. They concluded that $\mathrm{NO}_{\mathrm{x}}$ and coarse particles form half of the total emissions by mass but only $20 \%$ of the total damage. Their estimated MDs were lower than MDs estimated in later studies, which is partly due to the use of a simplified model that is limited in its representation of secondary pollutants. Their damage estimation was based on an assumption that $\mathrm{NO}_{\mathrm{x}}$ MDs do not change when emissions are reduced. We will show in chapter 7 that this assumption underestimates the monetary value of damages caused by $\mathrm{NO}_{\mathrm{x}}$ emissions. 
In another study (Muller and Mendelsohn 2009), Muller and Mendelsohn used the APEEP model to examine the performance of a cap-and-trade system with exchange rates defined based on the ratio of marginal damages. They constructed a case study for $\mathrm{SO}_{2}$ emissions from electric generating units that were regulated under title IV of the 1990 Clean Air Act Amendments (CAAA) in the year 2002. Their results indicated that MDs are higher in populated urban areas than low-populated rural areas, and the ratio of the highest MD to the lowest is about 150. Furthermore, they found that in urban areas, the elevation where the pollution is emitted is an important factor, and constructing tall smokestacks is an effective abatement method. Their results also showed that an annual gain of $\$ 310$ to $\$ 940$ million could be obtained by switching from the current $\mathrm{SO}_{2}$ cap-and-trade to spatially explicit taxation or by a damage-based trading ratio cap-and-trade system.

Muller (2011) in a similar study to Levy et al. (2009) investigated the uncertainty associated with the marginal damage estimation of 565 electric utility power plants in the U.S for five pollutants including $\mathrm{SO}_{2}, \mathrm{NO}_{\mathrm{x}}, \mathrm{VOC}, \mathrm{NH}_{3}$, and $\mathrm{PM}_{2.5}$. He utilized a Monte Carlo simulation and APEEP model to estimate how MDs vary in magnitude and across power plants. His results showed that the statewide average $\mathrm{NO}_{\mathrm{x}} \mathrm{MD}$ varies from $\$ 620 /$ ton (with a standard deviation of $\$ 1210 /$ ton) to $\$ 3520 /$ ton (with a standard deviation of $\$ 6140 /$ ton). His results also indicated that power plants in urban areas were more variable than power plants in the rural areas. Moreover, he showed that adult mortality dose-response, mortality valuation, and air quality modeling were the three main sources of uncertainties for marginal damage 
estimation. Furthermore, his results indicated that for all of the pollutants considered except $\mathrm{NO}_{\mathrm{x}}$, air quality modeling was the main source of uncertainty in calculation of exchange rates defined based on the ratio of marginal damages of pollutants. The main limitation of this study was the use of a dispersion model, which does not account for chemical and physical process occurring in the atmosphere for the estimation of MDs.

In another related study, Fann et al. (2009) used a reduced-form of an air quality model to predict marginal damage. They used the U.S. EPA's response surface model (RSM), generated from the EPA's Community Multiscale Air Quality (CMAQ) model results, and used the Environmental Benefits Mapping and Analysis Program (BenMAP) (Abt Associates 2009) to monetize the change in ambient air quality to dollar values. Their analysis estimated the benefits gained by $\mathrm{PM}_{2.5}$ reduction as the result of reduction in $\mathrm{NO}_{\mathrm{x}}, \mathrm{SO}_{2}, \mathrm{NH}_{3}$, organic particles, and VOC emissions from 9 urban areas in the U.S. They used RSM and estimated the impact of pollution from nine urban areas on the continental U.S. They found that the variability in MD was due to differences in the type of pollution, source type, and the location of polluters. Their calculation showed that $\mathrm{PM}$-based $\mathrm{NO}_{\mathrm{x}} \mathrm{MDs}$ range from $-\$ 4.5 \mathrm{k} /$ ton to $\$ 28 \mathrm{k} /$ ton for non-electricity generating units, and range from $\$ 1.1 \mathrm{k} /$ ton to $\$ 120 \mathrm{k} / \mathrm{ton}$ for electricity generating units. Their results also indicated that the largest portion of the reduction of the $\mathrm{PM}_{2.5}$ MD belongs to the direct reduction of $\mathrm{PM}_{2.5}$, the second largest portion belongs to $\mathrm{SO}_{2}$, and $\mathrm{NO}_{\mathrm{x}}$ has the lowest contribution to the $\mathrm{PM}_{2.5^{-}}$ related health damage. 
Another alternative for the calculation of source-receptor relationships is the use of the adjoint (backward) sensitivity model. As explained in chapter 1, the adjoint model is an efficient tool if the relationships between a few receptors (or metrics) and all sources is of interest. The adjoint model can calculate the contribution of individual sources to one receptor or a metric, such as health damage function, in a single simulation and is therefore efficient method for calculation of MDs. This model does not face the limitations of the brute-force method (i.e., computationally expensive for a large number of sources) or reduced form models (i.e., not accounting for chemical and physical processes in the atmosphere). The adjoint method will be introduced in further detail in section 2.4.

Pappin and Hakami (2013) combined epidemiological information with a sensitivity version of the CMAQ model (adjoint-CMAQ) to calculate the marginal impacts of $\mathrm{NO}_{\mathrm{x}}$ and VOC emissions from individual sources across North America on short-term mortality in Canada and the U.S. They estimated the health benefits based on 24-h average ozone and 1-h ozone concentrations. They found a significant variability in health benefits obtained by $\mathrm{NO}_{\mathrm{x}}$ reductions for different locations across North America. For example, their study showed that a $10 \%$ reduction of $\mathrm{NO}_{\mathrm{x}}$ in Hamilton, Canada, or in Detroit, U.S. results in a benefits in Canada and the U.S. equal to $\$ 253,000$ per day, or $\$ 47,000$ per day, respectively. They reported that $\mathrm{NO}_{\mathrm{x}}$ MD could be as high as $\$ 75,000 /$ ton in some locations in the U.S.

The MDs estimated by the studies presented in this short review vary (see Table 2.1) due to different assumptions and methods used. Different value of 
statistical life, concentration response factors, baseline mortality numbers, modeling years, and most importantly different methods used for calculation of source-receptor relationships are the main reasons for differences in the MD estimations of $\mathrm{NO}_{\mathrm{x}}$ emissions.

Table 2.1. MD estimations by different studies.

\begin{tabular}{|c|c|c|c|c|c|c|}
\hline & $\begin{array}{l}\mathrm{NO}_{\mathrm{x}} \mathrm{M} \\
(\$ / \text { ton })\end{array}$ & MD & Damage function & Model & $\begin{array}{l}\text { Base } \\
\text { year }\end{array}$ & Comment \\
\hline $\begin{array}{l}\text { Levy et al. } \\
(1999)\end{array}$ & 770 & & $\begin{array}{l}\mathrm{PM}_{10} \text { and ozone } \\
\text { mortality }\end{array}$ & $\begin{array}{l}\text { Dispersion } \\
\text { model }\end{array}$ & 1997 & Average MD is reported. \\
\hline $\begin{array}{l}\text { Levy et al. } \\
(2009)\end{array}$ & $\begin{array}{l}500 \\
15,000\end{array}$ & to & $\mathrm{PM}_{2.5}$ mortality & $\begin{array}{l}\text { Reduced- } \\
\text { form CRDM }\end{array}$ & 1999 & $\begin{array}{l}\text { Median MDs for power } \\
\text { plants are reported. }\end{array}$ \\
\hline Muller (2011) & $\begin{array}{l}620 \\
1210\end{array}$ & to & $\begin{array}{l}\mathrm{PM}_{2.5} \text { and ozone } \\
\text { mortality and } \\
\text { morbidity, } \\
\text { agriculture, etc. }\end{array}$ & $\begin{array}{l}\text { APEEP } \\
\text { based on a } \\
\text { reduced- } \\
\text { form CRDM }\end{array}$ & 2005 & $\begin{array}{l}\text { Average statewide MDs } \\
\text { are presented. }\end{array}$ \\
\hline $\begin{array}{l}\text { Fann et al. } \\
(2009)\end{array}$ & $\begin{array}{l}-4,500 \\
120,000\end{array}$ & to & $\mathrm{PM}_{2.5}$ mortality & $\begin{array}{l}\text { Reduced- } \\
\text { form CMAQ }\end{array}$ & 2015 & $\begin{array}{l}\text { Point source MDs from } 9 \\
\text { large urban locations are } \\
\text { presented. }\end{array}$ \\
\hline $\begin{array}{l}\text { Pappin and } \\
\text { Hakami (2013) }\end{array}$ & $\begin{array}{l}-60,000 \\
75,000\end{array}$ & to & Ozone mortality & $\begin{array}{l}\text { Adjoint- } \\
\text { CMAQ }\end{array}$ & 2007 & $\begin{array}{l}\text { MDs are based on } 1-\mathrm{h} \\
\text { max } \mathrm{O}_{3} \text { for Canada and } \\
\text { average } \mathrm{O}_{3} \text { for the U.S. }\end{array}$ \\
\hline
\end{tabular}

Despite the fact that the ranges of the calculated MDs were different for the studies mentioned, they all reported a considerable heterogeneity in MDs and highlighted the importance for polices to distinguish between emissions by MDs or source impacts. While some studies provided a qualitative insight for potential benefits under emission differentiated polices (Pappin and Hakami 2013, Levy et al. 1999, 2009; Fann et al. 2009; Muller 2011; Levy et al. 2009, Mauzerall et al. 2005), 
others quantified the costs and benefits of including source impact information within economic instruments (e,g., Muller and Mendelsohn 2009, Krupnick et al. 2000, Nobel et al. 2001). The objectives of chapters 4, 5, and 6 are to include source impact information within different economic instruments using the adjoint-CMAQ. The use of an adjoint model within economic instruments strengthens the air quality modeling side of the previous studies. It allows for the inclusion of a large number of sources, which was a major limitation for studies using the brute-force method (e.g., Krupnick et al. 2000, Nobel et al. 2001, Mauzerall et al. 2005, Tong et al. 2006). Moreover, the use of the adjont model improves the precision of MD estimation in comparison with studies using reduced-form or simplified models for a large number of sources (e.g., Muller and Mendelsohn 2009). As mentioned before, these simplified approaches/models oversimplify the complex atmospheric processes and may lack accuracy, especially for secondary pollutants such as ozone.

\subsubsection{Re-dispatching of electricity generation}

In addition to redistribution of emissions based on marginal damages, which lowers the system-wide damage, re-dispatching or shifting electricity generation from power plants with low to high generation intensity (i.e., the ratio of generation to emissions) is another strategy to reduce $\mathrm{NO}_{\mathrm{x}}$ emissions and their corresponding impacts on ozone-based health damages. Re-dispatching strategies can be achieved by imposing an emission fee to all electricity generating units (Martin 2008; Alhajeri et al. 2011; Sun et al. 2012). In a competitive electricity market, units with low cost per unit of generation win the competition and take a higher share of the system-wide 
generation. When units have to pay an emission fee, the cost per unit generation increases at a higher rate for units with a low generation intensity as compared to units with a high generation intensity. Therefore, if the emission fee is high enough, high generation intensity units can better compete in the market and take a higher share in generation, which results in a re-dispatching of generation and a reduction in system-wide emissions. Several studies have evaluated the impact of re-dispatching strategies on $\mathrm{NO}_{\mathrm{x}}$ and corresponding ozone reduction.

Martin (2008) investigated the impacts of re-dispatching through a time and location differentiated $\mathrm{NO}_{\mathrm{x}}$ control policy in the Pennsylvania-New Jersey-Maryland (PJM) region. Two different methods for modeling power networks were used: optimal power flow simulations and zonal model simulations. For both methods, the electricity network constraint, which limits the transmission of electricity between power plants, had little impact on re-dispatching. The findings showed that power plants could reduce region-wide hourly $\mathrm{NO}_{\mathrm{x}}$ emissions from $15 \%$ (6 tons) on the highest electricity demand day to $30 \%$ ( 8 tons) on average demand days. The flexibility in region-wide emission reductions was due to the hourly electricity demand for specific days. Using WorldPower simulations, it was found that setting the $\mathrm{NO}_{\mathrm{x}}$ price to $\$ 10 \mathrm{k} /$ ton, $\$ 20 \mathrm{k} /$ ton, $\$ 50 \mathrm{k} /$ ton, $\$ 100 \mathrm{k} /$ ton, or $\$ 125 \mathrm{k} /$ ton resulted in a $\mathrm{NO}_{\mathrm{x}}$ reduction of $7 \%, 10 \%, 12 \%, 13 \%$, or $14 \%$, respectively. However, the linkage between $\mathrm{NO}_{\mathrm{x}}$ reductions and the related change in ozone concentrations and the health damages is not addressed in the study conducted by Martin (2008). 
Alhajeri et al. (2011) investigated the effect of re-dispatching strategies on $\mathrm{NO}_{\mathrm{x}}$ reductions in the grid of the Electricity Reliability Council of Texas. They implemented an optimal power flow model to simulate the response of electricity generation to hourly demand. Different $\mathrm{NO}_{\mathrm{x}}$ pricing scenarios $(\$ 0 /$ ton, $\$ 2 \mathrm{k} /$ ton, $\$ 10 \mathrm{k} /$ ton, $\$ 25 /$ ton, $\$ 50 /$ ton) were tested while the $\mathrm{SO}_{2}$ price was kept constant ( $\$ 500 /$ ton). Their results indicated that $\mathrm{NO}_{\mathrm{x}}$ price setting strategies led to a $22.1 \%$ to $50.9 \% \mathrm{NO}_{\mathrm{x}}$ reduction as compared to the base case when the $\mathrm{NO}_{\mathrm{x}}$ price was set to $\$ 0 /$ ton. The co-benefits of re-dispatching strategies were also reported as $24.5 \%$ to $70.9 \%$ reductions in $\mathrm{SO}_{2}, 16 \%$ to $82 \%$ reductions in mercury, and $8.8 \%$ to $22 \%$ reductions in $\mathrm{CO}_{2}$. There was also a $4.4 \%$ to $8.7 \%$ reduction in water consumption used by power plants for cooling the steam from boilers. The significant emissions reductions were due to a shift in generations from coal plants to natural gas plants which resulted in $4 \%$ to $13 \%$ increase in generation costs.

Pacsi et al. (2013) examined the costs and air quality impacts of re-dispatching to shift water use away from regions with drought in southern Texas. They implemented the PowerWorld model to simulate power plants' generations. The results showed that the system has the capacity to shift up to $10 \%$ of electricity generation from power plants in regions with droughts to other locations. The Comprehensive Air Quality Model with Extensions (CAMx) was used to calculate the impact of re-dispatching on air quality. Their results indicated that the 8 -h ozone concentrations changed by $0.2 \mathrm{ppb}$ to $-0.55 \mathrm{ppb}, \mathrm{SO}_{2}$ decreased by $3 \%$ to $21 \%$, and $\mathrm{NO}_{\mathrm{x}}$ changed by $-2 \%$ to $8 \%$ compared to the base case (Pacsi et al. 2013). In their 
study, the improvement in ozone concentration gained while the re-dispatching was targeted for drought issues. In chapter 7, we will present a re-dispatching strategy that is targeted to minimize ozone-based health damages.

Thompson et al. (2013) investigated the impact of replacing $20 \%$ of gasolinebased vehicle miles travelled by plug-in hybrid electric vehicles (PHEV) in major cities in Texas by the year 2018. The additional power for the replacement was assumed to be supplied by power plants in the Electricity Reliability Council of Texas grid. They examined three different scenarios based on maximizing battery life, maximizing driver's convenience, and overnight charges. They used a forward sensitivity model (CAMx-DDM) to quantify the impact of sources on 8 -h ozone concentrations. Because their used approach had low efficiency for identifying the impacts from a large number of sources, they identified a subset of power plants $(20$, 28, and 45 sources under the three scenarios) for PHEVs' hourly power supply and calculated their impacts on ozone concentrations. Their results showed an increase in 8-h ozone concentrations overnight and a decrease in 8-h ozone concentrations during the day under all scenarios. They concluded that the positive impact of replacing gasoline cars with PHEVs outweighed the negative impacts of increased generation by power plants.

A recent study (Sun et al. 2012) examined a temporal emission differentiated policy focused on $\mathrm{NO}_{\mathrm{x}}$ reduction on days with the highest ozone concentrations. This policy would set a higher price for $\mathrm{NO}_{\mathrm{x}}$ when a high ozone day is forecasted, with no additional constraints for normal days. They implemented an optimal power flow 
(OPF) model to simulate power plants' electricity generation and corresponding $\mathrm{NO}_{\mathrm{x}}$ emissions when different prices are set for $\mathrm{NO}_{\mathrm{x}}$ emissions in the PJM region. They found that setting a $\mathrm{NO}_{\mathrm{x}}$ price of $\$ 30 \mathrm{k} /$ ton, $\$ 50 \mathrm{k} /$ ton, or $\$ 100 /$ ton resulted in $23 \%$, $30 \%$, and $41 \%$ lower ozone season $\mathrm{NO}_{\mathrm{x}}$ emissions when compared to a base case with $\mathrm{NO}_{\mathrm{x}}$ price of $\$ 2 \mathrm{k} /$ ton. The significant $\mathrm{NO}_{\mathrm{x}}$ reduction is obtained only by shifting electricity generation from high to low rate $\mathrm{NO}_{\mathrm{x}}$ units while the demand was fixed and no power was imported from other regions. This was comparable to the reduction obtained by installation of SCR technologies for $32 \%$ of power plants in the region, which resulted in a $28 \% \mathrm{NO}_{\mathrm{x}}$ reduction or installation of SNCR technology resulting in a $34 \% \mathrm{NO}_{\mathrm{x}}$ reduction. They also used the Comprehensive Air Quality Model with Extensions (CAMx) model to estimate the impacts of $\mathrm{NO}_{\mathrm{x}}$ control policies on ozone reduction. They found that setting the $\mathrm{NO}_{\mathrm{x}}$ price to $\$ 30 \mathrm{k} /$ ton, $\$ 50 \mathrm{k} /$ ton, or $\$ 100 /$ ton lowers the maximum 8 -h ozone concentrations by at least $1 \mathrm{ppb}$ over $14 \%, 23 \%, 33 \%$ of grids respectively. Installation of SNCR, or SCR lowers the maximum 8-h ozone concentration by 1 ppb over $14 \%$ and $55 \%$ of grids respectively.

In a similar study to those conducted by Martin (2008), Alhajeri et al. (2011), and Sun et al. (2012), we will examine the impact of emission fees on re-dispatching of generation. The aforementioned studies examined the use of a single emission fee for all participants under different hypothetical pricing scenarios, and reported a substantial reduction in $\mathrm{NO}_{\mathrm{x}}$ emissions and corresponding ozone obtained by redispatching generations. However, one-fee based polices do not account for heterogeneity in MDs, as discussed in section 2.2.3.1 and may result in a suboptimal 
ozone reduction. In chapter 6 , we will take a different approach and examine the performance of several re-dispatching strategies under which regulators set location or time specific emission fees based on adjoint-driven marginal damages.

\subsection{4. $\mathrm{NO}_{\mathrm{x}}$ Control Technologies}

Two main categories of $\mathrm{NO}_{\mathrm{x}}$ control technologies are combustion modification and post-combustion control technologies. Combustion technologies aim to prevent the generation of $\mathrm{NO}_{\mathrm{x}}$ emissions by modification of the combustions process, whereas post-combustion technologies aim to reduce $\mathrm{NO}_{\mathrm{x}}$ emissions that have already been produced in combustion. Combustion modification technologies can reduce $\mathrm{NO}_{\mathrm{x}}$ emissions by changing three main factors: peak flame temperature, the residence time of the peak flame, and the amount of air available for the flame. These technologies can also cause a reduction in a plant's efficiency because of incomplete combustion (Sloss et al., 1992).

The air-to-fuel ratio is an important factor that determines the amount of $\mathrm{NO}_{\mathrm{x}}$ emissions. The optimum ratio corresponds to the maximum efficiency of the plant. Changing air-to-fuel ratio from the optimum can reduce $\mathrm{NO}_{\mathrm{x}}$ emissions but also decreases efficiency. Combustion modification technologies provide different levels of air-to-fuel ratios in different flame regions to reduce $\mathrm{NO}_{\mathrm{x}}$ emissions. This can be achieved by air or fuel staging. Air staging can occur within the burner (low $\mathrm{NO}_{\mathrm{x}}$ burner technology) or in the furnace (over fire air technology).

A low $\mathrm{NO}_{\mathrm{x}}$ burner (LNB) generates a thin and long flame at a lower temperature, hence generating less $\mathrm{NO}_{\mathrm{x}}$. LNB can cause a $50 \%$ reduction in $\mathrm{NO}_{\mathrm{x}}$ 
emissions. In an over fire air (OFA) furnace, unburned carbons are burnt and the combustion is completed. This technology can cause a $20 \%$ reduction in $\mathrm{NO}_{\mathrm{x}}$ emissions. Fuel staging occurs within the furnace and usually on top of the burner (reburning technology). This technology generates a fuel rich region on top of the burner where some hydrocarbon radicals will be formed. The radicals reduce the $\mathrm{NO}_{\mathrm{x}}$ generated in the burner to molecular nitrogen (EPA, 1999).

Two common post-combustion control technologies for $\mathrm{NO}_{\mathrm{x}}$ are SNCR and SCR. Both of these control technologies are designed to convert $\mathrm{NO}_{\mathrm{x}}$ to $\mathrm{N}_{2}$ (EPA, 1999). For the SNCR technology, a reagent, ammonia or urea, is added to combustion gases. Ammonia reacts with $\mathrm{NO}_{\mathrm{x}}$ and the products are water and molecular nitrogen (Reaction 2-10). The efficiency of SNCR is usually between 30 to $50 \%$. The required temperature for the reaction $2-10$ is about $1600-2000^{\circ} \mathrm{F}$. The correct temperature is important because temperatures higher than $2000^{\circ} \mathrm{F}$ increase $\mathrm{NO}_{\mathrm{x}}$ production and temperatures less than $1600^{\circ} \mathrm{F}$ cause the production of ammonia byproducts that can cause corrosion problems for the equipment.

$$
4 \mathrm{NH}_{3}+4 \mathrm{NO}+\mathrm{O}_{2} \rightarrow 6 \mathrm{H}_{2} \mathrm{O}+4 \mathrm{~N}_{2}
$$

In SCR technologies, a reagent is mixed with the combustion gases and then the mixture goes to a catalytic reactor where a catalyst (e.g., titanium oxide) causes the formation of $\mathrm{N}_{2}$ and water. The difference between SCR and SNCR is that in $\mathrm{SCR}$, the catalyst can help reaction occur at a lower temperature $\left(600-800^{\circ} \mathrm{F}\right)$. The efficiency of an SCR can be up to $90 \%$ but the trade-off is that the capital cost of a SCR is higher than a SNCR (EPA 1999a; Miller 2011). 


\subsection{Theoretical cap-and-trade systems}

The design of an efficient cap-and-trade program depends on the nature of the pollutants being traded. In this context, pollutants are categorized into three main classes: uniformly mixed assimilative pollutants (such as biogenic VOCs over certain regions); uniformly mixed accumulative pollutants (e.g., $\mathrm{CO}_{2}$ ); and non-uniformly mixed assimilative pollutants $\left(\mathrm{NO}_{\mathrm{x}}\right)$ (Tietenberg 1985). For uniformly mixed pollutants, the location where the pollutant is emitted does not play a role in ambient air quality, whereas the location of emitters is very important for non-uniformly mixed pollutants. Accumulative pollutants are those that do not deteriorate easily, and last for a long time in the atmosphere. Note for the above categorization of pollutants, $\mathrm{NO}_{\mathrm{x}}$ is a non-uniformly mixed pollutant. However, an efficient $\mathrm{NO}_{\mathrm{x}}$ policy design has more complexity than that for other pollutants in this category (e.g., sulfur dioxide) because $\mathrm{NO}_{\mathrm{x}}$ contributes to the formation of secondary pollutants such as ozone and particulate matter.

Uniformly mixed assimilative pollutants are the simplest to regulate since the pollutant's lifetime is substantially longer than its characteristic mixing time, but is short enough that there is no carry over from one regulation year to the next. The emission and ambient quality relationship for these pollutants is (Tietenberg, 1985):

$A=a+\sum\left(e_{i}-r_{i}\right)$

where $A$ is the ambient quality, $a$ is background pollution mainly from biogenic and natural sources, $e_{i}$ is the baseline emission from source $i$, and $r_{i}$ is its emission 
reduction. To design a cap-and-trade system for these types of pollutants, an environmental authority can easily set a cap based on the environmental capacity and let traders exchange their emission on one-to-one unit bases.

Regulating uniformly mixed accumulative pollutants is more complicated since the pollutants accumulate with time. For this type of pollutant the relationship between ambient quality and emissions is as follow (Tietenberg, 1985):

$A_{t}=\mathrm{A}_{0}+\sum_{i} \sum_{t}\left(e_{i t}-r_{i t}\right)$

where $A_{t}$ is the ambient quality for year $t$, and $A_{0}$ is the initial ambient quality. $e_{i t}$ and $r_{i t}$ are the emissions and emissions reductions, respectively, from source $i$ and year $t$. The implementation of cap-and-trade programs for this type of trade is more complicated since the emissions from one year affect the ambient quality in future years. Allowance allocation, using allowances from one year for another year, and setting a compliance date are some difficulties for the environmental authority when regulating uniformly mixed accumulative pollutants.

Regulating the non-uniformly mixed assimilative pollutants is further complicated since the ambient quality varies from one location to another. Also, the location where the pollutant is emitted has a key role in determining the ambient quality. The ambient quality for these types of pollutants can be defined as follows (Tietenberg 1985): 
$A_{i}=\mathrm{a}_{\mathrm{i}}+\sum_{j} t_{i j}\left(e_{j}-r_{j}\right)$

where $A_{i}$ is the ambient quality for location $i, \mathrm{a}_{\mathrm{i}}$ is the background pollution for location $i, t_{i j}$ is the transfer coefficient from source $j$ to receptor $i$. For this category, one unit of emissions in one location is not equal to one unit of emissions in another location. In theory, there are two main methods for trading these types of pollutants: ambient quality permit trading and emissions permit trading. Under ambient quality permit trading, a source needs to collect ambient permits from all receptors it affects. Under emissions permit trading, permits are assigned to sources and they can trade their permits as long as the ambient quality does not deteriorate. This can occur by defining an exchange rate among sources. The exchange rate for two sources is a ratio that determines the number of additional emission units the buyer can emit when buying one unit of emissions from the seller.

Major theoretical trading systems for non-uniformly mixed assimilative pollutants are: the ambient-permit system (APS) (Montgomery, 1972), the pollutionoffset system (POS) (Krupnick et al., 1983), the modified pollution-offset (MPO) (McGartland and Oates, 1985), the non-degradation offset (NDO) (Atkinson and Tietenberg, 1984), the exchange-rate emission trading system (ERS) (Klaassen et al., 1994), the exposure based exchange rate (Krupnick et al., 2000), the trading ratio system (TRS) (Hung and Shaw, 2005), and marginal damage based exchange rates (Farrow et al., 2005; Muller and Mendelsohn, 2009). It should be noted that the current U.S. $\mathrm{NO}_{\mathrm{x}}$ cap-and-trade program is not based on any of these theoretical 
models for non-uniformly mixed pollutants. It applies a uniformly mixed concept (i.e., treats all emissions equally) to a non-uniformly mixed pollutant whose impact on ambient air quality is dependent on the time and location of emissions.

The ambient permit system (APS) is an ambient quality permit trading system. In this system, the environmental authority needs to define the ambient permits for all receptors and allocate the initial permits to sources. Then, sources can trade their ambient permits. They need to collect enough ambient permits from all affected receptors to cover their emissions. Under APS, when there are $n$ receptors, the constraint on the emissions from source $i$ is as follow (Montgomery, 1972):

$e_{i} \leq \min \frac{\mathrm{l}_{\mathrm{ij}}}{\mathrm{t}_{\mathrm{ij}}}$ for $\mathrm{j}=1, \ldots, \mathrm{n}$

where $e_{i}$ is the emissions form source $i, l_{i j}$ is the number of ambient permits that source $i$ holds at receptor $j$ and $t_{i j}$ is the transfer coefficient from source $i$ to receptor $j$. The implementation of this system is complicated since the environmental authority needs to assign many receptor sites, and allocate initial permits to sources for each receptor (Krupnick et al., 1983).

Modified pollution offset (MPO) is an extension to POS that is stricter about ambient quality (McGartland and Oates, 1985). Under MPO, the ambient quality must not degrade in any region after any trade even if the ambient quality is not violated in the region before trading occurs. In other words, the deterioration in ambient quality caused by one source must be offset by improvement of ambient quality caused by emissions reduction from another source. 
Non-degradation offset (NDO) is another system that is based on two restrictions: there must be no violation in ambient quality standards, and no exchange rate higher than one. The latter restriction means that in any trade, the aggregate emissions from two traders after the trade cannot exceed their aggregate emissions before the trade (Atkinson and Tietenberg, 1984). The exchange rates under PO, MPO, and NDO are not fixed and can vary as long as the corresponding system's restriction is not violated.

The Exchange Rate System (ERS) offers a fixed exchange rate for trading emission permits. Under ERS, the exchange rates are calculated based on the ratio of polluters' marginal abatement costs (marginal abatement cost is the derivative of abatement cost) at the optimal emissions level. The optimal emission level is a set of emissions that maximizes the total net benefit. The following cost minimizing equations clarify how the exchange rate is defined under ERS (Klaassen et al., 1994):

Minimize $\sum_{i} c_{i}\left(e_{i}^{0}-e_{i}\right)$

\section{Subject to:}

$\sum_{i} t_{i j} e_{i} \leq A_{j}^{*} j=1, \ldots, n$

where $c_{i}$ is the cost of emission reductions for source $i$ from $e_{i}^{0}$ to $e_{i}, t_{i j}$ is the transfer coefficient from source $i$ to receptor $j$, and $A_{j}^{*}$ is the target ambient quality at receptor $j$. 
The corresponding first-order condition is:

$c_{i}^{\prime}-\sum_{j} t_{i j} \lambda_{j}=0$

where $c_{i}^{\prime}$ is the marginal abatement cost of source $i$, and $\lambda_{j}$ is the Lagrangian multiplier that represents the shadow price on the target ambient quality at receptor $j$. The shadow price for receptor $j$ indicates the amount of cost-savings result from loosening the constraint on ambient quality at receptor $j$ by one unit when the systemwide abatement cost is minimized. From (2-16), the marginal cost corresponding to the optimal solution for source $i$ is: $c_{i}^{\prime}=\sum_{i} t_{i j} \lambda_{j}$. The exchange rate $\left(E R_{m n}\right)$ between source $m$ and source $n$ is then defined as the ratio of the marginal abatement costs (Klaassen et al., 1994):

$E R_{m n}=\frac{c_{m}^{\prime}}{c_{n}^{\prime}}=\frac{\sum_{j} t_{m j} \lambda_{j}}{\sum_{j} t_{n j} \lambda_{j}}$

Simply, $\lambda_{j}$ represents the cost savings in the system if the target ambient quality constraint $A_{j}^{*}$ shifts by one unit. If the ambient quality at receptor $j$ is binding $\left(A_{j}=A_{j}^{*}\right)$, the shadow price on receptor $j$ is positive. But if the ambient quality at a receptor is not binding $\left(A_{j}<A_{j}^{*}\right)$, the shadow price is zero. In other words, for binding receptors, releasing the constraint results in some cost savings for the system, and for non-binding receptors releasing the constraint does lead to cost savings. A disadvantage of ERS is that it needs the information of the abatement cost functions for all sources. 
Krupnick et al. (2000) examined the effectiveness of the $\mathrm{NO}_{\mathrm{x}}$ cap-and-trade programs in the eastern U.S. using a fixed exchange rate system. They defined exchange rates based on ozone exposure ${ }^{1}$ and calculated them using source-receptor relationships (i.e., $\mathrm{NO}_{\mathrm{x}}$ emissions from sources and ozone concentrations in receptors). The minimization problem under their proposed system is as follows:

$\operatorname{Minimize} \sum_{i}^{n} c_{i}\left(r_{i}\right)$

\section{Subject to:}

$\sum_{i}^{n} a_{i} r_{i} \geq L$

where $c_{i}$ is the cost of emission reduction for source $i\left(r_{i}\right), L$ is the target level of ozone exposure reduction, and $a_{i}$ is a source-receptor coefficient which converts emission reductions of source $i\left(r_{i}\right)$ to ozone exposure. From the first order conditions of this problem, the exchange rate $\left(E R_{i j}\right)$ of source $i$ and source $j$ can be calculated:

$E R_{i j}=\frac{c_{i}^{\prime}}{c_{j}^{\prime}}=\frac{a_{i}}{a_{j}}$

\footnotetext{
${ }^{1}$ Ozone exposure is defined as population times ozone concentration integrated over time.
} 
The exchange rate for source $i$ and source $j$ under this system shows the ratio of the total effect of $\mathrm{NO}_{\mathrm{x}}$ emissions on ozone exposure from source $i$ to that of source $j$.

The Trading Ratio System (TRS) is another cap-and-trade system with fixed exchange rates that is designed specifically for trading water quality permits in rivers. The unidirectional flow to the lowest level in rivers simplifies the design of trading programs in these systems. The TRS system has three main characteristics: (1) the zonal effluent cap is set by accounting for the water pollutant loads transferred from upstream zones; (2) the trading ratios are set equal to the exogenous transfer coefficients between zones; and (3) permits are freely tradable among dischargers according to the unidirectional trading ratios.. The minimization problem under TRS are as follow (Hung and Shaw, 2005):

Minimize $\sum_{i} c_{i}\left(e_{i}^{0}-e_{i}\right)$

Subject to:

$e_{i}-\sum_{k=1}^{i-1} t_{k i} T_{k i}+\sum_{k>i}^{n} T_{i k} \leq \overline{T_{i}}, \quad i=1, \ldots, n$

$T_{k i}, T_{k i}>0, \quad 0 \leq e_{i} \leq e_{i}^{0}$

where $c_{i}$ is the cost of effluent reduction for source $i$ from $e_{i}^{0}$ to $e_{i}, \overline{T_{i}}$ is the allocated permit to source $i, t_{k i}$ is the transfer coefficient from source $i$ (under this system there is only one source in each region) to the region $j, T_{k i}$ is the number of permits source $k$ buys from source $i$, and $T_{i k}$ is the number of permits source $k$ sells to source $i$. 
From the first order conditions of this problem, the trading ratio can be calculated (Hung and Shaw, 2005):

$c_{i}^{\prime}=\lambda_{i}, \quad \forall i$,

$\lambda_{i}=t_{i k} \lambda_{k} \quad(i<k)$

$E R_{i j}=\frac{c_{i}^{\prime}}{c_{j}^{\prime}}=\frac{t_{i k}}{t_{j k}}$

where $t_{i j}$ is the transfer coefficient from source $i$ to region $j . k$ could be any region downstream of the two traders. The main difference between ERS and TRS is the method of exchange rate calculation (equations 2-17 and 2-23). TRS is designed for water quality and benefits from the unidirectional river flow but can be applied (with simplifying assumptions) to strictly downwind trading. TRS calculates the exchange rates using the ratio of transfer coefficients, which is equal to the ratio of marginal abatement costs. The main advantage of TRS over ERS is that the cost information is not needed for calculation of exchange rates. Our proposed optimization framework in chapter 4 is an extension of TRS, but is designed for air pollutants and accounts for relationships between $\mathrm{NO}_{\mathrm{x}}$ emissions and ozone concentrations.

A similar study for water quality trading by Farrow et. al (2005) defines the exchange rate as the ratio of marginal damages for the sources. The marginal damage for a source is defined as the change in total damage in the system when the source increases its emission level by one unit. The total damage of each source is calculated using the transfer coefficients as well as household information (e.g., number of 
people affected, their ages, their willingness to pay, etc.). The general optimization problem becomes (Farrow et al., 2005):

Minimize $\sum_{i} c_{i}\left(e_{i}^{0}-e_{i}\right)$

Subject to:

$\sum_{i} D_{i}\left(e_{i}\right) \leq \overline{T D}$

$0 \leq e_{i} \leq e_{i}^{0}$

where $c_{i}$ is the cost of emission reduction for source $i$ from $e_{i}^{0}$ to $e_{i}, D_{i}\left(e_{i}\right)$ is the total damage from source $i$, and $\overline{T D}$ is the cap on total system wide damage.

From the first order conditions of this problem the trading ratio can be calculated:

$E R_{i j}=\frac{c_{i}^{\prime}}{c_{j}^{\prime}}=\frac{\frac{\partial D_{i}}{\partial e_{i}}}{\frac{\partial D_{j}}{\partial e_{j}}}$

where $E R_{i j}$ is the exchange rate between sources $i$ and $j$. This ratio represents the ratio of marginal damage from the two sources. The main difference between the system offered by Farrow et al. (2005) and TRS and ERS is the constraints on the cost minimization problem. Under TRS and ERS, there are many constraints that limit emissions in each zone, whereas under the system offered by Farrow et al. (2005) 
there is only one general constraint that limits the total damage in the system. Muller and Mendelsohn (2009) introduced a system similar to Farrow et al. (2005) but for air quality emission permit trading. The exchange rates are defined based on the ratio of the marginal damage of sources (equation 2-25).

The design of cap-and-trade policies for air quality trading differs from that of water quality due to the inherent differences of the two media. For example, unidirectional flow to the lowest level in rivers simplifies the design of trading programs while the fate of pollutants in air is affected by multidirectional wind. Hence, calculating source-receptor relationships and exchange rates for the atmosphere is more challenging than water. To calculate source-receptor relationships, Krupnick et al. (2000) ran an air quality model for a few days with a limited number of sources, and Muller and Mendelsohn (2009) used simplified dispersion models that do not adequately represent the chemistry and other atmospheric processes. In most cases, calculating accurate source-receptor relationships requires Eulerian air quality model simulations that can be computationally demanding.

\subsection{Sensitivity analysis}

Sensitivity analysis refers to general methods for calculating derivatives. Formal sensitivity methods are those that solve sensitivity equations while approximate methods such as the brute-force approach estimate sensitivity coefficients by introducing one-at-a-time perturbations into the model. The bruteforce approach is easy to implement but formal methods are more efficient and faster 
for calculating derivatives of outputs (i.e., ambient quality) with respect to inputs (e.g., emissions) for applications that involve a large number of inputs and outputs.

Brute-force methods calculate derivatives by running the model twice (or more); once with the base-case emissions followed by perturbed emissions. The difference in outputs is then used to calculate the derivatives. The brute-force method has been widely used to develop source-receptor relationships for different applications such as cap-and-trade (e.g., Krupnick et al., 2000, Nobel et al., 2001), estimation of the health damage of pollution (e.g., Mauzerall et al., 2005), and intercontinental pollution transport estimation (e.g., Jacob et al., 1999, Fiore et al., 2009).

Forward and backward sensitivity analyses are two general categories of formal sensitivity analysis. They are both used to calculate the derivative of model outputs with respect to the model inputs. Forward sensitivities are source-based while backward (or adjoint) sensitivity methods are receptor-based. The efficiency of these two general categories of sensitivity analyses is critically related to the number of sources and receptors for which sensitivity information is desired. In one forward sensitivity model run, the derivative of all receptors with respect to one single source can be calculated, while in one single backward sensitivity model run, the sensitivity of a receptor or a concentration-based function (a function at a lumped group of receptors) with respect to all inputs can be estimated. Correspondingly, if the problem of interest is to determine the effect of a particular power plant on the ambient quality in different regions, forward sensitivity analysis is more efficient. However, if the 
problem of interest is to find out the contribution of power plants to ambient air quality in different regions, then backward sensitivity analysis is the logical method of choice.

Assume a nonlinear operator $\boldsymbol{M}$, that projects the inputs vector $X$ (a collection of inputs $X_{k}$ for $k$-th input such as emissions from a power plant) into an output vector $C$ (e.g., concentrations of different species, $C_{j}$ ) (Hakami et al., 2007):

$$
C=M X
$$

Equation 2-26 is an operator form of the forward model. A perturbation in input such as emissions from a power plant, causes a perturbation in output such as the ozone concentration. The corresponding derivative equation is then:

$$
\delta C=\boldsymbol{L} \delta X
$$

where $\boldsymbol{L}$ is the Jacobian of model operator $\boldsymbol{M}$. Equation 2-27 is an operator form of the tangent linear model (TLM) or forward sensitivity model that is used to calculate sensitivities. The TLM is also referred to as the decoupled direct method (DDM; Dunker, 1981) in air quality modeling literature. To evaluate model output or use outputs for policy making purposes, one may define a metric (cost function) $(J=J(C))$ which is a function of concentrations (e.g., $J$ could be the average ozone concentration over the domain or the square of the difference between the predicted and observed concentrations). The variation of the cost function $J$ with respect to output $C$ is:

$$
\delta J=\left\langle\nabla_{C} J, \delta C\right\rangle
$$


where $\langle.,$.$\rangle represents the inner product. Substituting equation 2-27 into 2-28 and$ applying the duality principle, equation 2-28 turns to (see Wang et al., 2001, Hakami et al., 2007):

$$
\delta J=\left\langle\nabla_{C} J, \boldsymbol{L} \delta X\right\rangle=\left\langle\boldsymbol{L}^{*} \nabla_{C} J, \delta X\right\rangle
$$

where $\boldsymbol{L}^{*}$ is the transpose of the TLM operator $\boldsymbol{L}$. This equation shows that the gradient of $J$ with respect to input $I$ is:

$$
\nabla_{I} J=\boldsymbol{L}^{*} \nabla_{C} J
$$

Equation 2-30 is the main adjoint equation in an operator form and can be used within air quality models to calculate the sensitivities.

The governing equation for the forward model in air quality models is the atmospheric diffusion equation (ADE) (Seinfeld and Pandis, 2006):

$$
\frac{\partial C_{i}}{\partial t}=-\boldsymbol{u} \cdot \nabla C_{i}+\frac{1}{\rho} \nabla \cdot\left(\rho \boldsymbol{K} \nabla C_{i}\right)+R_{i}+E_{i}
$$

where $C_{i}$ is the mixing ratio of species $i$ and varies spatially and temporally, $\boldsymbol{u}$ is the vector of the wind field and has components in three directions, $\rho$ is the air density, $\boldsymbol{K}$ is the turbulent diffusivity tensor, $R_{i}$ is the chemical reaction rate for species $i, E_{i}$ is the emission rate of species $i$. The TLM and adjoint equations can also be developed starting from the ADE.

A perturbation in inputs (e.g., emissions) in equation 2-31 will perturb outputs (e.g., concentrations) and can be well represented by equation 2-32 (Hakami et al., 2004): 
$\frac{\partial \delta C_{i}}{\partial t}=-\boldsymbol{u} \cdot \nabla\left(\delta C_{i}\right)+\frac{1}{\rho} \nabla \cdot\left(\rho \boldsymbol{K} \nabla \delta C_{i}\right)+\boldsymbol{F}_{i} \delta \boldsymbol{C}+\delta E_{i}$

where $\delta C_{i}$ represents a perturbation in the concentration of species $i$, and $\boldsymbol{F}_{i}$ is the $i$ th row of the Jacobian of the chemical reaction rates. If the adjoint cost function $(J)$ is defined as the integration of the local cost functions $(g)$ over different times $(t)$ and locations $(w)$ as follows:

$J=\iint_{t w} g(\boldsymbol{C}, t, w) d t d w$

Then, the governing adjoint equation 2-34 can be derived by applying the Lagrange multiplier to equation 2-32 followed by integration by parts (see Sandu et al., 2005; Elbern et al., 2000):

$-\frac{\partial \lambda_{i}}{\partial t}=\nabla \cdot\left(\boldsymbol{u} \lambda_{i}\right)+\nabla \cdot\left(\rho \boldsymbol{K} \nabla \frac{\lambda_{i}}{\rho}\right)+\boldsymbol{F}_{i}^{T} \boldsymbol{\lambda}+\varphi_{i}$

where $\lambda_{i}$ is the adjoint variable for a specific time and location $\left(\frac{\partial J}{\partial C_{i}}\right), \boldsymbol{F}_{i}^{T}$ is the $i$ th row of the transposed Jacobian of the chemical reaction rates (transpose of $\boldsymbol{F}_{i}$ in equation 2-32). $\varphi_{i}$, the forcing term, is the derivative of the local cost function with respect to the concentration $\left(\frac{\partial g}{\partial C_{i}}\right)$ and is injected into the model for different times and locations in a manner equivalent to $E_{i}$ in the forward $\mathrm{ADE}$ equation.

There are two approaches for the integration of the adjoint equation: the continuous adjoint and discrete adjoint. In the continuous approach, first the adjoint 
equation is derived analytically and then the derived equation is solved numerically. In the discrete approach, an adjoint (transpose) model is developed for the discretized form of the forward equation.

In air quality modes, the ADE equation is usually solved numerically by a sequence of $N$ time steps $(\Delta t)$ through an operator splitting scheme. The result is an operator $\left(\mathcal{N}^{[t, t+1]}\right)$ that relates the concentration at time step $t\left(C^{t}\right)$ to the concentration at next time step $\left(C^{t+1}\right)$ as shown in equation 2-35 (Sandu et al., 2005).

$C^{t+1}=\mathcal{N}^{[t, t+1]} \circ C^{t}, C^{N}=\prod_{t=0}^{t=N-1} \mathcal{N}^{[t, t+1]} \circ C^{0}$

where $C^{0}$ is concentration at time 0 and $\mathcal{N}^{[t, t+1]}$ is the split numerical solution operator for the time interval $[t, t+1]$ and is calculated based on an splitting approach. In the operator splitting approach, various processes including chemistry, aerosols dynamics and thermodynamics, clouds, advection in three directions, horizontal diffusion, vertical diffusion, vertical advection, and emissions injections can be integrated separately and sequentially. The overall numerical solution for $N$ time steps and $m$ processes is then (Hakami et al., 2007):

$\mathcal{N}=\left(\mathcal{N}_{p_{1}}^{1} \circ \mathcal{N}_{p_{2}}^{1} \circ \ldots \circ \mathcal{N}_{p_{m}}^{1}\right) \circ \ldots \circ\left(\mathcal{N}_{p_{1}}^{N} \circ \mathcal{N}_{p_{2}}^{N} \circ \ldots \circ \mathcal{N}_{p_{m}}^{N}\right)$

where $\mathcal{N}_{p_{i}}^{t}$ is the numerical operator for process $i$ (e.g., chemistry, horizontal diffusion, etc.) and time step $t$. Similarly, the forward sensitivity and adjoint model 
with different governing equations are solved numerically. The numerical operators for forward sensitivity $(\mathcal{L})$ and adoint $\left(\mathcal{L}^{*}\right)$ are:

$\mathcal{L}=\left(\mathcal{L}_{p_{1}}^{1} \circ \mathcal{L}_{p_{2}}^{1} \circ \ldots \circ \mathcal{L}_{p_{m}}^{1}\right) \circ \ldots \circ\left(\mathcal{L}_{p_{1}}^{N} \circ \mathcal{L}_{p_{2}}^{N} \circ \ldots \circ \mathcal{L}_{p_{m}}^{N}\right)$

$\mathcal{L}^{*}=\left(\mathcal{L}_{p_{m}}^{N}\right)^{T} \circ\left(\mathcal{L}_{p_{m-1}}^{N}\right)^{T} \circ \ldots\left(\mathcal{L}_{p_{1}}^{N}\right)^{T} \circ \ldots \circ\left(\mathcal{L}_{p_{m}}^{1}\right)^{T} \circ\left(\mathcal{L}_{p_{m-1}}^{1}\right)^{T} \circ \ldots\left(\mathcal{L}_{p_{1}}^{1}\right)^{T}$

The gradients of the cost function $(J)$ with respect to the emissions $(E)$ can be calculated from the adjoint variable $(\lambda)$ during the integration (Hakami et al., 2007):

$\frac{\partial J}{\partial E^{t}}=\left(\frac{\partial C^{t+1}}{\partial E^{t}}\right)^{T}\left(\frac{\partial J}{\partial C^{t+1}}\right)=\left(\frac{\partial C^{t+1}}{\partial E^{t}}\right)^{T} \lambda^{t+1}$

Adjoint modeling has been widely used in meteorological studies since the 1970's (e.g., Marchuk, 1974) but not used in three-dimensional photochemical air quality models until the past decade. For air quality applications, an adjoint model was first developed for a Lagrangian model of the stratosphere (Fisher and Lary, 1995), and then for a Lagrangian model of the troposphere (Elbern et al., 1997). The first adjoint model for a chemical transport model (CTM) (i.e., European Air Pollution Dispersion Model, EURAD-CTM2) was developed by Elbern and Schmidt (1999). The adjoints of other air quality models have been developed recently including: HANK (Vukićević and Hess, 2000), CHIMERE (Vautard et al., 2000; Menut, 2003), STEM (Sandu et al., 2005), Polair (Mallet and Sportisse, 2005; Quélo et al., 2005), IMAGES (Müller et al. 2005), DRAIS (Nester et al., 2005), CIT (Martien and Harley, 2006), GOES-Chem (Henze et al., 2007), and CMAQ (Hakami et al., 2007). 


\section{CHAPTER 3:}

\section{METHODS AND MODELING SIMULATION TOOLS}

In this chapter, the components of the proposed decision support system and the tools used therein are introduced and discussed. Note that this section is only a general overview of the methods and simulations tools used in this thesis, and the detailed methodology for various sections will be explained in greater detail in the respective chapters.

\subsection{The decision support system (DSS)}

A DSS will be proposed to evaluate the performance of different emission control policies. The DSS includes the CMAQ model, its adjoint, and an optimization model (KNITRO). The forward CMAQ is used to calculate the evolution of concentrations with time, the adjoint of CMAQ is used to calculate the sensitivities or marginal health damages, and the optimization model is used to estimate the polluters' emission response to different policies and determine the polluter's posttrade emission levels and related health damages. Figure 3.1 shows the components of the proposed DSS which can be configured differently. The first component of the proposed DSS is a module for selecting/defining an emissions control policy. The DSS is able to evaluate the performance of the following policies: 1) command-andcontrol $(\mathrm{CaC}) ; 2)$ cap-and-trade $(\mathrm{CaT})$ with no exchange rate, which is the current policy in the U.S.; 3) cap-and-trade with an exchange rate (CaT-EX), which will be explained in detail in chapter 4; 4) damage minimization (DMIN); 5) and social cost 
minimization (SCMIN), (4) and (5) will be explained in chapter 5; and 6) temporal social cost minimization (TMP-SCMIN) policies which will be discussed in chapter 6 .

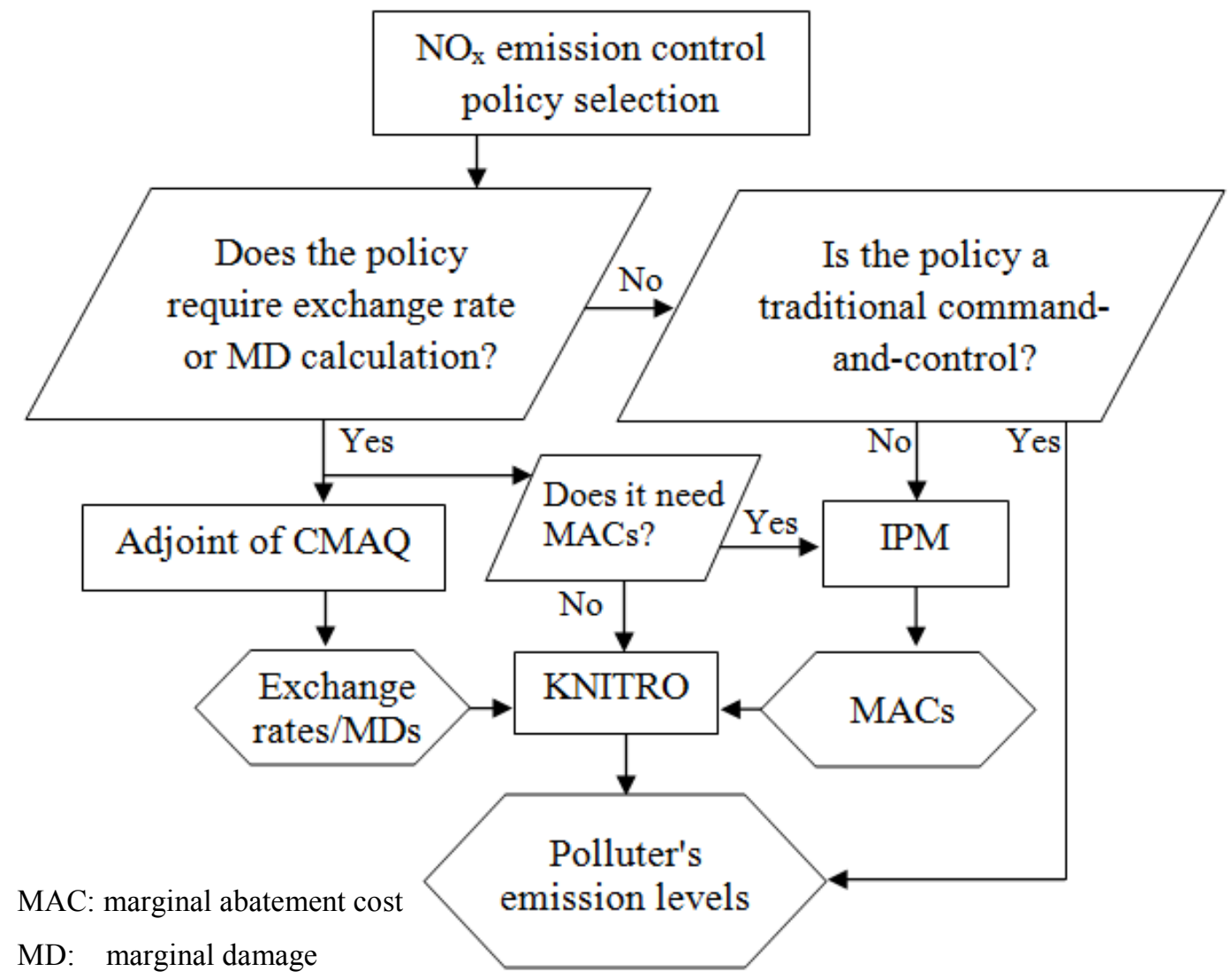

Figure 3.1. Components of the proposed decision support system.

Note that only the first two policies considered (i.e., $\mathrm{CaC}$ and $\mathrm{CaT}$ ) do not account for exchange rates or marginal health damages. Under the $\mathrm{CaC}$ policy, emissions reduction goals are set by the environmental authority and polluters are required to keep their emissions at the regulation level. Therefore, there is no need to predict the polluters' emission behavior with an optimization model. Under a CaT 
policy, allowances are allocated to the polluters, and it is the market that determines the post-trade level of emissions. For all other policies, emissions from different polluters are differentiated by exchange rates or marginal damages, and the adjoint model is used to estimate those values. The KNITRO model can be configured to find the optimal emission levels for different optimization objective functions and constraints. The details of the optimization problems and related formulations will be discussed in chapters 4,5 , and 6 .

\subsection{CMAQ and its adjoint}

Chemical Transport Models (CTMs) have been widely used to predict ambient air quality for different emission control policies. CTMs (and regional CTMs or air quality models) can calculate the temporal and spatial concentrations of multiple species affected by transformation and transport processes. CTMs do not calculate the dynamics of the atmosphere (e.g., wind field or temperature) but use outputs of meteorological models for atmospheric dynamics. The model used in this study is the CMAQ developed by the U.S. EPA (Byun and Schere, 2006). CMAQ is the most widely used air quality model in the U.S. and worldwide.

The CMAQ modeling system (Models-3 modeling platform) has three main components (Figure 3.2): an emissions model that provides CMAQ-ready gridded and allocated emissions files from inventory data; a meteorological model that simulates the atmospheric state and motion; and a chemical transport model that includes advection, diffusion, photolysis rate computation, gas-phase chemical reactions, 
aqueous-phase reactions, aerosol dynamics and thermodynamics, and dry and wet deposition (Byun and Schere, 2006).

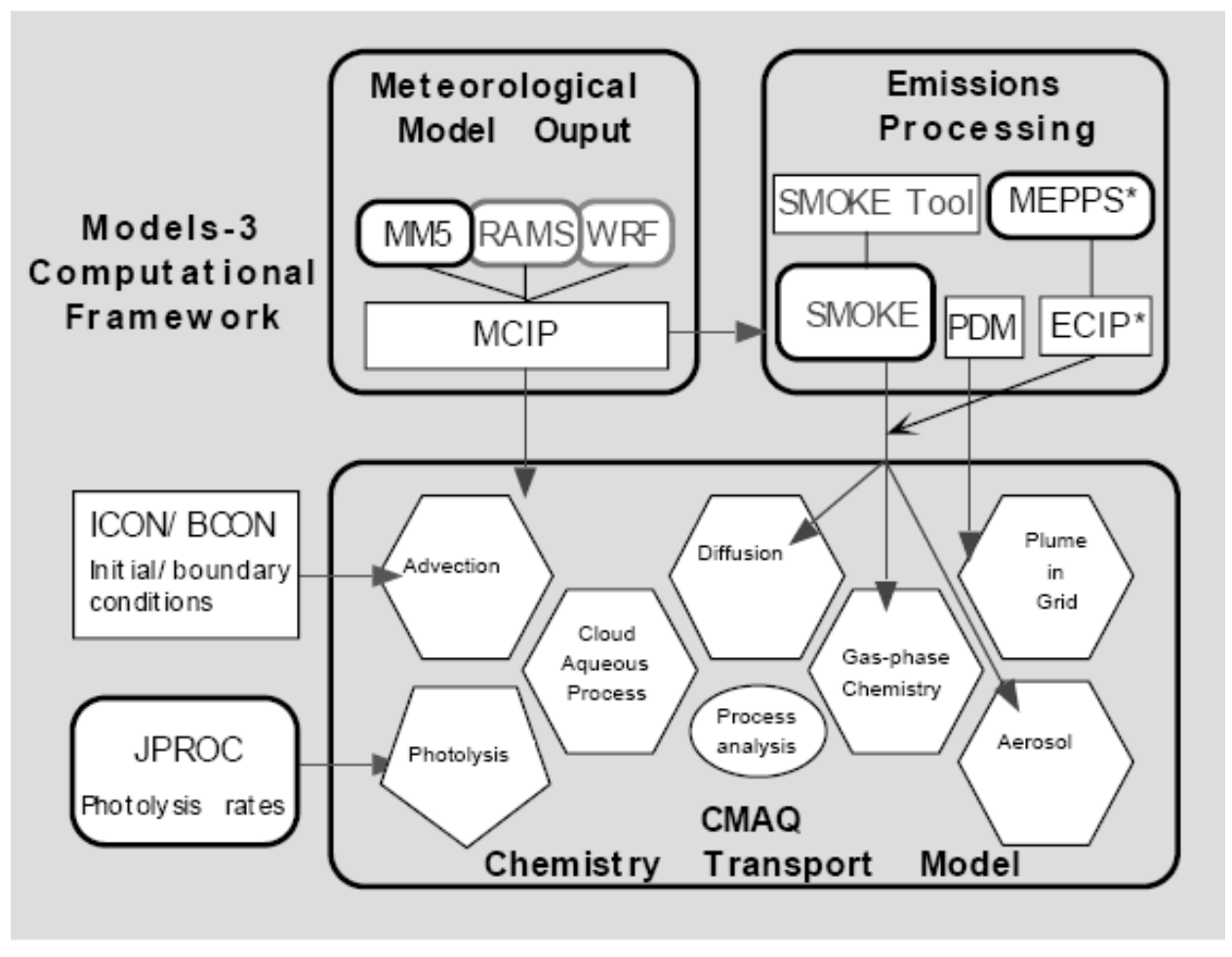

* Used in versions of CMAQ released before 2001

Figure 3.2. Model-3 components (Byun and Schere, 2006).

Other inputs for CTM include the initial and boundary conditions and photolysis rate coefficients. The initial condition and boundary conditions are processed in the initial condition processor (ICON) and boundary condition processor $(\mathrm{BCON})$, respectively. The JPROC processor calculates the clear sky photolysis rate for different times and latitudes. The photolysis rates affect the rate of chemical reactions and depend on the time of day, season, atmospheric composition, and latitude. 
CMAQ includes various chemical mechanisms including the Statewide Air Pollution Research Center, Version 1999 (SAPRC-99) photochemical mechanisms (Carter 2000) and the Carbon Bond version 5 mechanism (CB05) (Yarwood et al., 2005). Within each of these mechanisms, speciation and chemical reactions are defined. SAPRC-99 includes 214 reactions whereas CB05 includes 156. SAPRC-99 considers 80 different species whereas CB05 considers 59 species. The run time of SAPRC-99 is more than CB05 if all of the other conditions are equal (Luecken et al., 2008). The CMAQ model used in this thesis is the gas-phase variant of version 4.5.1 with the SAPRC-99 chemical mechanism.

The adjoint of CMAQ used in this study was developed for gas-phase processes $^{2}$ and was implemented in CMAQ version 4.5.1 (Hakami et al., 2007). As our application focuses on ozone concentrations, using the gas-phase version of the CMAQ adjoint is not problematic. The sequence of processes for the adjoint of CMAQ is similar to the forward CMAQ, but model integration is run backward in time. In the forward model, the concentrations of species are calculated for each time step by different processes, whereas for the CMAQ adjoint the sensitivities are calculated and written to the output files. The adjoint CMAQ also requires the concentration of species for nonlinear operators (for calculation of the transpose of the Jacobian in equation 2-34) such as the chemistry solver. As such, the forward CMAQ must save (i.e., write) the concentrations into checkpoint files before the adjoint run.

\footnotetext{
${ }^{2}$ The adjoint of aqueous-phase and the aerosol processes is under development.
} 
However, for subsequent adjoint sensitivity runs under the same baseline conditions, checkpoint files from previous runs can be re-used. This results in significant savings in computational time if multiple adjoint runs are performed.

For the adjoint of CMAQ, a discrete adjoint scheme is employed for chemistry, diffusion, and vertical advection and a continuous adjoint is employed for horizontal advection. The CMAQ adjoint uses the kenetic pre-processor (KPP) version 2.2 for chemistry integration, (Damian et al. 2002; Daescu et al. 2000), the piecewise parabolic method (Colella and Woodward 1984) for the horizontal advection process, and an upwind first order finite deference method for vertical diffusion.

CMAQ can run in serial (i.e., with a single processor) or parallel (i.e., with multiple processors) mode. Parallelization of adjoint models is particularly important because adjoint simulations are inherently expensive. In this thesis, we take advantage of parallelization of the CMAQ adjoint model. In parallel mode, depending on the number of available processors, the domain is divided into several sub-domains among available processors. In order to control the communication between processors, CMAQ uses the MPICH message passing interface (MPI) which builds a connection between sub-domains (Bridges et al., 1995).

The CMAQ domain in our study is a North American domain with a $36 \mathrm{~km}$ grid size, and 34 vertical layers. The running period is form July $1^{\text {st }}$ to September $30^{\text {th }}$ (Chapter 4) or from June $1^{\text {st }}$ to September $30^{\text {th }}$ (chapters 5, 6, and 7) of 2007. The adjoint cost functions are ozone concentration, exposure to ozone (Chapter 4), and 
short-term mortality health damages (chapters 5,6, and 7) which will be discussed in further detail in corresponding chapters.

Interactions with CMAQ and adjoint is done through a shellscript which is used to run CMAQ within a Linux operating system. All variables required for running the model are set in the script. These variables include: the start date, end date, grid name, number of assigned processors for a parallel run, input data path, output directory path, species and layer range for integrated average concentrations, and a parameter to determine whether the user wants CMAQ to rewrite the existing outputs or keep them.

The shellscript used for CMAQ and its adjoint are very similar with some minor differences. For the adjoint model, runs go backward in time, and therefore, the user needs to set the end of the modeling period as the start of the adjoint model run. Also, the adjoint model requires some additional inputs whose names and paths should be set in the script. These additional inputs are checkpoints containing the concentrations of species and the adjoint forcing terms explained in section 3.2.1.

\subsubsection{Adjoint cost function and forcing term}

As explained in section 2.5, the adjoint model calculates the derivatives of a metric known as the cost function with respect to model inputs (equation 2-33). In this section, some examples for the cost function and the related forcing terms are presented. Note that the forcing term is the local derivative of the cost function with respect to concentrations. The forcing can be written by any code (e.g., Fortran code) after the forward CMAQ has generated the concentration files. This section does not 
cover an explanation of how these codes are prepared. Instead, it details what the forcing terms are so that such code can be written in any programming language.

\subsubsection{Spatial average ozone}

Assume a simple modeling domain with only four grid cells with the ozone concentrations of $C_{1}$ to $C_{4}$ :

\begin{tabular}{|l|l|}
\hline $\mathrm{C}_{1}$ & $\mathrm{C}_{2}$ \\
\hline $\mathrm{C}_{3}$ & $\mathrm{C}_{4}$ \\
\hline
\end{tabular}

If the cost function $J$ is defined as the average of the ozone concentrations:

$$
J=\frac{C_{1}+C_{2}+C_{3}+C_{4}}{4}
$$

Then, the forcing terms are:

$$
\frac{\partial J}{\partial C_{1}}=\frac{\partial J}{\partial C_{2}}=\frac{\partial J}{\partial C_{3}}=\frac{\partial J}{\partial C_{4}}=\frac{1}{4}
$$

In this case, one can simply make a forcing file with the following values:

\begin{tabular}{|l|l|}
\hline $1 / 4$ & $1 / 4$ \\
\hline $1 / 4$ & $1 / 4$ \\
\hline
\end{tabular}




\subsubsection{Spatial and temporal averages of ozone concentrations}

For a similar domain but over multiple time periods concentrations can be represented as:

\begin{tabular}{|l|l|}
\hline $\mathrm{C}_{11}$ & $\mathrm{C}_{21}$ \\
\hline $\mathrm{C}_{31}$ & $\mathrm{C}_{41}$ \\
\hline
\end{tabular}

\begin{tabular}{|l|l|}
\hline $\mathrm{C}_{12}$ & $\mathrm{C}_{22}$ \\
\hline $\mathrm{C}_{32}$ & $\mathrm{C}_{42}$ \\
\hline
\end{tabular}

where $C_{i t}$ represents the ozone concentration at grid $i$ and time $t$, the average ozone cost function is defined as follows:

$J=\frac{\left(C_{11}+C_{21}+C_{31}+C_{41}\right) / 4+\left(C_{12}+C_{22}+C_{32}+C_{42}\right) / 4}{2}$

Then, the corresponding forcing terms are:

$\frac{\partial J}{\partial C_{11}}=\frac{\partial J}{\partial C_{21}}=\frac{\partial J}{\partial C_{31}}=\frac{\partial J}{\partial C_{41}}=\frac{\partial J}{\partial C_{12}}=\frac{\partial J}{\partial C_{22}}=\frac{\partial J}{\partial C_{32}}=\frac{\partial J}{\partial C_{42}}=\frac{1}{8}$

In this case, one can make a forcing file with two time steps and the following values:

\begin{tabular}{|l|l|}
\hline $1 / 8$ & $1 / 8$ \\
\hline $1 / 8$ & $1 / 8$ \\
\hline
\end{tabular}

\begin{tabular}{|l|l|}
\hline $1 / 8$ & $1 / 8$ \\
\hline $1 / 8$ & $1 / 8$ \\
\hline
\end{tabular}

\subsubsection{Spatially-averaged 1-hour maximum ozone}

For the same modeling domain but over a 24 hour period, ozone concentrations are presented as: 


\begin{tabular}{|l|l|}
\hline $\mathrm{C}_{11}$ & $\mathrm{C}_{21}$ \\
\hline $\mathrm{C}_{31}$ & $\mathrm{C}_{41}$ \\
\hline
\end{tabular}

\begin{tabular}{|l|l|}
\hline $\mathrm{C}_{12}$ & $\mathrm{C}_{22}$ \\
\hline $\mathrm{C}_{32}$ & $\mathrm{C}_{42}$ \\
\hline
\end{tabular}

\begin{tabular}{|l|l|}
\hline$C_{1,23}$ & $C_{2,23}$ \\
\hline$C_{3,23}$ & $C_{4,23}$ \\
\hline
\end{tabular}

\begin{tabular}{|l|l|}
\hline $\mathrm{C}_{1,24}$ & $\mathrm{C}_{2,24}$ \\
\hline $\mathrm{C}_{3,24}$ & $\mathrm{C}_{4,24}$ \\
\hline
\end{tabular}

where $C_{i t}$ is the ozone concentration at grid $i$ and time $t$. For the average maximum 1hour ozone, the cost function is:

$J=\frac{\operatorname{Max} 1 h r_{1}+\operatorname{Max} 1 h r_{2}+M a x 1 h r_{3}+\operatorname{Max} 1 h r_{4}}{4}$

where $\operatorname{Max}_{1 h r_{i}}$ is the maximum of 1-hour ozone concentration at grid $i$ over 24 hours. The forcing terms for this example are as follows:

$\frac{\partial J}{\partial C_{i t}}= \begin{cases}1 / 4 & t=t_{\text {Maxihr }} \\ 0 & t \neq t_{\text {Max1hr }}\end{cases}$

where $t_{\text {Max } 1 \text { hr }}$ is the time when the maximum 1-hour ozone occurs. For this case, one can make a forcing file with 24 time steps and assign $1 / 4$ to the grids and times where and when the maximum 1-hour ozone occurs.

\subsubsection{8-hour maximum ozone}

The process to make forcing files for 8-hour ozone is similar to that for 1-hour ozone. Assume the same example for 1-hour ozone, but this time for the following cost function: 
$J=\frac{M a x 8 h r_{1}+M a x 8 h r_{2}+M a x 8 h r_{3}+M a x 8 h r_{4}}{4}$

where $M a x 8 h r_{i}$ is the maximum of 8-hour averaged ozone concentration for grid $i$, and is defined as follows:

$\operatorname{Max}_{\mathrm{ahr}}=\operatorname{Max}\left(\frac{\sum_{t}^{t+7} C_{i t}}{8}\right), t=1, \ldots, 24$

The forcing terms for this example are as follows:

$\frac{\partial J}{\partial C_{i t}}= \begin{cases}1 /(4 * 8) & t \in t_{\text {Max8hr }}(i) \\ 0 & t \notin t_{\text {Max } 8 h r}(i)\end{cases}$

where $t_{\text {Max8hr }}(i)$ is the time when the maximum 8 -hour ozone occurs at grid $i$. For this example, a forcing file with 24 time steps can be created and 1/32 assigned to the grids and times where maximum 8-hour ozone occurs. Note the factor $1 / 32$ in equation 3-9 comes from the factor $1 / 4$ in equations $3-7$ and the factor $1 / 8$ in equation 3-8.

\subsubsection{Exposure}

Assume that a cost function is defined based on human exposure to ozone or population weighted ozone concentrations:

$J=\sum_{t=1}^{24} P_{i} C_{i t}$ 
where $P_{i}$ is the population at grid $i$, and $C_{i t}$ is the concentration at grid $i$ and time $t$. In this case, the forcing terms are:

$$
\frac{\partial J}{\partial C_{i t}}=P_{i}
$$

For this example, it is not necessary to create a forcing file, and the adjoint can simply be configured to read a population file within a subroutine called read forcing. Note that in equation 3-11, exposure is a linear function defined based on ozone concentrations. Linear cost functions do not require knowledge of model state, i.e. concentrations, whereas non-linear cost functions (e.g., maximum 8-h ozone) do require knowledge of concentrations from the forward run. For human exposure to 8hour and 1-hour ozone, the process is similar but forcing terms only have non-zero values in hours when 8-hour and 1-hour ozone occur.

\subsection{Other models}

The proposed decision support system also includes other models including: a meteorological model, an emission processing model, and an optimization model as described below.

\subsubsection{Meteorological model}

The meteorological model used in this study is the Weather Research and Forecasting (WRF, version 3.1) model. WRF includes two main parts: the WRF Preprocessing System (WPS) and the dynamic simulation model. The WPS prepares inputs to the dynamic model and includes three sub-programs named geogrid, ungrib, 
and metgrib. Geogrid defines the domain, ungrib extracts fields from the Gridded Information in Binary (GRIB) formatted data, and metgrib horizontally interpolates the extracted data. The dynamic model then vertically interpolates the data to the eta levels and integrates the state forward in time. An eta level is defined as a horizontal surface where the air pressure is constant.

In this thesis, the GRIB formatted North American Mesoscale (NAM) datasets are used (NCEP, 2005) for meteorological model initialization. The horizontal grid resolution is $36 \mathrm{~km}$, and the domain uses a Lambert conformal projection with 165 columns, 129 rows, and 34 vertical layers (eta levels). The WRF output file cannot be directly used as input in CMAQ and it needs a conversion in format. The Meteorology Chemistry Interface Processor (MCIP) converts WRF outputs to a format that CMAQ can read (Byun and Schere, 2006). MCIP is able to change the domain into a smaller domain horizontally and vertically. In this thesis MCIP projects the WRF files into a smaller domain with 148 columns, 112 rows, and 34 layers which is the domain used for the CMAQ simulations. Note that a larger WRF domain allows for the calculation of boundary conditions for the smaller CMAQ domain.

\subsubsection{Emission processing model}

The emission model used in this thesis is the Sparse Matrix Operator Kernel Emission (SMOKE) version 2.4 (CEP, 2009). The SMOKE model converts the resolution of the emission inventory data to a resolution that matches that of the air quality model. Air quality models usually need hourly emission data for each species in each grid cell. In SMOKE, different sub-programs such as chemical specification, 
temporal allocation, and spatial allocation convert the overall inventory data to the desired format. SMOKE can simulate toxic pollutants, particulate matter, and criteria pollutants. It can also provide air quality models with various outputs for various chemical mechanisms such as CB05 or SAPRC-99 chemical mechanisms.

SMOKE processes biogenic, area, non-road, mobile, and point sources separately and then merges them all into one file. Examples of biogenic and natural emissions include isoprene emissions from trees or $\mathrm{NO}_{\mathrm{x}}$ emissions from lightening. Biogenic emissions in SMOKE are processed using the Biogenic Emission Inventory Systems 2 and 3 (BEIS2 and BEIS3) (CEP, 2009). Area sources such as forest fires or residential heating are spread over an area. Non-road emissions include emissions from boats, gardening equipment, and construction vehicles. For mobile sources SMOKE uses MOBILE6 (and in more recent versions MOVES) which calculates emission factors from activity inventories. The activity inventory includes vehicle type, speed, and vehicle mile traveled (VMT). The point sources in SMOKE can be generated separately for non-electric unit utilities (non-EGUs) and electric unit utilities (EGUs). The emissions from power plants are calculated in point-source processes and SMOKE recognizes a power plant by its ORISPL (Office of Regulation Information System Plant Location). Knowing ORISPL code from a plant and filtering the point source inventory file, the emission from a specific plant can be generated in SMOKE.

In this thesis, the Inventory Data Analyzer (IDA) emission inventory format is used. The U.S. EPA prepared the IPA files from the National Emission Inventory 
(NEI). The IDA files include the yearly emission data, which SMOKE allocates into gridded and speciated hourly emission files. The IDA files were projected from 2005 to 2007 based on the change in population growth, industrial activities and land use patterns.

\subsubsection{Optimization model}

The optimization tool is used to optimize an objective function while the constraining criteria are met. The type of variables being optimized (i.e., real or integer), the type of objective function (i.e., linear, quadratic, nonlinear), and number of objective functions (single or multi-objective) and the form of constraints (linear, non-linear) have important impacts on the choice of the optimization technique. In this thesis, the KNITRO 8.0 optimization package is used to optimize a linear objective function.

KNITRO is an optimization software library for solving a variety of problems including: unconstrained and bound constrained problems; linear and non-linear least square problems; convex and non-convex quadratic programming problems; general convex and non-convex nonlinear non-linear constrained problems. The objective function and the constraints must be defined to run the KNITRO model. To solve a continuous nonlinear optimization problem, KNITRO uses a trust region approach based on the interior-point method (Byrd and Gilbert, 2000). In this method, the nonlinear programming problem is replaced by a series of barrier sub-problems. In each barrier sub-problem, one or more minimization steps are performed, then the barrier parameter is decreased and the process is repeated until the original problem 
has been solved towards the global optimum and by the desired accuracy (Waltz and Plantenga, 2010).

There are three main methods which interact with KNITRO and provide the required inputs for defining an optimization problem within KNITRO. Firstly, an optimization problem can be defined through a modeling language such as AIMMS, GMAS, AMPL, or MPL. Secondly, the problem can be defined by a numerical computing environment such MATLAB. Lastly, a programming language such as Java, Fortran, $\mathrm{C} / \mathrm{C}++$, or Python can be used to define the optimization problem. For all three methods, the user needs to define the optimization objective function and constraints. Defining an optimization problem with a programming language has more complexity because the user must calculate first and second order derivatives (i.e., Jacobian and Hessian matrixes). However, this method provides more control over the techniques used for solving the optimization problem (Waltz and Plantenga 2010). 


\section{CHAPTER 4:}

\section{IMPROVING NO ${ }_{\mathrm{X}}$ CAP-AND-TRADE SYSTEM WITH ADJOINT- BASED EMISSION EXCHANGE RATES ${ }^{3}$}

\subsection{Introduction}

Acute and chronic exposure to surface ozone, even in low concentrations, is harmful to public health (Bell et al. 2004; Jerrett et al. 2009). Ozone is formed in the atmosphere through a series of photochemical reactions in presence of adequate amounts of $\mathrm{NO}_{\mathrm{x}}$ (i.e., $\mathrm{NO}_{2}$ and $\mathrm{NO}$ ), volatile organic compounds (VOCs), and sunlight. The effectiveness of $\mathrm{NO}_{\mathrm{x}}$ emissions in producing ozone is greatly affected by factors such as location, time of release, and the predominant chemical regime along the transport trajectory. In other words, $\mathrm{NO}_{\mathrm{x}}$ emissions in different times and locations have different ozone formation potentials. As such, an environmentally effective $\mathrm{NO}_{\mathrm{x}}$ cap-and-trade program needs to account for temporal and spatial variability in ozone formation potential of various emissions trading partners.

Several regional $\mathrm{NO}_{\mathrm{x}}$ trading programs have been established in the past decade such as the $\mathrm{NO}_{\mathrm{x}}$ Budget Trading Program (NBP) and the Clean Air Interstate Rule (CAIR), which replaced the NBP in 2008. Under NBP and CAIR, each state would issue a certain number of allowances (one allowance is one short ton of $\mathrm{NO}_{\mathrm{x}}$ emissions), and then firms could trade their allowances, even between states. In NBP

\footnotetext{
${ }^{3}$ This chapter is a reformatted version of the following published article: (Mesbah et al. 2012).
} 
or CAIR, one unit of emissions at one location can be traded for one unit of emissions at any other location. Trading permits on a one-to-one basis is not problematic for long-lived pollutants such as $\mathrm{CO}_{2}$ because they live long enough to be uniformly mixed. However, the short lifetimes for ozone or its precursors result in spatial variability in net ozone formation along the transport path. In particular, the response of ozone to $\mathrm{NO}_{\mathrm{x}}$ emissions is very location-dependent and nonlinear (Hakami et al. 2004), as $\mathrm{NO}_{\mathrm{x}}$ can either help or hurt the production of ozone depending on the governing atmospheric regime. Within the current cap-and-trade framework, emissions are only differentiated based on their associated abatement costs. If all emissions are treated equally (like the CAIR program), trades may cause deterioration of ambient air quality despite a decreasing total emission cap. However, differentiating between emissions based on ozone formation potential has not been implemented by any $\mathrm{NO}_{\mathrm{x}}$ trading program in the U.S. since previous studies did not find a significant benefit for such differentiation (EPA 1998; Krupnick et al. 2000).

One of the pioneer cap-and-trade methods is the ambient permit system (APS) where polluters trade the ambient quality rather than the emissions (Montgomery 1972). APS is hard to implement due to complexities associated with collecting ambient permits from different receptors. Other trading systems allow the exchange of emission permits either with variable (Atkinson and Tietenberg 1984; Krupnick et al. 1983; McGartland and Oates 1985) or fixed exchange rates (Farrow et al. 2005; Hung and Shaw 2005; Klaassen et al. 1994; Krupnick et al. 2000). The exchange rate is the ratio by which a polluter can increase its emissions after buying a unit of emission 
from another polluter. Variable exchange rate systems are based on external restrictions on emissions trading (Atkinson and Tietenberg 1984; Krupnick et al. 1983; McGartland and Oates 1985). To ensure whether restrictions are met, these systems need air quality modeling for each trade and therefore are computationally expensive to design and maintain. Fixed exchange rate systems are easier to implement since the polluters trade their permits based on the exchange rates determined by the environmental authority. Fixed exchange rates are defined in different ways such as the ratio of marginal abatement costs of polluters (Klaassen et al. 1994), the ratio of polluters' impact on ambient quality (Hung and Shaw 2005), the number of people exposed to pollution (Krupnick et al. 2000), or the ratio of marginal damage of the pollutants (Farrow et al. 2005; Muller and Mendelsohn 2009; Muller 2011).

The calculation of exchange rates requires abatement cost information or the source-receptor relationships. As traditional approaches for quantifying sourcereceptor relationships require numerous simulations, calculating these relationships for a realistically long period has been infeasible. One way to overcome this high computational cost is using simplified versions of air quality models (Muller and Mendelsohn 2009; Muller 2011). Simplified models are computationally inexpensive but they do not account for physical and chemical processes in the atmosphere as well as the complexity involved in calculation of some parameters such as the photolysis rates (Binkowski et al. 2007). Another complication in using simplified models is that 
ozone is a secondary pollutant, and therefore, the source-receptor relationships need to account for transformation of $\mathrm{NO}_{\mathrm{x}}$ (and VOCs) to ozone.

In this work, we propose a sensitivity-based exchange rate system that employs an adjoint of the U.S. EPA's Community Multiscale Air Quality (CMAQ) model (Hakami et al. 2007). The efficiency of the proposed system is evaluated through a simulation-optimization model that can predict $\mathrm{NO}_{\mathrm{x}}$ emissions trading behavior and post-trade ozone concentrations. The environmental outcomes and cost performances of the proposed and current policies are examined in a case study for 218 coal-fired electric generation units that participated in the NBP during the ozone season of 2007.

\section{2. $\mathrm{NO}_{\mathrm{x}}$ control decision support system}

Figure 4.1 shows the components of a proposed decision support system consisting of three policies: 1) command-and-control $(\mathrm{CaC})$, which assumes all sources keep their emissions at the initial allocated levels, 2) cap-and-trade (CaT) with no exchange rate which is the current policy in the U.S., and 3) cap-and-trade with an exchange rate, which will be explained in more detail later. The exchange rate policy has been examined for two different scenarios: a) for the average daily maximum 8-hour (ADM8) ozone (CaT-EX), and b) for ozone exposure (CaT-EXP). Exposure is calculated based on 8-hour ozone to preserve consistency with the National Ambient Air Quality Standard (NAAQS). Note that ozone exposure in this work is defined as the population weighted ozone concentrations. This simplified definition does not account for all the complexities of personal exposure assessment 
such as the time spent indoors, activity level, or age. If the CaC policy is chosen, the emission distribution is predetermined, and the ambient air quality is calculated based on allocated emissions. If the selected policy is one of the two cap-and-trade policies, the optimization model is required for abatement cost minimization. The optimization model minimizes the total abatement cost in the system subject to different policy constraints by using plant-specific abatement cost information. For CaT-EX(P) policy, an environmental constraint limits the trade by fixed exchange rates. The exchange rates are calculated by the adjoint of gas-phase CMAQ. These simulations provide location-specific sensitivities that are used to establish exchange rates between trading partners based on their respective influences on ozone concentrations. The outputs from the optimization model are the total abatement cost and post-trade emissions distribution. The latter can be used for prediction of ozone concentrations. 


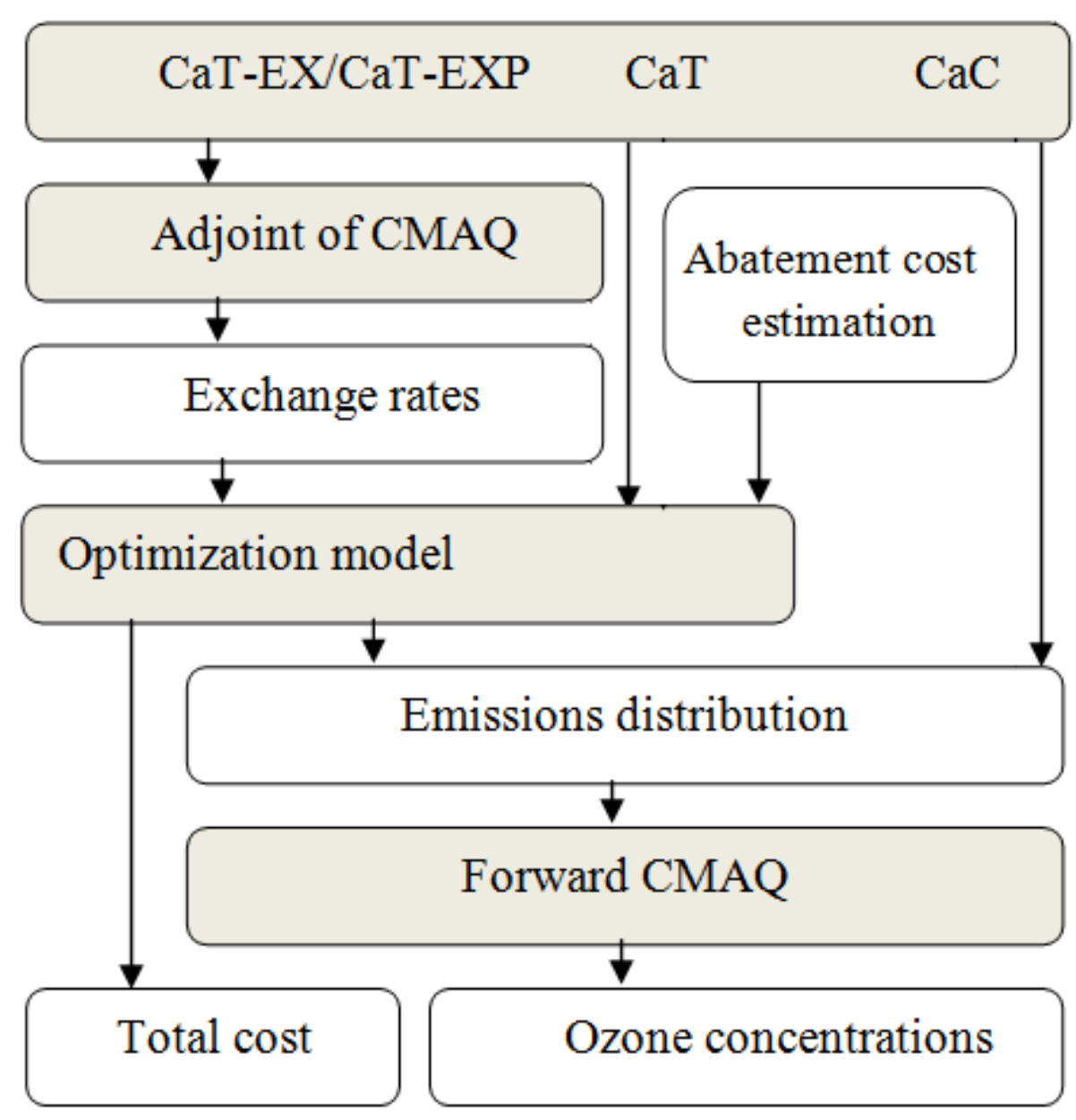

Figure 4.1. The components of the proposed decision support system.

\subsection{Sensitivity analysis}

Various sensitivity analysis methods can be used to calculate derivatives of concentrations with respect to emissions. Formal sensitivity methods entail integration of equations that carry sensitivity information. Two general categories of formal techniques for local sensitivity analysis are forward (such as the decoupled direct method (Dunker 1984) and backward (or adjoint) methods. Forward sensitivity 
models integrate evolution of model sensitivities forward in time while adjoint simulations integrate an auxiliary set of model sensitivities backward in time and space. Both forward and adjoint sensitivity methods calculate the derivatives of outputs (e.g., ambient quality) with respect to inputs (e.g., emissions). Forward sensitivities map influences of a predetermined single source (or a scaling of multiple sources) on all receptors (Dunker 1981, 1984; Hakami et al. 2003) but do not provide influences from individual sources on the receptors. Conversely, adjoint sensitivities map influences on a predetermined single receptor (or on an integrated metric based on multiple receptors) from individual sources (Hakami et al. 2007; Henze et al. 2007; Sandu et al. 2005). Therefore, adjoint sensitivities are considered source-specific (as they provide sensitivity information about individual sources) but they lack receptor specificity because they do not calculate the response at each receptor (Hakami et al. 2006). The efficiency of these two methods is related to the number of sources and receptors of concern in a specific application. Adjoint sensitivity analysis is significantly more efficient when influences (i.e., sensitivities) from many sources (of different species) are sought on a predetermined single receptor or receptor-based metric.

The focus of this chapter is on differentiating between individual sources in terms of their potential influence on ozone concentrations. Therefore, adjoint sensitivity analysis is the natural method of choice. As mentioned before, adjoint analysis can also be carried out for an integrated metric (in space and/or time) instead of one single receptor. This metric is referred to as the adjoint cost function and 
should not be mistaken with the "cost function" used in the abatement cost minimization within an emissions trading framework. The adjoint cost function can be defined as any function of concentrations of one or multiple species such as average ozone, maximum 8-hour ozone, ozone exposure, total mortality (e.g., from ozone and $\mathrm{PM}_{2.5}$ ), etc, as long as the functionality is mathematically established and differentiable. This function can be integrated over receptors, times, model columns, or species. In this study, the adjoint sensitivity term $\lambda_{i}$ is the sensitivity of the ozone metric $(J)$ to $\mathrm{NO}_{\mathrm{x}}$ emissions from polluter $i$, and the adjoint of the gas-phase CMAQ model is used to differentiate between $\mathrm{NO}_{\mathrm{x}}$ emissions based on their adjoint sensitivities as a measure of influence. More details about the adjoint of CMAQ and its formulation and verification can be found elsewhere (Hakami et al. 2007).

\subsection{Exchange rate enhanced cap-and-trade system}

Establishing a $\mathrm{NO}_{\mathrm{x}}$ trading system with exchange rates requires setting certain parameters (i.e., ozone target, emission quota, and exchange rates) by the environmental authority. Then, participants must meet the requirements by varying their emissions and trading permits. This system involves the following steps:

1. The target ozone air quality metric, a function of ozone concentrations (e.g., ADM8 or exposure), is defined by the environmental authority. This metric should be an integrated scalar across all receptors. We compare the change in environmental performance with a baseline taken as the $\mathrm{CaC}$ policy where all sources emit at their allocated quota. $\Delta J$ is then the change in the environmental metric as the result of 
implementation of a trading policy. Accordingly, $\Delta J_{i}^{0}$ is the change in the environmental metric from trades for polluter $i\left(\Delta J=\sum_{i=1}^{n} \Delta J_{i}^{0}\right)$ and is set by the environmental authority. We assume $\Delta J_{i}^{0}$ of zero to ensure that no environmental deterioration results from emissions trading for any source. However, the methodology presented below is general and $\Delta J_{i}^{0}$ can be set as a negative value to ensure a certain level of post-trade improvement in environmental quality.

2. The environmental authority allocates emission quota $\left(e_{i}^{0}\right)$ to each polluter, as well as the system-wide cap $\left(e_{t}=\sum_{i=1}^{n} e_{i}^{0}\right)$. The relationship between emissions from polluter $i\left(e_{i}\right)$ and the ozone metric is:

$$
\lambda_{i} \Delta e_{i}=\lambda_{i}\left(e_{i}-e_{i}^{0}\right)=\Delta J_{i}
$$

where $\Delta e_{i}$ represents the change in emissions from polluter $i$ compared to the allocated level, and $\Delta J_{i}$ is the resulting change in the ozone metric caused due to $\Delta e_{i}$.

3. Exchange rates $\left(\alpha_{i j}\right)$ are set by the environmental authority. $\alpha_{i j}$ is the amount of emissions polluter $j$ can increase by buying one unit of emissions from polluter $i$ :

$$
\alpha_{i j}=\frac{\lambda_{i}}{\lambda_{j}}
$$

where $\lambda_{i}$ and $\lambda_{j}$ are the ozone metric sensitivities to $\mathrm{NO}_{\mathrm{x}}$ emissions from polluters $i$ and $j$, respectively. 
In a $\mathrm{CaC}$ system, the environmental authority sets the emission quota, and all polluters must maintain their emissions below the allocated quota (i.e., $e_{i} \leq e_{i}^{0}$ ) which will ensure a negative or zero $\Delta J_{i}$. However, under a CaT system, polluters can have a higher emission level than their allocated quota if they buy permits. Theoretically, a CaT policy will minimize the system-wide abatement costs by directing emission reductions to least-cost cases. Therefore, we simulate post-trade emissions distribution by minimizing the system-wide abatement costs:

Minimize $\sum_{i=1}^{n} c_{i}\left(e_{i}^{0}-e_{i}\right)$

Subject to :

$$
\begin{aligned}
& e_{i} \leq e_{i}^{0}-\sum_{\forall j \neq i} T_{i j}+\sum_{\forall j \neq i} T_{j i}, i=1, \ldots, n ; j=1, \ldots, n, \\
& T_{i j}, T_{j i} \geq 0, \\
& e_{i} \in\left[0, e_{i}^{\max }\right] .
\end{aligned}
$$

where $c_{i}$ is the abatement cost for polluter $i$ and $T_{i j}$ is the amount of quota that polluter $i$ sells to polluter $j$. The post-trade emission level, $e_{i}$, is the minimization variable, and the maximum possible post-trade emission for a plant, $e_{i}^{\max }$, is dictated by the plant's physical capacity and its available control technology. Note that equation 4-3b is a sufficient condition for maintaining the system-wide cap.

Under a CaT-EX system, equation $4-3 b$ can be modified to include the exchange rates (equation 4-4b) and change in environmental metric: 
Minimize $\sum_{i=1}^{n} c_{i}\left(e_{i}^{0}-e_{i}\right)$

Subject to :

$$
\begin{aligned}
& \lambda_{i}\left(e_{i}+\sum_{\forall j \neq i} T_{i j}-\sum_{\forall j \neq i} \alpha_{j i} T_{j i}-e_{i}^{0}\right) \leq \Delta J_{i}^{0}, i=1, \ldots, n ; j=1, \ldots, n, \\
& \sum_{i=1}^{n} e_{i} \leq e_{t}, \\
& T_{i j}, T_{j i} \geq 0, \\
& e_{i} \in\left[0, e_{i}^{\max }\right] .
\end{aligned}
$$

where $e_{t}$ is the total cap on emissions and is added to the system to ensure that the total emissions remain below the total cap (equation 4-4c). The outputs of this optimization model are the optimal trading pattern, the corresponding post-trade emissions distribution, and abatement costs. Note that while equation 4-3b defines the total constraint in a traditional cap-and-trade system, equation 4-4b effectively imposes a cap on the ozone concentration metric. In other words, incorporation of exchange rates into the existing $\mathrm{NO}_{\mathrm{x}}$ emissions trading would transform the system into an ozone trading system. As CAIR is mainly concerned with ozone, this transformation is more likely to result in improved target air quality.

\subsection{Case study}

We evaluate the efficiency of the proposed decision support system in a case study of 218 coal-fired electric generation units with post-combustion control 
technologies (either SCR or SNCR) that participated in the NBP program in 2007. Emissions trading has long-term impacts and can affect strategic planning of generating units. Plants would plan to employ control technologies to properly position themselves in the trading framework. The decision of the plant will depend on a multitude of factors such as the cost of control technology, environmental constraints, and electricity and fuel prices. In the short-term (i.e., within the ozone season), it is reasonable to assume that capital is fixed. Firms then only have the choice to buy or sell emission permits and to adjust output (i.e., electricity generation). We assume that output adjustments due to emissions trading does not incur any opportunity cost from foregone electricity generation, which is consistent with other studies (EPA 2010a; Fowlie 2010). In the short-term, therefore, differences in marginal abatement costs between plants are merely a function of given control technologies and operating costs. In other words, we evaluate the trading system with the assumption that no new control technology can be introduced during the ozone season of a given year. The short-term variable abatement cost for the units are calculated using the EPA Integrated Planning Model (EPA 2010a).

For air quality modeling, the adjoint of the CMAQ model version 4.5.1 is used to calculate sensitivities of the ozone metric to $\mathrm{NO}_{\mathrm{x}}$ emissions. Forward and adjoint CMAQ models used in this study only include gas-phase processes because an adjoint for aerosol processes in CMAQ is not currently available. The simulation domain is the continental U.S. with $36 \mathrm{~km}$ grid resolution and 34 vertical layers, and the simulated period is from July $1^{\text {st }}$ to September $30^{\text {th }}$ of 2007 . This coarse resolution 
is chosen for reduced computational cost over the continental domain even though finer resolution may be required to better resolve local features such as $\mathrm{NO}_{\mathrm{x}}$ titration in power plant plumes. The adjoint cost function for the CaT-EXP policy is defined as the ozone exposure based on the daily maximum 8-hour (DM8) ozone. The cost function for the CaT-EX policy is based on the ADM8 ozone for critical grids where DM8 ozone is higher than $60 \mathrm{ppb}$. SMOKE version 2.4 (emission model) and WRF version 3.1 (metrological model) and MCIP version 3.4 (meteorological postprocessing) are used to generate inputs for CMAQ. Power plant emissions in SMOKE are augmented by Continuous Emission Monitoring (CEM) data ${ }^{4}$. For the abatement cost minimization modeling, a global optimization package, KNITRO version 8.0, is used (Waltz and Plantenga 2010). Our simulations have mean fractional error and bias of $16.5 \%$ and $+5.5 \%$, respectively, for a concentration cut-point of 60 ppb which is the same threshold used in the adjoint cost function definition.

\subsection{Exchange rates}

Exchange rates in this study are defined as the ratios of location-specific sensitivities (i.e., derivatives of the adjoint cost function with respect to emissions). These sensitivities are local derivatives and provide slopes. However, in a nonlinear

\footnotetext{
${ }^{4}$ Power plant emissions are from the CEM data for the year 2007, and emissions from other sources are based on the 2005 National Emissions Inventory (NEI) for the U.S., and the 2006 National Pollutant Release Inventory (NPRI) for Canada which are projected to the year 2007. This footnote was not included in the published paper.
} 
response surface, such as that expected in atmospheric chemistry, these slopes can change as the system shifts from one state to another. For large perturbations in emissions or in a highly nonlinear system, these local sensitivities, and accordingly the exchange rates, may need to be recalculated as trades take place.

In our study we assume fixed exchange rates, but examine how this assumption is affected by the existing nonlinearities. Previous studies have indicated that $\mathrm{NO}_{\mathrm{x}}$ emission changes up to about $30 \%$ result in a near-linear response (Cohan et al. 2005; Dunker 1981; Dunker et al. 2002). The exchange rates are calculated and compared for pre-trade and post-trade emission distributions (Figure 4.2). Due to computational costs associated with adjoint calculations, this comparison is performed for one randomly chosen week.

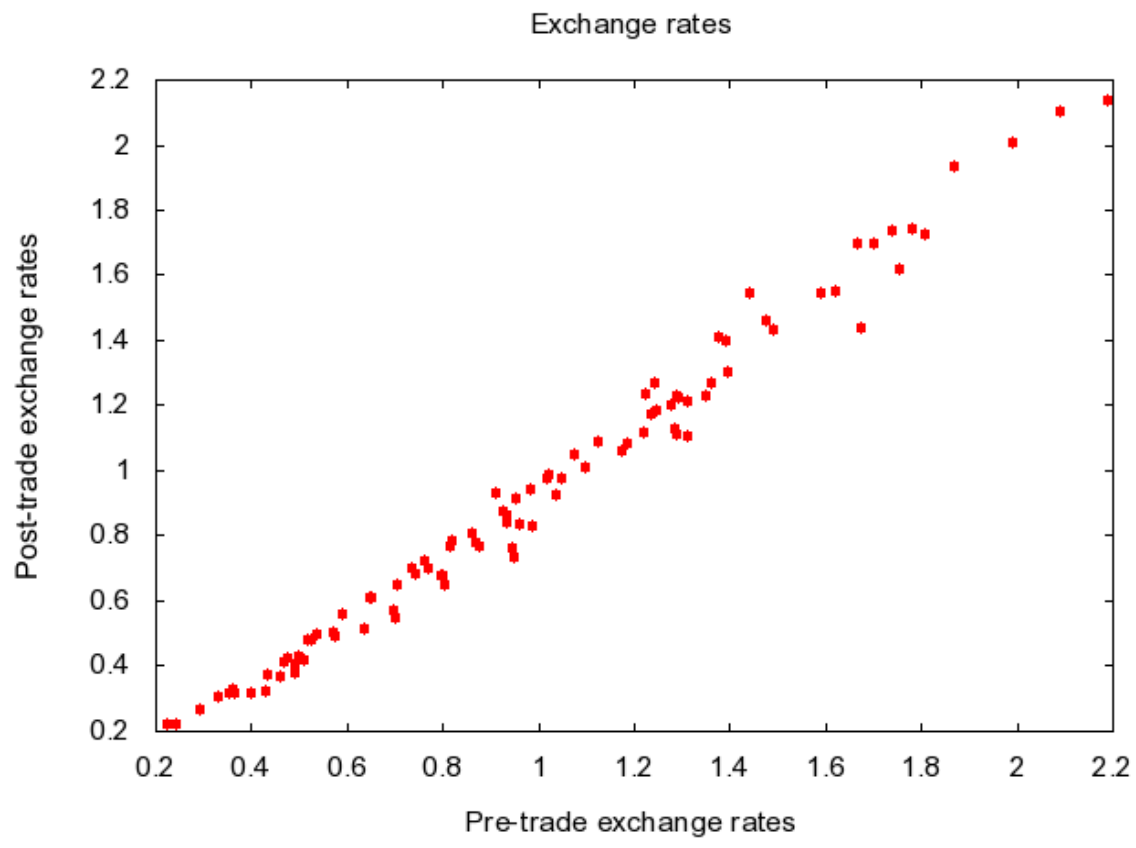

Figure 4.2. Exchange rates for all plants before and after trade (CaT-EX policy). All exchange rates are for trades with the plant with the average pretrade sensitivity. 
Some plants shown in Figure 4.2 experience significant changes in their emissions as the result of trading. The ratio of post-trade to allocated emissions ranges between zero to 6.4 under various policies. Despite large changes in emissions, the exchange rates do not exhibit much sensitivity to changes in emissions distribution. Nonlinearity in atmospheric response occurs when there is sufficient change to trigger a shift in the chemical regime of the atmosphere (Hakami et al. 2004). Previous studies of nonlinearity in response to emission changes have used forward sensitivities where a domain-wide perturbation in emissions was employed. Domainwide changes in emissions are much more likely to shift the atmospheric state and trigger nonlinear behavior than changes in individual sources. In other words, while some plants may have large trade volumes, these changes, while influential along the plume path, are not large enough to significantly affect the overall chemical state of the atmosphere. Therefore, a fixed set of exchange rates seems to be adequate for capturing differences in source influences on the adjoint cost function in our case study.

Results shown in Figure 4.2 only address nonlinearity and justify the use of fixed exchange rates within a single episode; exchange rates are likely to vary temporally across multiple episodes or years. Also, these results are calculated for a coarse resolution $(36 \mathrm{~km})$, which may include multiple power plants in one grid cell. A finer grid resolution is required to better delineate nonlinear chemistry in individual plumes. Furthermore, consistency of exchange rates shown in Figure 4.2 should not be interpreted as a linear response to emission changes. Exchange rates are ratios of 
local derivatives and as long as two sources exhibit similar nonlinear behavior towards emissions redistribution, the ratio may remain unaffected while the sensitivities change. Finally, our case study of 218 power plants is not a close representation of the actual trading system in place. As the number of trading partners and the trading volume becomes larger than our case study, a more nonlinear behavior than that seen in Figure 4.2 is possible.

\subsection{Results and discussion}

Here, we contrast the current trading policy $(\mathrm{CaT})$ to the proposed policies (CaT-EX and CaT-EXP) with regards to their impact on air quality (ozone concentrations) in the U.S., as well as the costs and benefits associated with their implementation. We examine each policy's impact on the average and the $99^{\text {th }}$ percentile DM8 ozone over 92 days in the summer of 2007 (Figure 4.3). The $99^{\text {th }}$ percentile is used as a proxy for the regulatory attainment dependence on the $4^{\text {th }}$ highest concentration in the year. We assume that all 4 highest concentrations occur during the 5-month ozone season, and that our 3-month simulation captures $60 \%$ of those occurrences.
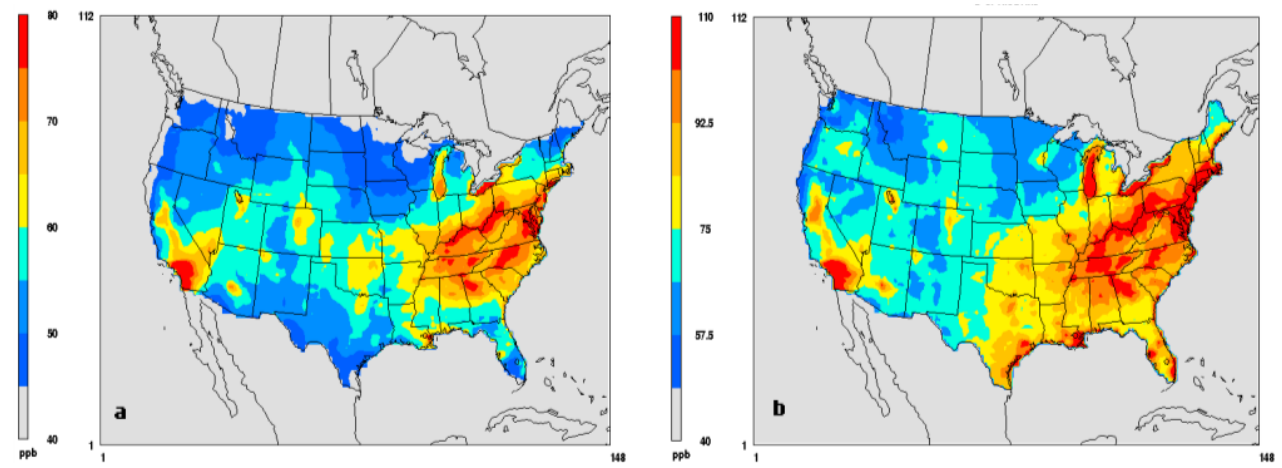

Figure 4.3. a) Average daily maximum 8-hour, and b) $3^{\text {rd }}$ highest daily maximum 8-hour ozone for the base case simulation. 
The choice of the adjoint cost function has some impact on the calculated exchange rates (Figure 4.4). The differences between exchange rates under CaT-EX and CaT-EXP policies are driven by the inclusion of population in the exposure-based adjoint cost function. While some differences exist, consistent features persist across both policies. For instance, lower than average exchange rates along the Ohio River Valley, particularly for CaT-EXP policy, reflect the existing chemical regime in this region. The high density of $\mathrm{NO}_{\mathrm{x}}$-rich plumes along the river creates a more persistent $\mathrm{NO}_{\mathrm{x}}$-inhibited chemical regime, resulting in smaller emissions reduction benefits (or even dis-benefits) immediately downwind of the source region before larger benefits materialize further downwind. As a result, the overall ozone improvement from $\mathrm{NO}_{\mathrm{x}}$ emission control from this region is subdued.

To compare the environmental performance of various policies, post-trade ozone concentrations from CaT-EX and CaT-EXP policies are compared to that of CaT policy (Figure 4.5). CaT-EX and CaT-EXP have different influences on ozone concentrations as they are driven by somewhat different exchange rate distributions (Figure 4.4). Under the CaT-EX policy, the ADM8 ozone decreases in the eastern and southeastern U.S., while concentrations in some areas in the northeast increase (Figure 4.5a). Under the CaT-EXP policy, the ADM8 ozone decreases in the southeast without any significant increase in the northeast. The largest improvement in the ADM8 ozone (averaged over 92 days) is $1.1 \mathrm{ppb}$ under CaT-EX and $2 \mathrm{ppb}$ under CaT-EXP. Larger daily improvements are observed on numerous days. 

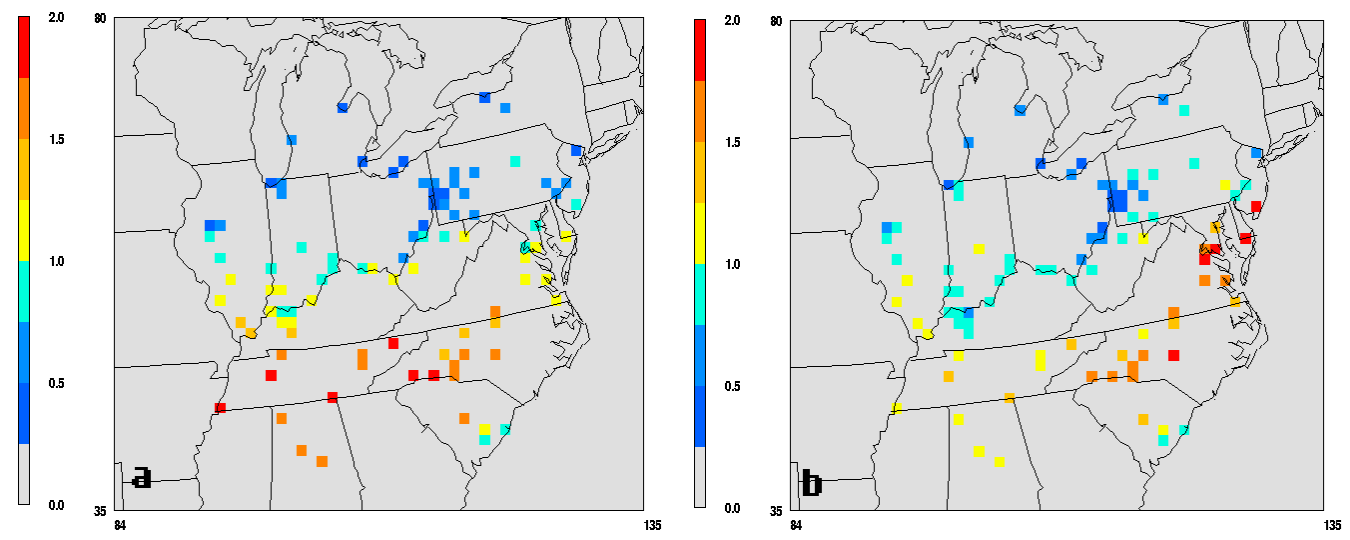

Figure 4.4. Normalized exchange rates for CaT-EX (a) and CaT-EXP (b) policies. The normalized exchange rate represents the ratio by which a power plant can exchange its emissions with the plant with the average sensitivity in the base case simulation.
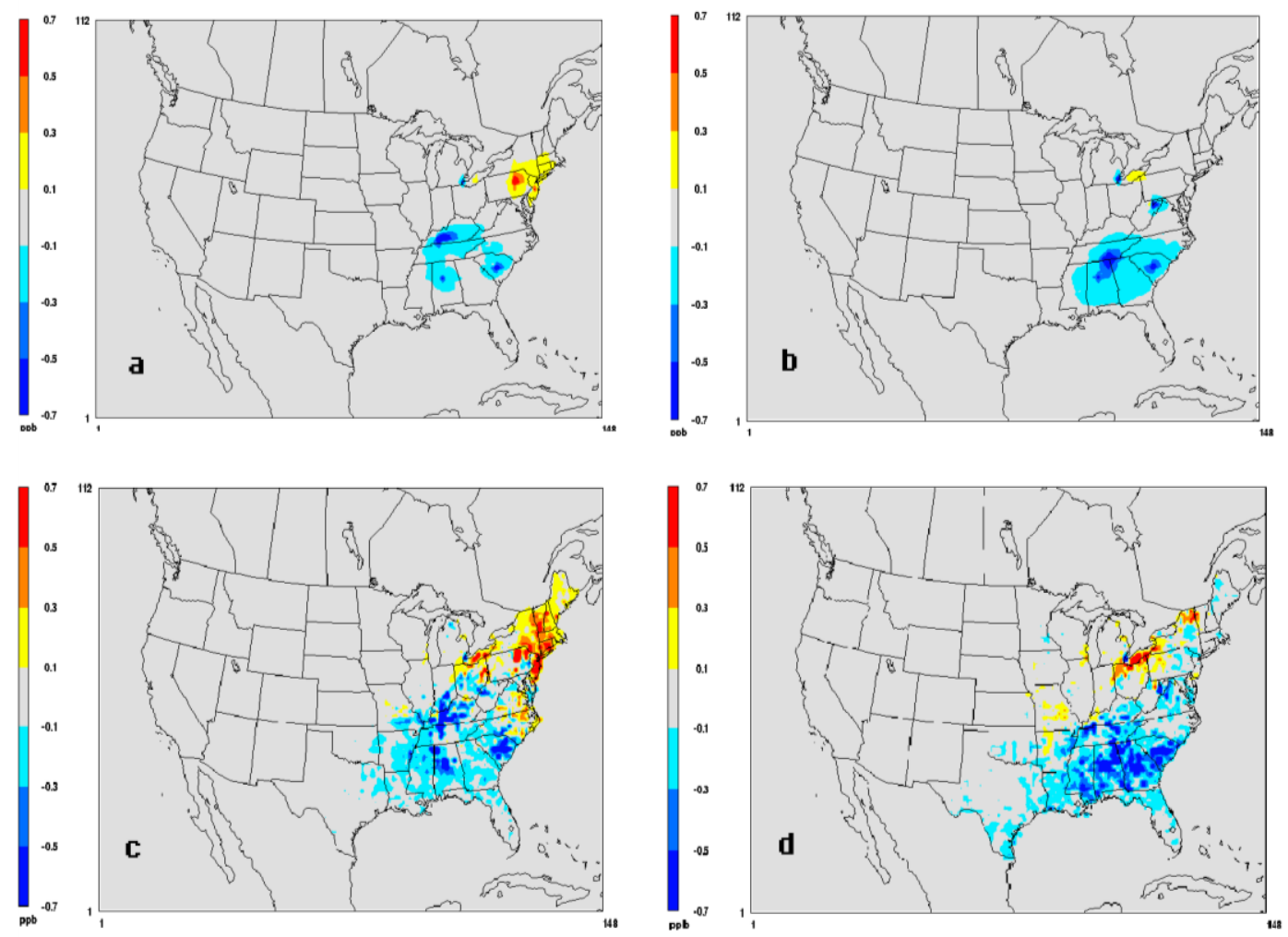

Figure 4.5. Differences between CaT and CaT-EXP (left) policies. The panels show differences in ADM8 ozone (top) and 99th percentile DM8 ozone (bottom). Negative values correspond to air quality improvements. Values in each plot are calculated (as average or percentile) from 92 daily values. 
Under both CaT-EX and CaT-EXP policies, the $99^{\text {th }}$ percentile DM8 ozone decreases in most areas in comparison to the CaT policy (Figure 4.5c and $4.5 \mathrm{~d}$ ). These improvements are spread over a wider area under CaT-EXP than CaT-EX, which is consistent with the simulated improvement in ADM8 ozone (Figure 4.5a and 4.5b). Like the ADM8 ozone, $99^{\text {th }}$ percentile DM8 ozone concentrations under the CaT-EX policy increase in some areas of the northeast, but such instances of air quality deterioration are fewer under the CaT-EXP policy.

Various explanations can be offered for air quality deteriorations seen in Figure 4.5. In the case of CaT-EX policy, the adjoint cost function (which defines an environmental constraint for the trading system) only includes grid cells where DM8 ozone is larger than $60 \mathrm{ppb}$. A number of grid cells with deteriorating ozone are not included in the adjoint cost function (see Figure 4.3), and therefore, their environmental deterioration is not penalized in the optimization. A no-threshold adjoint cost function is likely to prevent these deteriorations but at the expense of reduced improvement in other regions. Also, both CaT-EX and CaT-EXP exchange rates are calculated for the whole episode, and therefore, environmental performances in individual days are not considered. Furthermore, ADM8 ozone and $99^{\text {th }}$ percentile ozone performances are not explicitly part of the adjoint-based exposure constraint in the CaT-EXP policy. Finally, and most importantly, the adjoint-based exchange rates constrain the trades by their overall environmental impact. Therefore, a trade that results in deteriorated environmental performance in one region, but larger improvement in another, is considered permissible. This reflects an inherent limitation 
in using adjoint sensitivity analysis for the development of exchange rates. While the adjoint method provides source specificity required for calculation of exchange rates for individual sources, it lacks receptor specificity to allow for inclusion of receptorspecific constraints.

Daily environmental performance of exchange rate policies is further examined in Figure 4.6 where the change in DM8 ozone for each grid is depicted. Under CaT-EX, largest improvements occur in areas where the DM8 ozone concentration under $\mathrm{CaT}$ is between 60 and $110 \mathrm{ppb}$ (Figure 4.6a). Also, the deterioration outweighs the improvement in air quality for grids with DM8 ozone concentrations higher than $120 \mathrm{ppb}$. The pattern of change in DM8 ozone under the CaT-EXP policy is different than that of CaT-EX (Figure 4.6b) and most improvements occur when the DM8 ozone concentration under CaT is between 40 to $120 \mathrm{ppb}$. Like the CaT-EX policy, deterioration in grids with DM8 ozone concentrations above $120 \mathrm{ppb}$ persists in the CaT-EXP policy. Frequency distribution plots (Figure 4.6c and 4.6d) for both policies suggest that improvements outweigh deteriorations, particularly for the CaT-EXP policy. 

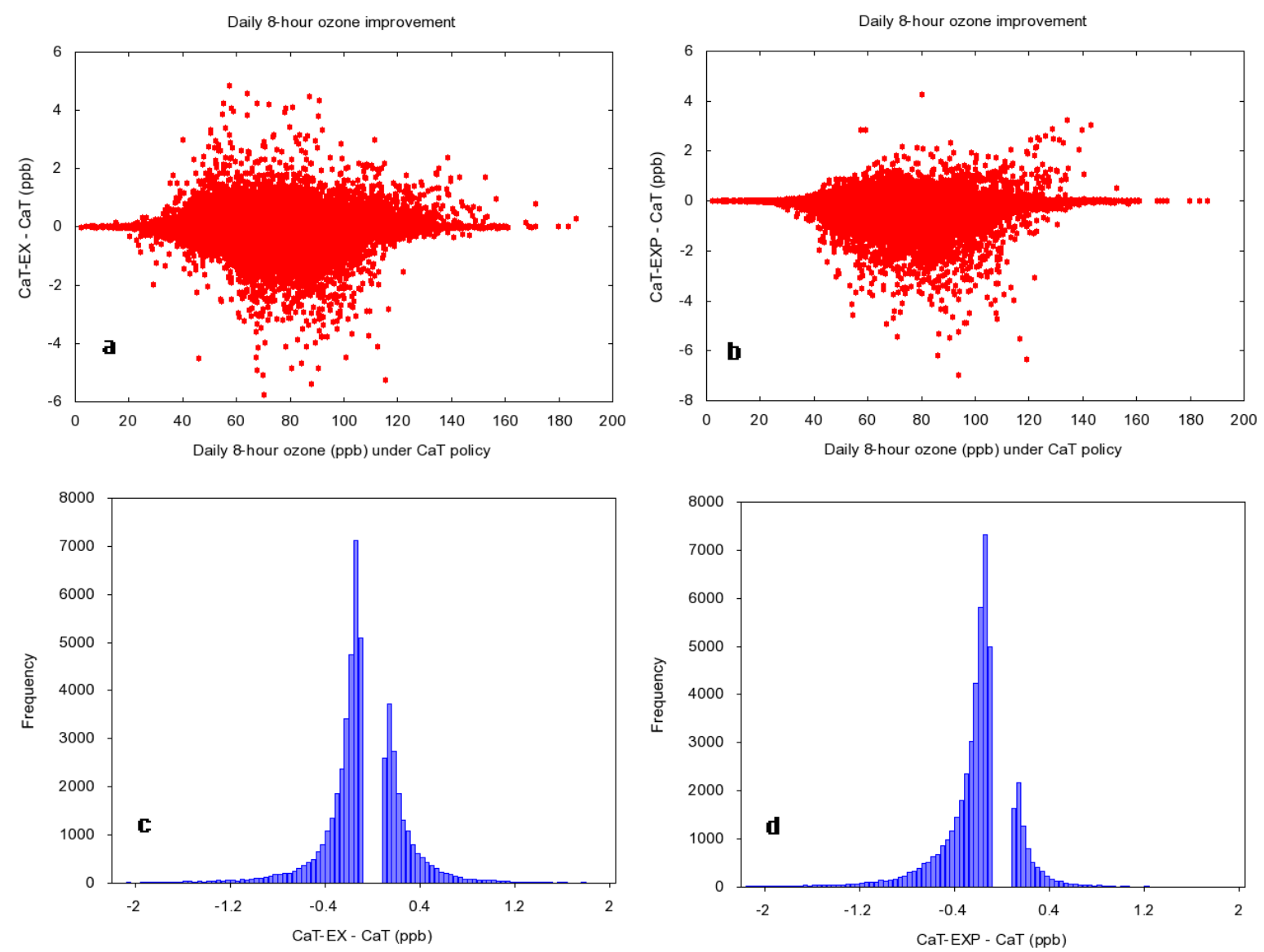

Figure 4.6. Change in DM8 ozone between CaT and CaT-EX (left) and CaT-EXP (right) policies. Each data point is the DM8 ozone in one grid-day. Days with small changes $([-0.1,0.1])$ are not included in the frequency distributions. Negative values indicate air quality improvements.

The abatement costs for various policies are compared in Table 4.1 with reference to the $\mathrm{CaC}$ policy. As expected, the $\mathrm{CaT}$ policy has the lowest cost as it is designed to minimize the system-wide abatement costs without any environmental constraint except the total imposed cap. The total abatement costs for the exchange rate policies are about $0.6 \%$ greater than the $\mathrm{CaT}$ policy. It should be noted that the total emissions under all policies are the same and only the distribution of emissions change from one policy to another. 
Abatement costs of various policies can also be compared to valuation of benefits resulting from changes in concentrations. Here we consider health benefits associated with reduced mortality due to short-term exposure to ozone in each policy. We assume the following relationship between changes in mortality $(\Delta M)$ and concentrations (EPA 1999b):

$$
\Delta M=M_{0} P\left(1-e^{-\beta \Delta C}\right)
$$

where $M_{0}$ is the baseline non-accidental mortality rate, $\beta$ is an epidemiological concentration response factor, $\Delta C$ is the change in ozone concentration, and $P$ is the population. $M_{0}$ is taken as a nationwide average of $0.7448 \%$ for non-accidental mortality rate $\left(\mathrm{Xu}\right.$ et al. 2010). The response factor $\left(\beta=0.00051 p p b^{-1}\right)$ is taken from Zanobetti and Schwarts (Zanobetti and Schwartz 2008) since they report values based on DM8 ozone concentrations. Mortality benefits are then monetized using the value of statistical life (VSL), taken to be $\$ 6.8$ million in 2007 dollars (EPA 2010b). The high benefit-cost ratio for CaT-EXP in Table 4.1 indicates the effectiveness of this exchange rate policy compared to the current system (CaT). A move from $\mathrm{CaT}$ to CaT-EX does not result in net health benefits as CaT-EX imposes a constraint on ADM8 ozone rather than exposure. CaT-EX results in increased concentrations in more populous northeast regions compared to improvements in the southeast. The costs in Table 4.1 do not include administrative and transaction costs of trading. On the other hand, benefits are likely to be underestimated, as they do not include morbidity and mortality from long-term exposure to ozone. An analysis that includes all sources in the NBP is likely to result in correspondingly larger benefits and costs. 
Table 4.1. Abatement costs and health benefits of CaT, CaT-EX, and CaT-EXP policies (million \$).

\begin{tabular}{lllll}
\hline & CaT & CaT-EX & CaT-EXP \\
\hline Abatement cost savings (compared to $\mathrm{CaC}^{1}$ ) & 411 & 405 & 406 \\
Health benefits for the season (switching from CaT) & - & -21 & 177 \\
\hline
\end{tabular}

${ }^{1}$ Total abatement cost for the CaC policy in this case study is 1409 .

It is important to emphasize that all trade-based policies in our case study, including those with exchange rates, are designed to minimize system-wide abatement costs; however, policies based on exchange rates do so while imposing an environmental constraint. As a result, cost performances of all trade-based policies are very similar. If emission redistributions were driven entirely or partly by environmental (or health) damages rather than abatement costs, benefits would be substantially higher but at the expense of higher system-wide abatement costs.

Our benefit-cost comparisons differ from those reported by Krupnick et al. (Krupnick et al. 2000). They examined the effectiveness of the $\mathrm{NO}_{\mathrm{x}}$ cap-and-trade programs in the Eastern U.S. by calculating exposure-based exchange rates through source-receptor relationships extracted from air quality model simulations (Urban Airshed Model UAM-V) for three two-day episodes in 1990. They concluded that the EPA's CaT policy was considerably more cost-effective than a $\mathrm{CaC}$ approach but they did not find any discernible benefit in using a spatially differentiated (based on exchange rates) trading approach. There are important differences between Krupnick 
et al. and our work that could explain the discrepancy in findings. First, emissions in the reference years are very different due to significant reductions in power plant emissions in recent years. Second, Krupnick et al. assigned significantly lower mortality benefits to reduced ozone exposure than this work due to the overall lack of consensus about the topic in epidemiological literature and the EPA at the time. Finally, and most importantly, Krupnick et al. used source-receptor matrices developed by forward sensitivity analysis, which limited their ability for spatial differentiation to 6 source regions. By contrast, using adjoint sensitivity analysis models, this study is able to differentiate between all 218 individual sources.

\subsection{Conclusions}

The results presented here are based on a number of simplifying assumptions and are meant as a proof-of-concept study rather than a conclusive endorsement of exchange rate enhanced emissions trading systems. Our study only included a fraction of all power plants in the U.S. and did not consider long-term abatement costs for the installation of new control technologies and the opportunity cost of electricity output reduction. Various sources of uncertainty, including those associated with air quality modeling, emission inventory, cost estimations, epidemiological factors, or the VSL, can affect our findings. Inter-annual consistency of exchange rates, multi-pollutant (including $\mathrm{PM}_{2.5}$ ) performance of the proposed system, and the impact of model resolution are among topics that require further research. Finally, important practical issues such as details of exchange rate calculations, methods for exchange of credits, and monitoring of trades should also be addressed before implementation is feasible. 
These limitations notwithstanding, our findings suggest that potentially significant benefits may arise from introduction of exchange rates into the existing $\mathrm{NO}_{\mathrm{x}}$ emissions trading systems. 


\section{CHAPTER 5:}

\section{OPTIMAL OZONE REDUCTION POLICY DESIGN USING ADJOINT-BASED MARGINAL DAMAGE INFORMATION ${ }^{5}$}

\subsection{Introduction}

Ozone is formed through photochemical reactions involving $\mathrm{NO}_{\mathrm{x}}$ and volatile organic compounds (VOCs). Ozone, even in low concentrations, can inflict damage on human health (Bell et al. 2004), ecosystems, and agriculture (Mauzerall and Wang 2001). $\mathrm{NO}_{\mathrm{x}}$ cap-and-trade (CaT) programs were established in the eastern U.S. to reduce surface ozone (EPA 2008). These programs have expanded over time and have led to substantial reductions in emissions because they were designed to control ozone indirectly by lowering the cap on total $\mathrm{NO}_{\mathrm{x}}$ emissions. While ozone concentrations have decreased in much of the country, it is unclear whether the CaT system has resulted in environmentally optimal performance. The ozone formation potentials from $\mathrm{NO}_{\mathrm{x}}$ emissions vary spatially depending on the governing atmospheric regime. Correspondingly, the damage to human health caused by $\mathrm{NO}_{\mathrm{x}}$ emissions changes spatially. A suboptimal performance in the $\mathrm{NO}_{\mathrm{x}} \mathrm{CaT}$ program is possible since it does not account for the spatial heterogeneity in ozone-related damage. Recent studies have suggested that inclusion of spatial variability in $\mathrm{NO}_{\mathrm{x}}$ health damage can improve the

\footnotetext{
${ }^{5}$ This chapter is a reformatted version of the following published article: (Mesbah et al. 2013).
} 
performance of $\mathrm{NO}_{\mathrm{x}} \mathrm{CaT}$ programs (Mesbah et al. 2012; Muller and Mendelsohn 2009).

The socially acceptable emission level of a particular pollutant from an emitter depends on the marginal abatement cost (MAC) and the marginal damage (MD) caused by the polluter. The MAC for a polluter is the cost of reducing an additional ton of emissions, whereas the MD is the dollar value of (health, ecosystem, or climate) damage caused by an additional ton of emissions from the polluter. In a $\mathrm{CaT}$ system, tradable emission allowances are allocated to polluters and emissions must be kept lower than the available allowances for each polluter. Low-MAC polluters (i.e., polluters with a MAC lower than the market-based permit price) reduce their emissions and benefit by selling unused allowances. On the other hand, high-MAC polluters emit more than their allocated allowances and benefit from buying allowances at a lower price than their MACs. Therefore, under a CaT system, emissions are differentiated based on MACs through market driven cost-saving incentives, and the system-wide abatement cost is minimized with no consideration for source-specific MDs. Under a CaT system, the number of emission allowances is the only constraint on total damage (TD).

Whether the impacts of emissions are spatially homogeneous or locationdependent is an important aspect in emission control policy design. For pollutants for which the damages are not location-dependent, the TD does not change as the result of trading and redistribution of emissions. Therefore, a cap on total emissions can effectively reduce the TD. However, for pollutants whose damages are location- 
dependent, the trading impact on TD is unknown. To limit the TD for these pollutants, a CaT system can be reformed by inclusion of exchange rates that are set by the environmental authority. An exchange rate for two polluters adjusts the exchange of allowances between the two polluters by a rate that can be defined as the ratio of their MDs.

In chapter 4, we showed that the proposed exchange rate CaT system could reduce ozone concentrations at little extra cost (Mesbah et al. 2012). While chapter 4 provided a formal framework for some consideration of MDs through exchange rates, it mainly aimed to minimize system-wide abatement costs and thus remained a $\mathrm{CaT}$ system in concept. When emissions are instead differentiated based on damages and the emitters are assessed fees based on their MDs, high-damage polluters have higher incentives to reduce their emissions. These incentives can be provided to high-damage polluters by either subsidizing their emission reduction, or by imposing a higher price on their emissions (Banzhaf 2004; Mauzerall et al. 2005). In this chapter, we investigate the environmental performance of two other $\mathrm{NO}_{\mathrm{x}}$ control policies under which polluters' emissions are differentiated based on their impacts on public health. In these policies, the socially effective emissions distribution is found based on minimizing the inflicted damage rather than minimizing the system-wide abatement cost alone. To do so, we employ a recently developed approach for estimation of source-specific health damages through backward or adjoint sensitivity analysis in air quality models (Pappin and Hakami 2013). 


\subsection{Methodology}

In a mathematical framework, MD for a polluter is defined as the derivative of the total damage function with respect to emissions from the polluter. To estimate source-specific MDs, the traditional brute-force approach is the most commonly used method in the literature. In this method, an air quality model (or a simplified representation of it) needs to be run twice for each individual polluter. The first run simulates the concentrations using baseline emissions from all sources, while in the second run emissions from the source of concern are increased (or decreased) by a certain amount. The MD for the polluter is the finite difference approximation of the total damage calculated in conjunction with epidemiological coefficients, which relate the change in concentrations to damage. The brute-force method for the calculation of MDs requires an additional simulation per polluter and therefore becomes computationally infeasible as the number of polluters increase. To overcome this computational barrier against the estimation of source-specific impacts, previous studies have used advanced air quality models but only for a limited number of sources (Mauzerall et al. 2005; Tong et al. 2006), or regionally grouped sources (Fann et al. 2009; Krupnick et al. 2000) or employed simplified or reduced form models for large number of sources (Fann et al. 2009; Muller and Mendelsohn 2009; Muller 2011). Grouping of sources assumes a prescribed regional homogeneity in MDs that is not supported by the existing literature. On the other hand, simplified models address the issue of computational cost but do not account for complex transport and 
transformation processes in the atmosphere, and therefore lack accuracy in physical representations of source-receptor relationships.

A more recent method for the calculation of derivatives is backward or adjoint sensitivity analysis. The adjoint method is an effective approach for estimation of derivatives with respect to multiple parameters such as emissions at various locations. Unlike the brute-force method and the forward sensitivity analysis techniques (Dunker 1984; Yang et al. 1997), the adjoint method traces influences and sensitivities back to individual sources in a single simulation (Hakami et al. 2006). The brute-force and forward sensitivity methods provide receptor by receptor sensitivity information about the influence of a single source, or a single group of sources. As such, they can differentiate between the impacts exerted on different receptors but they cannot feasibly distinguish between individual source impacts. Adjoint sensitivity analysis, on the other hand, provides information about influences of individual sources on a collective metric and is therefore an ideal choice for differentiation between sources in policy or economic instruments. A more detailed description and formulation of adjoint sensitivity analysis in air quality models can be found elsewhere (Hakami et al. 2007; Henze et al. 2007; Sandu et al. 2005).

The critical point in an adjoint application is the policy metric for which sensitivity information is desired. This metric is known as the adjoint cost function (not to be mistaken with abatement cost). The adjoint cost function must be a scalar function of model outputs (i.e., concentrations) but can be integrated in space, time, or across multiple species. Examples of adjoint cost functions include average or 
maximum domain-wide concentrations, attainment, total mortality, deposition onto a lake, crop damage caused by ozone, etc. In other words, so long as the policy concern can be expressed as a single number, the adjoint method is an ideal approach to provide source-specific sensitivity information. The total damage function is a good example of an adjoint cost function. In this work, we define the adjoint cost function as the total health damage, and therefore, our calculated adjoint sensitivities with respect to $\mathrm{NO}_{\mathrm{x}}$ emissions are used as MDs. Our definition of the total health damage is limited and only refers to mortality due to short-term exposure to ozone and does not include morbidity, mortality from other pollutants, and ecosystem or climate related damage ${ }^{6}$. Change in total damage $(\triangle T D)$ is defined as (Anenberg et al. 2010):

$$
\Delta T D=V_{S L} M_{0} P\left(1-e^{-\beta \Delta C}\right)
$$

where $V_{S L}$ is the value of statistical life, $M_{0}$ is the baseline non-accidental mortality rate, $P$ is the population, $\beta$ is the epidemiological concentration response factor which correlates the air pollution mortality to ozone concentrations, and $\Delta C$ is the change in ozone concentrations from a baseline. As $\beta$ is usually a very small number, equation 5-1 can be linearized using a Taylor expansion (i.e., $\Delta T D=V_{S L} M_{0} P \beta \Delta C$ ). The adjoint cost function is introduced into the adjoint model through the adjoint forcing term $(\varphi)$ defined as (Pappin and Hakami 2013):

\footnotetext{
${ }^{6}$ Note that the damage function in this work is defined as the damage to human health in the U.S., and Canada and Mexico are not included. This footnote was not included in the published paper.
} 


$$
\varphi=\partial T D / \partial C=V_{S L} M_{0} P \beta
$$

The forcing terms in adjoint models can be regarded as the source of influences on the adjoint cost function and its role is similar to that of emissions in a forward model. In a forward model, the emissions are injected into the model and the concentrations are integrated after each atmospheric process (i.e., advection, diffusion, chemical reactions). Similarly, in an adjoint model, forcing terms are injected into the adjoint model, and derivatives evolve backward in time through each process and toward the originating sources. More details on using the adjoint model for sensitivity analysis of ozone mortality (or its cost valuation) can be found elsewhere (Pappin and Hakami 2013).

\subsection{Optimization framework}

An optimization framework is used as the prototype for a decision support system (DSS) under which the performance of damage-based emission-differentiated policies can be evaluated. The components of the proposed system are shown in Figure 5.1. The considered policies include: (1) a CaT policy which minimizes the system-wide abatement costs, (2) a damage minimization (DMIN) policy which minimizes damages for a given allowance allocation, (3) and a social cost minimization (SCMIN) policy which minimizes the summation of damages and abatement costs (i.e., the social cost) for a given cap. MDs and MACs for polluters are calculated by the adjoint of the Community Multiscale Air Quality (CMAQ) model and the U.S. EPA's Integrated Planning Model (IPM) (EPA 2010a), respectively. Under the CaT policy, only MACs are used in the optimization process 
to minimize the abatement costs, and to predict the post-trade emissions distribution. On the other hand, under the DMIN policy, only MDs of polluters are used to differentiate between emissions for the minimization of the total damage. Under the SCMIN policy, the DSS uses both MACs and MDs to provide optimal emissions distribution under which the social cost is minimized. For all policies, the postoptimization emissions distribution can be used by CMAQ to simulate the spatial and temporal ozone concentration distribution, and the corresponding health benefit/cost due to adoption of that policy.

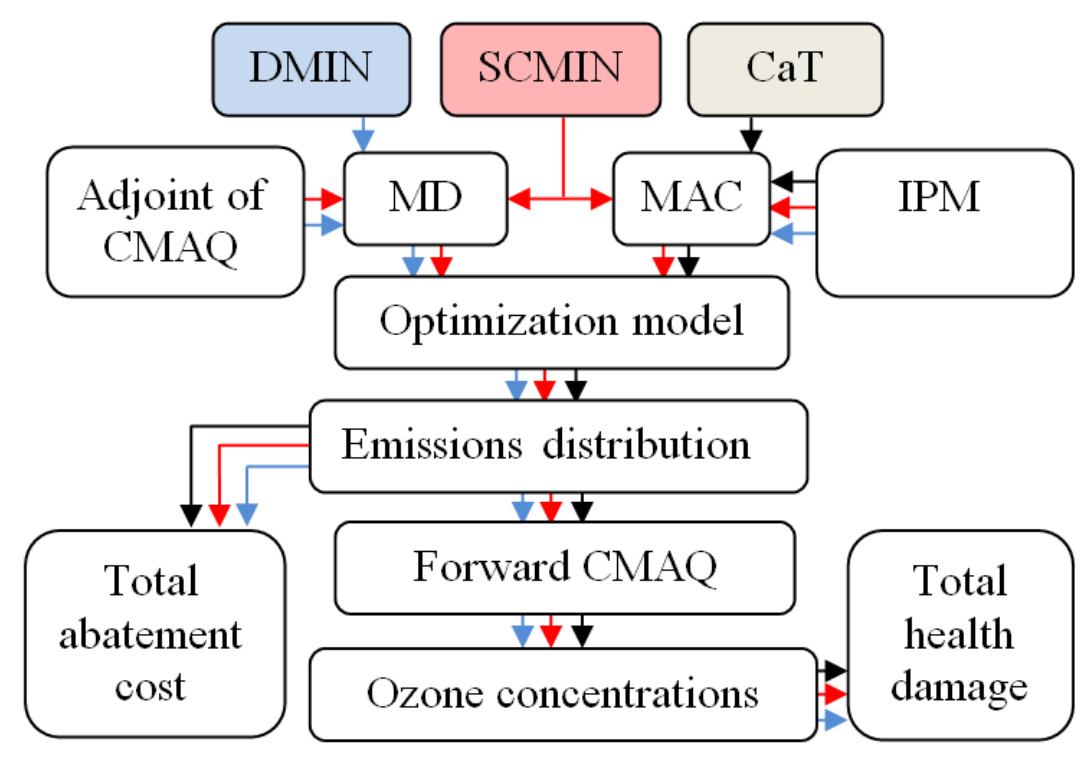

Figure 5.1. Components of the proposed decision support system for emission differentiation.

\subsection{Optimization model}

The optimization framework defined in this chapter is different from chapter 4 in two ways. First, the optimization problem in chapter 4 aimed to model the market in a $\mathrm{CaT}$ system and, therefore, minimized the total abatement cost for a given 
aggregate emission target, whereas the optimization problem in this chapter minimizes the system-wide health or social cost. Second, the optimization problem in chapter 4 had an additional constraint for exchange rates, whereas such a constraint is not necessary in this chapter.

To estimate how power plants change their emissions under various policies, different optimization problems are constructed. Under the CaT policy the total abatement cost is minimized:

Minimize :

$\sum_{i=1}^{n} c_{i}\left(e_{i}^{0}-e_{i}\right)$

\section{Subject to :}

$\sum_{i=1}^{n} e_{i} \leq E_{t}$

$e_{i} \in\left[0, e_{i}^{\max }\right]$

where $c_{i}$ is the abatement cost of source $i, n$ is the number of sources, $e_{i}^{0}$ is the allocated allowances for source $i, e_{i}$ is a variable representing the ozone season emissions from source $i, e_{i}^{\max }$ is the maximum possible emissions from source $i$, and $E_{t}$ is the total ozone season (May to September, inclusive) cap on emissions.

Under the DMIN policy, the optimization problem minimizes the total damage in the system:

Minimize :

$\sum_{i=1}^{n} D_{i}\left(e_{i}\right)$ 


$$
\begin{aligned}
& \text { Subject to: } \\
& \sum_{i=1}^{n} e_{i}=E_{t}, \\
& e_{i} \in\left[0, e_{i}^{\max }\right] .
\end{aligned}
$$

where $D_{i}$ is the damage function for source $i$ which is defined as the MD of source $i$ times its emissions $\left(D_{i}\left(e_{i}\right)=M D_{i} e_{i}\right)$. Note that equation $5-4 \mathrm{~b}$ is not the same as $5-3 \mathrm{~b}$ because, if the summation of emissions from all sources has no lower bound, damage minimization will result in zero emissions for all polluters. The solution of the problem 5.4a to $5.4 \mathrm{c}$ leads to an emissions distribution that minimizes the damage. On the other hand, under the SCMIN policy, the social cost minimization problem considers both abatement costs and health damages:

Minimize :

$\sum_{i=1}^{n}\left(D_{i}\left(e_{i}\right)+c_{i}\left(e_{i}^{0}-e_{i}\right)\right)$

Subject to :

$\sum_{i=1}^{n} e_{i}=E_{t}$

$e_{i} \in\left[0, e_{i}^{\max }\right]$

\subsection{Case study}

The potential improvement in the current $\mathrm{CaT}$ system is examined through simulations for a case study of 218 coal-fired electric generation units. These are chosen as the major units with selective catalytic reduction (SCR) or selective noncatalytic reduction (SNCR) post-combustion control technologies that took part in the $\mathrm{NO}_{\mathrm{x}}$ budget trading program in 2007 . The allocated allowances to these 218 units 
were about $37 \%$ of the total cap $(534,000$ tons) allocated to all 2594 participating units in 2007. The cost estimation in this study is for the short-term (i.e., one ozone season) when the capital costs are fixed and power plants do not get an opportunity to switch to other control technologies. Therefore, only variable costs (i.e., cost of operation and maintenance) are taken into consideration. In the short term, power plants trade allowances or adjust electricity generation to meet their allocation requirements. The short-term abatement costs are estimated using the U.S. EPA's IPM (EPA 2010a) and are based on the control technology and the capacity of the power plants.

For air quality simulation and sensitivity analysis, the gas-phase CMAQ version 4.5.1 and its adjoint are used (Hakami et al. 2007). The modeling period is the ozone season (May to September, inclusive) of 2007, and the modeling domain is the contiguous U.S. with a $36 \mathrm{~km}$ horizontal grid resolution and 34 vertical layers. The Sparse Matrix Operator Kernel Emissions (SMOKE) version 2.4 is used for emissions processing. The emission inventory files used by SMOKE are the 2006 National Pollutant Release Inventory (NPRI) for Canada, and the 2005 National Emissions Inventory (NEI) for the U.S., which are projected to 2007 based on the change in population growth, industrial activities and land use patterns. ${ }^{7}$ The Weather Research Forecasting Model (WRF) version 3.1 is used to generate meteorological inputs. The

\footnotetext{
${ }^{7}$ The emissions for the power plants are based on the Continuous Emission Monitoring (CEM) data for 2007. This explanation was not included in the published paper.
} 
CMAQ-ready meteorological inputs are processed by the Meteorology-Chemistry Interface Processor (MCIP) version 3.6. The mean normalized error and bias for the simulations for ozone are $18 \%$ and $+1 \%$, respectively.

For the optimization, a global optimization package (KNITRO, version 8.0) is used (Byrd et al. 2006). For the calculation of MDs, the value of statistical life $\left(V_{S L}\right)$ is taken as $\$ 6.8$ million in 2007 (EPA 2010b), and the baseline non-accidental mortality rate is calculated using the International Classification of Disease (ICD)-10 codes A-R (Bell et al. 2004). ${ }^{8}$ The epidemiological concentration response factor ( $\beta$ ) in this work is taken as $0.051 \%$ based on the daily maximum 8 -h ozone (Zanobetti and Schwartz 2008) to conform with the averaging time of the current U.S. standard for ozone. We note again that our damage calculation is only based on short-term ozone mortality and does not include long-term effects, morbidity, particulate matter (PM) mortality, or environmental and climate damages.

\subsection{Result and discussion}

The two derivatives (i.e., MACs and MDs) used for distinguishing between emissions show significant spatial variability (Figure 5.2). The spatial variation in MACs is due to the variation in abatement costs for power plants depending on their

\footnotetext{
${ }^{8}$ The baseline mortality rates are spatially variable, which is different from the study conducted by Anenberg et al. (2010) which used a constant baseline mortality. This footnote was not included in the published paper.
} 
location, electricity generation capacity, and emission control technologies. Power plants can change their MACs by switching to other control technologies in the long term, but they have little control over their MDs because they are determined by meteorology, governing atmospheric regime, baseline mortality rates, and population distribution. The outputs of the adjoint model are temporal and spatial MDs (i.e., the damage caused by 1 ton $\mathrm{NO}_{\mathrm{x}}$ in any day at different locations). To calculate sourcespecific ozone season MDs, an emission-weighted aggregation of the daily MDs is used:

$$
M D_{(x, y)}=\frac{1}{\sum_{t} \sum_{k} e_{k t}(x, y)} \sum_{t} \sum_{k}\left(e_{k t}(x, y) M D_{k t}(x, y)\right)
$$

where $\operatorname{MD}(x, y)$ is the ozone season MD at grid $(x, y) ; e_{k t}(x, y)$ is the emissions at $\operatorname{grid}(x, y)$, layer $k$, and day $t$; and $M D_{k t}(x, y)$ is the daily $\mathrm{MD}$ at $\operatorname{grid}(x, y)$, layer $k$, and day $t$. MDs are different for various days and effective stack heights and the equation 5-6 preserves the relative spatiotemporal emission pattern of each source in the overall MD calculation. Non-weighted MDs over the ozone season are lower than those shown in Figure 5.2. Under the current $\mathrm{CaT}$ program, power plants have no restriction on their daily emissions and can adjust them to meet the daily electricity demand so long as their total ozone season emissions meet the requirements. Power plants are likely to generate more electricity (and emit more $\mathrm{NO}_{\mathrm{x}}$ ) on hot summer days when the electricity demand and the ozone formation potential are both likely to be larger (Martin 2008). Since high-emission days are also high-damage days, the weighted average results in higher seasonal MDs. 

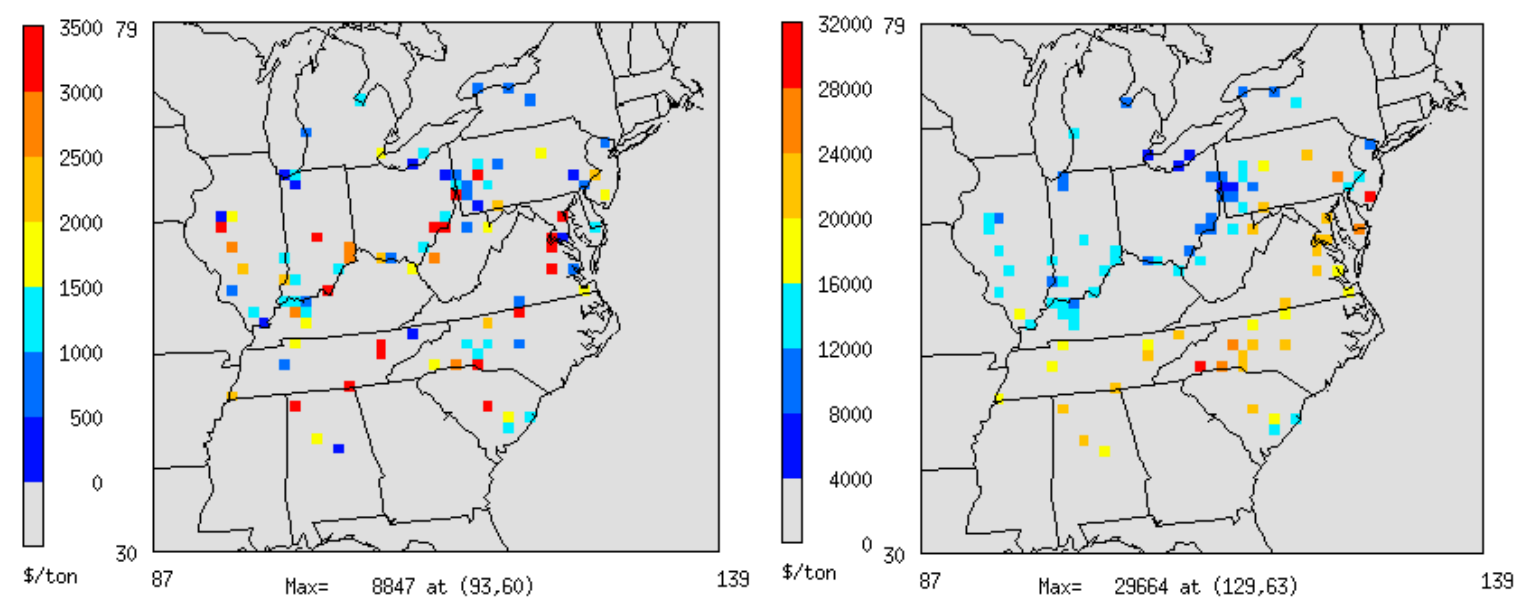
study.

Figure 5.2. MACs (left) and MDs (right) for the power plants in the case

Ozone-based health damage from $\mathrm{NO}_{\mathrm{x}}$ emissions can be negative (Fann et al. 2009; Pappin and Hakami 2013) but none of the power plants in this study had an overall negative seasonal MD. The negative MDs occur in $\mathrm{NO}_{\mathrm{x}}$-inhibited atmospheric regimes with high $\mathrm{NO}_{\mathrm{x}}$ to $\mathrm{VOC}$ ratios. In such regimes, decreasing $\mathrm{NO}_{\mathrm{x}}$ emissions results in increased ozone and consequently causes increased damage to human health. The power plants located in the Ohio River Valley have lower MDs compared to power plants elsewhere (Figure 5.2). In this region, numerous power plants emit a considerable amount of $\mathrm{NO}_{\mathrm{x}}$ in a confined area which results in a $\mathrm{NO}_{\mathrm{x}}$ inhibited atmospheric regime. As such, any decrease in $\mathrm{NO}_{\mathrm{x}}$ emissions from these power plants leads to increased ozone (i.e., negative influence) in the valley but decreased ozone (positive influence) further downwind where the atmospheric regime becomes $\mathrm{NO}_{\mathrm{x}^{-}}$ limited. The overall damages from power plants in the valley are still positive because their downwind positive influences overweigh their local negative influences. 
However, local negative influences cause MDs for these power plants to be lower compared to those in other locations.

Largest MDs are calculated for power plants in the eastern U.S. where a number of densely populated cities exist in a small region. Calculated MDs are also large for the power plants in southeastern U.S. where the governing atmospheric regime is predominantly $\mathrm{NO}_{\mathrm{x}}$-limited (Duncan et al. 2010). It should be noted that if a high-damage power plant is far removed from populous areas, it can be inferred that the damage occurs somewhere further downwind, but where it occurs is not known from the adjoint-based MDs as the adjoint method lacks receptor specificity (Pappin and Hakami 2013). To calculate the spatial distribution of the damage from a specific power plant or a group of power plants, forward sensitivity analyses are required.

To investigate the potential improvement in the system's performance, two damage-based emissions-differentiated policies (DMIN and SCMIN) are compared with the current $\mathrm{CaT}$ policy. The CaT policy is formulated to model the current trading system. The initial allocation of allowances under the CaT policy is based on the actual data from the U.S. EPA clean air market for the $\mathrm{NO}_{\mathrm{x}}$ trading program. Under all three policies, the total emission cap is the same. Note that no new technology is introduced under different policies, and redistribution of emissions is the only reason for potential health benefits. The average daily maximum 8-hour (ADM8) ozone and the 4th highest seasonal daily maximum 8-hour (DM8) ozone for the CaT policy can be found in Figure 5.3. These metrics are of particular policy importance as the ADM8 ozone is the basis for health damage estimation (equation 5- 
1) and the 4th highest DM8 (4DM8) ozone (averaged over three years) is the regulatory indicator of attainment. Our results suggest that the 4DM8 ozone for large areas in the U.S. were above the standard of $75 \mathrm{ppb}$ for the simulated ozone season in 2007. Note that in this study, we assume that all of the four highest DM8 ozone days occur during the ozone season.
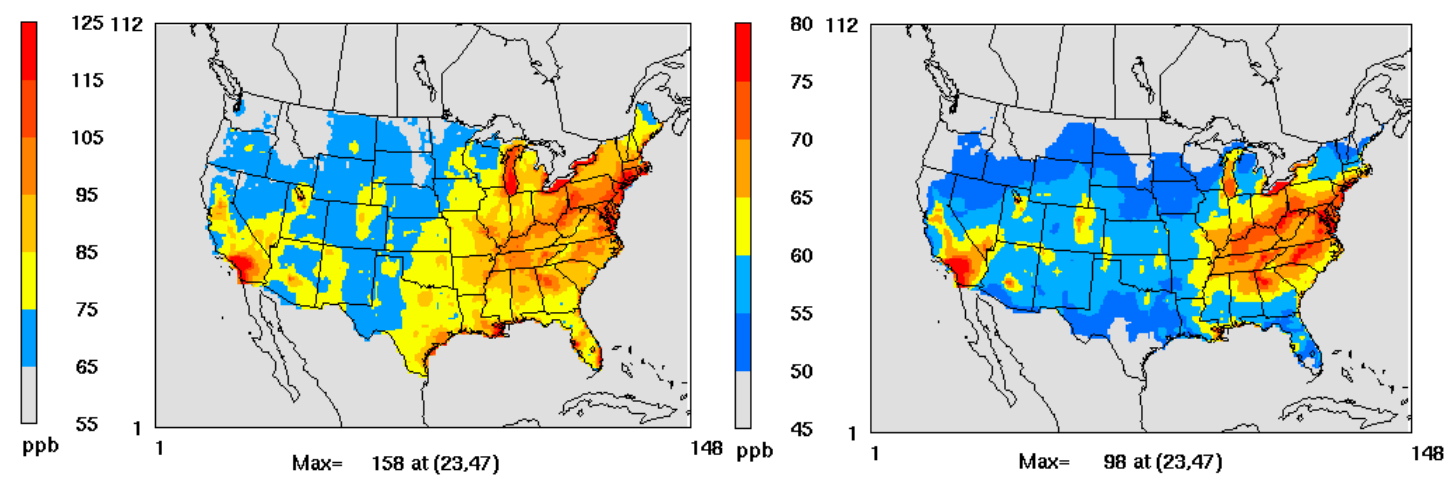

Figure 5.3. a) The ADM8 ozone (left) and b) the 4th highest DM8 ozone (right) for a 5-month modeling period for the CaT policy. 

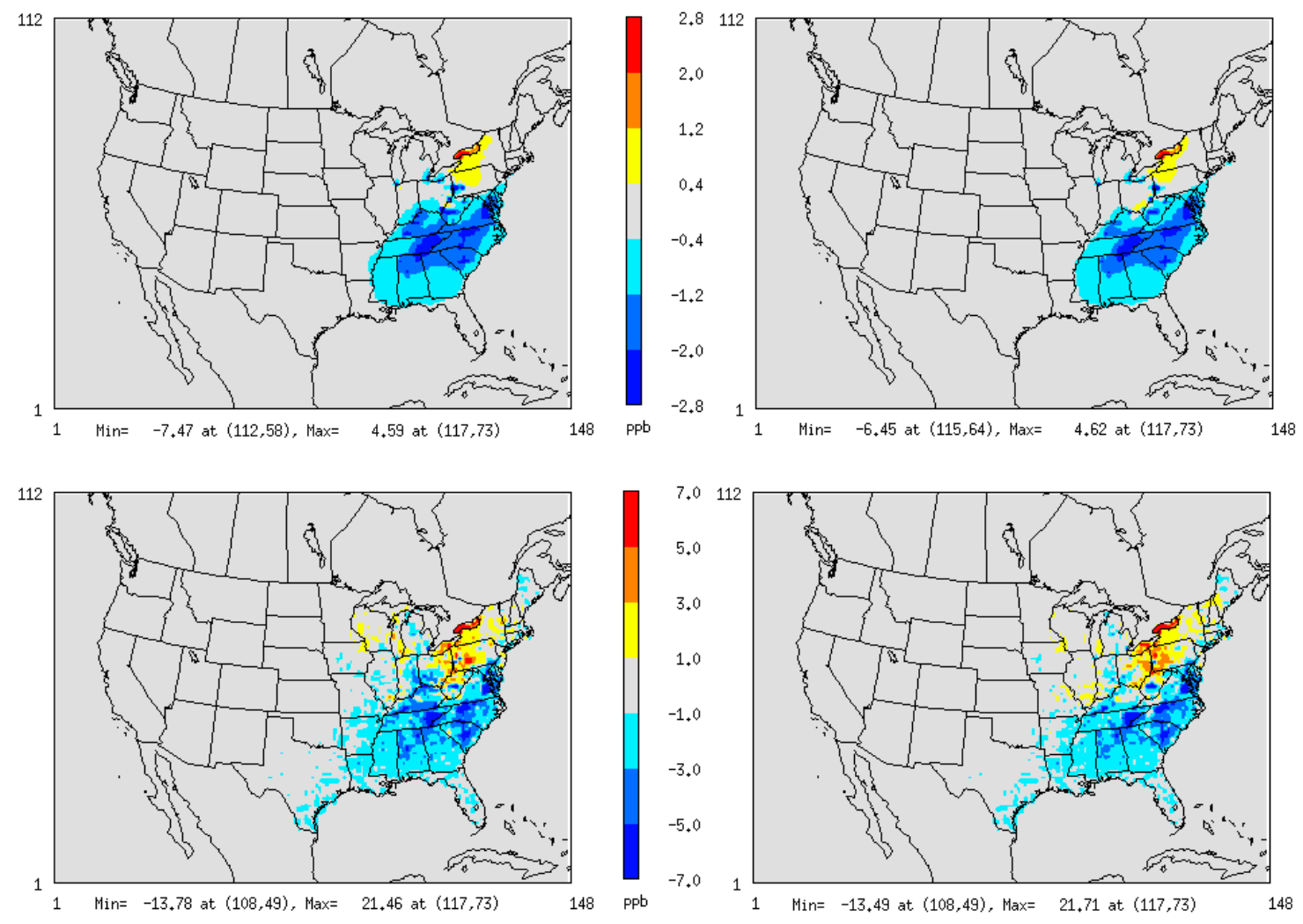

Figure 5.4. Differences in ozone concentrations by switching from the CaT policy to the DMIN policy (left), and to the SCMIN policy (right). The panels show change in the ADM8 ozone (top) and the 4th highest DM8 ozone (bottom) for the 5-month modeling period. Negative values represent improvements.

The ADM8 ozone and the 4DM8 ozone under the DMIN and SCMIN policies are evaluated in comparison with the CaT policy (Figure 5.4). The patterns of decreasing ozone concentrations are similar for the DMIN and SCMIN policies. The DMIN policy minimizes the total damage and the SCMIN policy minimizes the summation of damages and abatement costs. Since the MDs are higher compared to MACs (Figure 5.2), the dominant gradients in the minimization process for the SCMIN policy are MDs rather than MACs, hence the similarity of the impact induced by both policies. A consistent and significant decrease in both the 4DM8 ozone and 
the ADM8 ozone occur in wide regions in the eastern and southeastern U.S. under both policies, while smaller increases are simulated in the Northeast and the Great Lakes region. It should be noted that the increase in ozone concentrations does not necessarily represent an increase in the total damage because some of the areas with increased ozone (e.g., over the Lake Ontario) are not populated and therefore have no contribution to the total health damage. Furthermore, air quality deterioration and increased damage in some locations is acceptable in our formulation, so long as this increased damage is outweighed by reduced damage elsewhere. Achieving air quality improvement in all locations would require multi-objective optimization, which is not straightforward with the adjoint approach.

The air quality improvements for the DMIN and SCMIN policies occur in a wide area in the eastern U.S. where ozone concentrations are high under the CaT policy (Figure 5.3). Under both damage-based policies, the maximum improvements in the ADM8 ozone and the 4DM8 ozone are about 7 and $14 \mathrm{ppb}$, respectively. The changes in air quality under different policies in Figure 5.3 occur when emissions are redistributed while constraining them by the same total cap. One of the limitations on health damage minimization is the maximum emission from low-MD units (i.e., equations 5-5c and 5-6c). If new power plants are built in low-impact damage regions, the possible improvement can be more than what is shown in Figure 5.4. Furthermore, the results presented in this chapter are based on spatial emissions differentiation and the temporal effect is not included. Shifting power plant emissions from high-damage to low-damage hours can also reduce ozone concentrations (Sun et al. 2012). 
The air quality improvement in ADM8 ozone can result in increased health benefits if it takes place in locations with high baseline mortality rates and/or population. The decreased damages under different policies are calculated using equation 5-2 and presented in Figure 5.5. The decreased ADM8 ozone concentrations for the differentiated policies (shown in Figure 5.4) result in a corresponding decrease in damages (Figure 5.5). For both policies the benefits obtained by switching from the CaT policy to the DMIN or SCMIN occur in densely populated regions in the eastern U.S. Maximum benefits are estimated in Detroit, Michigan at \$39 million (5.8 deaths/season) and \$33 million (4.9 deaths/season) for the DMIN and SCMIN policies, respectively. Maximum increases in damage are $\$ 4.1$ million under the DMIN and \$4.4 million under the SCMIN policy, both in Buffalo and its vicinity.
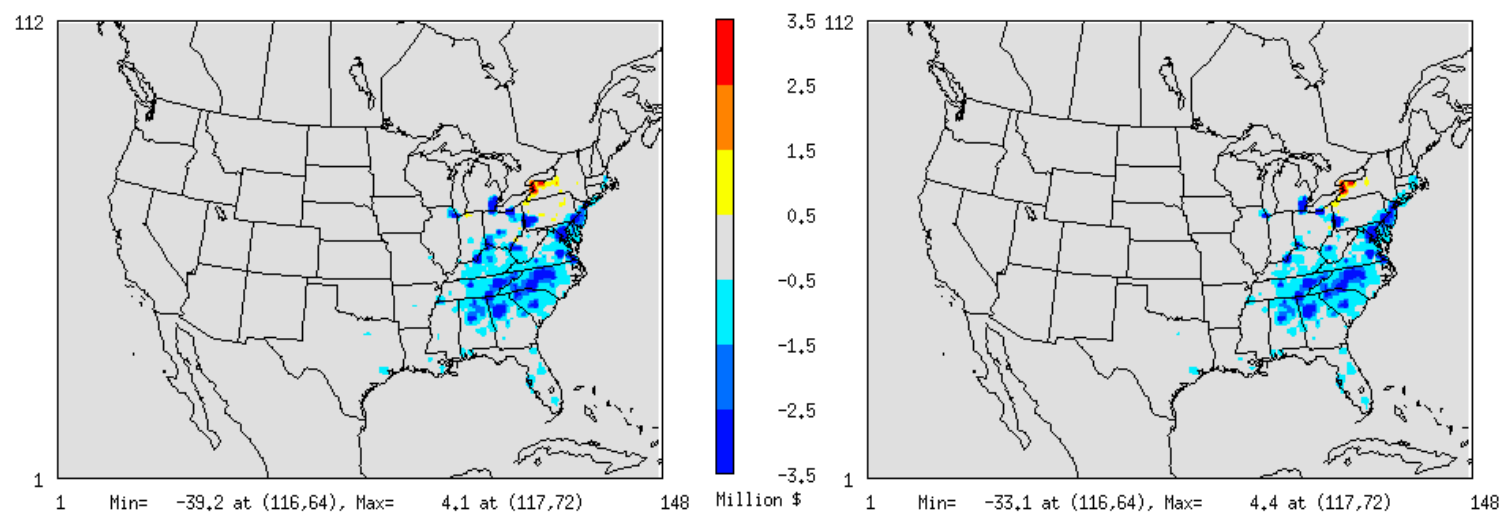

Figure 5.5. Differences in damages caused by the CaT and DMIN (left) or the SCMIN (right) policies.

The improvements in air quality under the DMIN and SCMIN policies are greater than those under an exchange rate $\mathrm{CaT}$ (CaT-EX), which was examined in chapter 4. Under CaT-EX policy, emission allowances for different power plants are 
not treated equally and have different values. The exchange rate between two polluters determines a ratio under which their allowances can be traded. When these ratios are defined based on the MDs of polluters (or their contribution to exposure), the allowances allocated to high-damage power plants are assigned a higher value, which in turn motivates them to reduce their emissions and sell their allowances. Exchange rate inclusion can improve the environmental performance of a traditional CaT system but does not necessarily achieve the minimum social cost because different initial allocations of allowances under exchange rate systems can result in different outcomes (Førsund and Nævdal 1998; Krupnick et al. 1983). For pollutants whose damages are location-dependent, a CaT-EX policy limits the TD. This limit on the TD corresponds to the damage caused by the initial emissions allocation. To achieve an optimal state, a CaT-EX approach would lower the limit on the TD by inclusion of MD information in initial emission allocation, which in turn results in a lower pre-trade limit on TD. However, an exchange rate system is still a CaT concept designed to minimize abatement costs rather than the total damage. The improvements (in the 4DM8 and spatial health damage) under the CaT-EX policy in comparison to the CaT policy for the ozone season are presented in Figure 5.6. The maximum improvement under the CaT-EX policy as compared to the CaT policy is about $1.8 \mathrm{ppb}$ for the ADM8 ozone and $4.1 \mathrm{ppb}$ for the 4DM8 ozone which are considerably smaller than the corresponding values for the DMIN and SCMIN policies (Figure 5.4). 

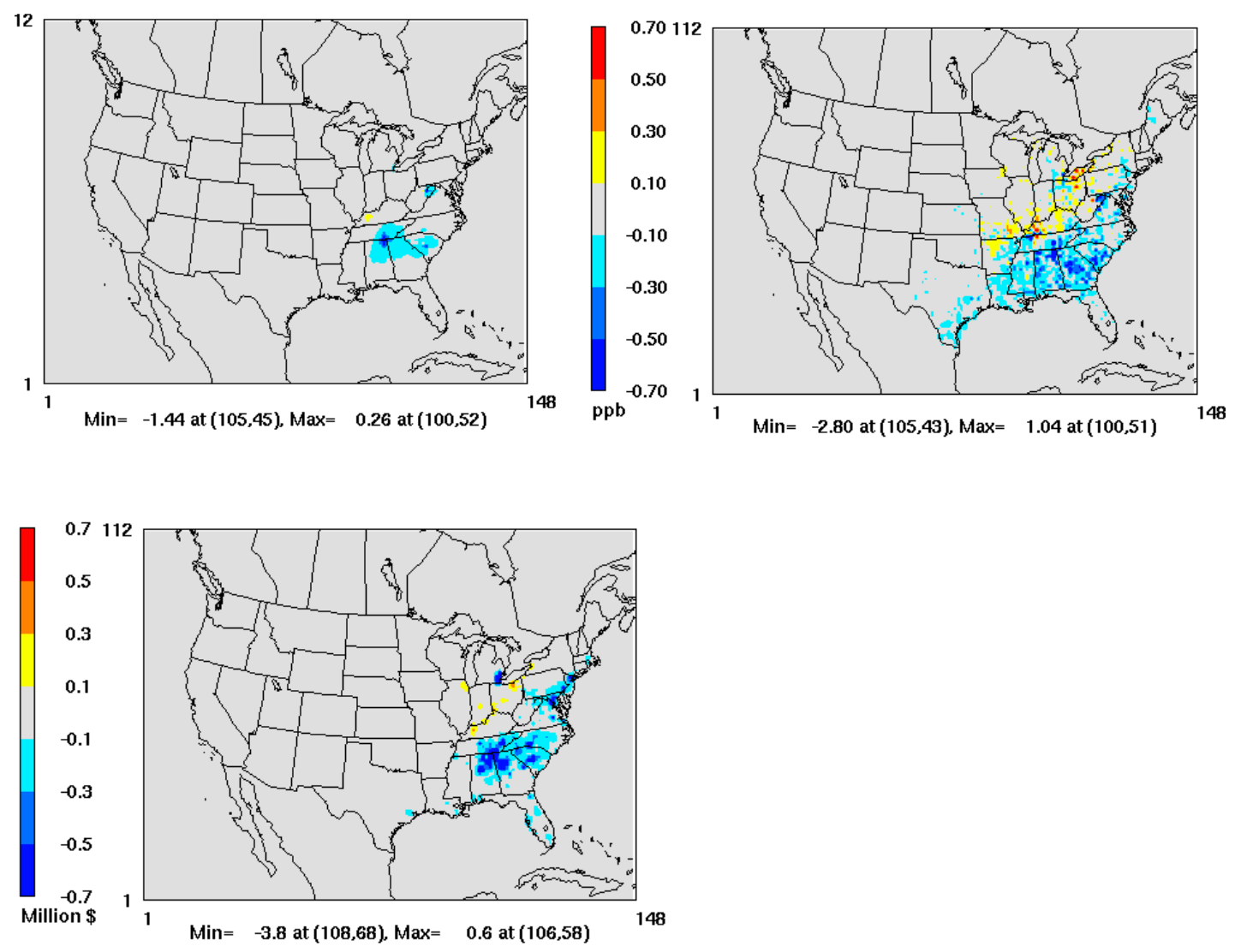

Figure 5.6. The spatial differences in the ADM8 ozone (up-left), the 4th highest DM8 ozone (up-right), and the spatial differences in health damage (bottom-left) comparing the CaT-EXP and CaT policies. The negative values represent improvement.

To better compare the heath damages under different policies with their associated costs, a summary of system-wide costs and benefits (i.e., reduction in the total damage) for all these policies are presented in Table 5.1. To examine the nonlinearity involved in the calculation of the total damage, the change in the total damage in Table 5.1 is calculated in two different ways: first, by using equation 5-1, i.e., the spatial summation of values presented in Figure 5.5, and second by using a linear estimation based on the adjoint MDs and optimization induced change in emission behavior: 


$$
\Delta T D=\sum_{i} M D_{i} \Delta e_{i}
$$

where $\Delta e_{i}$ is the change in emissions from polluter $i$ occurring under different policies. The first method (i.e., equation 5-1) calculates the change in health damage from the change in ozone concentrations obtained by re-running CMAQ with postoptimization emissions distribution. As this method accounts for the nonlinearity involved in concentration response to changes in emissions, we refer to it as a global projection of health benefits. The second method (i.e., equation 5-7) assumes that MDs are constant and estimates the change in health damage by a linear extrapolation based on MDs, and therefore, we refer to it as the local projection of the health benefits.

Table 5.1. Abatement costs and health benefits for different policies (\$ million).

\begin{tabular}{|c|c|c|c|c|}
\hline \multirow{2}{*}{ Policy } & \multirow{2}{*}{$\begin{array}{l}\text { Abatement costs } \\
\text { compared to the } \\
\text { CaT policy* }\end{array}$} & \multicolumn{2}{|c|}{$\begin{array}{l}\text { Health benefits compared } \\
\text { to the CaT policy }\end{array}$} & \multirow{2}{*}{$\begin{array}{l}\text { Net benefits } \\
\text { (Global health } \\
\text { benefit minus } \\
\text { abatement cost) }\end{array}$} \\
\hline & & $\begin{array}{c}\text { Local } \\
\text { projection }\end{array}$ & $\begin{array}{c}\text { Global } \\
\text { projection }\end{array}$ & \\
\hline DMIN & 520 & 1522 & 1189 & 669 \\
\hline SCMIN & 372 & 1440 & 1089 & 717 \\
\hline CaT-EX & 7 & 196 & 128 & 121 \\
\hline
\end{tabular}


The values reported in Table 5.1 are short-term and do not represent long-term and implementation costs. Similarly, the benefits do not account for morbidity, reduction in secondary $\mathrm{PMs}$ due to reduced $\mathrm{NO}_{\mathrm{x}}$ emissions, and long-term health benefits achieved by $\mathrm{NO}_{\mathrm{x}}$ control, nor do they include environmental and climate benefits. The lowest costs are realized in the CaT policy which minimizes the total abatement cost, but the minimum total damage occurs in the DMIN policy which is designed to minimize the total damage with no regards for costs. Under the DMIN policy, reduction in health damage is higher, but the net benefit is lower, than that of the SCMIN policy.

Projection estimates in Table 5.1 suggest that MDs are not constant and vary with emission levels, as one would expect to see in a nonlinear system. If the MDs were constant, both methods for the calculation of change in the total damage would lead to the same result, but the difference between the results of the two methods is a measure of the degree of nonlinearity in damage estimations. Our benefit estimations indicate that there is up to $35 \%$ difference between the local and global estimations of damages, suggesting that MDs are nonlinear in emissions. This is a limitation of the methods that rely on MDs for projection over ranges that are large enough to induce a nonlinear response. One solution to avoid this shortcoming is to perform a stepwise optimization where changes in each polluter's emissions at each step are limited such that near-linear response is assured (Mesbah et al. 2012).

The nonlinearity in the calculation of MDs can be further investigated to establish source-specific MD curves. An MD curve represents how MD varies with 
increasing emissions from a power plant. To establish such curves, multiple adjoint runs are required to update the value of the MD at different emission levels. Note that nonlinearity is different under the DMIN policy and the SCMIN policy. The emission behavior under the SCMIN policy is driven by both MDs and MACs. Since abatement costs are linear with emissions in our analysis, the overall nonlinearity driven by damage estimations is more heavily influenced by damage estimations and relative slope of MD curves for low- and high-MD power plants. Furthermore, the lack of a cost constraint in the DMIN policy allows for more substantial changes in emissions than under the SCMIN policy where both MDs and MACs control the optimal distribution of emissions. This, in turn, results in larger deviations from the baseline emissions and different nonlinear behavior.

This work should be treated as a proof-of-concept study as its practical reach is limited by a number of simplifying assumptions and limitations. Different types of uncertainties associated with air quality modeling, emission inventories, meteorological conditions, abatement cost estimations, valuation of statistical life, mortality response factors, etc, are not considered in this study. MACs are assumed to be constant for various emission levels and days, while in reality they can change on a daily basis depending on the electricity price and demand in the electricity market. Furthermore, MDs in this study are averaged over the ozone season resulting in overall positive values. However, daily MDs exhibit significant variability and are sometimes negative. MDs can also vary from year to year, and multi-year simulations are required to gain confidence in their robustness. Finally, our analysis is performed 
for a fraction of power plants in the trading market. We believe emission differentiation becomes more effective as more units are included in the analysis because a wider range of differences in MACs and MDs can be exploited in determining the optimal distribution of emissions.

\subsection{Conclusions}

The calculated benefits in this study are based on the short-term mortality due to ozone exposure alone; PM exposure and long-term effects are not taken into account. The latter health impacts are believed to be substantial (Fann et al. 2012; Jerrett et al. 2009), and as such the MDs presented here are likely to be underestimates. Nevertheless, our results indicate that marginal damages in the form of mortality valuations significantly outweigh marginal abatement costs. Based on our results the average value of MD from the studied power plants was about $\$ 14700$ per ton of $\mathrm{NO}_{\mathrm{x}}$ in the ozone season, approximately 10 times larger than average MAC estimates. This disparity in damages and costs underlines the need for more refined policy instruments that formally include damage information. To compare estimated MDs with the electricity price, we use power plants' emissions and electricity generation in the ozone season and converted the average value of MD from \$/ton to $\$ / M W h$. This simple conversion results in an average MD of $\$ 7.8 / \mathrm{MWh}$. In comparison to the typical spot prices for the study region, this average MD constitutes 5 to $14 \%$ of the retail price, that is, a sizable but modest fraction of the electricity price. This would only reinforce what we have demonstrated in this study, that is, that MDs can play an important role in making environmentally effective policy choices. 
We note that the implementation of the SCMIN policy requires source-specific MD information, the calculation of which is affected by different uncertainties. These include uncertainty in epidemiological concentrations response factors, economic valuations, emissions, meteorology, model formulation, grid resolution, inter-annual and seasonal variability, etc.

Based on our results, the exchange rate policy, which allocates allowances based on historical electricity generation of units, leads to a lower improvement in environmental performance as compared to the two other damage-based policies considered. Our findings suggest that it is prudent to pay close attention to the location-specific MDs of power plants when devising pollution control strategies, as inclusion of damage information allows for development of more targeted policy instruments. Policies that rely on damage-based emissions differentiation can be implemented in different ways by creating higher incentives for high-MD polluters to reduce their emissions. One possible approach within a $\mathrm{CaT}$ system is to consider power plants' MDs when the initial allowances are allocated under an exchange rate CaT system. Imposing a tax based on a power plant's MD is another alternative for inclusion of damage information. The effects of initial allowance allocation on the performance of an exchange rate $\mathrm{CaT}$ system, regional health impacts, and the burden on the local or state utilities should be further explored in future work. 


\section{CHAPTER 6:}

\section{OPTIMAL OZONE CONTROL WITH INCLUSION OF SPATIOTEMPORAL MARGINAL DAMAGES AND ELECTRICITY DEMAND}

\subsection{Introduction}

In the U.S., $37 \%$ of electricity is generated by coal-burning power plants (EIA 2010), placing them among the major contributors to the formation of ground level ozone. Ozone is a secondary pollutant, which is dependent on the amount of nitrogen oxides $\left(\mathrm{NO}_{\mathrm{x}}\right)$, volatile organic compounds (VOC), and sunlight available. The ozone formation potential of these precursors may vary significantly by location and time. Due to these temporal and spatial differences, health impacts of $\mathrm{NO}_{\mathrm{x}}$ emissions can vary up to 6 times in magnitude (Mauzerall et al. 2005) on a regional scale or up to 68 times on a national scale (Muller and Mendelsohn 2009). Inclusion of such differences in policy design can result in improved public health (Mauzerall et al. 2005; Mesbah et al. 2012; Muller and Mendelsohn 2009) simply by redistributing emissions without a need for emission reduction. Furthermore, re-dispatching or shifting electricity generation from high to low $\mathrm{NO}_{\mathrm{x}}$ rate (i.e., emissions per unit generation) plants can reduce $\mathrm{NO}_{\mathrm{x}}$ emissions significantly and result in a reduction in ozone concentrations while meeting the electricity demand (Martin et al. 2007; Sun et al. 2012). A Previous study suggests that dispatching based on local meteorological conditions and electricity demand may be an efficient method for control of surface 
ozone, comparable to other emission control technologies such as installation of selective catalytic reduction (SCR) or selective non-catalytic reduction (SNCR) (Sun et al. 2012). Re-dispatching has also been considered for introducing electric vehicles into the fleet (Thompson et al. 2011), or for reducing water consumption of power plants at regions affected by drought (Alhajeri et al. 2011).

An effective $\mathrm{NO}_{\mathrm{x}}$ emissions control policy aims to minimize the system-wide social cost which includes emission abatement costs for all polluters and the damage they impose on the environment and human health (external costs). The cost of damages caused by a polluter (hereafter damage) is calculated by the polluter's marginal damage (MD), defined as the dollar value of damage per ton of emissions (Muller and Mendelsohn 2007). Cap-and-trade programs are designed to achieve lower social costs by providing cost-saving incentives for participants while capping the total emissions. For uniformly mixed pollutants with long atmospheric lifespans (e.g., carbon), an optimal cap on total emissions can limit the system-wide damage and minimize the social costs. However, a cap on total emissions does not limit the system-wide damage for short-lived pollutants such as $\mathrm{NO}_{\mathrm{x}}$, whose MDs vary by location and time. By differentiating emissions by MDs through exchange rate capand-trade policies (Førsund and Nævdal 1998; Mesbah et al. 2012; Muller and Mendelsohn 2009; Nobel et al. 2001) or taxation (Montgomery 1972; Tietenberg 1995; Tong and Mauzerall 2006), the system-wide impact of $\mathrm{NO}_{\mathrm{x}}$ emissions can be reduced. 
Both exchange rate and taxation policies provide higher emission reduction incentives for high-MD polluters than low-MD emitters. Under an exchange rate policy, emission quotas are valued based on polluters' contributions to total damage, and under the taxation policy, polluters are charged fees based on their damage. A fee per ton of emissions provides emission reduction incentives for high-MD polluters because their marginal abatement costs (MACs), or costs per additional ton of emission reduction, is less than the imposed fee.

The accurate determination of the $\mathrm{MD}$ for $\mathrm{a} \mathrm{NO}_{\mathrm{x}}$ polluter then becomes crucial for determining the exchange rates or taxes required to minimize ozone concentration and corresponding damages. The MD of a polluter is the derivative of the systemwide damage function with respect to emissions from the polluter. There have been various efforts to calculate MDs with differing level of complexity. Some studies have used traditional sensitivity analysis methods which require running an air quality model for each additional source. This method is computationally expensive and has only been used for a limited number of sources (Nobel et al. 2001; Tong et al. 2006; Wang et al. 2007). Simplified or reduced-form models have been used to estimate MDs for a large number of sources (Fann et al. 2009; Levy et al. 2009; Muller and Mendelsohn 2007). However, these simplified approaches do not account for all different physical and chemical processes influencing the fate of pollutants in the atmosphere. Recent studies have used backward (adjoint) sensitivity method to calculate MDs for a large number of sources (Mesbah et al. 2013; Pappin and Hakami 2013). The adjoint method accounts for different physical and chemical process 
included in the atmospheric model and computes MDs at comparatively low computational expense. The adjoint model is efficient for calculating the sensitivity of a desired function of outputs, such as ozone induced mortality, known as the adjoint cost function, with respect to individual inputs, such as emissions from sources at different times and locations (Pappin and Hakami 2013). Further details on the adjoint model and its mathematical formulations can be found elsewhere (Errico 1997; Hakami et al. 2007; Sandu et al. 2005; Wang et al. 2001).

In this work, the adjoint method is used to calculate source-specific MDs at various times. The calculated MDs are then used within an optimization framework to investigate how setting variable $\mathrm{NO}_{\mathrm{x}}$ prices based on MDs would impact the redispatching strategy and the system-wide health damage. In comparison to previous studies on re-dispatching (Alhajeri et al. 2011; Martin et al. 2007; Sun et al. 2012; Thompson et al. 2011), this work does not model the electricity network but accounts for electricity demands. However, this study includes the spatiotemporal MD information to investigate the impact of re-dispatching strategies on ozone concentrations and the corresponding damage to human health. As such, MD information is used to set different spatial or temporal emission fees rather than setting one fee under different hypothetical scenarios used in previous studies.

\subsection{Methodology}

An adjoint model is combined with an optimization tool to include the MDs in the design of an improved $\mathrm{NO}_{\mathrm{x}}$ emissions control policy. The adjoint model is used to calculate the MDs, which are then used as inputs into the optimization model to 
predict the emission levels under different policies. The MDs in this work are defined based on a linearized form of the damage function which only includes the short-term ozone mortality in the U.S. (Anenberg et al. 2010).

$$
M D=\frac{\partial T D}{\partial E}=V_{S L} M_{0} P \beta \lambda
$$

where $\frac{\partial T D}{\partial E}$ is the derivative of total damage $(T D)$ with respect to emissions $(E) ; V_{S L}$ is a value of statistical life; $M_{0}$ is the baseline non-accidental mortality rate; $P$ is the population; $\beta$ is the concentration response factor; and $\lambda$ represents the adjoint gradient $\left(\frac{\partial C}{\partial E}\right)$ which relates concentration $(C)$ to emissions and is the main source of non-linearity in the damage function (Mesbah et al. 2013).

The optimization framework in this work is an extension of our previous study (Mesbah et al. 2013) with a few notable differences. Firstly, the MDs in this work are location- and time-specific, whereas the previous work did not consider temporal variability in MDs. Secondly, in the current optimization framework, the relationship between the power plants' electricity generation and emissions has been included as an additional constraint within the optimization framework. This constraint has been added to account for power plants' emission behavior in the electricity and emission markets where they have to supply electricity while meeting the emission requirements. 


\subsubsection{Polluters' behavior}

Cap-and-trade systems are designed to minimize the system-wide emission reduction costs and this governs the polluters' behavior under such systems. The following optimization problem can be used to predict the distribution of polluters' emissions leading to the minimum of system-wide abatement costs:

$$
\begin{aligned}
& \text { Minimize: } \\
& \sum_{t=1}^{24} \sum_{i=1}^{n} c_{i}\left(e_{i t}\right)
\end{aligned}
$$

Subject to:

$$
\sum_{t=1}^{24} \sum_{i=1}^{n} e_{i t} \leq E_{T}
$$

$$
\sum_{t=1}^{24} \sum_{i=1}^{n} q_{i t}=\sum_{t=1}^{24} \sum_{i=1}^{n} e_{i t} R_{i}=Q_{T},
$$

$$
q_{i t} \in\left[0, G_{i}\right]
$$

where equation 6-2-a is the objective function of the optimization problem and is defined as the summation of the source-specific abatement cost functions $\left(c_{i}\right)$ of $n$ polluters; $e_{i t}$ is a variable representing the emissions from polluter $i$ at hour $t$ integrated over the ozone season; $E_{T}$ is the system-wide cap on emissions; $q_{i t}$ is a variable representing electricity generation; $R_{i}$ is a constant representing the generation intensity (i.e., the ratio of generations to emissions) for polluter $i ; Q_{T}$ is the total electricity demand in the ozone season, and $G_{i}$ is the hourly generation capacity of polluter $i$. Equation 6-2-b ensures that the total emissions are less than the 
total cap while equation 6-2-c ensures that the total electricity demand in the system is supplied by the power plants.

Equations 6-2-a through 6-2-d extend our previous application of this approach, which included no consideration of temporal effects (Mesbah et al. 2013). Our previous study also did not address electricity demand and therefore the emission constraint was set equal to the total cap (as opposed to less than or equal as in equation 6-2-b) to avoid a value of zero for the optimized emissions for all polluters. In this work; however, power plants must supply electricity based on demand (equation 2-b) and, therefore, their emission levels cannot be zero when minimizing the system-wide abatement costs.

Equations 6-2-a through 6-2-d are designed to find a distribution of emissions regardless of their spatial and temporal impacts on human health. To account for spatial and temporal effects of the emissions, a spatiotemporal social cost minimization problem can be defined as follows:

Minimize :

$\sum_{t=1}^{24} \sum_{i=1}^{n} c_{i}\left(e_{i t}\right)+D_{i t}\left(e_{i t}\right)$

Subject to :

$\sum_{t=1}^{24} \sum_{i=1}^{n} e_{i t} \leq E_{T}$

$\sum_{t=1}^{24} \sum_{i=1}^{n} q_{i t}=\sum_{t=1}^{24} \sum_{i=1}^{n} e_{i t} R_{i}=Q_{T}$,

$q_{i t} \in\left[0, G_{i}\right]$.

where (6-3-a) represents the spatiotemporal social cost of emissions and accounts for 
both abatement costs and health damage costs $\left(D_{i t}\left(e_{i t}\right)=M D_{i t} e_{i t}\right)$ from individual polluters. Equation 6-3-c guarantees that power plants supply the total electricity demand, but it does not provide any restriction on hourly generation and therefore equations 6-3-a to 6-3-d are referred to as flexible social cost minimization, and allow power plants to change their hourly generation from one hour to another. This assumes flexibility in demand, meaning that consumers are willing to adjust the revised damage-driven electricity demand. Without such an assumption, the hourly electricity generation must meet the hourly electricity demand, which we refer to as demand-based social cost minimization. This optimization problem is similar to equations 6-3-a to 6-3-d, but 6-3-c is replaced with 6-3-e, shown below:

$$
\sum_{i=1}^{n} e_{i t} R_{i}=\sum_{i=1}^{n} q_{i t}=Q_{t} \quad, t=1, . ., 24
$$

Equation 6-3-e guarantees that the hourly system-wide electricity generation is equal to the electricity demand for hour $t\left(Q_{t}\right)$.

\subsubsection{Case study}

A case study of 218 coal-fired electricity generating units in the eastern U.S. is conducted to examine the spatiotemporal effects of $\mathrm{NO}_{\mathrm{x}}$ emissions under different policies. These policies include: 1) the cost minimization (CMIN) policy, similar to cap-and-trade, which only accounts for abatement costs (equations 6-2-a to 6-2-d); 2) a social cost minimization policy (equations 6-3-a to 6-3-d) under which power plants are flexible in hourly electricity generation (F-SCMIN); and 3) a social cost minimization policy based on equations 6-3-a, 6-3-b, 6-3-d, and 6-3-e, under which 
power plants must supply hourly electricity demand (D-SCMIN). For each policy, a global optimization package (KNITRO 8.0) (Byrd et al. 2006) is used to solve the corresponding optimization problem and find the post-optimization emissions distribution.

The adjoint of the gas-phase Community Multiscale Air Quality (CMAQ) model version 4.5.1 is used to calculate the source-specific MDs (Byun and Schere 2006, Hakami et al. 2007). The CMAQ model is driven by meteorological inputs generated by the Weather Research and Forecasting (WRF) model (Skamarock et al. 2005) and emission inputs generated by the Sparse Matrix Operator Kernel Emissions (SMOKE) model (CEP 2007). The emission inventory used for the SMOKE model is based on the 2006 National Pollutant Release Inventory (NPRI) for Canada and the 2005 National Emissions Inventory (NEI) for the U.S., which are projected to the year 2007 based on population and economic growth factors. The power plant emissions are based on the Continuous Emission Monitoring (CEM) data for 2007. Modeling is conducted over a North American domain with a $36 \mathrm{~km}$ grid resolution with 34 vertical layers, for a period corresponding to the ozone season (May to September, inclusive) of 2007. The performance evaluation of ozone simulations results in an $18 \%$ mean normalized error and a $1 \%$ mean normalized bias. The hourly electricity generation and emissions are taken from U.S. EPA clean air market (EPA). The generation intensity for each power plant is calculated based on the ratio of the plant's total electricity generations to its total emissions during the ozone season. Cost estimation is for the short-term and is based on the U.S. EPA Integrated Planning 
Model (EPA 2010a). The damage function in this study is for short-term ozone mortality and is defined based on a value of statistical life of 6.8 million (EPA 2010b), and an epidemiological response factor of $0.051 \%$ estimated for average $8 \mathrm{~h}$ ozone (Zanobetti and Schwartz 2008). The International Classification of Disease (ICD)-10 codes A-R (Bell et al. 2004) is used to calculate spatially variable baseline non-accidental mortality rates.

\subsection{Result and discussion}

The location of selected power plants and their average location-specific MDs are shown in Figure 6.1. The outputs of the adjoint model are location- and hourspecific MDs for the running period. For the five-month simulation period, each location has $153 \times 24$ hour-specific MDs. To calculate the average location- and hourspecific MD, the model outputs are integrated as follows:

$$
M D_{t}(x, y)=\frac{1}{\sum_{k} \sum_{d} e_{k d t}(x, y)} \sum_{k} \sum_{d}\left(e_{k d t}(x, y) M D_{k d t}(x, y)\right)
$$

where $M D_{t}(x, y)$ is the location- and hour-specific MD at the grid location $(x, y)$ and hour $t ; e_{k d t}(x, y)$ and $M D_{k d t}(x, y)$ are emissions and MD, respectively, at layer $k$, day $d$, hour $t$, and grid location $(x, y)$. Note that $M D_{t}(x, y)$ is the MD at hour $t$ averaged over 153 days.

To investigate the temporal and spatial effects separately, two average MDs are introduced. The first is the average time-specific $\mathrm{MD}\left(\overline{M D}_{t}\right)$, which is calculated by averaging MDs over $N$ grids ( $N$ is the number of grids in color shown in Figure 
6.1) for a particular hour (equation 6-6). The second is the average location-specific $\operatorname{MD}(\overline{M D}(x, y))$, which is calculated by averaging hourly MDs over 24 hours for a specific location (equation 6-7).

$$
\begin{aligned}
& \overline{M D}_{t}=\frac{\sum_{x, y} M D_{t}(x, y)}{N} \\
& \overline{M D}(x, y)=\frac{\sum_{t} M D_{t}(x, y)}{24}
\end{aligned}
$$

The average location-specific MDs (Figure 6.1) exhibit specific patterns. Power plants in the southeast region generally have high MDs because of the governing $\mathrm{NO}_{\mathrm{x}}$-limited atmospheric regime where ozone concentrations are highly and positively sensitive to $\mathrm{NO}_{\mathrm{x}}$ reduction; power plants on the east coast also have high MDs because this region is densely populated; and power plants in the Ohio River Valley have low MDs due to an abundance of $\mathrm{NO}_{\mathrm{x}}$ in this region.

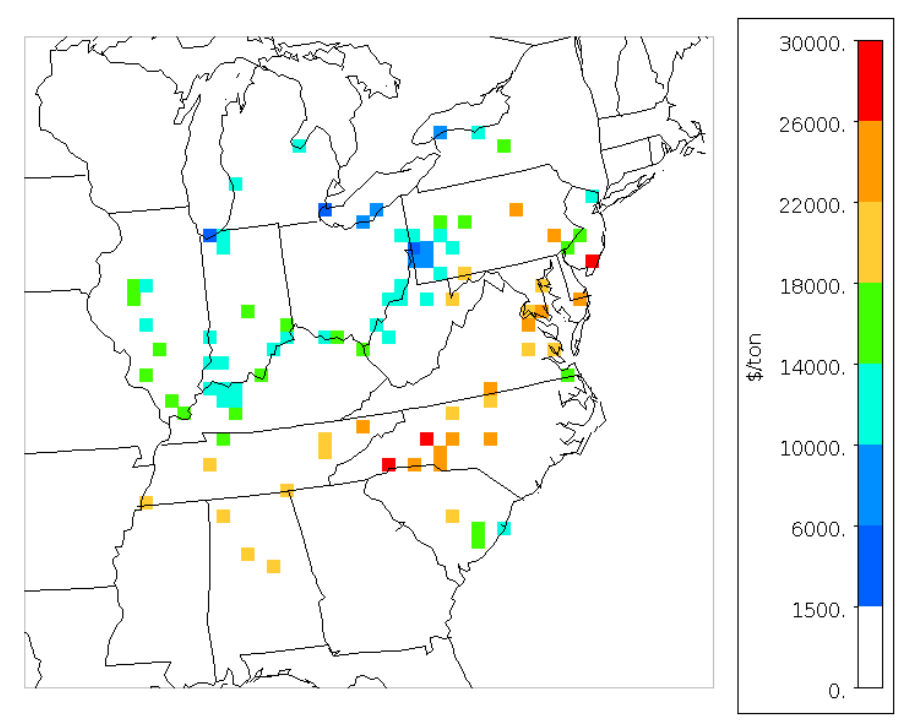

Figure 6.1. Average location-specific MDs for the selected power plants. 
Location and hour-specific MDs are shown in a color-coded matrix in Figure 6.2. Each row of this matrix represents the MD at a specific location for different hours. While there is similarity in average location-specific MDs within some states, which supports the calculation of one state-wide MD used in some studies (Fann et al. 2009; Muller 2011), there is significant variability in average location-specific MDs for other states. For example, New Jersey contains three grid cells with average location-specific MDs of \$11500/ton, \$15100/ton, and \$29700/ton. 

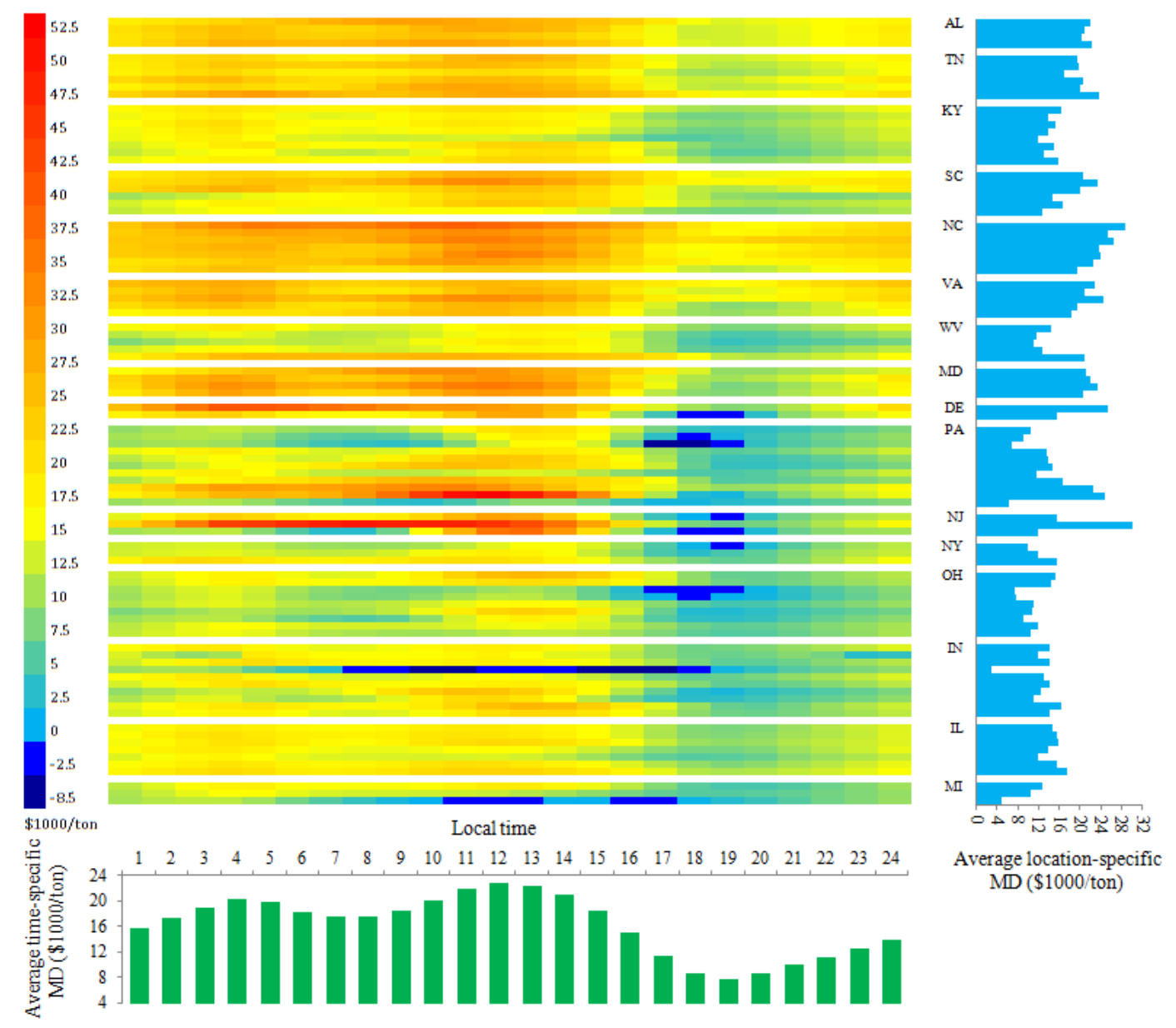

Figure 6.2. Color-coded location- and hour-specific MDs for the studied power plants. The dark blue cells of the matrix are locations and times with negative MDs. The graph on the right panel is the average of each row and represents the average location-specific MDs $(\overline{M D}(x, y))$. The graph at the bottom is the average of each column and represents the average time-specific $\operatorname{MDs}\left(\overline{M D}_{t}\right)$.

The lowest value of the time and location specific MD shown in the color coded matrix in Figure 6.2 is $-\$ 8500 /$ ton and belongs to a grid cell in Clarion, Pennsylvania at hour 18 . The highest value, (\$52700/ton) occurs for Phoenixville, Pennsylvania at hour 12. This grid cell also contains the highest ratio of maximum MD (hour 12) to minimum MD (hour 19). This discrepancy in hourly MDs amounts 
to an avoided mortality per season for transfer of 132 tons of $\mathrm{NO}_{\mathrm{x}}$ emissions from hour 12 to hour 19 during the ozone season.

The general pattern of change for hourly MDs is also consistent for different locations. The highest average time-specific MD is $\$ 22300 /$ ton for hour 12 , and the lowest average time-specific MD is $\$ 7400 /$ ton at hour 19 . Overall, hours 11 to 14 are high-MD hours (with MDs greater than $\$ 20000 /$ ton), and hours 18 to 21 appear as low-MD hours (with MDs less than \$10000/ton). Hourly MDs increase from morning to noon when the highest MDs occur in most locations, and reach a minimum in the evening. This pattern for hourly MDs exists because of the dependency of photochemical ozone formation reactions on the intensity of sunlight and temperature. Different hourly MD-based fees on power plants' generation affect the generation pattern. However, hourly generation is also a function of electricity demand, which is usually higher in the late afternoon and evening when people are at home and engage in cooking and other energy intensive activities. High demand for electricity in the evening is beneficial for damage minimization because it shifts generation and the corresponding emissions to evening hours when emissions are less harmful. Shifting emissions to low-MD hours lowers health damages and thus favors damage minimization. In contrast, seasonal electricity demand fluctuations are not in favor of damage minimization because demand is high on hot summer days (usually late summer) when MD is also high. It should be noted that the current cap-and-trade program in the eastern U.S. has no limitations on hourly or daily emissions and only caps the total $\mathrm{NO}_{\mathrm{x}}$ emissions during the ozone season when $\mathrm{NO}_{\mathrm{x}}$ are more harmful. 
Therefore, higher demand on late summer days results in disproportional and more use of emission quotas on days when emissions are more harmful resulting in an increase in health damages (Martin 2008). One approach to alleviate this problem would be to allocate total emission allowances separately for peak and off-peak ozone season.

It should be mentioned that there is no negative average time-specific or average location-specific MD for the power plants studied. This finding is consistent with the previous finding (Fann et al. 2009) that some urban polluters had negative $\mathrm{NO}_{\mathrm{x}} \mathrm{MDs}$, but electricity generating power plants did not. Note that the hour and location specific MDs reported are averaged over 153 days and the daily values have more variability and occasionally include negative values. In fact, some of the studied electricity generating units, with positive average location-specific MDs, have negative MDs for some hours (see the MD matrix in Figure 6.2). The negative hourly values are observed in ten locations. For the majority of these locations, the negative MDs occur in hours 17 to 19. Exceptions are power plants in Indiana and Michigan, which have negative values for some hours in the morning and around noon. A negative $\mathrm{MD}$ indicates a $\mathrm{NO}_{\mathrm{x}}$-inhibited atmospheric regime along the emission trajectory where the ratio of ambient $\mathrm{NO}_{\mathrm{x}}$ to VOCs is high. Note that $\mathrm{NO}_{\mathrm{x}}$ availability in a particular location is not necessarily limited to $\mathrm{NO}_{\mathrm{x}}$ emissions in the same location and can include $\mathrm{NO}_{\mathrm{x}}$ emissions in upwind locations.

The three sets of gradients shown in Figure 6.2 can be used to evaluate the temporal and spatial effects of $\mathrm{NO}_{\mathrm{x}}$ emissions redistribution. As explained before, 
social costs can be minimized using the location-specific and time-specific MDs, both with and without limitations on hourly electricity generation (D-SCMIN and FSCMIN, respectively). To consider only spatial effects, the two social cost minimization problems are conducted with one average location-specific MD for all 24 hours. Since these optimizations only account for spatial differences in MDs, they are referred to as the SPT-D-SCMIN and SPT-F-SCMIN policies. Similarly, to account for only temporal effects of $\mathrm{NO}_{\mathrm{x}}$ emissions, social cost minimizations are carried out with the same average time-specific MD in all locations regardless of where the power plants are located. These social cost minimizations account only for temporal effects and are referred to as the TMP-D-SCMIN and TMP-F-SCMIN policies. Table 6.1 summarizes different aspects of the policies examined in this study.

Table 6.1. Differences under considered cost minimization policies.

\begin{tabular}{lccccccc}
\hline & CMIN & $\begin{array}{c}\text { SPT-D } \\
\text { SCMIN }\end{array}$ & $\begin{array}{c}\text { TMP-D } \\
\text { SCMIN }\end{array}$ & $\begin{array}{c}\text { D- } \\
\text { SCMIN }\end{array}$ & $\begin{array}{c}\text { F- } \\
\text { SCMIN }\end{array}$ & $\begin{array}{c}\text { SPT-F } \\
\text { SCMIN }\end{array}$ & $\begin{array}{c}\text { TMP-F- } \\
\text { SCMIN }\end{array}$ \\
\hline $\begin{array}{l}\text { Temporal } \\
\text { specificity }\end{array}$ & No & No & Yes & Yes & Yes & No & Yes \\
$\begin{array}{l}\text { Spatial } \\
\text { specificity }\end{array}$ & No & Yes & No & Yes & Yes & Yes & No \\
$\begin{array}{l}\text { Hourly } \\
\begin{array}{l}\text { electricity } \\
\text { demand }\end{array}\end{array}$ & Yes & Yes & Yes & Yes & No & No & No \\
\hline
\end{tabular}


Social cost minimization, results in different total damages and costs under each policy (Table 6.2). All policies are then compared with the CMIN policy which minimizes the abatement costs (not social costs) for the short term.

Table 6.2. Abatement costs and health benefits (million dollar) for different policies compared to the CMIN policy. ${ }^{1}$

\begin{tabular}{|c|c|c|c|c|c|c|}
\hline & $\begin{array}{l}\text { SPT-D } \\
\text { SCMIN }\end{array}$ & $\begin{array}{l}\text { TMP-D } \\
\text { SCMIN }\end{array}$ & $\begin{array}{l}\text { D- } \\
\text { SCMIN }\end{array}$ & $\begin{array}{l}\text { F- } \\
\text { SCMIN }\end{array}$ & $\begin{array}{l}\text { SPT-F } \\
\text { SCMIN }\end{array}$ & $\begin{array}{l}\text { TMP-F- } \\
\text { SCMIN }\end{array}$ \\
\hline $\begin{array}{l}\text { Total emissions } \\
\text { (1000 ton) }\end{array}$ & 108.2 & 100.8 & 108.2 & 109.9 & 108.2 & 102.3 \\
\hline $\begin{array}{l}\text { Increase in abatement } \\
\text { cost ( } \$ \text { million) }\end{array}$ & 93.9 & 88.8 & 93.5 & 94.2 & 88.8 & 88.5 \\
\hline $\begin{array}{l}\text { Decrease in seasonal } \\
\text { damage ( } \$ \text { million })\end{array}$ & 1263 & 1154 & 1285 & 1315 & 1248 & 1202 \\
\hline Net benefit ( $\$$ million) & 1169.1 & 1065.2 & 1191.5 & 1220.8 & 1159.2 & 1113.5 \\
\hline
\end{tabular}

In all cases, total emissions are lower than the total cap on emissions (i.e., 204 thousand ton). This implies that the actual emission cap was not stringent enough as additional net gains could be realized by reducing aggregate emissions. Hourly electricity generation under demand-based optimizations (SPT/TMP-D-SCMIN, DSCMIN) and total generation under flexible demand optimizations (SPT/TMP-FSCMIN, F-SCIM) is, however, a binding constraint. Note that the total electricity generation under the CMIN policy and the SCMIN policies are the same but generation and corresponding emissions are transferred from low-efficiency to highefficiency power plants. A high-efficiency power plant has a higher generation 
intensity and thus generates electricity with lower emissions. The main reason for differences in total emissions under the CMIN and SCMIN policies is the imposed additional external damage on power plants under the SCMIN policies. Such extra costs will provide high-efficiency power plants in low-MD locations an advantage over low-efficiency units in high-MD locations. In other words, power plants with lower damage per unit of electricity generation $(\$ / G W h)$ are among those that generate more electricity when the social cost is minimized. Shifting emissions from high to low emission intensity power plants results in a significant emissions reduction and corresponding health benefits under the SCMIN policies (Table 6.2).

One important finding from the comparison of different social cost minimizations is that the net benefit of policies that account for averaged spatial or temporal effects are comparable with those that account for spatiotemporal effects combined. Although using average MDs under the SPT/TMP-D/F-SCMIN policies results in a lower net benefit compared to the D/F-SCMIN policies, the additional benefits from inclusion of spatiotemporal damages are relatively small (i.e., 2 to $11 \%$ additional benefits) (Table 6.2). This is because under social cost minimization, emission reductions are beneficial as long as the MAC is less than the additional benefit of emission reduction (MD). The MDs used under the SPT/TMP-D/F-SCMIN policies are average location-specific and time-specific MDs. Based on our previous estimations, the average MAC is approximately 10 times smaller than the average location specific MDs (Mesbah et al. 2013). Because these MDs are still higher than the MACs, social cost minimization under these policies results in more or less 
similar emissions reduction and net benefits when compared to the CMIN policy. It should be noted that the costs of emissions reduction for different hours are assumed to be the same, and therefore the differences in hourly abatement costs are not reflected in the results. This is one of the limitations of this study because the opportunity cost of emissions reductions by reducing electricity level changes with fluctuation in electricity prices. The difference in outcomes for different SCMIN policies is also dependent on the variation in MDs under different policies. The ratio of the 95 percentile to the 5 percentile values are 3.5 for the average location-specific MDs and 2.7 for the average time-specific MDs, while this ratio is 6.7 for the spatiotemporal MDs. The variability in MDs is important because it provides more flexibility for transfer of emissions from high-MD to low-MD locations or times, resulting in more substantial reduction in total damage. Results shown in Table 6.2 also suggest that although the assumption of flexible demand increases the net benefit, the increase is not significant. The TMP-D-SCMIN and TMP-F-SCMIN policies encourage a shifting of emissions from high-MD hours to low-MD hours, and differ only in the constraint on hourly electricity generation. This difference changes the distribution of hourly emissions (Figure 6.3c) from a shape similar to that of hourly electricity generation under base case (Figure 6.3a) to a shape with peaks at high and low MD hours (Figure 6.3b). The resulting difference in net benefits ( $\$ 48$ million) is not significant because low-MD hours, which emissions are shifted to, are also highdemand hours (Figure 6.3a). The difference in total emissions between the two policies at hour 19 is about 2000 ton and at hour 13 is about 1000 ton (Figures 6.3b and c). Note that for the most part, the net benefit under both the TMP-D-SCMIN and 
TMP-F-SCMIN policies is a result of a $44 \%$ reduction in emissions as compared to the CMIN policy (an average of 3000 ton per hour).
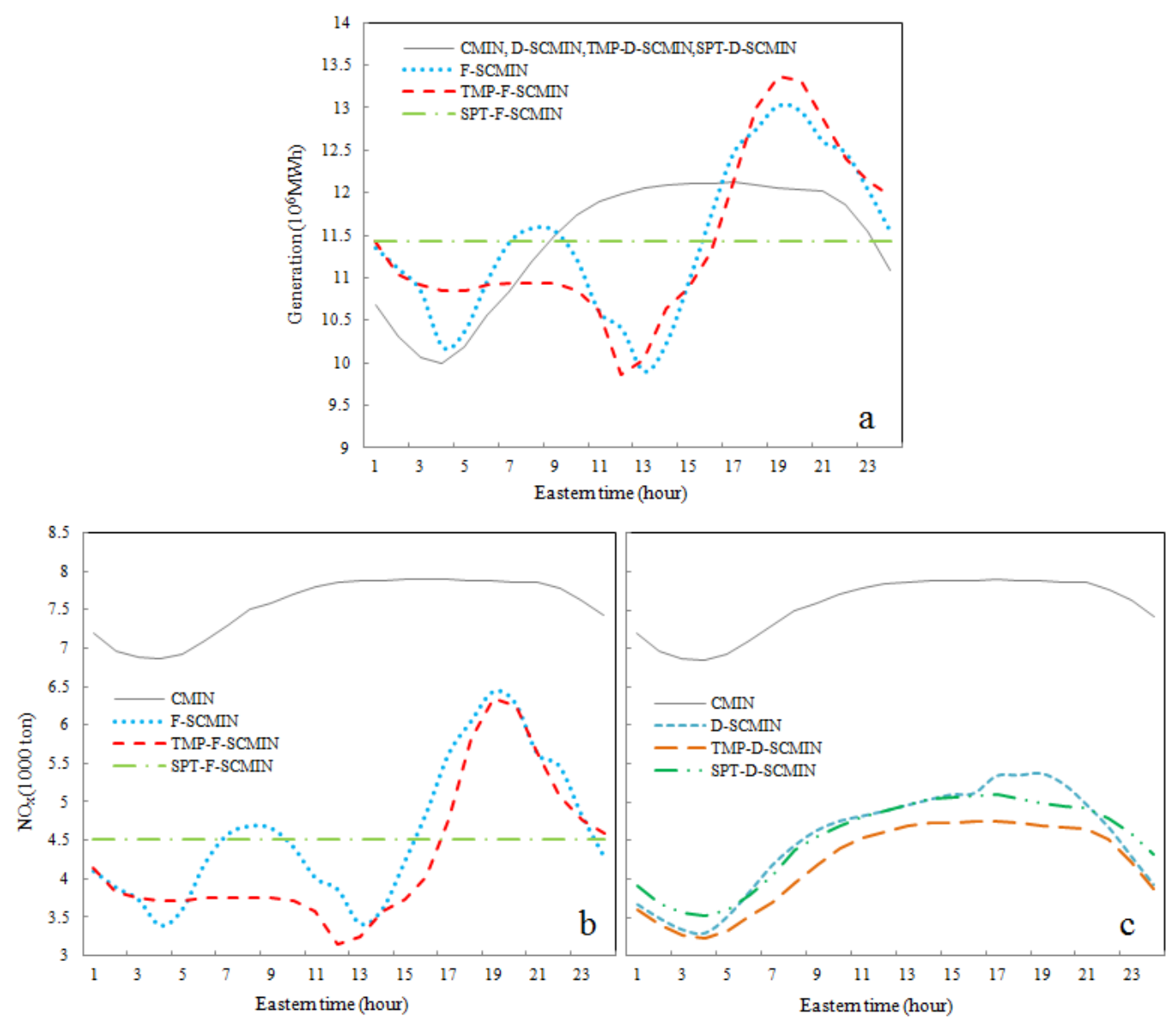

Figure 6.3. Hourly electricity generation (a) and hourly $\mathrm{NO}_{\mathrm{x}}$ emissions from the power plants studied during the ozone season under flexible demand policies (b) and demand-based policies (c).

\subsection{Conclusions}

The cost-benefit analysis and sensitivity models used have restrictions and limitations, such as being subject to uncertainty in the air quality model, abatement and damage cost estimations (Mesbah et al. 2012, 2013) However, our study provides further evidence in support of the inclusion of time-based damage information in 
economic instruments for ozone control. Another limitation of the current work is that the optimization framework presented does not account for the electricity generation dynamics and network transmission constraints, which limits the extent to which redispatching is possible. However, this constraint is not believed to have a significant impact on the $\mathrm{NO}_{\mathrm{x}}$ redistribution patterns (Martin 2008). A previous study on the subject suggests that the insignificant influence from transmission constraints is possibly due to spatial heterogeneity caused by low and high generation intensity units within a single electricity generating zone, allowing for re-dispatching within the zone without a significant increase in the use of transmission lines (Martin 2008).

The SCMIN policies considered in this study result in a decrease in total damage by $44 \%$ to $50 \%$, comparable reductions in total emissions, and a $4 \%$ increase in abatement costs as compared to the baseline CMIN policy. For all of the policies considered, the total electricity generation is the same, and the only difference is that power plants supply different amounts of electricity under each policy. The benefits obtained under the SCMIN policies are mainly due to the redistribution of electricity generation so that a higher portion of the generation is assigned to high-efficiency power plants with higher generation intensities located in low-damage regions. A key policy insight is that more power generation during peak hours may be beneficial even if by units with lower specific generation intensities are used.

Flexibility in demand can improve the performance of the system, but with less significance than temporal or spatial effects. The effect of flexibility in demand increases the net benefit by $5 \%$ under a TMP-F-SCMIN policy as compared to a non- 
flexible temporal SCMIN policy (TMP-D-SCMIN). Flexibility in demand can be created to some extent by setting higher costs for electricity in high-MD hours so that consumers use less electricity during those times. The impact is not very significant since the demand for electricity is not price-elastic, i.e., the demand does not decrease by the same rate as the price increases. In the U.S., the range of price elasticity for residential electricity demand is between -0.20 and -0.35 in the short-term and between -0.3 to -0.8 in the long-term, (Alberini and Filippini 2011) meaning that for a $1 \%$ decrease in electricity consumption for a particular hour, the price needs to be increased by 3 to $5 \%$.

Consideration of temporal effects under the TMP-D/F-SCMIN policies is almost as effective as consideration of spatial effects under the SPT-D/F-SCMIN policies or both effects together under the D/F-SCMIN policies. For example, the increase in net benefit by switching from a TMP-D-SCMIN policy to a SPT-DSCMIN policy is $10 \%$ and to a D-SCMIN policy is $12 \%$. Policymakers need to address if the additional net benefit provides adequate motivations to switch to spatial policies considering the complexity added to the system under spatial or spatiotemporal policies. Under temporal policies, participants and decision makers are only exposed to 24 unique MDs as compared to many spatial MDs under spatial or spatiotemporal policies. To moderately increase system performance, inclusion of regional hourly MDs can also be considered. On an operational basis, emission redistribution can be achieved through electricity rate adjustments and shifting to different energy sources based on the time of day. Besides, spatial differentiation of 
emissions from power plants in different regions can lead to equity considerations and subsequent legal complications and political conflicts between states. Temporal differentiation of emissions does not cause the same level of complexity and interregional inequities. In addition, the temporal MD regulations can be tailored to the specific consumption patterns of a region or state. This advantage can ease the path towards the implementation of damage-based economic instruments and more effective internalization of external costs of health damage. 


\section{CHAPTER 7:}

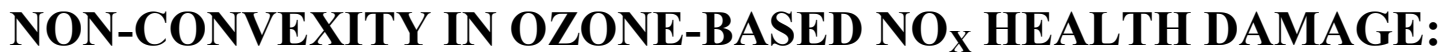

\section{AN APPLICATION OF THE ADJOINT OF CMAQ}

\subsection{Introduction}

Estimation of external costs, or damage costs caused by emissions, are critical in the environmental decision making process as they can be used to set the optimal emission reduction targets. Damage functions represent the total monetary value of health and environmental damages caused by a pollutant change with emissions or with ambient concentrations. The derivative of the damage function is often referred to as the marginal damage (MD) of the emission (or marginal benefit due to its reduction) and is defined as the damage (or benefit) associated with a ton of emission. Damage functions are usually considered as convex in environmental economics, meaning that the monetary value of the damage increases with an increasing (or nondecreasing) rate when emissions increase. This convexity amounts to decreasing MD values with decreasing emissions or positively sloped MD curves. This behavior is due to the fact that the assimilative capacity of the environment deteriorates as the emissions increase. However, this work examines this widely accepted assumption and explores if it is correct for secondary pollutants such as ozone.

Various forms of MD curves are considered in environmental economics literature: positively sloped MD curves, flat MD curves (e.g., damages caused by carbon dioxide), MD curves with a threshold (e.g., toxic pollutants with a health- 
based threshold), and negatively sloped MD curves. Generally, the negatively sloped MD curves are associated with aesthetic valuation of pollution (Anderson and Francois 1997; Randall et al. 1974). For example, an additional unit of pollution lowers the price of houses in a clean environment at a higher rate than houses in a polluted environment (Cropper and Arriaga-Salinas 1980). Similarly, first units of pollution disturb the beauty of a tourist attraction (and lowers their willingness to pay) more than subsequent units (Buhyoff and Leuschner 1978; Schultze and Brookshire 1983). Another example of a recognized non-convex damage function is that of acid rain in lakes. Initially, the MD increases with a positive rate because the acidification causes damages the lake ecosystem, but once the habitats has been destroyed, an increase in the acidity of the lake does not lead to any additional damage and thus the slope of MD curve becomes zero (Crocker and Forster 1981).

The ozone damage function has been implicitly recognized as being nonconvex for some time (Goodstein 1995; Pappin and Hakami 2013; Starrett 1972). A particular case of non-convexity of ozone MD curves with respect to precursor emissions is widely known in the literature. The response of ground-level ozone to nitrogen oxides $\left(\mathrm{NO}_{\mathrm{x}}\right)$ emissions depends on the atmospheric regime. In a $\mathrm{NO}_{\mathrm{x}^{-}}$ limited regime, where the ratio of $\mathrm{NO}_{\mathrm{x}}$-to-VOCs is low, a decrease in $\mathrm{NO}_{\mathrm{x}}$ emissions slows down ozone production and thus leads to reduced ozone concentrations, i.e., a positive $\mathrm{MD}$ value. Conversely, under a $\mathrm{NO}_{\mathrm{x}}$-inhibited regime, ozone concentrations increase with reduction in $\mathrm{NO}_{\mathrm{x}}$ availability, indicating a negative MD. The transition 
from negative to positive $\mathrm{NO}_{\mathrm{x}} \mathrm{MDs}$ through reduced emissions is an indication of non-convexity in the ozone-based $\mathrm{NO}_{\mathrm{x}}$ damage function (Fraas and Lutter 2011).

While negative $\mathrm{MD}$ values for $\mathrm{NO}_{\mathrm{x}}$ emissions due to atmospheric chemistry have been recognized (Hall and Hall 1997; Repetto 1987) and calculated (Hakami et al. 2004), the shape of the $\mathrm{NO}_{\mathrm{x}} \mathrm{MD}$ damage curve has only been discussed briefly and by a few sources (Goodstein 1995; Perman et al. 2011). However, designation of a general shape for $\mathrm{NO}_{\mathrm{x}} \mathrm{MD}$ curves by these references is often speculative, qualitative, and incompatible with the chemical behavior of $\mathrm{NO}_{\mathrm{x}}$ in producing ozone. Quantitative estimation of $\mathrm{NO}_{\mathrm{x}} \mathrm{MD}$ values requires use of atmospheric models that account for chemical transformations that lead to production of ozone from $\mathrm{NO}_{\mathrm{x}}$ emissions. However, such calculation by traditional methods is computationally expensive and is only feasible for a limited number of sources (Mauzerall et al. 2005; Tong et al. 2006). Reduced-form (response surface) or simplified (dispersion) models have been used for $\mathrm{NO}_{\mathrm{x}} \mathrm{MD}$ estimations (Fann et al. 2009; Levy et al. 2009; Muller 2011). However, these approaches are not able to account for the nonlinearities involved in calculation of source-receptor relationships; a simplification that can lead to sizeable changes in estimated health damages (Mesbah et al. 2013).

An alternative for calculation of MDs is the use of the adjoint of an air quality model. Adjoint (or backward) sensitivity analysis allows for simultaneous calculations of derivatives with respect to a large number of parameters (Hakami et al. 2006; Sandu et al. 2005), making it an ideal tool for the estimation of source-specific MDs (Mesbah et al. 2013; Pappin and Hakami 2013). In this work, the adjoint of a state of 
the art air quality model is used to estimate health-based $\mathrm{NO}_{\mathrm{x}} \mathrm{MD}$ values. $\mathrm{MD}$ calculations by the adjoint model are conducted at various domain-wide emission levels to construct MD curves for several urban and rural source locations in the U.S.

\subsection{Methodology}

We consider the damage function to be the monetary value of premature mortality in the U.S. due to short-term exposure to ozone exposure, and as such we do not account for environmental or non-fatal health damages. This simplification does not cause any loss of generality in our approach, as the shape of $\mathrm{NO}_{\mathrm{x}}$ damage curve is dictated by the ozone- $\mathrm{NO}_{\mathrm{x}}$ relationship rather than the damage end point. Our damage estimation is based on the following equation (Anenberg et al. 2010):

$$
\Delta D=V_{S L} M_{0} P\left(1-e^{-\beta \Delta C}\right) \approx V_{S L} M_{0} P \beta \Delta C
$$

where $\Delta D$ is the change in the damage function; $V_{S L}$ is the value of a statistical life taken as $\$ 6.8$ million in 2007 (EPA 2010b); $M_{0}$ is the spatially variable baseline nonaccidental mortality rate which is estimated based on the International Classification of Disease (ICD)-10 codes A-R (Bell et al. 2004); $P$ is the population; $\beta$ is a concentration response factor that correlates air pollution mortality to non-accidental death; and $\Delta C$ is the change in ozone concentration. A $\beta$ of $0.051 \%$ was taken from an epidemiological study of 48 U.S. cities based on an 8-hour ozone averaging time in summer (Zanobetti and Schwartz 2008).

The adjoint model calculates derivatives of a scalar metric with respect to emissions at various locations. This scalar metric is referred to as the adjoint cost 
function and for this study is considered to be nation-wide damage $(D)$ in equation 7-1. The adjoint cost function is introduced to the ajdoint model via the adjoint forcing term or the derivative of the adjoint cost (damage) function with respect to concentration. The forcing term $(\varphi)$ for the damage function is (Pappin and Hakami 2013):

$$
\varphi=\frac{\partial D}{\partial C}=V_{S L} M_{0} P \beta
$$

The role of the forcing term in the adjoint model is similar to the role of emissions in the forward air quality models. Emissions are injected into the forward model and propagate forward in time to impact concentrations. Similarly, forcing terms are injected into the adjoint field and propagate backward in time to "force" influences on the damage function. A single adjoint run can calculate source-specific MDs in a large domain, but does not provide any information about how MDs change with emissions. To construct source-specific MD curves, multiple adjoint runs are required to calculate MDs at different emission reduction levels. The steps required to construct source-specific MD curves are as follows:

1. A meteorological model (WRF 3.1 (Skamarock et al. 2005)) is used to prepare meteorological input files, which are converted to the air quality model input format by the MCIP model.

2. An emission processing model (SMOKE 2.4(CEP 2007)) is utilized to create emission files from all sectors (e.g., point, mobile, biogenic, wildfires, area, non-road). 
3. An air quality model (CMAQ 4.5.1 (Byun and Schere 2006)) is run with the meteorological and emission files. The forward CMAQ creates spatial and temporal concentration files (known as checkpoints) that are required for backward simulations. This requirement is due to the fact that the derivatives of nonlinear processes (e.g., chemical process) are functions of concentrations.

4. Spatial and temporal forcing files are created using equation 7-2 and checkpoint files.

5. The adjoint of gas-phase CMAQ (Hakami et al. 2007) is run using checkpoint and forcing files. The adjoint model creates temporal and spatial MDs, which indicate damages caused by an additional ton of $\mathrm{NO}_{\mathrm{x}}$ for a particular day and location.

To calculate MDs for different emission levels, the emissions are reduced uniformly. Then, steps 3 to 5 are repeated to create new sets of MDs corresponding to the reduced emissions. In addition to MDs for baseline emissions, we generate MDs for several additional scenarios. In these scenarios, emissions from all point or mobile sources, or combined point and mobile sources are reduced uniformly by $20 \%, 40 \%$, $60 \%, 80 \%$, and $100 \%$. The difference between these scenarios is that the CMAQ model uses different emission files in step 3, which results in different concentrations checkpoints and forcing files used by the adjoint model. Differences in concentrations reflect the change in the atmospheric regime that is induced by various $\mathrm{NO}_{\mathrm{x}}$ emission reduction levels. In our simulations, the adjoint model is configured to create daily 
MDs over the domain. To calculate the source-specific seasonal MDs, an emission weighted aggregation of daily MDs is used:

$$
M D(x, y)=\frac{1}{\sum_{d} \sum_{k} e_{d k}(x, y)} \sum_{d} \sum_{k} e_{d k}(x, y) M D_{d k}(x, y)
$$

where $M D(x, y)$ is the seasonal MD at grid $(x, y) ; e_{d k}(x, y)$ and $M D_{d k}(x, y)$ are the emissions and MD at grid $(x, y)$, layer $k$, and day $d$. Note that for averaging daily MDs, the emissions in equation 7-3 can be either point source (PNT-MD) or mobile source (MB-MD) emissions. The daily MDs are calculated over a North American domain with $36 \mathrm{~km}$ grid resolution and 34 vertical layers. The simulation period is from May 1st to September 30th (the ozone season) of 2007.

\subsection{Result and discussion}

The outputs of the adjoint model, i.e., MB-MDs and PNT-MDs, are calculated under different emission reduction scenarios and presented in this section. Note that PNT-MDs are weighted averages for all 34 vertical layers (Figure 7.1), while the MBMDs represent the damages caused by ground-level emissions (Figure 7.2). A value of zero for the PNT-MDs in Figure 7.1 indicates that no point source emissions were present in a location. If a new point source is established in those locations, an average daily MD (not weighted by emissions) can be used to estimate its potential MD. These zero-MD locations do not exist for MB-MDs as all locations (grids) in the domain have non-zero mobile $\mathrm{NO}_{\mathrm{x}}$ emissions. 

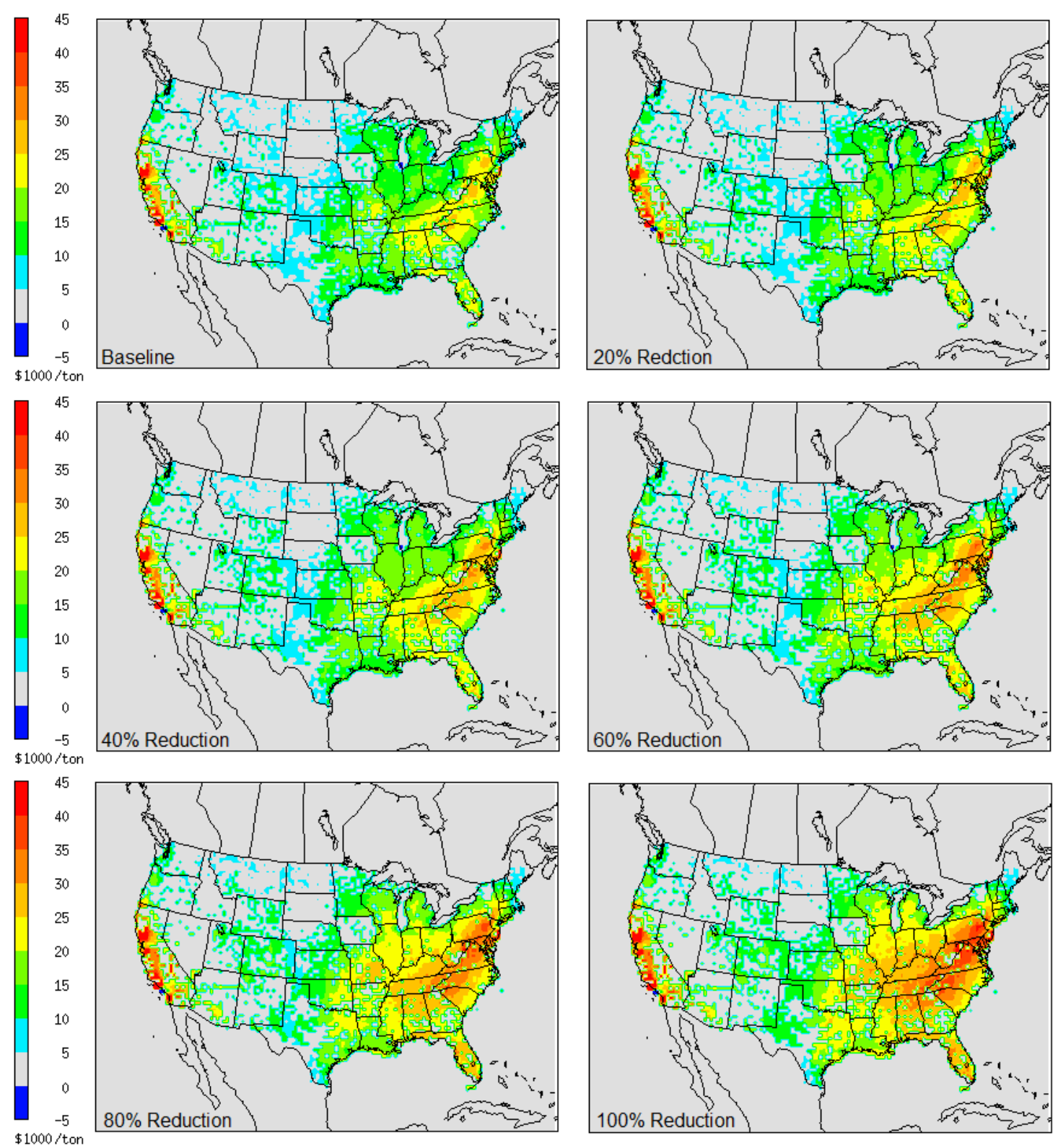

Figure 7.1. PNT-MDs for different emission reduction scenarios when point source emissions are reduced uniformly across the domain. Each panel shows PNT-MDs as average daily $\mathrm{NO}_{\mathrm{x}}$ MDs weighted by point-source emissions in various model layers. 

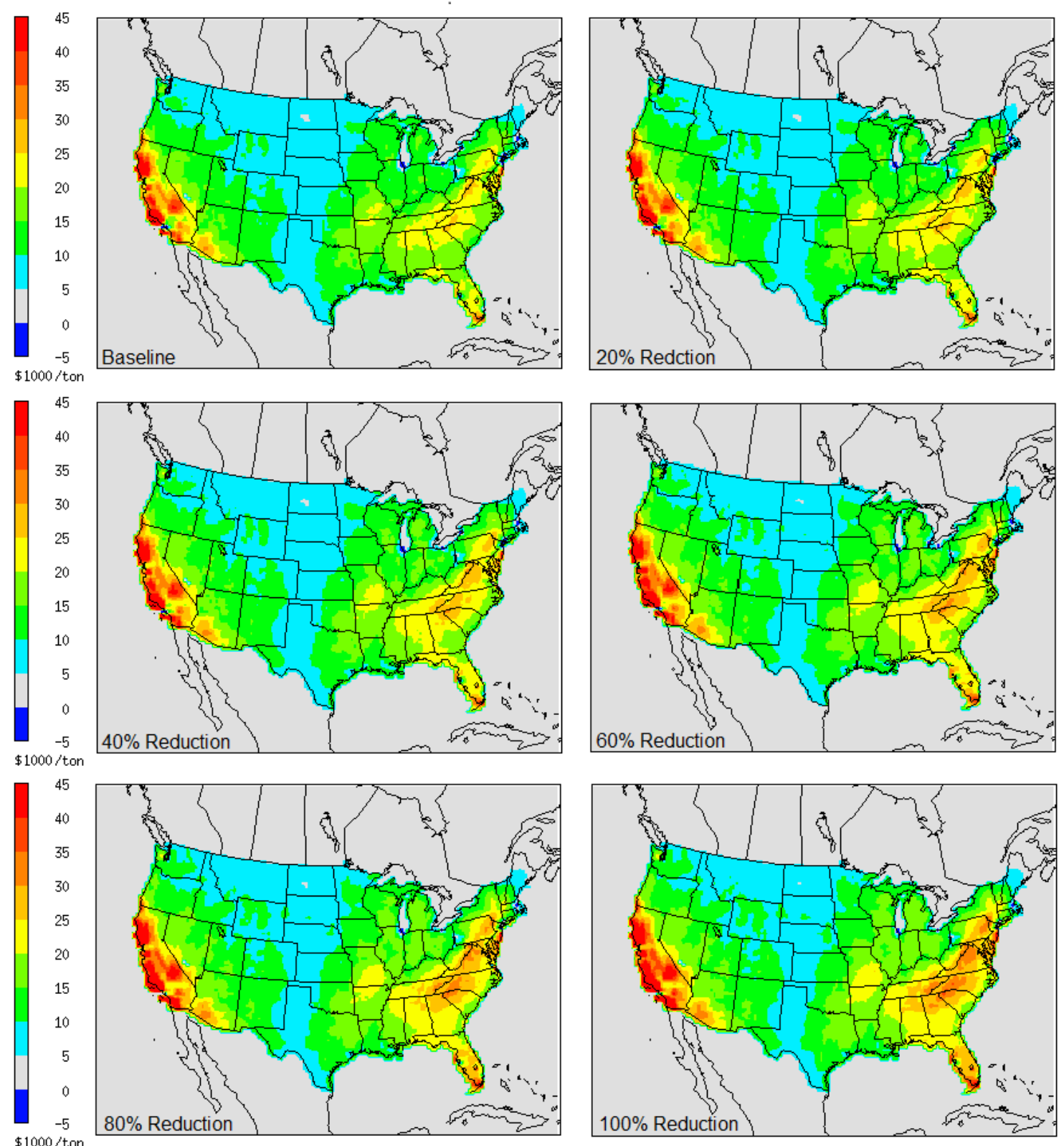

Figure 7.2. MB-MDs when mobile emissions are reduced uniformly across the domain. MB-MDs are average daily $\mathrm{NO}_{\mathrm{x}}$ MDs weighted by mobile-source emissions.

For both PNT-MDs and MB-MDs, high-MD locations (shown in yellow, orange, and red in Figures 7.1 and 7.2) grow with emission reductions. This important finding indicates that the same unit of emission reduction carries larger benefits at 
lower emission levels (i.e., MDs are higher). Note that positive MDs become more positive and negative MDs become less negative with emission reductions. This is due to the nature of atmospheric chemical reactions contributing to ozone production. The availability of $\mathrm{NO}_{\mathrm{x}}$ is a determining factor in these reactions. When $\mathrm{NO}_{\mathrm{x}}$ is abundant, there is great competition for additional $\mathrm{NO}_{\mathrm{x}}$ molecules, and therefore, the impact of increased $\mathrm{NO}_{\mathrm{x}}$ availability on the ozone concentration is small or even negative (in $\mathrm{NO}_{\mathrm{x}}$-inhibited regimes). When little $\mathrm{NO}_{\mathrm{x}}$ is available, additional $\mathrm{NO}_{\mathrm{x}}$ molecules face little competition in producing ozone, leading to high ozone formation efficiency and larger MD. 

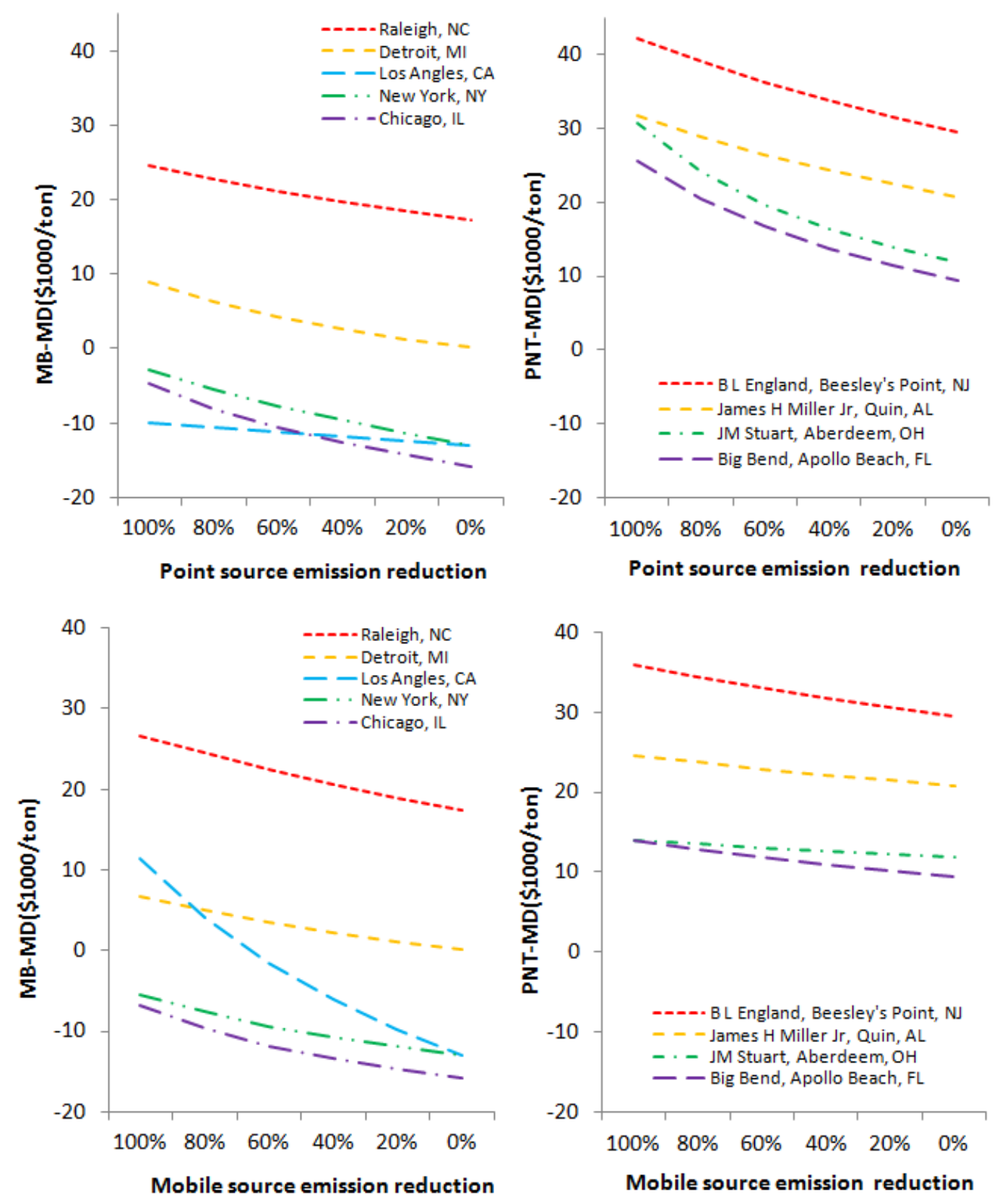

Figure 7.3. MDs at different locations when point (top) or mobile source emissions (bottom) are reduced. MD values are MB-MDs for few major cities (left) and PNT-MDs for selected power plants (right).

The change in MDs with emissions can be better depicted if source-specific MD curves are extracted and presented for power plants and cities (Figures 7.3). 
Three of four selected power plants in Figure 7.3, are large power plants and were among the top facilities with highest ozone season emissions in 2007. These three power plants are: the James H Miller Power Plant in Alabama with a capacity of 2640 MW, the JM Stuart Power Plant in the Ohio River Valley with a capacity of 2340 MW, and the Big Bend Power Plant in Florida with a capacity of 1823 MW. The fourth power plant, the B L England Power Plant, with a capacity of $450 \mathrm{MW}$ was selected because it is located in a high-MD region of New Jersey. As shown in Figure 7.3, all four power plants have negatively sloped MD curves.

Large urban regions such as New York City, Los Angles, and Chicago have negative MDs at baseline emissions (i.e., no emission reductions), whereas smaller cities have positive MDs. This is because of the governing $\mathrm{NO}_{\mathrm{x}}$-inhibited atmospheric regime under which $\mathrm{NO}_{\mathrm{x}}$ emission reductions have negative influence on ozone formation (Pappin and Hakami 2013).

For both mobile and point source emission reductions, MDs are very similar for all five cities expect for Los Angles where MDs increase drastically with mobile source emission reductions, but are not sensitive to point source emission reductions. Elimination of mobile source emissions in Los Angeles changes the MDs from $-\$ 13000 /$ ton to $\$ 11500 /$ ton. This significant change is due to the large amount of mobile source emissions in the western U.S. For Los Angeles, change in the MD sign occurs for a mobile source emission reductions of about $70 \%$. A change in the MD sign from negative to positive indicates that emission reductions increase ozone concentrations initially (negative MD) but decrease ozone concentrations eventually 
because the atmospheric regime turns from $\mathrm{NO}_{\mathrm{x}}$-inhibited to $\mathrm{NO}_{\mathrm{x}}$-limited and MDs become positive. Note that the adjoint method is not able to predict the locations at which these transitions in the chemical regimes occur. Instead, the adjoint results indicate that emissions generated in that location (Los Angeles) experience an overall change of behavior somewhere along their trajectory in the domain as reflected in the estimated damage.

The change in sign of the MD does not occur for either New York or Chicago when emissions are reduced from point or mobile sources separately. However, the MDs became less negative in both cases. Removing both sources simultaneously results in a greater change in MDs and a change the sign of the MDs (Figure 7.4). Note that MD curves for point and mobile source emission reductions are constructed through different adjoint runs when emissions are simultaneously and uniformly reduced for both sources. 

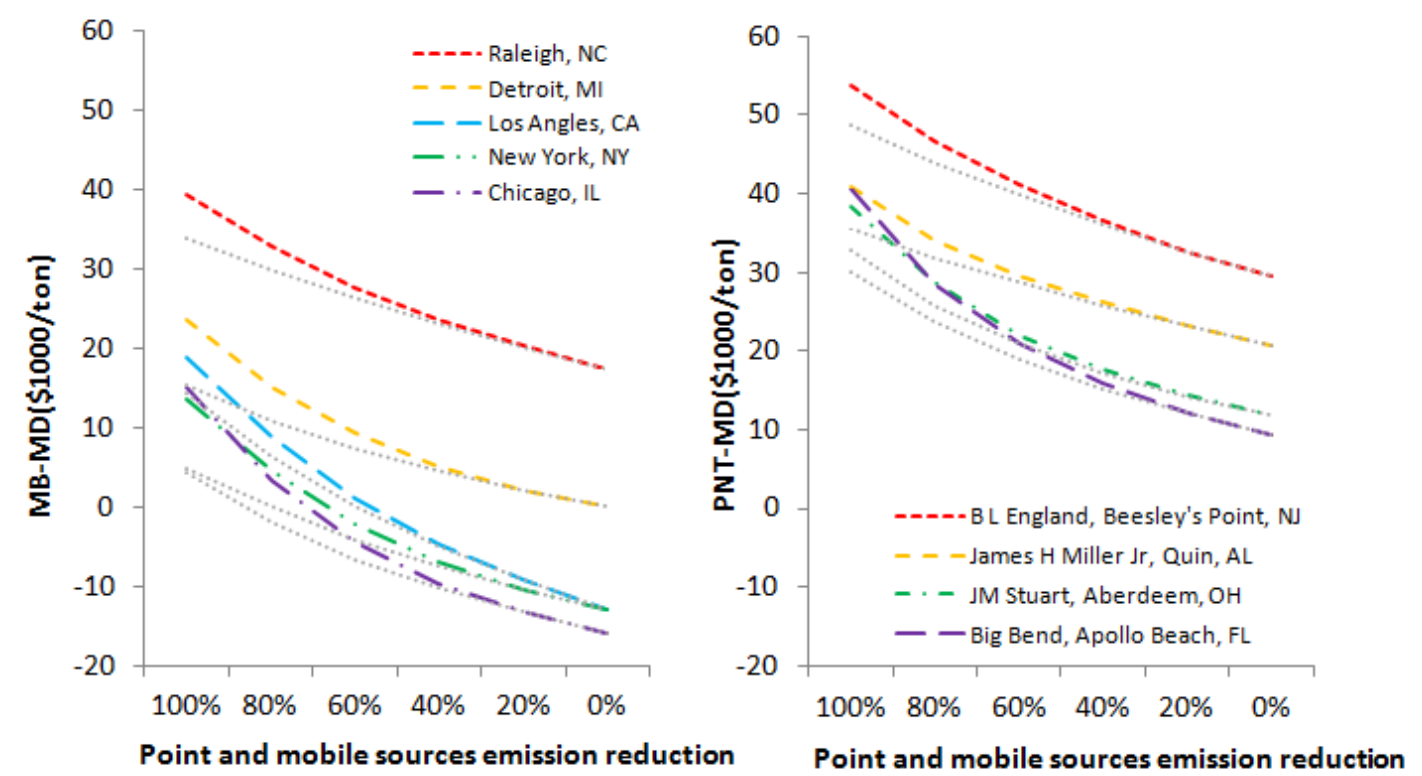

Figure 7.4. MDs at different locations when point and mobile source emissions are reduced. The MD values are MB-MDs for a few major cities (left) and PNT-MDs for selected power plants (right). The grey dashed lines are the aggravation of MDs from point source and mobile source emission reductions presented in Figure 7.3.

Note that the aggregation of MDs when emissions from point sources are reduced and the MDs when emissions from mobile sources are reduced (grey lines in Figure 7.4) are lower than the combined MDs when point and mobile sources are reduced simultaneously. This indicates not only that MDs increase when emissions are reduced, but also the rate of increase in MDs (or the slope of MD curves) increases when emissions are reduced.

The shape of the MD curve also impacts the estimation of total damage as the area underneath the MD curves. Some studies (Levy et al. 2009; Muller and Mendelsohn 2007; Muller et al. 2011) assume that source-specific MDs do not change with $\mathrm{NO}_{\mathrm{x}}$ emissions and estimate the total damage by multiplying fixed MDs and 
emissions. This linear approximation of total damage is prone to underestimation as it neglects the negative slope of $\mathrm{NO}_{\mathrm{x}} \mathrm{MD}$ curves.

An MD curve is important from a policy perspective because it is often used along with a marginal abatement cost (MAC) curve to devise economically optimal emission control policies. MAC curves are usually negatively sloped, meaning that the cost per ton of emission reduction increases as emission level decreases. Under an ideal emission control policy, polluters operate at an emission level where their MAC is equal to their MD (Montgomery 1972; Tietenberg 1995). This is due to the fact that the cost of removing an additional unit of emissions is justified by larger external benefits up to the point where the MD curve intersects with the MAC curve. After this point of economic equilibrium, further reduction in emissions is not economically justified. However, for a negatively sloped MD curve, the intersection point will occur at a lower emission level than that suggested by the traditional view in environmental economics literature (see Figure 7.5). Note that MDs at baseline emission levels are often much higher than MACs (Mesbah et al. 2013). If the MDs were lower than the MACs for baseline emissions, the negatively sloped MD curve could have resulted in a higher or lower optimal emission level than the traditional optimal level, depending on the relative slope of the MAC and MD curves. This finding has implications for the current U.S. cap-and-trade program. The target system-wide emission cap for a cap-and-trade system is often set based on the perceived equilibrium point where MAC and MD are equal. Negatively sloped MD 
curves, as those found in this study, suggest a lower system-wide emission cap as that suggested by the traditional literature.

The particular shape of the $\mathrm{NO}_{\mathrm{x}} \mathrm{MD}$ curves calculated in this work are due to the fact that ozone is a secondary pollutant. For primary pollutants an MD curve with positive (or zero) slope that conforms to the traditional view is expected. However, production of ozone from $\mathrm{NO}_{\mathrm{x}}$ occurs through nonlinear chemistry that is inherently non-convex in precursor concentration or availability. Note that our definition of MDs calculated in this paper are based on only short-term mortality of ozone exposure, and the damages caused by particulate matter (PM) formed by $\mathrm{NO}_{\mathrm{x}}$ emissions are not included. The overall form of $\mathrm{NO}_{\mathrm{x}} \mathrm{MD}$ curve with inclusion of $\mathrm{PM}$ related damages may be different than those presented here. However, as contribution of $\mathrm{NO}_{\mathrm{x}}$ to $\mathrm{PM}$ is also due to secondary inorganic constituent formed through chemical equilibrium, one would expect persisting, or even enhanced non-convexity with inclusion of PM in the damage function. Nevertheless, overall $\mathrm{NO}_{\mathrm{x}} \mathrm{MD}$ curves require further investigation to explore this hypothesis. 


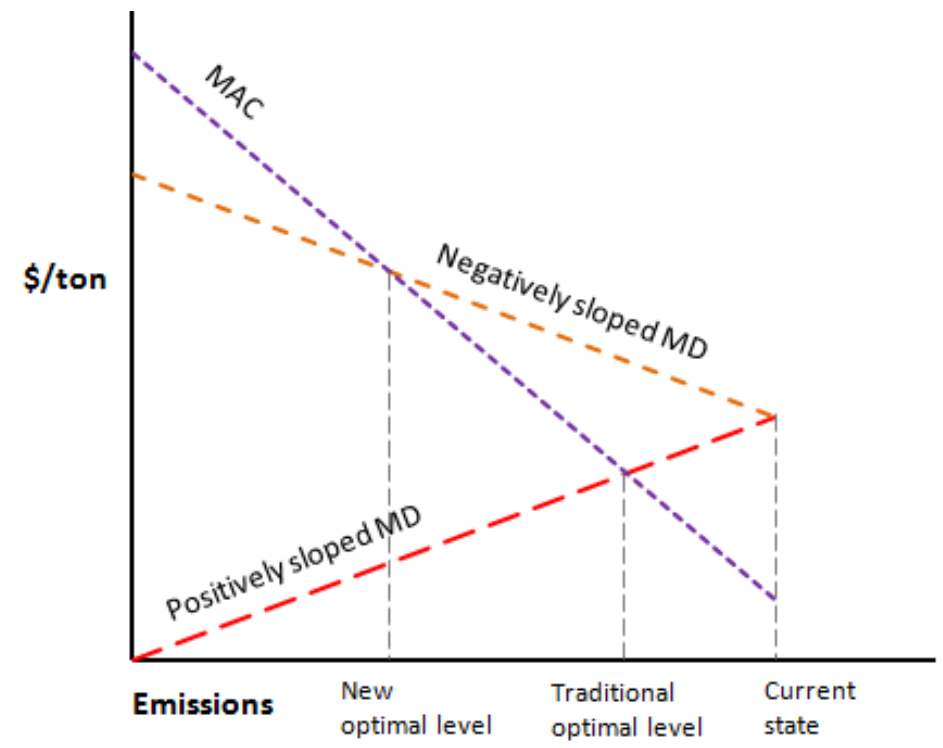

Figure 7.5. Schematic of traditional and negatively sloped MD curves in an economic equilibrium framework.

It should be noted the MD curves presented are based on a uniform emission reduction over the entire domain, not emission reductions only from the selected power plant or urban mobile emissions while other emissions are kept constant. As such, our MD curves should be regarded as projection of response to global rather than local changes in emission patterns. The change in emissions from one source in a large domain is small compared to available ambient $\mathrm{NO}_{\mathrm{x}}$ in the system, and therefore one can assume emissions from one source have no tangible impact on the atmospheric regime. Such an assumption results in a flat MD curves when other sources do not change their emission levels. Changes in sectoral emissions such as mobile or electricity generating sources seldom happen in isolation and commonly materialize in a broader nationwide context. As such, we believe that our depiction of MD curves as response to global changes provides a more realistic and relevant view. 


\subsection{Conclusions}

This work demonstrates that unlike the traditional form of MD curves, $\mathrm{NO}_{\mathrm{x}}$ MD curves are negatively sloped. This finding is in favor of policies supporting more aggressive emission reductions because further reductions increase marginal benefit or benefit per ton. The benefit of $\mathrm{NO}_{\mathrm{x}}$ emission reductions has been debatable in some cities where the atmospheric regime is $\mathrm{NO}_{\mathrm{x}}$-inhibited and the initial MD is negative (Pappin and Hakami 2013). While for these locations, emission reductions may not be beneficial in the short-term, consideration of MD curves along the emission control path provides support for continued $\mathrm{NO}_{\mathrm{x}}$ control in urban environments. Inclusion of information garnered from MD curves into policy design is beneficial as it influences the determination of the optimal cap for the cap-and-trade program. In presence of negatively sloped MD curves, such as those for $\mathrm{NO}_{\mathrm{x}}$ damage through ozone, lower emission targets than previously thought would be advisable. 


\section{CHAPTER 8:}

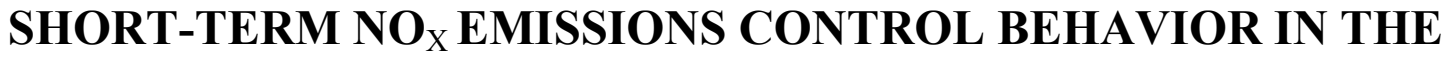 REGULATED AND RESTRUCTURED ELECTRICITY MARKET}

\subsection{Introduction}

Coal-fired electric generating power plants are among the main sources of nitrogen oxides $\left(\mathrm{NO}_{\mathrm{x}}\right)$ emissions. The amount of electricity (output) that a power plant generates is highly dependent on the price of electricity and the restrictions on emissions. $\mathrm{NO}_{\mathrm{x}}$ emissions are among the main precursors of surface ozone (a major constituent of smog), and are usually regulated during hot seasons, which are referred to as ozone seasons (May to September, inclusive), when $\mathrm{NO}_{\mathrm{x}}$ emissions have higher ozone formation potentials. Under $\mathrm{NO}_{x}$ cap-and-trade programs, facilities receive allocated emission quotas which determine how much they are permitted to emit; one quota allows a facility to emit one ton of $\mathrm{NO}_{\mathrm{x}}$ during the ozone season. Power plants can adjust their electricity generation or buy quotas in the short-term to meet emission requirements (i.e., holding enough quotas to cover their ozone season emissions). The main objective of this chapter is to predict how power plants behave in the short-term to comply with emission requirements while facing different electricity regulations and opportunity costs. Fowlie (2010) compared power plants' outputs for two years (before and after a $\mathrm{NO}_{\mathrm{x}}$ trading program was in place in the eastern U.S.), and concluded that output reduction is not a compliance option for power plants in the long-term. This study finds that output adjustment is a short-term compliance option 
for power plants and investigates how this option is affected by control technology and electricity market structure.

The United States divided into two different types of electricity markets: regulated and restructured. In a typical regulated market, power plants receive a predetermined rate of return on their investments, whereas power plants in a restructured market are not guaranteed such returns. This difference in electricity markets provides more of an incentive for power plants in the regulated market to invest in abatement technologies in the long-term (Fowlie 2010). In this chapter, we investigate the shortterm behavior of power plants and discuss whether they choose to adjust output or buy emission quotas. To predict the short-term behavior of power plants, we develop an analytical method to estimate plant level marginal abatement costs (MAC) for purchasing emission quotas that accounts for unit-level emissions control technologies as well as the opportunity $\operatorname{cost}^{9}$ of output reduction.

The MAC has been calculated in three main ways (Vijay et al. 2010): the microeconomic method, the econometric method, and the engineering-economic method. Microeconomic methods are based on cost function and distance function approaches. In the cost function approach emissions are considered as one of many inputs contributing to cost for plants (Kolstad and Turnovsky 1998). The cost function approach minimizes the plant's cost and calculates the change in that cost when the emission levels change. The distance function approach (Färe et al. 1993) treats

\footnotetext{
${ }^{9}$ Opportunity cost is defined as the foregone benefit of selling electricity.
} 
emissions as bad outputs and calculates the MAC as the shadow price ${ }^{10}$ of reducing one unit of output using the duality between the revenue function and distance function. The econometric method (e.g., Becker 2005) uses data on capital and operation costs from plants and estimates the MAC. The engineering-economic method is based on technical information on control technologies and their corresponding costs (Wanger and Schopp 2007). The microeconomic and econometric methods do not consider the effect of control technologies on the abatement, whereas the engineering-economic method does not consider the opportunity cost of abatement (Vijay et al. 2010). In this work, we propose a method for the calculation of MAC that includes both control technology costs and the opportunity costs of output reduction. Then, we assume different output adjustment behavior (and different opportunity cost) for power plants under the regulated and restructured markets, and estimate MACs for U.S. coal-fired power plants. Next, we perform a regression analysis to examine how power plants' output adjustment behavior differs by electricity market structure. Subsequently, a firm's predicted behavior based on the estimated MACs is compared to actual emissions compliance in the $\mathrm{NO}_{\mathrm{x}}$ trading market. Finally, we perform another regression analysis to identify the significant parameters affecting power plants' emission trading behaviors and construct a supply and demand function for emission quotas.

\footnotetext{
${ }^{10}$ Shadow price in an optimization problem (e.g., abatement cost minimization) is the change in the objective function by strengthening the constraint (e.g., external cap on emissions) by one unit.
} 


\section{2. $\mathrm{NO}_{\mathrm{x}}$ control technologies and regulations}

Both control technologies and regulations can affect abatement costs. Stricter emission standards lead to higher costs, and more cost-effective control technologies can lead to lower abatement costs for a power plant. Two main categories of $\mathrm{NO}_{\mathrm{x}}$ control technologies are combustion modification and post-combustion control. Combustion technologies aim to prevent the generation of $\mathrm{NO}_{\mathrm{x}}$ emissions by modifying the combustion processes, whereas the post-combustion technologies aim to reduce the $\mathrm{NO}_{\mathrm{x}}$ emissions that have already been produced. Combustion modification can also reduce the plant's efficiency due to sub-optimal combustion. ${ }^{11}$ Two common post-combustion control technologies for $\mathrm{NO}_{\mathrm{x}}$ are selective noncatalytic reduction (SNCR) and selective catalytic reduction (SCR). Both of these technologies are designed to reduce $\mathrm{NO}_{\mathrm{x}}$ using a chemical reaction. ${ }^{12}$

The Clean Air Act (CAA) amendment of 1990 is the main air quality regulation in the U.S. and has led to significant efforts to control $\mathrm{NO}_{\mathrm{x}}$ emissions. Title

\footnotetext{
${ }^{11}$ More information about $\mathrm{NO}_{\mathrm{x}}$ combustion modification technologies can be found elsewhere (e.g., Sloss et al. 1992).

12 The reaction converts $\mathrm{NO}_{\mathrm{x}}$ into water and molecular nitrogen $\left(\mathrm{N}_{2}\right)$ which is a harmless gas and can be released to the atmosphere. In both technologies, a reagent, ammonia or urea, is added to the $\mathrm{NO}_{\mathrm{x}}$ stream. The difference between the two technologies is that in SNCR, the reaction occurs at high temperature $\left(1145-1365^{\circ} \mathrm{K}\right)$, whereas in SCR, adding a catalyst allows the reaction to occur at a lower temperature $\left(590-700^{\circ} \mathrm{K}\right)$. The efficiency of SNCR is usually between $30 \%$ to $50 \%$ reduction, whereas the efficiency of SCR is about 90\% (Ziadi and Kumar 1995).
} 
I and title IV of the 1990 CAA amendment both relate to $\mathrm{NO}_{\mathrm{x}}$ emissions control. Title IV led to creation of the acid rain program that required a 2 million ton per year reduction in $\mathrm{NO}_{\mathrm{x}}$ emissions from coal-fired power plants. Title I included provisions for attainment and maintenance of the National Ambient Air Quality Standard (NAAQS). It outlined a timetable for states to meet the NAAQS (Burtraw et al. $2005){ }^{13}$

The CAA also gave authority to the U.S. EPA to create an emissions trading program. The emissions trading program caps the total emissions of $\mathrm{NO}_{\mathrm{x}}$ during the ozone season by allocating quotas to plants. The allocation is based on a unit's type (e.g., voluntary ${ }^{14}$, industrial, electric utility, etc.) and their average net output (in $\mathrm{MWh}$ ) during the two ozone seasons prior to the compliance year. The plants can trade their emission quotas, but they must have enough allowances at the trading deadline (December 31) to cover their emissions. The clean air interstate rule (CAIR) which included provisions for an emissions trading system was promulgated in 2005 and replaced the $\mathrm{NO}_{\mathrm{x}}$ budget program (NBP) in 2008 (EPA 2008) after a series of litigations. CAIR is similar to NBP but it covers more states. CAIR remains in effect while the U.S. EPA reviews the now vacated cross-state air pollution rule (CSAPR).

13 A comprehensive regulatory history of $\mathrm{NO}_{\mathrm{x}}$ regulations can be found elsewhere (Burtraw and Szambelan 2009).

14 "Opt in" units voluntarily agree to participate in NBP. They are subject to all the requirements for NBP sources. 
Power plants that participate in the U.S. cap-and-trade program face different electricity regulations. Under a regulated electricity market, the regulators set rates for power plants and allow them to gain a reasonable (and sometimes inflated) rate of return on their investments and costs. Rate of return regulation would, therefore, favor investment into cleaner technologies compared to restructured competitive markets that compete on marginal cost pricing. In the 1990s, there was a large difference in rate of return across U.S. states (Warwick 2002). By 2001, 19 out of 50 U.S. states switched to a restructured market system, and 12 of these 19 states were among the 19 states participating in the NBP program. ${ }^{15}$

\subsection{Methodology}

Power plant emissions can be controlled either by reducing electricity generation or through abatement activities (e.g., combustion modification or postcombustion technologies). In the short-term, when power plants do not have enough time to install a new control technology, they meet their emission requirements, imposed by a cap-and-trade program, by output reduction or by purchasing emission quotas. Therefore, the amount that power plants are willing to pay for the emission quota depends on the opportunity cost of output reduction. Here we present a method to calculate the unit-level MACs. The benefit maximization problem for a plant participating in both the electricity and emissions market is:

\footnotetext{
${ }^{15}$ Among NBP states, CT, DE, IL, MA, MD, MI, NJ, NY, OH, PA, RI, and VA were under restructured electricity markets, and $\mathrm{AL}, \mathrm{IN}, \mathrm{KY}, \mathrm{NC}, \mathrm{SC}, \mathrm{TN}$, and $\mathrm{WV}$ were under a regulated system.
} 
Maximize: $P_{q} q-c(q, A)$

Subject to :

$$
e(q, A) \leq \bar{e}
$$

where $P_{q}$ is the exogenous electricity price, $q$ is the electricity generation level, $c$ is the cost function that depends on output $(q)$ and abatement activity $(A), e$ is the emission level of the plant that is also function of $q$ and $A$, and $\bar{e}$ is the exogenous constraint on emissions.

The Lagrangian problem function associated with equation 8-1 is:

$$
L=P_{q} q-c(q, A)-\lambda(e(q, A)-\bar{e})
$$

The first-order conditions are:

$$
\begin{aligned}
& \frac{\partial L}{\partial q}=P_{q}-\frac{\partial c}{\partial q}-\lambda \frac{\partial e}{\partial q}=0 \\
& \frac{\partial L}{\partial A}=-\frac{\partial c}{\partial A}-\lambda \frac{\partial e}{\partial A}=0 \\
& \frac{\partial L}{\partial \lambda}=-e(q, A)+\bar{e}=0
\end{aligned}
$$

From (8-4) and (8-5), $\lambda$ is:

$$
\lambda=\frac{-\frac{\partial c}{\partial A}}{\frac{\partial e}{\partial A}}=-\frac{\partial c}{\partial e}=\frac{P_{q}-\frac{\partial c}{\partial q}}{\frac{\partial e}{\partial q}}
$$

where $\lambda$ is the Lagrangian multiplier that is equal to the marginal cost or shadow 
price of $e$. Equation 8-6 is valid if the constraint on emissions (equation 8-1) is binding. If there is a market in place and the quota price is not zero, the total emissions cap in the system and caps for firms are binding (Farrow et al. 2005). To estimate unit-level MAC, we use the following cost function:

$$
c=\left(P_{i} R_{i o}+c_{p}+c_{c}\right) q
$$

which is a function of:

$$
\begin{aligned}
& q=\text { Electricity generation }(\mathrm{MWh}) \\
& P_{i}=\text { Input }(\text { coal) price }(\$ / \mathrm{MMBtu}) \\
& c_{p}=\text { Power plant's capital and operating cost }(\$ / \mathrm{MWh}) \\
& c_{c}=\text { Control technology's capital and operating cost }(\$ / \mathrm{MWh}) \\
& R_{i o}=\text { Rate of transformation between input and output }(\mathrm{MMBtu} / \mathrm{MWh})
\end{aligned}
$$

From equations 8-7 and 8-8, the unit-level MAC can be calculated as follows:

$$
M A C=\left(P_{q}-P_{i} R_{i o}-c_{p}-c_{c}\right) R_{o e}
$$

where $P_{q}$ is the electricity price and $R_{o e}$ is the rate of transformation between output and emissions (MWh/ton).

Equation 8-8 is used to estimate MAC for power plants in regulated and restructured electricity markets. We assume that $P_{q}=$ average regulated retail market price and that $P_{q}=$ minimum retail market price in a restructured market. We base our reasoning on the fact that power plants in restructured markets have an incentive to 
meet the ozone season emission requirements by reducing emissions (giving up outputs) on days when the electricity price is lower (Martin 2008; Martin et al. 2007). As a rate of return is set based on power plants' average costs, the average electricity price is used to approximate short-term benefit under the regulated market. We will perform a regression analysis later to examine this assumption and investigate how power plants' output adjustment behavior differs by market structure. The MAC for a plant is important since it is one of the main factors for a plant's decisions to exchange emission quotas in the emissions market. When electricity is demanded, a plant operates with full capacity (or maximum emission level) if its MAC is higher than the emission quota price. In this case, the plant prefers not to reduce any output to control emissions because the additional cost for the plant is more than the price of the quota. As such, the plant prefers to pay for buying emission quotas as needed. A plant operates at its minimum emission level when its MAC is less than the emission quota price. For this case, the price of a quota is higher than the additional cost of one unit of emissions reduction. As a result, the plant would prefer to reduce its electricity level to the minimum possible level and sell its emission quotas to other plants. Note that the amount of emissions reduction and trading on the emissions market depends on the initial allocation of quotas. ${ }^{16}$

${ }^{16}$ All explained behaviors are only valid with the assumption of a perfect market in place. 


\subsection{Data and cost estimation}

The proposed method is used to calculate MACs for coal-fired electric generation units with SCR or SNCR control technologies that participated in the NBP program during the ozone season of 2007 . The capital and operating costs for the control technologies are calculated using the U.S. EPA Integrated Planning Model (EPA 2010). The power plants' capital and operating costs, the coal price, and the electricity price (minimum monthly retail price, and average monthly retail price) for the ozone season are taken from the U.S. Energy Information Administration that provides prices by location (EIA 2010, 2008, n.d.). To calculate rate of transformations, the emission-output and output-input rates are estimated using the daily unit-level data from the U.S. EPA clean air market (EPA n.d.) and a standard ordinary least square regression.

In the following section, an application of the proposed methodology for the unit-level MAC calculation is demonstrated for the Rochester Power Plant (RPP), which is a good representative of an emissions quota buyer in the system. We proceed by estimating MACs for the selected units and contrast them by technology and location. The RPP is located in New York and has four units with SNCR control technology. The emission-output and output-input relationship for these units are demonstrated in Figures 8.1 and 8.2 respectively. 

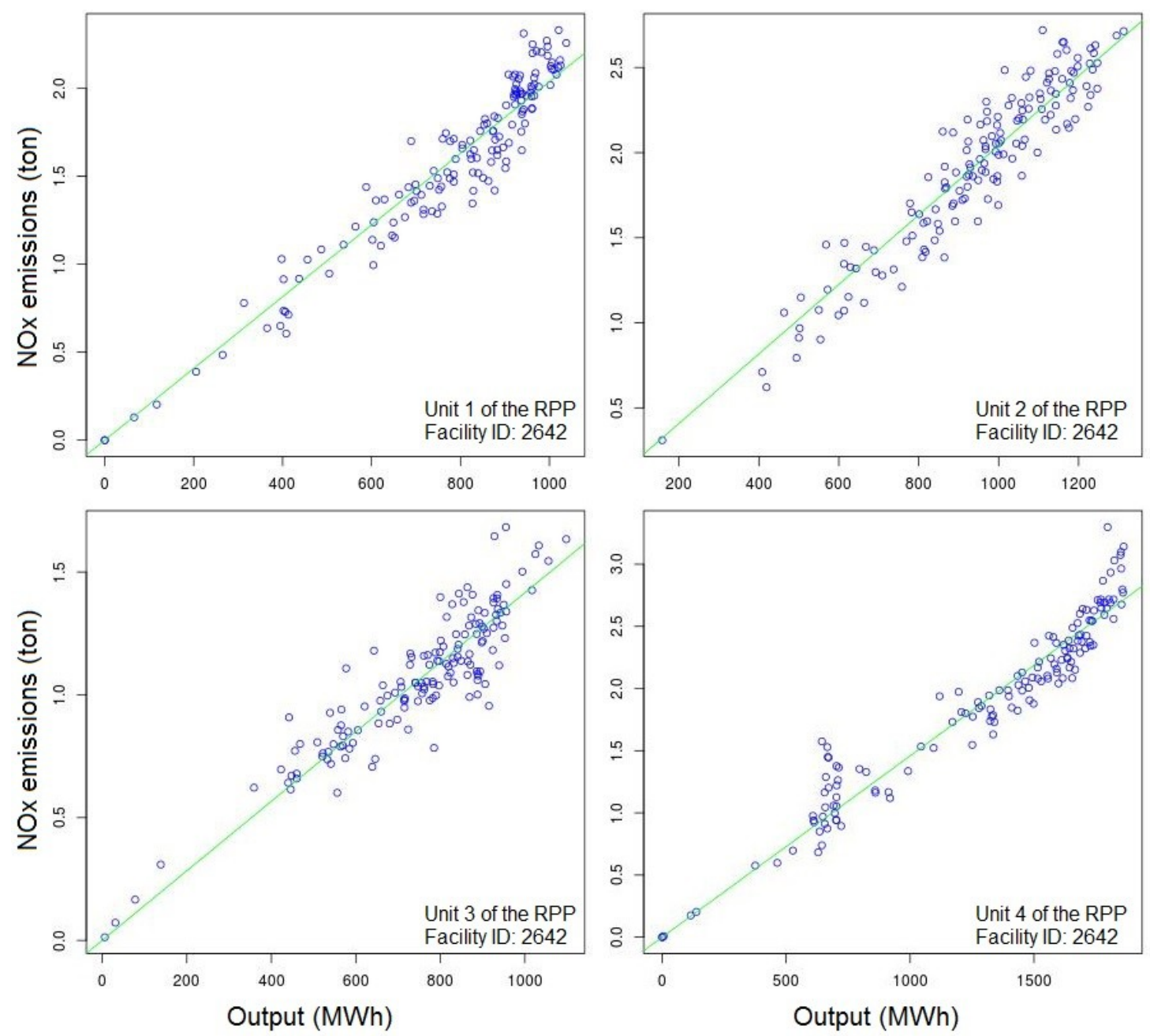

Figure 8.1. Output-emission relationship for units of the Rochester Power Plant. Each point represents the daily emissions and the daily output. 

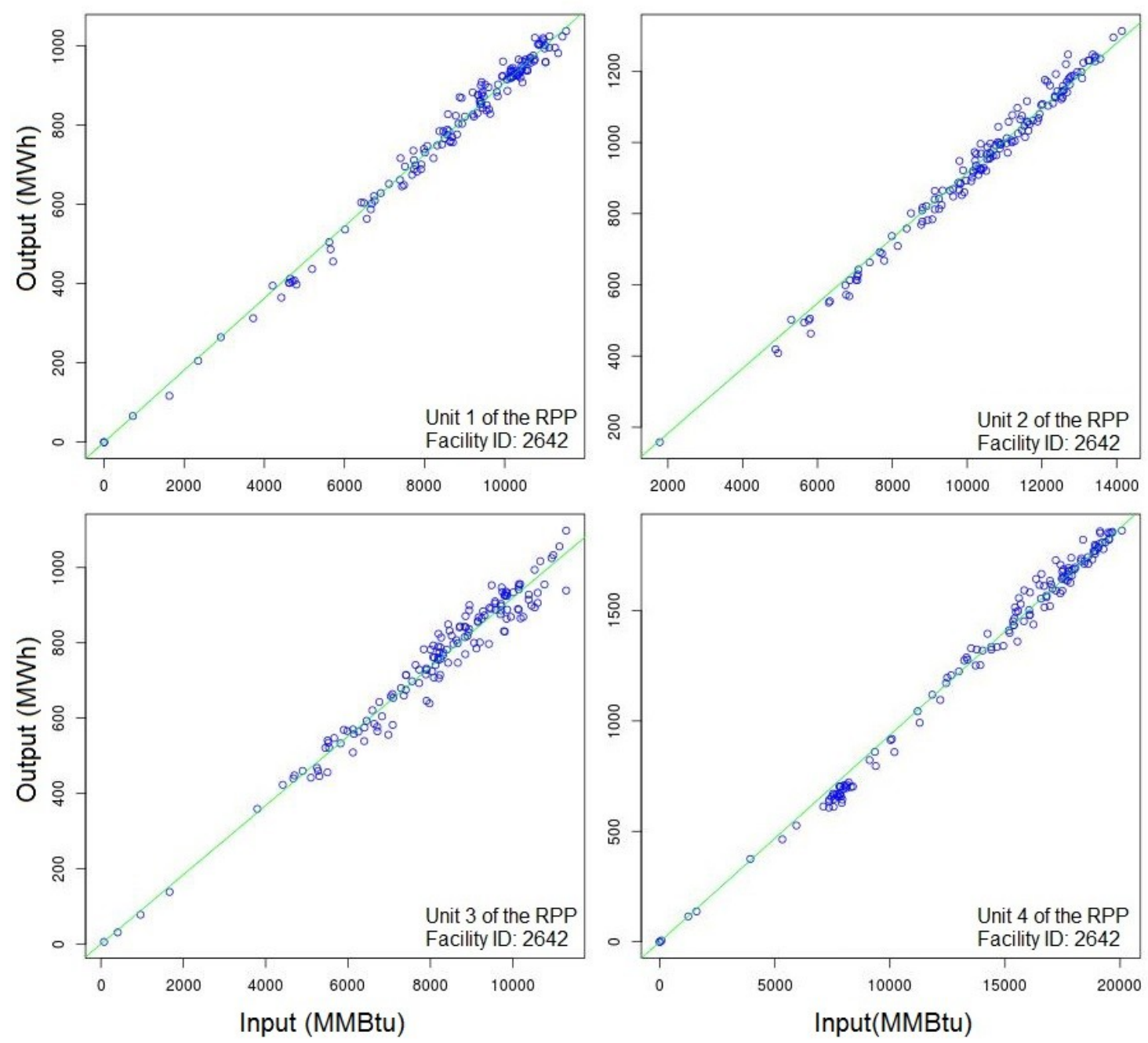

Figure 8.2. Input-output relationship for units of the Rochester Power plants. One point represents daily input and daily output.

The ozone season MACs for all units of the RPP are presented in Table 8.1. All MACs are higher than the average quota price (\$825/ton) for the ozone season (EPA, 2008) meaning that this power plant should always try to buy quotas. The compliance data indeed confirms that the power plant was a quota buyer. 
Table 8.1. MAC for the Rochester Power Plant in the ozone season of 2007.

\begin{tabular}{lllll}
\hline & Unit 1 & Unit 2 & Unit 3 & Unit 4 \\
\hline MAC (thousand \$/ton) & 19.5 & 20.1 & 29.2 & 29.4 \\
\hline
\end{tabular}

Compliance data for the RPP for the ozone season are presented in Table 8.2.

Table 8.2. Compliance data for the Rochester Power Plant in the ozone season of 2007 (Clean air market U.S. EPA).

\begin{tabular}{lllllll}
\hline & Unit 1 & Unit 2 & Unit 3 & Unit 4 & Overdraft & Total \\
\hline Allocated & 96 & 131 & 128 & 276 & 0 & 531 \\
Banked & 66 & 3 & 4 & 5 & 0 & 78 \\
Current held & 3 & 4 & 4 & 33 & 1049 & 1093 \\
Total held & 69 & 7 & 8 & 38 & 1049 & 1171 \\
Required deduction & 264 & 263 & 219 & 219 & 0 & 965 \\
Current deduction & 3 & 4 & 4 & 33 & 872 & 916 \\
Banked deduction: & & & & & & \\
1 to1 & 16 & 1 & 1 & 1 & 0 & 19 \\
2 to 1 & 50 & 2 & 3 & 4 & 0 & 59 \\
Total deduction & 69 & 7 & 8 & 38 & 872 & 994 \\
Carried over & 0 & 0 & 0 & 0 & 177 & 177 \\
\hline
\end{tabular}

The RPP's overall quota withdrawal in 2007 was 994, whereas its required deduction was 965 (Table 8.2). The required deduction is determined based on the emissions of the power plant in the ozone season. The extra deduction of quotas was 
because of the use of banked quotas. Overall, the plant used all its 78 banked quotas, and 59 of them were subject to a 2-to- 1 exchange rate and could cover 30 ton of $\mathrm{NO}_{\mathrm{x}}$. The plant ended up with more quotas than needed in the current year, and 177 of them (total held - total deducted) were carried to the next year. From the compliance data, the plant was a quota buyer and bought 542 (current (1093) - allocated (531) - carried from last year (38)) quotas in 2007.

In 2007, 2589 units took part in the NBP. Among them, 2018 units were electric utility generations (EGUs), and 640 units were coal-fired. Only 250 of the latter had SCR or SNCR control technologies. These 250 units generated more than 165 kilotons $(\mathrm{kt})$ of $\mathrm{NO}_{\mathrm{x}}$ emissions in the ozone season of 2007 , which accounted for about $40 \%$ of the total coal-fired EGU emissions (418 kt), and $37 \%$ of total EGU emissions (442 kt), or $32 \%$ of the total emissions of all facilities (including nonEGUs) in the NBP (506 kt). In this study, 218 of these 250 units were selected based on the available electricity generation data for the units.

The same procedure (as that applied to the RPP) is repeated for all other selected units. To show how the MAC changes from one location to another, 4 different regions were chosen (Figure 8.3). Note that some of the states in Figure 8.3 did not participate in the NBP (e.g., Georgia). Also, to show how the MAC changes for different technologies, units with SCR and SNCR were considered separately. The 
control technology of the selected units in different regions, as well as the type of electricity market (i.e. regulated or restructured) are also shown in Figure 8.3. ${ }^{17}$

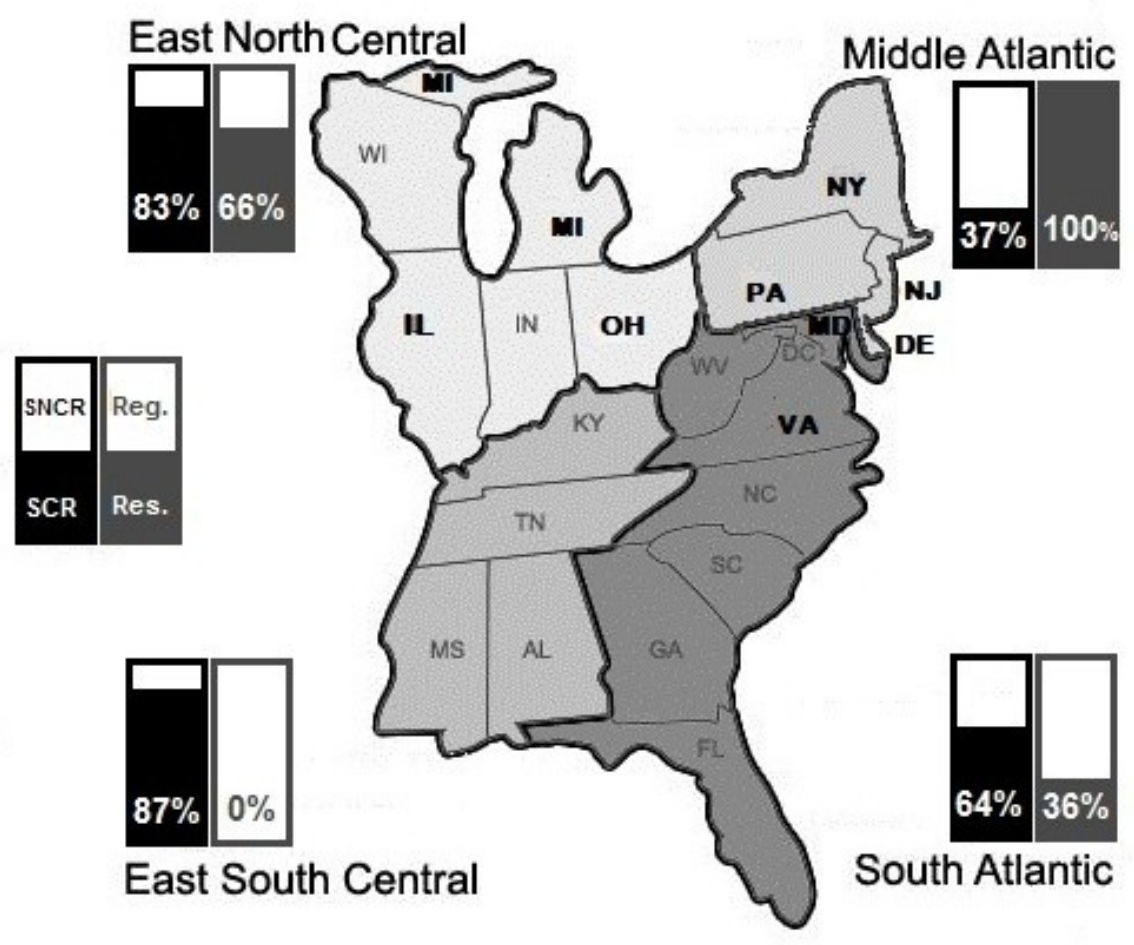

Figure 8.3. Selected units by region. The restructured states are shown in bold text. The columns represent the percentage of selected units in the restructured market and the percentage of units with SCR control technologies at each region.

A summary of unit-level information including the estimated MACs are presented in Table 8.3.

1771 units were selected in the East North Central region, 38 in the Middle Atlantic region, 45 in the South Central region, and 64 in the South Atlantic region. 
Table 8.3. Unit-level descriptive statistics by region. ${ }^{\text {a }}$

\begin{tabular}{lllll}
\hline & $\begin{array}{l}\text { East North } \\
\text { Central }\end{array}$ & $\begin{array}{l}\text { Middle } \\
\text { Atlantic }\end{array}$ & $\begin{array}{l}\text { East South } \\
\text { Central }\end{array}$ & $\begin{array}{l}\text { South } \\
\text { Atlantic }\end{array}$ \\
\hline Capacity (MW) & $436(257)$ & $346(297)$ & $429(288)$ & $444(293)$ \\
$\begin{array}{l}\text { Ozone season generation } \\
\text { (GWh) }\end{array}$ & $1297(866)$ & $1028(1035)$ & $1438(1003)$ & $1384(977)$ \\
Ozone season emissions (ton) & $755(667)$ & $794(558)$ & $574(407)$ & $635(486)$ \\
$\begin{array}{l}\text { Emission-output rate } \\
\text { (lb/MWh) }\end{array}$ & $1.53(1.56)$ & $2.76(1.68)$ & $0.98(0.96)$ & $1.15(0.81)$ \\
$\begin{array}{l}\text { Avg. electricity price } \\
\text { (\$/MWh) }\end{array}$ & $77.3(8)$ & $109.7(26.2)$ & $68.6(6.8)$ & $75.8(17.7)$ \\
$\begin{array}{l}\text { Min. electricity price } \\
\text { (\$/MWh) }\end{array}$ & $75.2(7.6)$ & $105(22.7)$ & $65.4(7.7)$ & $71.2(14.5)$ \\
Input cost (\$/MWh) & $17.4(7)$ & $31.6(7.3)$ & $20.8(1.5)$ & $27.7(4.9)$ \\
$\begin{array}{l}\text { Power plant cost (\$/MWh) } \\
\text { Control technology cost }\end{array}$ & $67.6(3.6)$ & $68.9(4.2)$ & $67.8(4)$ & $67.5(4.1)$ \\
(\$/MWh) & $11.4(4.3)$ & $6.8(4.1)$ & $12(4.2)$ & $9.1(4.8)$ \\
$\begin{array}{l}\text { MAC (1000 \$/ton) } \\
\text { Number of quotas traded b }\end{array}$ & $-43(31)$ & $-6.7(22)$ & $-102(60)$ & $-89(78)$ \\
Percent of buyers in the region & 24 & 58 & 13 & 31 \\
\hline
\end{tabular}

${ }^{a}$ Values are average over the region. Standard deviations are in parentheses.

${ }^{b}$ Values are from the actual compliance data, the negative values represent the number of quotas a power plant bought.

Among the regions studied, all states in the middle Atlantic are part of the restructured electricity market (Figure 8.3). Power plants in the middle Atlantic region have the highest average electricity price and highest predicted MACs compared to the other regions (Table 8.3). In our model a high-MAC plant prefers to buy quotas 
instead of controlling its emissions by output reductions. This predicted behavior is consistent with the actual market data which indicates that there are more quota buyers in the middle Atlantic region (Table 8.3) as compared to other regions.

Power plants in the middle Atlantic region also have the highest average emission-output rate because they mainly use lower efficiency and cheaper control technologies (i.e., SNCR) to meet regulations. 63 percent of studied units in the middle Atlantic region have SNCR control technologies and the rest are equipped with SCR control technologies. The majority of plants in this region had not invested in SCR. Being in a restructured electricity market under which a return on power plants' investment is not guaranteed could have been a contributing factor. Therefore, power plants are less likely to invest in higher efficiency, and thus more expensive technologies in the long-term (Fowlie, 2010).

In the east south central region, where all states are in the regulated electricity market, the electricity price and the estimated MACs are the lowest among all regions (Table 8.3). The low predicted MACs show that plants are not willing to buy quotas. This prediction is consistent with the actual market data which indicates that power plants in the south central region sold more quotas on average than other regions. In this region, most power plants have SCR control technologies, and thus the emissionoutput rate is the lowest, and the control technology is the most expensive among all regions.

We first conduct a simple OLS regression to investigate how power plants' short-term output adjustment is affected by the type of technology and electricity 
market. ${ }^{18}$ For this regression, the dependent variable is a ratio which represents average used capacity. The latter is defined as the ratio of actual seasonal electricity generation to the full seasonal generation capacity. The independent variables are a constant, a dummy variable for control technology (i.e., $1=\mathrm{SCR}$ technology, and $0=$ SNCR technology), and a dummy variable for the type of electricity market (i.e., the $1=$ regulated market and $0=$ restructured market). Table 8.4 summarizes the regression coefficients and related statistics.

Table 8.4. Regression statistics and estimated regression variables. ${ }^{a}$

\begin{tabular}{lccc}
\hline Variable & Coefficient & Std. error & $\mathrm{t}$ stat \\
\hline Intercept & 0.730 & 0.021 & 35.08 \\
Control technology & 0.095 & 0.024 & 4.01 \\
Type of market & 0.037 & 0.022 & 1.70 \\
\hline
\end{tabular}

${ }^{a}$ The dependent variable is a ratio representing the used capacity.

The Intercept in the regression model represents the average capacity used for the power plants studied. From coefficients presented in Table 8.4, it is inferred that only $73 \%$ of capacity is used on average, but SCR increases capacity used by $9.5 \%$ and a regulated market by a further $3.7 \%$. Power plants with SCR technology make better use of capacity because of higher efficiency. The cleaner control technologies provide an opportunity for power plants to generate more electricity while being

${ }^{18}$ The SPPS Statistics version 22 is used for the regression analysis. 
constrained by emission regulations. The regulated market also encourages power plants to use a higher percentage of their generation capacity. This is because in the regulated market, the profit of power plants is less sensitive to fluctuation in electricity price and power plants generate based on pre-determined rates of return. A lower use of capacity by power plants in the regulated market indicates that the output adjustment behavior differs by market structure and supports our assumption presuming different opportunity costs for power plants in the two types of electricity markets. Note that the regression results presented in Table 8.4 are based on seasonal output adjustment and indicate different seasonal output adjustment behaviors. However, they do not indicate that power plants reduce their output on days when electricity price is high. We did not perform a regression analysis based on daily output adjustment due to lack of daily electricity price data in the regions studied.

To evaluate the accuracy of the estimated unit-level MACs, they are compared with the actual compliance data. Sellers are expected to have a MAC lower than the quota price. On the other hand, the number of quotas that quota sellers hold at the beginning of a trading timeline are expected to be higher than the number of quotas that they hold at the end of trading timeline. The number of quotas at the beginning of the timeline is allocated quotas plus those carried from the previous year, and the required quotas for a unit at the end of the timeline is equal to its aggregate ozone season emissions. According to the compliance data from the EPA, 153 units out of $218(70 \%)$ are quota sellers. Overall, for 154 units (71\%), the compliance data and predicted MACs are in agreement. The MAC is compared with the traded quotas 
(allocated quotas plus quotas carried from last year minus actual emissions) in Figure 8.4 .

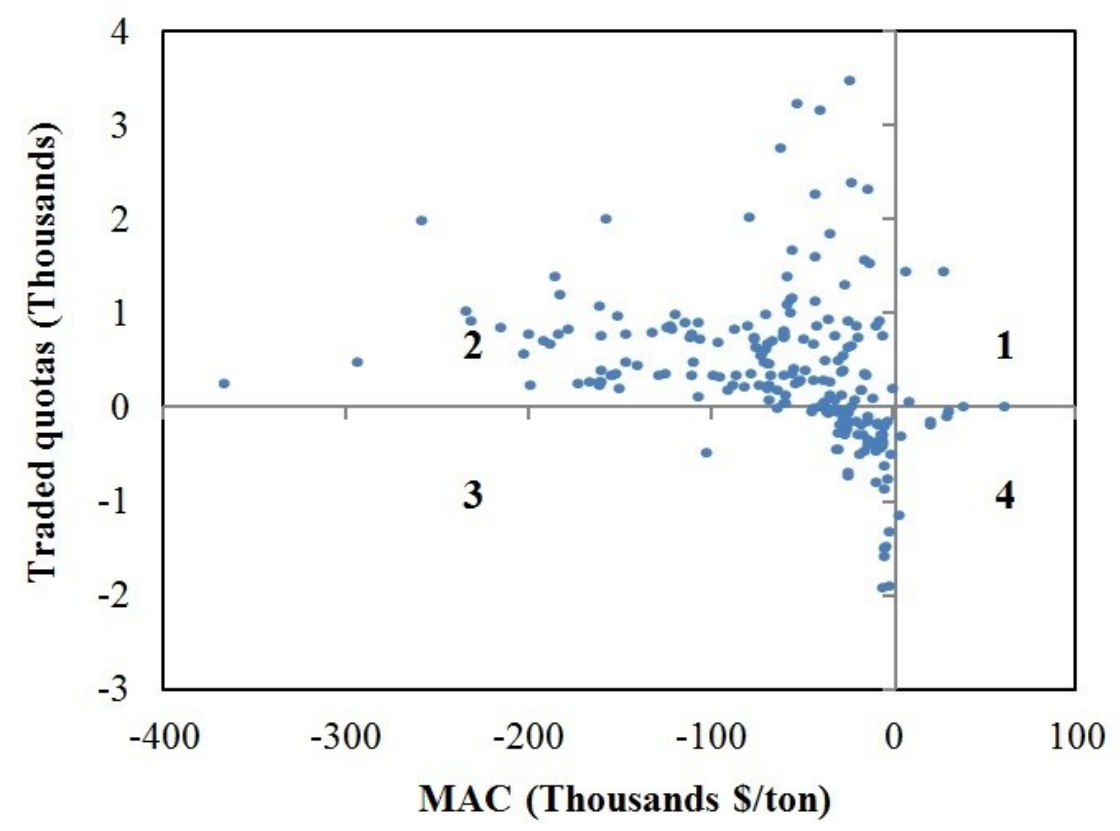

Figure 8.4. Comparison of the units' behavior (seller/buyer) based on the estimated MACs and actual compliance data. A positive number of traded quotas indicates the number of quotas sold. Note that the vertical axis intersects with the horizontal axis where MAC is equal to quota price (i.e., $\$ 825 /$ ton).

The vertical axis in Figure 8.4 represents the number of traded quotas based on compliance data in 2007 . The positive values on the vertical axis represent units that had more quotas than their actual emissions (quota seller), and the negative values are quota buyers. Correspondingly, the points on the right hand side of the vertical axis suggests that units are quota buyers because their MACs are more than the quota price, while the points on the left side of the vertical axis are units with a MAC smaller than the quota price (likely quota buyers). Region 2 (68\% of points) and 4 ( $2 \%$ of points) are areas where estimated MAC predicts the units' behavior (seller/buyer) correctly and region 1 (3\% of points) and 3 (27\% of points) are the area 
where estimated MAC does not match actual trading behavior. An ordinary least square fit for the presented data in Figure 8.4 leads to a p-value of $1.83 \times 10^{-5} \mathrm{R}^{2}$, which indicates that the estimated MACs are good predictors of the trading behaviors.

The discrepancy in trading behavior in Figure 8.4 can be attributed to a number of reasons. The assumption that units would operate at their maximum benefit level may not be completely accurate especially when the plant is unsure about the future year's market conditions and regulations. The possibility to bank quotas into the future years is an incentive for potential sellers to operate at an unfavorable shadow price in anticipation that the quota price would increase in the future. This motivation caused the accumulations of unused quotas under NBP. The U.S. EPA used the progressive flow control provisions to resolve this issue that existed under NBP.

More importantly, the initial quota allocation method is a major source of discrepancy. The allocation of the allowances based on plants' historic output levels is a strong incentive for plants to maintain outputs to secure more allowances for future years. This incentive can affect plant's behavior in the market, and can prevent potential quota sellers from selling their quotas. Important future research extension is to predict a plant's behavior in a multi-year time frame using a dynamic optimization model which accounts for the effect of future year quota allocation on the plant's current behavior.

Besides banking and grandfathering quotas, internal quota transaction is another possible reason for potential sellers to deviate from the predicted behavior. A 
power plant is responsible for all of its units' compliance and emissions. For example, if one unit of the plant has a high MAC and another unit has a low MAC, the plant can use the quotas from one unit to cover the emissions from the other, and that causes discrepancy in the estimated unit-level behavior. To explore this discrepancy, the Cross Power Plant located in South Carolina is examined in more detail. The plant has three units and its behavior from compliance is not correctly predicted by the estimated MAC. From MAC estimation, all 3 units are quota sellers, whereas from compliance data one of the units (unit 3) is not a quota seller. Units 1 and 2 have a high number of allocated quotas, whereas unit 3 has a low number of quotas (Table 8.5). The reason of low allocation for unit 3 is that the unit was shut down in 2006 (EPA clean air market) and as quotas are grandfathered based on the output level from two previous years, unit 3 received a low number of quotas.

Table 8.5. Compliance data for Cross Power Plant in the ozone season of 2007 (Clean air market U.S. EPA).

\begin{tabular}{llllll}
\hline & Unit 1 & Unit 2 & Unit 3 & Overdraft & Total \\
\hline Allocated & 1433 & 1450 & 120 & 0 & 3003 \\
Quotas held at deadline & 943 & 970 & 120 & 487 & 2520 \\
Emissions (ton) & 943 & 970 & 597 & & 2510 \\
Total deduction & 943 & 970 & 120 & 477 & 2510 \\
Carried over to next year & 0 & 0 & 0 & 10 & 10 \\
\hline
\end{tabular}

Low quota allocation to unit 3 created a high demand for this unit to buy quotas. On the other hand, unit 1 and 2 had excess quotas because they received significantly higher number of quotas. The plant sold 483 quotas $(3003-2520)$ of the 
spare quotas from unit 1 and 2, used 477 quotas to cover part of emissions form unit 3 (internal transfer of quotas), and saved 10 quotas for next year.

As discussed above, MAC is not the only factor affecting the number of emission quotas traded. To construct a supply and demand function for emission quotas, we perform a multivariable linear regression, which estimates the traded quotas as a function of different parameters including the number of allowances transferred from last year, capacity, control technology, electricity market structure, and MAC. A summary of the regression variables, the estimated coefficients, and relevant statistics are listed in Table 8.6.

Table 8.6. Regression statistics and estimated regression variables. ${ }^{\text {a }}$

\begin{tabular}{lclll}
\hline Variable & Coefficient & Std. error & t stat & Significance \\
\hline Intercept & -361.0 & 86.94 & -4.15 & 0.000 \\
Allowance form last year & 0.934 & 0.044 & 21.36 & 0.000 \\
Capacity (MW) & -0.757 & 0.372 & -2.04 & 0.043 \\
Capacity squared $\left(\mathrm{MW}^{2}\right)$ & 0.002 & 0.000 & 4.91 & 0.000 \\
Technology (SCR=1, SNCR=0) & 543.0 & 92.60 & 5.86 & 0.000 \\
Type of market (Reg.=1, Res.=0) & 148.5 & 69.29 & -2.14 & 0.033 \\
MAC (\$/ton) & -0.002 & 0.001 & -2.71 & 0.007 \\
\hline
\end{tabular}

${ }^{\mathrm{a}}$ The dependent variable is traded quotas and the $\mathrm{R}$ square for this regression is 0.786 .

All parameters reported in Table 8.6 significantly impact the emission trading behavior and all have the expected signs. MAC is negatively related to the number of 
quotas sold. We included the a second-order term (capacity squared) in our regression to account for the scale effect. A coefficient of -0.757 for the capacity and 0.002 for the capacity squared represent a convex function with negative starting value which turns to a positive effect at a capacity of $378.5 \mathrm{MW}$. This indicates that smaller power plants are more likely to buy emission quotas, whereas larger plants are more likely to sell emission quotas. Larger plants also can generate more electricity, which results in more allocated emission quotas for the next compliance year. Due to the multicolinearity between capacity and allocated quotas, we only included capacity in our regression analysis.

We also included two dummy variables in our regression analysis to distinguish between SCR and SNCR control technologies, and between regulated and restructured electricity markets. The positive coefficient for the control technology indicates that units with SCR sell more quotas. Units with SCR have lower emissionoutput rates and can generate more electricity (and obtain more emission quotas) than units with SNCR if they face the same emission caps, and therefore these units are more likely to sell their unused quotas.

The positive coefficient for the market structure suggests that power plants in the regulated market are more likely to sell quotas. This short-term behavior of power plants is consistent with their long-term behavior in the regulated market where plants have more incentive to invest in SCR (Fowlie 2010). In other words, power plants in the regulated market are more willing to invest in SCR rather than buying quotas to comply with the requirements on their emissions. In the restructured market, on the 
other hand, power plants are more likely to buy quotas when opportunity costs are high and reduce output when opportunity costs are low, rather than investing in SCR to comply with their emission requirements. Power plants in the regulated market do not need to adjust their generation according to market conditions since they can factor emission costs in their average cost price or rate of return regulation.

\subsection{Conclusions}

Unit-level MACs are key decision making factors for power plants as they can help them operate at optimal emissions/output levels. Emissions abatement can occur by output reduction, abatement activities, or purchasing emission quotas. The study of U.S. coal-fired power plants with SCR or SNCR post-combustion technologies shows that the MAC for $\mathrm{NO}_{\mathrm{x}}$ quotas vary significantly from one region to another because of differences in the structure of the electricity market, power plant's emission-output rates, their control technologies and the capacity for electricity generation.

Our results suggest that power plants' short-term output adjustment behavior is affected by control technology and the type of electricity market. The control technology is a significant factor with a large impact on capacity use while the market structure has significant but smaller impact. Power plants with more efficient control technologies have lower emissions and will use their electricity generation capacity more. Furthermore, units in the regulated electricity market are more likely to sell quotas in the short-term. Units in the restructured market show a different behavior; they are not as willing to invest in the more expensive SCR technology, but instead buy more quotas in order to comply with emission requirements. Our results also 
indicate that the strategic behavior of a plant is significantly dependent on a number of factors including MAC, capacity, structure of the electricity market, control technology, and the number of quotas allocated or transferred from previous year.

Quota allocation under current regulations is based on historic output levels. When units install a high efficiency control technology, they can have lower emissions with the same level of output and quotas. The motivation for plants to switch to higher efficiency control technologies to gain spare quotas for trading in the market is more pronounced in the regulated markets where power plants have a regulated rate of return on their investments.

Unit-level MACs can be used by regulators for the prediction of plant's responses to different regulations. The prediction of short-term behavior of power plants can provide some insights into where emission reductions occur, and how the total target emission reductions are distributed spatially. This prediction is particularly important for $\mathrm{NO}_{\mathrm{x}}$ emissions because the location where they are emitted matters in their contribution to the formation of surface ozone (a secondary pollutants that forms most of smog) and corresponding health damage (Pappin and Hakami 2013). Future research can compare the location specific marginal damage of $\mathrm{NO}_{\mathrm{x}}$ emissions from power plants and their MACs, and investigate whether the current sets of regulatory incentives, created by electricity and emissions markets, are in favor of health damage minimization. Under a social cost minimization policy, power plants with higher marginal damages emit less as compared to low-marginal damage power plants. For example, power plants located in the East coast of the U.S. have relatively higher 
marginal damages (Mesbah et al. 2013; Muller 2011) as compared to other regions. Most of these power plants are in the restructured electricity market which is not likely to provide a high incentive for emission reductions.

Knowledge of the unit-level responses can provide information on how emissions distribution changes spatially in a system as a result of a new policy, and where the priorities for innovation and investment into cleaner technologies are. The effect of system-wide emissions redistribution on ambient air quality and human health can be quantified using air quality models. This, in turn, would help decision makers to predict both the impact of different policies and various emissions trading scenarios on human health and the reaction of firms to different quota allocation frameworks. 


\section{CHAPTER 9:}

\section{CONCLUSIONS AND FUTURE WORK}

Cap-and-trade programs have proven to be effective instruments for achieving environmental goals while incurring minimum costs. The nature of the pollutant, however, affects the design of these programs. $\mathrm{NO}_{\mathrm{x}}$, an ozone precursor, is a nonuniformly mixed pollutant with a short atmospheric lifetime. $\mathrm{NO}_{\mathrm{x}}$ cap-and-trade programs in the U.S. are successful in reducing total $\mathrm{NO}_{\mathrm{x}}$ emissions but may result in sub-optimal environmental performance because location-specific ozone formation potentials are neglected. Addressing this shortcoming was the main motivation for this thesis. To do so, a model-based decision support system was developed combining economic instruments with an advanced engineering modeling tool. The model was used to evaluate the costs and benefits of different $\mathrm{NO}_{\mathrm{x}}$ emission control policies distinguishing emissions based on their temporal and spatial differences.

The current U.S. program for $\mathrm{NO}_{\mathrm{x}}$ control is a cap-and-trade system which assigns tradable emission quotas to participants, and controls the total emissions by the number of quotas allocated to participants. A reformed cap-and-trade system can distinguish between emissions by assigning different values to emission quotas at different times and locations. This discrimination between emission quotas assigns higher values for quotas in locations with high ozone formation potential and therefore provides emission reduction motivations for units with higher damages. The results in chapter 4 indicated that better environmental performance at negligibly 
higher system-wide abatement costs can be achieved through inclusion of emission exchange rates. Exposure-based exchange rates resulted in better environmental performance than those based on concentrations.

Another approach for distinguishing between emissions is to assign location specific emission fees for polluters. Assigning the fee based on the damage per ton of $\mathrm{NO}_{\mathrm{x}}$ results in targeted emission reduction for locations where emissions are more harmful. In chapter 5, we showed that inclusion of location-specific damage information in policy design could significantly enhance public health performance of the current cap-and-trade system. The results presented in this chapter also indicated that the net benefit under the policy that minimizes the social cost (i.e. health costs plus abatement costs) was six times larger than that of an exchange rate cap-and-trade policy. This difference shows the importance of utilizing damage information in allocation of emission quotas under an exchange rate system.

The emission differentiated policies considered in chapters 4 and 5 were designed to shift emissions from high impact to low impact locations without accounting for electricity supply in the system. However, power plant emission adjustment is also a factor of electricity demand. Re-dispatching or shifting electricity generations to high efficiently units (i.e., units with low generations to emissions ratio) is an efficient method of emission reduction while the demand in the system is supplied. Re-dispatching occurs in the system when a high price for $\mathrm{NO}_{\mathrm{x}}$ emission quotas is set which provides high incentives for electricity generation by low emission rate units, and in turn results in lower emissions and correspondingly lower health 
damage in the system. Lower emissions; however, do not ensure that reductions occur at high MD locations and times. Therefore, charging polluters fees based on their temporal (as well as spatial) MD information results in further reduction in systemwide health damage. In chapter 6 , we investigated the impact of inclusion of temporal and spatial marginal damages in emission and electricity markets. The results from a case study of U.S. power plants indicated that time-specific MDs were high around noon and low in the evening in all locations. Furthermore, a substantial emission reduction and net benefits could be gained if high-efficiency power plants in lowdamage hours/locations supplied a greater portion of the electricity. The results also indicated that inclusion of temporal effects in $\mathrm{NO}_{\mathrm{x}}$ control policies results in a comparable net benefit as compared to policies which included only spatial or spatiotemporal effects. This is an important finding as strategies and trading markets that are based on temporally differentiated MDs are far less complicated than instruments that rely on spatial differentiation.

The MD information can also be used to set optimal emission levels. However, the specific shape of the MD curve affects the optimal emission level. The results presented in chapter 7 indicated that MDs in all locations are higher for lower baseline emissions, which means source-specific $\mathrm{NO}_{\mathrm{x}} \mathrm{MD}$ curves are negatively sloped. This finding was in contrast with the traditional concept in environmental economics, which assumes a positive slope for source-specific MD curves. This unconventional behavior of $\mathrm{NO}_{\mathrm{x}} \mathrm{MD}$ curves was due to the atmospheric photochemical reactions of $\mathrm{NO}_{\mathrm{x}}$ and ozone. This finding is important from a policy 
perspective as using a negatively sloped MD curve instead of a positively sloped curve results in a lower emission reduction targets.

Power plants participating in cap-and-trade programs are faced with requirements from both emission and electricity markets. The type of electricity market plays an important role in power plants' behavior and how they adjust their emission level and trade emission quotas. In a regulated electricity market, power plants sell electricity based on a pre-determined rated of returns, whereas such rates do not exist under a restructured electricity market. In chapter 8 , we investigated the short-term $\mathrm{NO}_{\mathrm{x}}$ emission behavior in the regulated and restructured electricity market and found that power plants in the restructured electricity market are willing to pay more for emission quotas. These behaviors were due to differences in the opportunity cost of output reduction.

All emission differentiation policies presented in this thesis are dependent on the accurate calculation of source-specific impacts or marginal damages and the accuracy of the adjoint model. For a normal air quality model, the performance evaluation can be done through comparison of concentrations calculated by the model and observation data. For an adjont model; however, there is no observation to be compared with because the outputs are derivatives. This shortcoming is a general limitation of sensitivity methods. The adjoint model used in this thesis has been validated extensively against the forward model (Hakami et al., 2007). As is often the case with sensitivity studies, consistency with the underlying model (i.e. forward 
CMAQ) is the main form of validation but the uncertainties and limitations existing in CMAQ remain unaddressed in the adjoint of CMAQ as well. MDs calculated by the adjoint model in this thesis were used within an optimization framework to reduce the system-wide damage. The fact that the examined policies resulted in a significantly lower damage is an indicator of the consistency of the adjoint and forward models. However, these findings are only as reliable as the forward model.

It is also worth mentioning that the modeling domain in this study was a North American domain with a $36 \mathrm{~km}$ grid resolution. This coarse resolution may overestimate some potential health damages (Thompson and Sin 2012) but it was chosen due to the computational limitations for continental simulations. While grid resolution can affect the results presented in the thesis, a larger domain and inclusion of other continents is likely to have little impact on the estimated MDs because $\mathrm{NO}_{\mathrm{x}}$ has a very short life-time in the atmosphere and cannot travel on a continental scale.

Furthermore, we did not account for uncertainties associated with economic valuation, epidemiological concentration response factors, baseline mortality rates, or source-receptor relationships, all of which affect the estimated MDs and the subsequent outcomes under different economic instruments. Incorporating uncertainty in MDs within economic instruments is of interest of policymakers from several perspectives. Firstly, the uncertainty involved with source-receptor relationships, caused by large uncertainty in emissions and meteorology, affects the relative magnitude of source-specific MDs, which are important for performance 
enhancement under exchange rate policies. Moreover, using the probability distribution function of source-specific MDs, policymakers can determine the likelihood of MDs being greater than the MACs, which is essential for sizeable net benefits under taxation policies. In other words, policymakers would be aware of the magnitude of net benefits as well as the likelihood of achieving such benefits. Lastly, information on uncertainty in MDs can be used by policymakers to set the optimal emission level with a reasonable level of confidence. Failure to identify and set the optimal level accurately may result in a substantial loss in system-wide costs.

It should be noted that the $\mathrm{NO}_{\mathrm{x}}$ damage function in our study was based on ozone exposure in the U.S. only (Canada and Mexico not included). Additionally, mortality due to exposure to $\mathrm{NO}_{2}$ was not included in our damages function as in the U.S., there is not enough evidence to link exposure to $\mathrm{NO}_{2}$ with mortality. Inclusion of $\mathrm{NO}_{2}$-based damages for calculation of MDs results in larger $\mathrm{NO}_{\mathrm{x}}$ MDs and subsequently larger benefits obtained under differentiated policies. Inclusion of $\mathrm{NO}_{2}$ based MDs is particularly important in large cities where ozone-based $\mathrm{NO}_{\mathrm{x}}$ MDs are initially negative and emissions reduction is not beneficial. Accounting for $\mathrm{NO}_{2}$-based damages results in an upward shift in the MD curve, indicating that emissions reduction will be beneficial earlier than expected when only ozone-based damages are included. This, in turn, further supports policies in favor of emissions reduction in large cities. 
It should be noted that all results presented in this thesis are proof-of-concept and are not recommended for direct policy applications. There are several limitations in the proposed decision support system. Firstly, the calculated MDs were the integration of temporal and spatial MDs over one summer season. Modeling of longer time intervals is required to investigate how MDs vary from one year to another. Secondly, the modeling grid cells were large due to computational limitations, and sometimes included more than one power plant. Thirdly, various uncertainties are associated with the calculation of MDs, which we did not account for. Furthermore, the calculated MDs were only short-term ozone-based mortality damages; long-term effects, morbidity, and PM related damages were not included, and the analysis only covered short-term behaviors. Also, modeling electricity markets and emissions as discussed in chapter 6, did not include different types of electricity markets. Lastly, the case study presented in this thesis considered only a portion (albeit sizable portion) of the emission market; including all participants is an area of future research development. The following research topics are suggested for further investigation.

\section{- Uncertainty in exchange rates}

One of the main concerns about the implementation of location differentiated control policies is the uncertainty associated with calculation of exchange rates. Prediction of the exchange rates with a known degree of confidence can help the decision makers to set exchange rates with a safety factor to decrease the impact of uncertain estimation of exchange rates and prevent potential litigation. Using a Monte 
Carlo simulation, the proposed DSS can be propagate the uncertainties from inputs to the estimated MDs in an effort to account for uncertainty in exchange rates.

\section{- Long-term cap-and-trade with exchange rate}

Our current work did not consider the long-term market behavior. Future work can potentially extend to prediction of the long-term behavior of firms in the market. The capital cost of different control technologies and the effect of future year permit allocation on the current year should be considered for the estimation of the long-term marginal abatement cost curves. Then, using the estimated long-term costs, firms can decide whether they should install a new control technology, or keep their old technology. The behavior of firms in the emission market can be predicted using the long-term marginal abatement cost curves and an optimization model.

- Multi-objective (ozone and particulate matter) $\mathrm{NO}_{\mathrm{x}}$ cap-and-trade system

In the current work, $\mathrm{NO}_{\mathrm{x}}$ emission trading was examined based on ozone formation potential of emitters. $\mathrm{NO}_{\mathrm{x}}$ also contributes to the formation of $\mathrm{PM}$ particularly in certain regions in the U.S. and Canada and also at times other then the ozone season. The adjoint of CMAQ for PM is under development and can be used for development and examination of multi-objective exchange rate or social cost minimization systems. 


\section{- Hypothetical Canada- U.S. emission cap-and-trade}

Given that there is significant cross-border pollutant transport between Canada and the U.S., especially for the states and provinces located near the border, there is a logical argument to be made for coordinated regulatory mechanisms that can benefit both countries in a cost-effective fashion. This is particularly true as regulations and approaches in Canada tend to be made in coordination with the U.S.

\section{- Real-time decision support system}

The proposed decision support system aimed to enable decision makers to compare the environmental performance of different $\mathrm{NO}_{\mathrm{x}}$ control policies. Our approach did not aim to provide real-time decision support information. However, the proposed framework can be extended to a real-time decision support system under which an adjoint model combined with an air quality forecasting model predict the next-day source-specific marginal damages. Such information then can be used for setting the short-term exchange rates or emission fees. 


\section{REFERENCES}

Abt Associates, I. (2009). Environmental benefits mapping and analysis program (Version 3.0). NC.

Alberini, A., and Filippini, M. (2011). "Response of residential electricity demand to price: The effect of measurement error." Energy Economics, 33(5), 889-895.

Alhajeri, N. S., Donohoo, P., Stillwell, A. S., King, C. W., Webster, M. D., Webber, M. E., and Allen, D. T. (2011). "Using market-based dispatching with environmental price signals to reduce emissions and water use at power plants in the Texas grid." Environmental Research Letters, 6(4), 044018.

Anderson, S., and Francois, P. (1997). "Environmental cleanliness as a public good: welfare and policy implications of nonconvex preferences." Journal of Environmental Economics and Management, 34(3), 256-274.

Anenberg, S. C., Horowitz, L. W., Tong, D. Q., and West, J. J. (2010). “An estimate of the global burden of anthropogenic ozone and fine particulate matter on premature human mortality using atmospheric modeling." Environmental Health Perspectives, 118(9), 1189-95.

Atkinson, S. E., and Tietenberg, T. H. (1984). "Approaches for reaching ambient standards in non-attainment areas: financial burden and efficiency considerations." Land Economics, 60(2), 148-159.

Banzhaf, H. S. (2004). "Efficient emission fees in the US electricity sector." Resource and Energy Economics, 26(3), 317-341.

Becker, R. a. (2005). "Air pollution abatement costs under the Clean Air Act: evidence from the PACE survey." Journal of Environmental Economics and Management, 50(1), 144-169.

Bell, M. L., Mcdermott, A., Zeger, S. L., and Samet, J. M. (2004). "Ozone and shortterm mortality in 95 US urban communities, 1987-2000." Journal of the American Medical Association, 292(19), 2372-2378.

Binkowski, F. S., Arunachalam, S., Adelman, Z., and Pinto, J. P. (2007). "Examining photolysis rates with a prototype online photolysis module in CMAQ." Journal of Applied Meteorology and Climatology, 46(8), 1252-1256. 
Bridges, P., Doss, N., Gropp, W., Karrels, E., Lusk, E., and Skjellum, A. (1995). Users' Guide to mpich, a portable implementation of MPI. Argonne National Laboratory, Lemont, IL.

Buhyoff, G., and Leuschner, W. (1978). "Estimating psychological disutility from damaged forest stands." Forest Science, 24(3), 424-432.

Burtraw, D., Palmer, K., Paul, A., Bharvirkar, R., and Paper, A. P. (2001). Costeffective reduction of NOx emissions from electricity generation. Resources for the Future, Washington, DC.

Burtraw, D., Evans, D. A., Krupnick, A. J., Palmer, K., and Toth, R. (2005). Economics of pollution trading for $\mathrm{SO} 2$ and NOx. Resources for the Future, Washington, DC.

Burtraw, D., and Szambelan, S. J. (2009). "US emissions trading markets for SO2 and NOx." Resources for the Future Discussion Paper, Resources for the Future, Washington, DC.

Byrd, R., and Gilbert, J. (2000). "A trust region method based on interior point techniques for nonlinear programming." Mathematical Programming, 89(1), $149-185$.

Byrd, R. H., Nocedal, J., and Waltz, R. A. (2006). "KNITRO: an integrated package for nonlinear optimization." Large-scale Nonlinear Optimization, 83, 35-39.

Byun, D., and Schere, K. L. (2006). "Review of the governing equations, computational algorithms, and other components of the Models-3 Community Multiscale Air Quality (CMAQ) modeling system." Applied Mechanics Reviews, 59(2), 51-77.

Carter, W. (2000). Documentation of the saprc-99 chemical mechanism for VOC reactivity assessment volume 1 of 2. Final Report to California Air Resources Board. Center for Environmental Research and Technology University of California, Riverside, CA.

CEP. (2007). Sparse matrix operator kernel emissions modeling system (SMOKE) v2.4 User 's manual. Carolina Environmental Program, Chapel hill, NC.

Cho, S., Morris, R., McEachern, P., Shah, T., Johnson, J., and Nopmongcol, U. (2012). "Emission sources sensitivity study for ground-level ozone and PM2.5 due to oil sands development using air quality modelling system: Part II - Source apportionment modelling." Atmospheric Environment, 55, 542-556. 
Cohan, D. S., Hakami, A., Hu, Y., and Russell, A. G. (2005). "Nonlinear response of ozone to emissions: Source apportionment and sensitivity analysis." Environmental Science \& Technology, 39(17), 6739-6748.

Colella, P., and Woodward, P. R. (1984). "The piecewise parabolic method (PPM) for gas-dynamical simulations." Journal of Computational Physics, 54(1), 174-201.

Crocker, T. D., and Forster, B. a. (1981). "Decision problems in the control of acid precipitation: Nonconvexities and irreversibilities." Journal of the Air Pollution Control Association, 31(1), 31-37.

Cropper, M., and Arriaga-Salinas, A. (1980). "Inter-city wage differentials and the value of air quality." Journal of Urban Economics, 254, 236-254.

Daescu, D., Carmichael, G. R., and Sandu, A. (2000). "Adjoint implementation of Rosenbrock methods applied to variational data assimilation problems." Journal of Computational Physics, 165(2), 496-510.

Damian, V., Sandu, A., Damian, M., Potra, F., and Carmichael, G. R. (2002). "The kinetic preprocessor KPP-a software environment for solving chemical kinetics." Computers \& Chemical Engineering, 26(11), 1567-1579.

Duncan, B. N., Yoshida, Y., Olson, J. R., Sillman, S., Martin, R. V., Lamsal, L., Hu, Y., Pickering, K. E., Retscher, C., Allen, D. J., and Crawford, J. H. (2010). "Application of OMI observations to a space-based indicator of NOx and VOC controls on surface ozone formation." Atmospheric Environment, 44(18), 22132223.

Dunker, A. M. (1981). "Efficient calculation of sensitivity coefficients for complex atmospheric models." Atmospheric Environment, 15(7), 1155-1161.

Dunker, A. M. (1984). "The decoupled direct method for calculating sensitivity coefficients in chemical kinetics." The Journal of Chemical Physics, 81(5), 2385.

Dunker, A. M., Yarwood, G., Ortmann, J. P., and Wilson, G. M. (2002). "Comparison of source apportionment and source sensitivity of ozone in a three-dimensional air quality model." Environmental Science \& Technology, 36(13), 2953-2964.

EIA. (n.d.). Electrictricity data browser, average retail price of electricity. US energy information administration, available online at $<$ http://www.eia.gov/electricity/data/browser>.

EIA. (2008). Annual coal report, DOE/EIA-0584. US Energy Information Administration, Office of Coal, Nuclear, Electric, and Alternate Fuels, Washington, DC. 
EIA. (2010). Annual energy outlook 2010 with projections to 2035. DOE/EIA-0383, US Energy Information Administration, Office of Integrated Analysis and Forcasting, Washington, DC.

Elbern, H., Schmidt, H., and Ebel, A. (1997). "Variational data assimilation for tropospheric chemistry modeling." Journal of Geophysical Research, 102(D13), $15967-15985$.

Elbern, H., Schmidt, H., Talagrand, O., and Ebel, a. (2000). "4D-variational data assimilation with an adjoint air quality model for emission analysis." Environmental Modelling \& Software, 15(6-7), 539-548.

EPA. (n.d.). "Clean air market, data and maps. US Environmental Protection Agancey, Office of Air and Radiation, available online at $<$ http://www.epa.gov/airmarkets/>."

EPA. (1991). Guideline for regulatory application of the urban airshed model. EPA, EPA-450/4-91-013, Research Triangle Park, NC.

EPA. (1998). Regulatory impact analysis for the NBP. EPA, Office of Air and Radiation, Washington DC.

EPA. (1999a). Nitrogen oxides (NOx) why and how they are controlled. EPA-456/F99-006R, Research Triangle Park, NC.

EPA. (1999b). The benefits and costs of the Clean Air Act, 1990 to 2010: EPA report to Congress.

EPA. (2003). Ozone transport commission NOx budget program 1999-2002 progress report. EPA-430-R-03-900, Office of Air and Radiation, Washington, DC.

EPA. (2007). Acid rain and related programs 2006. EPA-430-R-07-011,Office of Air and Radiation, Washington, DC.

EPA. (2008). NOx budget trading program: compliance and environmental results. EPA-430-R-08-008, US Environmental Protection Agency, Office of Air and Radiation, Washington, DC.

EPA. (2010a). Integrated planning model, chapter 5: emission control technologies. US Environmental Protection Agency, Office of Air and Radiation, Washington, DC.

EPA. (2010b). Guidelines for preparing economic analyses. EPA 240-R-10-001, National Center for Environmental Economics, Office of Policy, Washington, DC. 
EPA. (2013). Clean air interstate rule, acid rain program, and former NOx budget trading program, 2012 progress report. US Environmental Protection Agency, Office of Air and Radiation, Washington, DC.

Errico, R. (1997). "What is an adjoint model?" Bulletin of the American Meteorological Society, 78(11), 2577-2591.

European Commission. (1995). ExternE: External Costs of Energy, Vol. 4: Oil and Gas.

Fann, N., Fulcher, C. M., and Hubbell, B. J. (2009). "The influence of location, source, and emission type in estimates of the human health benefits of reducing a ton of air pollution." Air Quality, Atmosphere, \& Health, 2(3), 169-176.

Fann, N., Lamson, A. D., Anenberg, S. C., Wesson, K., Risley, D., and Hubbell, B. J. (2012). "Estimating the national public health burden associated with exposure to ambient PM2.5 and ozone." Risk Analysis, 32(1), 81-95.

Färe, R., Grosskopf, S., Lovell, C. A. K., and Yaisawarng, S. (1993). "Derivation of shadow prices for undesirable outputs: a distance function approach." The review of Economics and Statistics, 75(2), 374-380.

Farrell, A., Carter, R., and Raufer, R. (1999). "The NOx Budget: market-based control of tropospheric ozone in the northeastern United States." Resource and Energy Economics, 21, 102-124.

Farrow, R. S., Schultz, M. T., Celikkol, P., and Houtven, G. L. Van. (2005). "Pollution trading in water quality limited areas : use of benefits assessment and cost-effective trading ratios." Land Economics, 81(2), 191-205.

Fiore, a. M., Dentener, F. J., Wild, O., Cuvelier, C., Schultz, M. G., Hess, P., Textor, C., Schulz, M., Doherty, R. M., Horowitz, L. W., MacKenzie, I. a., Sanderson, M. G., Shindell, D. T., Stevenson, D. S., Szopa, S., Van Dingenen, R., Zeng, G., Atherton, C., Bergmann, D., Bey, I., Carmichael, G., Collins, W. J., Duncan, B. N., Faluvegi, G., Folberth, G., Gauss, M., Gong, S., Hauglustaine, D., Holloway, T., Isaksen, I. S. a., Jacob, D. J., Jonson, J. E., Kaminski, J. W., Keating, T. J., Lupu, a., Marmer, E., Montanaro, V., Park, R. J., Pitari, G., Pringle, K. J., Pyle, J. a., Schroeder, S., Vivanco, M. G., Wind, P., Wojcik, G., Wu, S., and Zuber, a. (2009). "Multimodel estimates of intercontinental source-receptor relationships for ozone pollution." Journal of Geophysical Research, 114(D4), 1-21.

Fisher, M., and Lary, D. (1995). "Lagrangian four-dimensional variational data assimilation of chemical species." Quarterly Journal of the Royal Meteorological Society, 121, 1681-1704. 
Førsund, F., and Nævdal, E. (1998). "Efficiency gains under exchange-rate emission trading." Environmental and Resource Economics, 12(4), 403-423.

Fowlie, M. (2010). "Emissions trading, electricity restructuring, and investment in pollution abatement." The American Economic Review, 100(3), 837-869.

Fraas, A., and Lutter, R. (2011). "Do some NOx emissions have negative environmental damages? evidence and implications for policy." Environmental Science \& Technology, 45, 7613-7614.

Goodstein, E. S. (1995). Economics and the environment. Prentic-Hall, Inc., Englewood Cliffs, New Jersy, 575.

Hakami, A., Odman, M. T., and Russell, A. G. (2003). "High-order, direct sensitivity analysis of multidimensional air quality models." Environmental Science \& Technology, 37(11), 2442-2452.

Hakami, A., Bergin, M. S., and Russell, A. G. (2004). "Ozone formation potential of organic compounds in the eastern United States: a comparison of episodes, inventories, and domains." Environmental Science \& Technology, 38(24), 67486759 .

Hakami, A., Odman, M. T., and Russell, A. G. (2004). "Nonlinearity in atmospheric response: A direct sensitivity analysis approach." Journal of Geophysical Research, 109(D15303), 1-12.

Hakami, A., Seinfeld, J. H., Chai, T., Tang, Y., Carmichael, G. R., and Sandu, A. (2006). "Adjoint sensitivity analysis of ozone nonattainment over the continental United States." Environmental Science \& Technology, 40(12), 3855-64.

Hakami, A., Henze, D. K., Seinfeld, J. H., Singh, K., Sandu, A., Kim, S., Byun, D., and Li, Q. (2007). "The adjoint of CMAQ." Environmental Science \& Technology, 41(22), 7807-17.

Hall, D. C., and Hall, J. V. (1997). "Estimating the benefits of emissions reductions in complex atmospheres." International Journal of Global Energy Issues, 9(4), 286-298.

Henze, D. K., Hakami, A., and Seinfeld, J. H. (2007). "Development of the adjoint of GEOS-Chem.” Atmospheric Chemistry \& Physics, 7, 2413-2433.

Hung, M. F., and Shaw, D. (2005). "A trading-ratio system for trading water pollution discharge permits." Journal of Environmental Economics and Management, 49, 83-102. 
Jacob, D. J., Logan, J. A., and Murti, P. P. (1999). "Effect of rising Asian emissions on surface ozone in the United States." Geophysical Research Letters, Citeseer, 26(14), 2175-2178.

Jerrett, M., Burnett, R. T., Pope, C. A., Ito, K., Thurston, G., Krewski, D., Shi, Y., Calle, E., and Thun, M. (2009). "Long-term ozone exposure and mortality." The New England Journal of Medicine, 360(11), 1085-1095.

Klaassen, G. A. J., Førsund, F. R., and Amann, M. (1994). "Emission trading in Europe with an exchange rate." Environmental and Resource Economics, 4(4), 305-330.

Kolstad, C. D., and Turnovsky, M. H. L. (1998). "Cost functions and nonlinear prices: estimating a technology with quality-differentiated inputs." Review of Economics and Statistics, 80(3), 444-453.

Krupnick, A. J., Oates, W. E., and Van De Verg, E. (1983). "On marketable airpollution permits: The case for a system of pollution offsets." Journal of Environmental Economics and Management, 10, 233-247.

Krupnick, A. J. (1986). "Costs of alternative policies for the control of nitrogen dioxide in Baltimore." Journal of Environmental Economics and Management, 13, 189-197.

Krupnick, A. J., Mcconnell, V., Cannon, M., Stoessell, T., and Batz, M. (2000). Costeffective NOx control in the eastern United States. Resources for the Future, Washington, DC.

Levy, J. I., Hammitt, J. K., Yanagisawa, Y., and Spengler, J. D. (1999). "Development of a new damage function model for power plants: methodology and applications." Environmental Science \& Technology, 33(24), 4364-4372.

Levy, J. I., Baxter, L. K., and Schwartz, J. (2009). "Uncertainty and variability in health-related damages from coal-fired power plants in the United States." Risk analysis, 29(7), 1000-14.

Luecken, D. J., Phillips, S., Sarwar, G., and Jang, C. (2008). "Effects of using the CB05 vs. SAPRC99 vs. CB4 chemical mechanism on model predictions: Ozone and gas-phase photochemical precursor concentrations." Atmospheric Environment, 42(23), 5805-5820.

Mallet, V., and Sportisse, B. (2005). "A comprehensive study of ozone sensitivity with respect to emissions over Europe with a chemistry-transport model." Journal of Geophysical Research, 110(D22), 1-15. 
Marchuk, G. I. (1974). Numerical methods in weather prediction. Academic Press, 227.

Martien, P. T., and Harley, R. a. (2006). "Adjoint sensitivity analysis for a threedimensional photochemical model: application to Southern California." Environmental Science \& Technology, 40(13), 4200-10.

Martin, K. C., Joskow, P. L., Ellerman, A. D., and others. (2007). Time and location differentiated NOx control in competitive electricity markets using cap-and-trade mechanisms. MIT Center for Energy and Environmental Policy Research, MI.

Martin, K. C. (2008). Implementing a time-and location-differentiated cap-and-trade program: flexible nitrogen oxide abatement from power plant in the eastern united states. PhD thesis, Department of Technology, Management, and Policy, Massachusetts Institute of Technology, MI.

Mauzerall, D., and Wang, X. (2001). "Protecting agricultural crops from the effects of tropospheric ozone exposure: reconciling science and standard setting in the United States, Europe, and Asia." Annual Review of Energy and the Environment, 26, 237-268.

Mauzerall, D., Sultan, B., Kim, N., and Bradford, D. (2005). "NOx emissions from large point sources: variability in ozone production, resulting health damages and economic costs." Atmospheric Environment, 39(16), 2851-2866.

McGartland, A. M., and Oates, W. E. (1985). "Marketable permits for the prevention of environmental deterioration." Environmental Economics and Management, 12, 207-228.

McKitrick, R. (1999). "A derivation of the marginal abatement cost curve." Journal of Environmental Economics and Management, 37(3), 306-314.

Menut, L. (2003). "Adjoint modeling for atmospheric pollution process sensitivity at regional scale." Journal of Geophysical Research, 108(D17), 1-17.

Mesbah, S., Hakami, A., and Schott, S. (2012). "Improving NOx cap-and-trade system with adjoint-based emission exchange rates." Environmental Science \& Technology, 46(21), 11905-12.

Mesbah, S. M., Hakami, A., and Schott, S. (2013). "Optimal ozone reduction policy design using adjoint-based NOx marginal damage information." Environmental Science \& Technology, 47(23), 13528-35.

Miller, B. G. (2011). Clean coal engineering technology. Butterworth-Heinemann, 696. 
Montgomery, W. D. (1972). "Market in licences and efficient pollution control program." Journal of Economic Theory, 5, 395-418.

Müller, J. F., Stavrakou, T., and others. (2005). "Inversion of CO and NO x emissions using the adjoint of the IMAGES model." Atmospheric Chemistry and Physics, 5(5), 1157-1186.

Muller, N. Z., and Mendelsohn, R. (2007). "Measuring the damages of air pollution in the United States." Journal of Environmental Economics and Management, 54, $1-14$.

Muller, N. Z., and Mendelsohn, R. (2009). "Efficient pollution regulation : getting the prices right." American Economic Review, 99(5), 1714-1739.

Muller, N. Z. (2011). "Linking policy to statistical uncertainty in air pollution damages." The BE Journal of Economic Analysis \& Policy Contributions, 11(1).

Muller, N. Z., Mendelsohn, R., and Nordhaus, W. (2011). "Environmental accounting for pollution in the United States economy." The American Economic Review, 101(August), 1649-1675.

NCEP. (2005). "National center for environmental predictions, GRIB data." $<$ http://www.nco.ncep.noaa.gov/pmb/docs/grib2/grib2_doc.shtml>.

Nester, K., Panitz, H. J., and others. (2005). "Sensitivity analysis by the adjoint chemistry transport model DRAIS for an episode in the Berlin ozone (BERLIOZ) experiment." Atmospheric Chemistry and Physics Discussions, 5(5), $8715-8754$.

Nobel, C. E., Mcdonald-buller, E. C., Kimura, Y., and Allen, D. T. (2001). "Policy analysis accounting for spatial variation of ozone productivity in NOx emission trading." Environmental Science \& Technology, 35(22), 4397-4407.

Pacsi, A. P., Alhajeri, N. S., Webster, M. D., Webber, M. E., and Allen, D. T. (2013). "Changing the spatial location of electricity generation to increase water availability in areas with drought: a feasibility study and quantification of air quality impacts in Texas." Environmental Research Letters, 8(3), 035029.

Pappin, A. J., and Hakami, A. (2013). "Source attribution of health benefits from air pollution abatement in Canada and the United States: an adjoint sensitivity analysis." Environmental Health Perspectives, 121(5), 572-9.

Pechan, E.H., and Associates, I. (1997). NOx, The emission reduction and cost analysis model for (ERCAM-NOx). EPA-68-D3-0035, Ozone Policy and Strategies Group, Research Triangle Park, NC. 
Perman, R., Ma, Y., Common, M., Maddison, D., and McGilvray, J. (2011). Natural Resource and Environmental Economics. Pearson Education Limited, Harlow, 712.

Quélo, D., Mallet, V., and Sportisse, B. (2005). "Inverse modeling of NOx emissions at regional scale over northern France: Preliminary investigation of the secondorder sensitivity." Journal of Geophysical Research, 110(D24), 1-18.

Randall, A., Ives, B., and Eastman, C. (1974). "Bidding games for valuation of aesthetic environmental improvements." Journal of Environmental Economics and Management, 1, 132-149.

Repetto, R. (1987). "The policy implications of non-convex environmental damages : a smog control case study." Journal of Environmental Economics and Management, 14, 13-29.

Ridge, O. (1994). Estimating fuel cycle externalities : analytical methods and issues. Washington, DC.

Rowe, R. D. ., Lang, C. M. ., Chestnut, L. G. ., Latimer, D. A. ., Rae, D. A. ., Bernow, S. M. ., and White, D. E. (1995). The New York electricity externality study volume I: introduction and methods. Empire State Electric Energy Research Corporation, New York.

Sandu, A., Daescu, D. N., Carmichael, G. R., and Chai, T. (2005). "Adjoint sensitivity analysis of regional air quality models." Journal of Computational Physics, 204(1), 222-252.

Schultze, W., and Brookshire, D. (1983). "Economic benefits of preserving visibility in the national parklands of the southwest." Natural Resources Journal, 23, 149173.

Seinfeld, J. H., and Pandis, S. N. (2006). Atmospheric chemistry and physics: from air pollution to climate change. John Wiley and Sons, New York, 1232.

Seskin, E. P., Anderson, R. J., Reid, R., Christofaro, A., Clark, T., Hoffman, J., Ingle, B., Luken, S., and Smith, W. (1983). "An empirical analysis of economic strategies for controlling air pollution." Journal of Environmental Economics and Management, 112-124.

Skamarock, W., Klemp, J., Dudhia, J., Gill, D. O., Barker, D. M., Wang, W., and Powers, J. G. (2005). A description of the advanced research WRF version 2. NCAR Tech Notes, NCAR/TN-468+STR; National Center for Atmospheric Research: Boulder, CO. 
Sloss, L. L., Hjalmassson, A. K., Hermine, N. S., Campbell, L. M., Stone, D. K., Shareef, G. S., Emmel, T., Maibodi, M., Livengood, C. D., and Markussen, J. (1992). Nitrogen oxides control technology fact book. Noyes Data Corporation, New Jersy, 635.

Starrett, D. (1972). "Fundamental nonconvexities in the theory of externalities." Journal of Economic Theory, 120(3), 253-290.

Sun, L., Webster, M., Mcgaughey, G., Mcdonald-buller, E. C., Thompson, T., Prinn, R., Ellerman, A. D., and Allen, D. T. (2012). "Flexible NOx abatement from power plants in the eastern United States." Environmental Science \& Technology, 46, 5607-5615.

Thompson, T. M., King, C. W., Allen, D. T., and Webber, M. E. (2011). "Air quality impacts of plug-in hybrid electric vehicles in Texas: evaluating three battery charging scenarios." Environmental Research Letters, 6(2), 024004.

Thompson, T. M., and Selin, N. E. (2012). "Influence of air quality model resolution on uncertainty associated with health impacts." Atmospheric Chemistry and Physics, 12(20), 9753-9762.

Tietenberg, T. H. (1985). Emission trading, an excersie in reforming pollution policy. Resources for the Future, Washington, DC.

Tietenberg, T. (1995). "Tradeable permits for pollution control when emission location matters: What have we learned?" Environmental and Resource Economics, 5, 95-113.

Tong, D. Q., and Mauzerall, D. L. (2006). "Spatial variability of summertime tropospheric ozone over the continental United States: Implications of an evaluation of the CMAQ model." Atmospheric Environment, 40(17), 3041-3056.

Tong, D. Q., Muller, N. Z., Mauzerall, D. L., and Mendelsohn, R. O. (2006). "Integrated assessment of the spatial variability of ozone impacts from emissions of nitrogen oxides.” Environmental Science \& Technology, 40(5), 1395-1400.

Vautard, R., Beekmann, M., and Menut, L. (2000). "Applications of adjoint modelling in atmospheric chemistry: sensitivity and inverse modelling." Environmental Modelling \& Software, 15(6-7), 703-709.

Vijay, S., DeCarolis, J. F., and Srivastava, R. K. (2010). "A bottom-up method to develop pollution abatement cost curves for coal-fired utility boilers." Energy Policy, 38(5), 2255-2261. 
Vukićević, T., and Hess, P. (2000). "Analysis of tropospheric transport in the Pacific Basin using the adjoint technique." Journal of Geophysical Research, 105(D6), 7213-7230.

Waltz, R., and Plantenga, T. (2010). KNITRO user's manual. Ziena Optimization Inc., Evanston, IL.

Wang, K. Y., Lary, D., Shallcross, D., Hall, S., and Pyle, J. (2001). "A review on the use of the adjoint method in four-dimensional atmospheric-chemistry data assimilation." Quarterly Journal of the Royal Meteorological Society, 127(576), 2181-2204.

Wang, L., Thompson, T., Mcdonald-buller, E. C., Webb, A., and Allen, D. T. (2007). "Photochemical modeling of emissions trading of highly reactive volatile organic compounds in Houston, Texas. 1. reactivity based trading and potential for ozone hot spot formation." Environmental Science \& Technology, 41(7), 2095-2102.

Wang, L., Mcdonald-buller, E., and Allen, D. T. (2007). "Photochemical modeling of emissions trading of highly reactive volatile organic compounds in Houston, Texas. 2. Incorporation of chlorine emissions." Environmental Science \& Technology, 41(7), 2103-7.

Wanger, F., and Schopp, W. (2007). Comparison of the RAIN emission control cost curves for air pollutants with emission control costs computed by the GAINS model. IR-07-008, International Institute for Applied Systems Analysis, Laxenburg, Austria.

Warwick, W. M. (2002). A primer on electric utilities, deregulation, and restructuring of US electricity markets. prepared for the US Department of Energy, Federal Energy Management Mrogram, Office of Eneregy and Renewable Energy, Washington, DC.

Xu, J., Kochanek, K. D., Murphy, S. L., and Tejada-Vera, B. (2010). National vital statistics reports births: Final data for 2007. National Center for Health Statistics, Hyattsville, MD.

Yang, Y.-J., Wilkinson, J. G., and Russell, A. G. (1997). "Fast, direct sensitivity analysis of multidimensional photochemical models." Environmental Science \& Technology, 31(10), 2859-2868.

Yarwood, G., Rao, S., Yocke, M., and Whitten, G. (2005). Updates to the carbon bond chemical mechanism: CB05. Final report to the US EPA, RT-04-00675, Research Triangle Park, NC. 
Zanobetti, A., and Schwartz, J. (2008). "Mortality displacement in the association of ozone with mortality: an analysis of 48 cities in the United States." American Journal of Respiratory and Critical Care Medicine, 177(2), 184-9.

Ziadi, A., and Kumar, S. (1995). "Combustion control techniques to reduce NOx emissions from industrial boliers: what's available and how to compare cost effectiveness." Pulp and Paper Canada, 96(6), 84-88. 